\title{
A VALIAÇÃO DE CRUZAMENTOS DIALÉLICOS DE SOJA EM GERAÇÕES AVANÇADAS DE ENDOGAMIA
}

\section{CARLOS EDUARDO PULCINELLI \\ Engenheiro Agrônomo}

Orientador: Prof. Dr. Isaias Olívio Geraldi

Tese apresentada à Escola Superior de Agricultura "Luiz de Queiroz", da Universidade de São Paulo, para obtenção do título de Doutor em Agronomia, Área de Concentração: Genética e Melhoramento de Plantas.

\section{PIRACICABA}

Estado de São Paulo - Brasil

Abril - 1997 
Dados Internacionais de catalogação na Publicação (CIP) DIVISÃO DE BIBLIOTECA E DOCUMENTAÇÃO - Campus "Luiz de Queiroz"/USP

\author{
Pulcinelli, Carlos Eduardo \\ Avaliação de cruzamentos dialélicos de soja em geraçōes avançadas de
} endogamia / Carlos Eduardo Pulcinelli. - - Piracicaba, 1997.

$165 \mathrm{p}$.

Tese (doutorado) - Escola Superior de Agricultura Luiz de Queiroz, 19.97. Bibliografia.

1. Cruzamento dialélico 2. Endogamia 3. Melhoramento 4. Soja 


\section{AVALIAÇÃO DE CRUZAMENTOS DIALÉLICOS DE SOJA EM GERAÇÕES AVANÇADAS DE ENDOGAMIA}

\section{CARLOS EDUARDO PULCINELLI}

Aprovada em:

Comissão Julgadora:

Prof. Dr. Isaias Olívio Geraldi ESALQ / USP

Prof. Dr. Cláudio Lopes de Souza Júnior ESALQ / USP

Prof. Dr. Natal Atônio Vello ESALQ / USP

Prof. Dr. João Bosco dos Santos UFLA / Lavras

Prof. Dr. Lázaro José Chaves

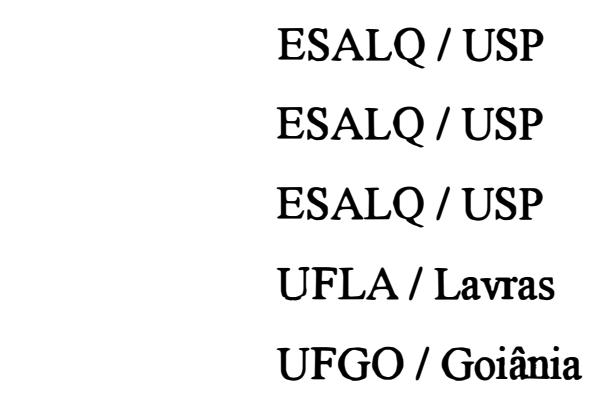

Prof. Dr. Isaias Olívio Geraldi

Orientador 
à minha família dedico,

a você leitor, ofereço. 


\section{AGRADECIMENTOS}

O autor agradece a todos aqueles que colaboraram para a realização deste trabalho, e em especial:

- Ao Prof. Dr. Isaias Olívio Geraldi por todos os ensinamentos que recebi durante minha formação pessoal e profissional, e pelos dados experimentais que possibilitaram a realização deste trabalho.

- Aos docentes do Departamento de Genética da ESALQ / USP, pelo estímulo e ensinamentos recebidos durante o curso de doutoramento.

- Ao Prof. Dr. Carlos Tadeu dos Santos Dias pelo valioso auxílio na utilização do SAS para realização das análises de variância das tabelas dialélicas.

- Ao CNPq Conselho Nacional de Desenvolvimento Científico e Tecnológico pela bolsa de estudos fornecida no período de março a novembro de 1993.

- À Empresa Brasileira de Pesquisa Agropecuária e ao CNPq Conselho Nacional de Desenvolvimento Científico e Tecnológico por parte dos recursos utilizados neste trabalho.

- À Souza Cruz S/A, em especial ao Dr. Leopoldo Caruso pelas facilidades que me foram concedidas.

- Aos funcionários do Setor de Genética Aplicada às Espécies Autógamas, do Departamento de Genética da ESALQ/USP, em especial a José Fernandes de 
Araujo, Claudinei Antônio Didoné, Antônio Roberto Cogo e Gustavo Perina, pelo auxílio na condução dos experimentos.

- Ao amigo Otavio Figueiredo pelo empenho efetuado para que parte das análises estatísticas pudessem ser realizadas.

- Ao amigo Nelson Sidney Massola Júnior por todas as facilidades que sempre me ofereceu durante o período em que este trabalho foi conduzido.

- A Lúcia Lopes Scuciato pelo valioso auxílio na digitação dos dados experimentais.

- A meu pai, Carlos Pulcinelli pela pacenciosa conferência das análises efetuadas, bem como das tabelas apresentadas.

- Aos funcionários da DIBD ESALQ/USP pelo valioso auxílio que me foi concedido, em especial a Eliana Maria Garcia Sabino, Katia Maria Andrade Ferraz, e Silvana Marchizelli Gregório pela conferência das referências bibliográficas. 


\section{SUMÁRIO}

Página

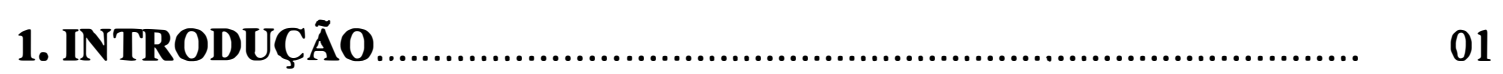

2. REVISÃO DE LITERATURA ....................................................... 05

2.1 Teoria e Conceitos da Análise de Cruzamentos Dialélicos........... 05

2.2 Cruzamentos Dialélicos em Soja.............................................. 13

2.3 Análise Dialélica em Gerações Avançadas................................ 24

2.4 Predição do Potencial de Cruzamentos para Freqüência de Obtenção de Linhagens Superiores......................................... 28

3. MATERIAL E MÉTODOS....................................................... 34

3.1 Caracterização do Ambiente Experimental e Genótipos Utilizados............................................................................. $\quad 34$

3.2 Análises de Variância dos Dados Experimentais........................ 40

3.3 Análise Dialélica......................................................................... 43

3.5 Predição da Proporção de Linhagens Superiores por

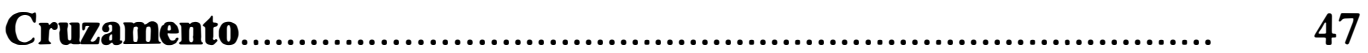

4. RESULTADOS E DISCUSSÃO............................................... 49

4.1 Análises de Variância ao Nível dos Cruzamentos da Tabela Dialélica.................................................................................. 49

4.2 Análises de Variância ao Nível de Progênies............................... 54

4.3 Análises Dialélicas..................................................................... 59

4.4 Predição da Freqüência de Linhagens Superiores por

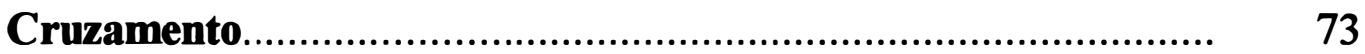

5. CONCLUSÕES..................................................................... 78

REFERÊNCIAS BIBLIOGRÁFICAS.......................................... 80

LISTA DE TABELAS E FIGURAS............................................. 91 


\title{
AVALIAÇÃO DE CRUZAMENTOS DIALÉLICOS DE SOJA EM GERAÇÕES AVANÇADAS DE ENDOGAMIA
}

\author{
Autor: Carlos Eduardo Pulcinelli \\ Orientador: Prof. Dr. Isaias Olívio Geraldi
}

\section{RESUMO}

Oito linhagens de soja, sendo três introduzidas dos Estados Unidos da América (grupo não adaptado) e cinco brasileiras (grupo adaptado) foram avaliadas em um esquema dialélico na geração $F_{2: n}$, com o objetivo de avaliar $o$ potencial genético das mesmas e também a possibilidade de seleção de parentais para programas de cruzamento em gerações tão precoces como $\mathrm{F}_{2}$.

Os experimentos de avaliação dos cruzamentos foram conduzidos em Piracicaba SP, em quatro anos, com um total de 12 repetições e 25 tratamentos (cruzamentos oriundos de um dialelo $8 \times 8$ ). Utilizou-se, em cada ano, um látice triplo $5 \times 5$ (três repetições), sendo cada tratamento constituído por 20 "bulks" (sub-parcelas), representados por uma linha de 1 metro, com espaçamento de 0,60 metros entre linhas, e com 17 plantas após o desbaste, no estande ideal. Para este estudo foram considerados os caracteres Produtividade de Grãos e Altura da Planta na Maturação.

As análises dialélicas foram efetuadas de acordo com o modelo de GRIFFING (1956), método 4, modelo misto 2, enquanto que as freqüências esperadas de linhagens superiores foram calculadas com base na metodologia de 
TOLEDO (1987). Realizou-se também uma análise dialélica conjunta entre as quatro avaliações da geração $F_{2: n}$, sendo as análises efetuadas na geração $F_{2: n}$ comparadas às análises da geração $F_{2}$ (PIMENTEL, 1991), para verificar a concordância entre as estimativas dos parâmetros obtidas em diferentes gerações.

As análises comparativas indicaram que os efeitos da capacidade geral de combinação (CGC) foram mais importantes que os da capacidade específica de combinação (CEC) para a composição das médias de tratamentos, tanto em $\mathrm{F}_{2}$ quanto em $\mathrm{F}_{2: \mathrm{n}}$. Consequentemente, os melhores cruzamentos envolveram os parentais com valores mais altos para a capacidade geral de combinação, e vice-versa. Alguns desvios desta norma ocorreram devido as altas magnitudes da capacidade específica de combinação em alguns cruzamentos. Os efeitos das interações entre as capacidades geral e específica de combinação com anos foram significativos para Produtividade de Grãos; todavia, as magnitudes destes efeitos não foram suficientes para provocar alteração de classificação das médias e dos efeitos da capacidade geral de combinação nos diferentes anos.

Para os dois caracteres, verificou-se concordância entre as médias dos cruzamentos estimadas através de um modelo reduzido, baseado apenas na capacidade geral de combinação $\left(\mu+1 / 2 g_{i}+1 / 2 g_{j}\right)$ e as médias observadas dos cruzamentos em $F_{2: n}$, bem como com a freqüência observada de linhagens superiores em $\mathrm{F}_{2: \mathrm{n}}$. Tais resultados indicam que para os caracteres Produtividade de Grãos e Altura da Planta na Maturação em soja a seleção de parentais para cruzamentos pode ser feita com base nos efeitos da capacidade geral de combinação estimados na geração $F_{2}$. 


\title{
EVALUATION OF DIALLEL CROSSES IN ADVANCED GENERATIONS OF SELFING IN SOYBEN
}

\author{
Author: Carlos Eduardo Pulcinelli \\ Adviser: Prof. Dr. Isaias Olívio Geraldi
}

\section{SUMMARY}

Eight soybean inbred lines, three introduced from the United States of America (non adapted set), and five brazilian cultivars (adapted set), were evaluated in a diallel scheme in $\mathrm{F}_{2: \mathrm{n}}$ generation in order to provide information on the genetic potential of the lines and to evaluate the possibility of selecting parents for breeding purposes in earlier generations, as in $\mathrm{F}_{2}$.

Evaluation trials were carried out at Piracicaba (State of São Paulo) in four years with a total of 12 replications. Entries (plots) consisted of 25 crosses (from a $8 \times 8$ diallel) evaluated in a $5 \times 5$ triple lattice (three replications), were each entry was composed of $20 \mathrm{~F}_{2: \mathrm{n}}$ bulks (sub-plot). Each sub-plot consisted of single 1 meter long row spaced 0.60 meter apart with 17 plants after thinning. Seed Yield and Plant Height were considered for this study. Diallel analysis were performed according to GRIFFING's (1956) method 4, mixed model 2, and the expected frequency of superior lines was based on TOLEDO's (1987) method. Diallel analysis in $F_{2: n}$ were combined with those in $F_{2}$ (PIMENTEL, 1991) in order to compare the results. 
Comparative analysis indicated that for both traits general combining ability effects (GCA) were more important than specific combining ability effects (SCA) in $F_{2}$ and $F_{2: n}$ generations. Generally the most favorable crosses involved parents with high general combining ability and vice-versa. Some exceptions ocurred because of the magnitude of specific combining ability. General and specific combining ability by year effects were significant for yield; however, these effects showed low magnitude and the ranking of means and general combining ability effects were nearly the same during the four years considered.

For both traits a good agreement was observed between estimated means in $F_{2}$, based only in general combining ability effects $\left(\mu+1 / 2 g_{i}+1 / 2 g_{j}\right)$ and the performance of inbred lines in $F_{2: n}$, as well as the frequency of superior lines in $F_{2: n}$ for each cross. General results indicate that for Yield and Plant Height in soybean the predicting of inbred lines performance based on general combining ability effects in $\mathrm{F}_{2}$ is possible. 


\section{INTRODUÇÃO}

A cultura da soja ocupa posição de destaque no cenário agrícola brasileiro, representando importante fonte de divisas para o país e de receita para os agricultores que a cultivam. $\mathrm{O}$ potencial produtivo da espécie aliado à composição química dos grãos foram os fatores determinantes para a rápida expansão da área cultivada no País, ocorrida nos anos 70 e 80, e pela consolidação da cultura como uma das maiores em área plantada e volume de grãos produzidos atualmente.

Pela importância que a cultura apresenta, muitos esforços têm sido feitos para a coleta e conservação de germoplasma de soja, o que tem possibilitado a organização de coleções bastante completas que armazenam variabilidade genética essencial aos programas de melhoramento, mas apesar destas coleções de germoplasma estarem disponíveis aos melhoristas, a maioria dos cultivares que estão sendo utilizadas comercialmente têm base genética estreita. Nestes programas, maior ênfase tem sido dada aos caracteres relacionados à produtividade de grãos e ao teor de óleo das sementes, muito embora a espécie ofereça um ótimo potencial em relação ao teor de proteína nos grãos, sendo atualmente a mais importante fonte de proteína vegetal cultivada comercialmente, para utilização em rações animais. 
Tradicionalmente, os trabalhos de melhoramento genético da soja têm utilizado a síntese de cruzamentos bi ou tri-parentais, e a condução das populações segregantes à homozigose, segundo diferentes metodologias, com o propósito de se disponibilizar variabilidade genética para seleção, obtendo-se em consequência novos cultivares que apresentam características mais favoráveis.

A seleção de parentais em um programa de melhoramento é um dos aspectos mais críticos, uma vez que o sucesso do programa depende diretamente desta etapa. FEHR (1987) comenta com detalhes fatores importantes a serem levados em consideração durante esta fase do programa. Várias metodologias têm sido propostas para auxiliar o melhorista na escolha de parentais, sempre levando em consideração a divergência genética e a capacidade de combinação dos genitores, além de caracteres específicos de interesse.

Após o desenvolvimento de metodologias para análise de cruzamentos dialélicos, este tem sido o método mais amplamente utilizado para se conhecer o valor genético dos genitores, bem como sua capacidade de se combinar para originar populações segregantes com potencial para seleção. Através da análise de tabelas dialélicas também é possível conhecer o controle genético dos caracteres de interesse, possibilitando a condução das populações segregantes de maneira mais técnica.

Os modelos propostos para análise dialélica assumem algumas restrições a saber: segregação diplóide, genes distribuídos independentemente nos parentais, ausência de alelismo múltiplo, e ação independente de genes não alélicos. Dentre estas restrições, BAKER (1978) ressalta como bastante relevantes a ausência de epistase e a distribuição independente dos genes nos parentais. Tais 
restrições, segundo o autor, não podem ser obedecidas para a maioria das espécies.

Em espécies autógamas, onde são utilizados materiais homozigóticos como cultivares, a inobservância das restrições ao modelo de análise dialélica, principalmente a ausência de epistase, deve produzir estimativas tendenciosas dos componentes do modelo de análise dialélica, a partir da análise. efetuada na geração $F_{2}$. Análise dialélica de gerações com nível de endogamia elevado tem sido raramente utilizada para este grupo de espécies.

Além da análise dialélica a metodologia para predição da freqüência de linhagens superiores a serem obtidas após endogamia, a partir de um cruzamento entre duas linhagens homozigóticas, também tem sido utilizada com sucesso em espécies autógamas, pois permite que esforços sejam concentrados somente nos cruzamentos onde existem maiores chances de se obter sucesso com seleção. Neste sentido, esta metodologia é extremamente útil, pois permite que se poupe tempo e recursos destinados aos programas de melhoramento.

Para que os programas de melhoramento a serem conduzidos com a cultura da soja possam ser melhor elaborados, torna-se de grande importância a discussão a respeito das diferentes implicações relacionadas com a utilização das metodologias de seleção de parentais, baseadas em análises de médias e de variâncias. Neste sentido, este trabalho tem os seguintes objetivos:

a) Avaliar a viabilidade de predição do comportamento de cruzamentos com base na avaliação da geração $\mathrm{F}_{2}$; 
b) Avaliar o potencial de oito genótipos de soja para o melhoramento, com ênfase nos caracteres produtividade de grãos e altura da planta na maturação;

c) Avaliar a importância relativa dos efeitos da capacidade geral e específica de combinação na geração $F_{2}$ e em gerações avançadas de endogamia;

d) Avaliar a importância da interação dos efeitos da capacidade geral e específica de combinação com anos; 


\section{REVISÃO DE LITERATURA}

\subsection{Teoria e Conceitos da Análise de Cruzamentos Dialélicos}

JNKS \& HAYMAN (1953) definiram como tabela dialélica as $n^{2}$ observações de um conjunto de cruzamentos entre $n$ parentais. As linhas e as colunas da tabela dialélica correspondem à progênie de cada parental, e os $n$ parentais homozigotos fazem parte da diagonal da tabela. Antes mesmo do desenvolvimento de metodologias específicas para análise dialélica, este tipo de tabela já era empregada no estudo de capacidade de combinação, conforme discutido por HAYES \& JOHNSON (1939).

O desenvolvimento da teoria de análise dialélica teve início após a introdução dos conceitos de capacidade geral e específica de combinação por SPRAGUE \& TATUM (1942). Os autores definiram como capacidade geral de combinação o comportamento médio de uma linhagem, cultivar ou outro material genético, em um conjunto de cruzamentos, e como capacidade específica de combinação o resultado de uma combinação híbrida em particular que difere do que se poderia prever com base no desempenho médio dos respectivos parentais.

Dentre os vários métodos propostos para análise dialélica poderíamos citar como os mais importantes os métodos de JINKS \& HAYMAN 
(1953), o desenvolvido por GRIFFING (1956), e o proposto por GARDNER \& EBERHART (1966). Basicamente os três métodos permitem estimar os efeitos genéticos aditivos e de dominância, os componentes da variância genética, bem como parâmetros genéticos como herdabilidades no sentido amplo e restrito e grau médio de dominância.

O método desenvolvido por JINKS \& HAYMAN (1953) foi adaptado por HAYMAN (1954 b) que discute a teoria e os mais importantes aspectos relacionados à análise dialélica. Estes trabalhos foram complementados por HAYMAN (1954 a) onde são apresentadas metodologias para análise de variância das tabelas dialélicas. HAYMAN (1958) amplia a discussão sobre os aspectos teóricos relacionados à análise dialélica. JINKS (1954) desenvolveu metodologia para estimativa de componentes de variância através de análise dialélica, e JINKS (1956) adaptou a metodologia proposta para análise de cruzamentos dialélicos nas gerações $F_{2}$ e retrocruzamentos. Uma nova evolução do método foi desenvolvida por JONES (1965), que ampliou a metodologia para análise de meia tabela dialélica, o que também foi discutido por FERREIRA (1985).

Basicamente este método, através de suas adaptações, permite que se trabalhe com as gerações $F_{1}, F_{2}$, e retrocruzamentos, utilizando a tabela dialélica completa com as $n^{2}$ combinações, ou com meia tabela não considerando os cruzamentos recíprocos. $\mathrm{O}$ modelo utilizado é um modelo aditivo-dominante, e parâmetros genéticos podem ser estimados. HAYMAN (1954 b) propôs ainda uma análise gráfica que permite a classificação dos materiais genéticos utilizados com base na proporção dos alelos dominantes em relação aos recessivos presentes no material. A análise gráíca torna possível, segundo RAMALHO et al. (1993), 
estabelecer limites seletivos que mostram o potencial das populações avaliadas no cruzamento dialélico para fins de seleção.

Para espécies autógamas, de difícil manipulação e síntese de cruzamentos como a soja, tem sido mais freqüentemente utilizada a análise de meia tabela dialélica, e a geração $F_{2}$ para avaliação. Os dados para a análise normalmente se referem à média de repetições obtidas a partir de experimentos em delineamento estatístico apropriado. É usual também serem obtidas estimativas da variância ambiental através da avaliação de plantas individuais das gerações parentais e $F_{1}$.

YATES (1947) desenvolveu metodologia para análise de variância de um conjunto de dados referentes a todos os cruzamentos e seus recíprocos entre um grupo de linhagens. $O$ propósito da metodologia se referia a análise da capacidade de combinação em cruzamentos.

A metodologia proposta por GRIFFING (1956) utiliza um modelo estatístico-genético apropriado para serem obtidas estimativas das capacidades geral e específica de combinação dos parentais do cruzamento dialélico. Esta metodologia foi desenvolvida para quatro tipos de tabelas dialélicas, correspondendo aos quatro métodos discutidos pelo autor, podendo-se considerar ainda o modelo como fixo ou aleatório, dependendo dos genótipos utilizados como genitores.

GRIFFING (1956) definiu como método 1 o esquema de análise para tabela completa, ou seja as $p^{2}$ combinações entre os parentais, os cruzamentos recíprocos e os próprios parentais. Já o método 2 prevê a análise dos 
parentais e seus híbridos, excluindo-se os recíprocos. O método 3 emprega os híbridos e seus recíprocos, excluindo-se os parentais. E o método 4 utiliza para análise apenas os híbridos de um conjunto de parentais, excluindo-se os próprios parentais e os recíprocos.

Ainda segundo GRIFFING (1956) o modelo utilizado pode ser fixo ou aleatório. O modelo fxo supõe que os parentais foram escolhidos criteriosamente em relação a uma população de referência, e portanto, as estimativas obtidas da análise dialélica não podem ser extrapoladas para a população. Já no modelo aleatório os parentais escolhidos ao acaso representam a população de referência, neste caso podendo serem extrapoladas as estimativas obtidas à população.

RAMALHO et al. (1993) avaliaram as implicações da escolha do modelo mais apropriado afirmando que quando o modelo é fixo o interesse do melhorista está centrado nos componentes genético e ambiental que são estimados na análise da tabela dialélica. Já quando o modelo é aleatório, o interesse se volta para parâmetros populacionais. Os autores discutem ainda que em espécies autógamas a escolha dos parentais para síntese de um cruzamento dialélico deve ser bastante criteriosa, baseada nos caracteres agronômicos de interesse, e que portanto estes não podem ser considerados uma amostra representativa de uma população. Neste caso é aconselhável que os efeitos do modelo sejam considerados fixos, tendo as estimativas de componentes de variância utilidade limitada.

Em espécies autógamas onde são utilizadas linhas puras como material melhorado o conhecimento da capacidade geral de combinação, que é 
função dos efeitos aditivos dos genes, torna-se de grande interesse. RAMALHO et al. (1993) também citam a capacidade geral de combinação como o parâmetro de maior importância prática ao melhorista, uma vez que, a partir dela podem ser obtidas informações sobre a participação dos efeitos aditivos dos genes na amplitude de variação das gerações segregantes de um dado cruzamento, permitindo traçar as melhores estratégias para o programa de melhoramento.

No entanto, CHOO et al. (1988) advertem que o modelo estatísticogenético utilizado nas análises das tabelas dialélicas impõe como restrição a ausência de epistase, o que na maioria das vezes não ocorre. Neste caso as estimativas dos efeitos aditivos dos genes obtidas a partir de gerações com nível de endogamia baixo, devem estar superestimadas. Segundo os autores, a análise dialélica deveria ser feita a partir de gerações que apresentem nível de endogamia elevado, ou seja próximas à homozigose.

Um terceiro método de análise dialélica foi proposto por GARDNER \& EBERHART (1966), que possibilita análise de tabelas dialélicas completas e também de meias tabelas. As diferenças entre médias de cruzamentos na tabela são analisadas com base em parâmetros genéticos estimados a partir de um modelo de efeitos fixos. Neste método o efeito de variedades na análise de variância é decomposto em efeito de parentais e heterose. $O$ efeito de heterose por sua vez é decomposto em heterose média, heterose de parentais e heterose específica.

Segundo RAMALHO et al. (1993), no modelo de Gardner \& Eberhart, a significância da fonte de variação de parentais indica que suas contribuições para as médias de cruzamentos não são constantes, e que portanto, 
os parentais são heterogêneos. Da mesma forma são testadas a significância para heterose e suas decomposições. Se detectada significância para parentais e heteroses podem ser estimados componentes de médias que provêm explicações detalhadas sobre suas diferenças.

Muitos autores têm discutido a respeito das restrições impostas aos modelos utilizados para análise dialélica. Entre estes, NASSAR (1965) usando dados produridos por simulação, concluiu que a ausência de distribuição independente dos genes nos parentais causa sérios desvios nos parâmetros estimados para interpretação dos efeitos genéticos presentes. Estes desvios foram detectados em tabelas dialélicas com número de parentais semelhantes aos mais empregados pelos melhoristas, entretanto a análise dos dados simulados não permitiu afirmar que os desvios foram causados pela falta de independência dos genes nos parentais, podendo ser devido à interações não alélicas, como sugerem JNKS (1954, 1956), HAYMAN (1958), e JOHNSON (1963).

Críticas às interpretações dos parâmetros genéticos estimados através de análise dialélica, segundo os modelos de HYMAN (1954), HYMAN \& JONES (1965), GRIFFING (1956) e GARDNER \& EBERHART (1966), também foram efetuadas por BAKER (1978). Segundo o autor, devido à correlação dos genes nos parentais a interpretação genética dos parâmetros estimados só pode ser efetuada se os parentais utilizados para síntese dos cruzamentos dialélicos forem obtidos a partir de um trabalhoso processo de acasalamento ao acaso, seguido por autofecundações sem seleção, não sendo este um procedimento usual aplicável aos programas de melhoramento. 
ARUNACHALAM (1976) revisou modelos genéticos e os métodos para análise de tabelas dialélicas. $\mathrm{O}$ autor comparou e discutiu a análise gráfica de Jinks \& Hayman com a análise de capacidade de combinação proposta por Griffing, e afirma que o método de Griffing é capaz de gerar todas as informações que o melhorista necessita para condução dos programas de melhoramento. $O$ autor relata ainda diversos lapsos de interpretação dos parâmetros estimados nas análises dialélicas que vêm sendo cometidos, principalmente devido à inobservância das restrições impostas aos modelos utilizados. Também são apresentadas críticas ao uso da geração $F_{2}$ para análise dialélica, já que diferentes populações $F_{2}$ apresentam diferentes segregações.

GARDNER (1967) critica a metodologia proposta por Griffing particularmente pela estimativa do parâmetro $s_{\mathrm{ii}}$, que se refere à capacidade específica de combinação de uma variedade em relação a ela mesma. Segundo o autor este parâmetro não tem significado lógico, nem tão pouco validade estatística, sendo também discutível o fato da capacidade geral de combinação ser devido tanto aos efeitos do comportamento das variedades "per se", quanto em combinações híbridas. Neste caso o modelo de GARDNER \& EBERHART (1966) seria mais apropriado, já que estima separadamente os efeitos de variedades e da heterose varietal, que seriam desdobramentos dos efeitos da capacidade geral de combinação.

No entanto, CRUZ \& VENCOVSKY (1989) comparando as metodologias de Griffing e Gardner \& Eberhart em termos dos parâmetros genéticos estimados e da quantidade de informações obtidas da análise dialélica, concluem que os dois métodos são equivalentes e relacionáveis. Os autores consideram o método 2 de Griffing igualmente eficiente em termos das 
informações contidas nos efeitos do modelo, apesar do modelo de Gardner \& Eberhart ser parametrizado.

Uma outra limitação ao uso de cruzamentos dialélicos nos programas de melhoramento é o grande número de cruzamentos que precisam ser sintetizados quando se dispõe de um conjunto numeroso de parentais. KEMPTHORNE \& CURNOW (1961) desenvolveram metodologia para análise de cruzamentos dialélicos baseada em uma amostra de todos os possíveis cruzamentos entre um grande número de parentais. Esta metodologia passou a ser denominada de análise de cruzamentos dialélicos parciais circulantes. $\mathrm{O}$ número de cruzamentos é reduzido em relação ao cruzamento dialélico completo, mas a eficiência da metodologia para estimativa de variâncias e capacidade de combinação não é afetada, uma vez que são avaliados um grande número de parentais.

MIRANDA-FILHO \& GERALDI (1984) adaptaram o modelo de Gardner \& Eberhart para análise de dialélicos parciais envolvendo dois conjuntos fixos de variedades e os híbridos entre os conjuntos. Os autores incluíram ainda no modelo mais um parâmetro que mede as diferenças entre os grupos de variedades. Através das fórmulas apresentadas é possível a obtenção de estimativas dos parâmetros de interesse, comparáveis às obtidas através do modelo original.

Estudos comparativos visando estabelecer as relações entre as metodologias de análise dialélica e suas modificações têm sido relativamente freqüentes na literatura. MATZINGER et al. (1959) analisando tabelas dialélicas de cruzamentos entre linhagens de milho, procuraram estabelecer a relação entre 
a metodologia de análise dialélica e os delineamentos I e II de Comstock \& Robinson. ROBINSON et al. (1949) em um estudo parecido, incluíram na comparação o delineamento III. Com o mesmo objetivo KEMPTHORNE \& CURNOW (1961) propuseram metodologia para análise de dialélicos parciais, e compararam teoricamente a metodologia para análise dialélica com os delineamentos de Comstock \& Robinson, concluindo que os dialélicos parciais seriam mais poderosos do que os delineamentos I e II, todavia o delineamento III seria a mais eficaz metodologia para estimativa de parâmetros populacionais.

KEARSEY (1965) comparou as metodologias para análise de dialélicos completos, meias tabelas, dialélicos parciais e os delineamentos I e II da Carolina do Norte. $\mathrm{O}$ autor considera a análise de meia tabela dialélica como a melhor metodologia para estimativa de parâmetros populacionais. Neste sentido, MURTY \& ANAND (1966) através da comparação entre dialélicos completos e dialélicos parciais, mostraram que quando se trabalha com um conjunto de híbridos por parental igual ou maior do que a metade do número de parentais, dialélico parcial é a metodologia de melhor performance, uma vez que as informações obtidas são comparáveis às informações obtidas nos dialélicos completos, mas o esforço dispendido é bastante reduzido.

\subsection{Cruzamentos Dialélicos em Soja}

Pela importância econômica que a cultura historicamente apresentou, o uso da metodologia de análise de cruzamentos dialélicos em soja teve seu início concomitantemente ao desenvolvimento da própria técnica. No 
entanto, pela dificuldade de manipulação da espécie no que se refere à síntese de cruzamentos, e por ser a cultura relativamente recente do ponto de vista do melhoramento genético, se comparada a outras grandes culturas como o milho e o trigo, poucos trabalhos têm sido descritos na literatura envolvendo cruzamentos dialélicos em soja. Dentre os trabalhos encontrados a grande maioria se refere ao teor de óleo nos grãos e aos caracteres relacionados à produtividade, como altura de plantas, número de internódios, número de vagens por plantas, ciclo, etc.

LEFFEL \& WEISS (1958) sintetizaram um cruzamento dialélico envolvendo dez parentais com alto teor de óleo nos grãos, e demais caracteres desejáveis relacionados à produtividade. A análise dialélica foi efetuada utilizando a geração $F_{1}$, e as metodologias de Griffing e Hayman foram usadas, respectivamente, para se estudar capacidade de combinação e estimativa de parâmetros genéticos. Os resultados indicaram que as capacidades geral e específica de combinação foram importantes para os caracteres produtividade, dias para florescimento, teor de óleo, e qualidade de sementes. Efeitos de capacidade geral de combinação foram ainda importantes para os caracteres dias para maturação e tamanho das sementes, que não apresentaram efeitos de capacidade específica de combinação. Os autores também relataram uma associação positiva entre os efeitos aditivos e dominantes dos genes com a capacidade geral de combinação.

WEBER et al. (1970) estudando a resposta heterótica e capacidade de combinação em cruzamentos bi-parentais de soja, utilizaram a metodologia de Griffing para análise dialélica e obtiveram estimativas significativas da capacidade geral de combinação para os caracteres produtividade, dias para maturação, altura de plantas e teor de óleo nas sementes. Efeitos significativos 
para capacidade específica de combinação também foram observados para os mesmos caracteres, com exceção do teor de óleo nas sementes. Os autores estimaram heterose para produtividade de grãos, que se mostrou significativa, e sugerem que o tamanho dos grãos pode não ser o caráter responsável pela heterose de produtividade, já que os híbridos apresentavam sementes menores do que os respectivos parentais. $\mathrm{O}$ número de sementes por vagem foi apontado como o caráter preponderante para heterose da produtividade.

PASCHAL \& WILCOX (1975) avaliaram um cruzamento dialélico parcial entre doze linhagens de soja sendo três das mais importantes cultivares comerciais americanas, três representando germoplasma exótico de origem chinesa, três coreanas, e três de origem na Manchúria. A heterose manifestada para o caráter produtividade de grãos, foi maior do que para qualquer outro caracter, sendo o híbrido $8 \%$ mais produtivo do que o pai superior, na média de dois anos de experimentação. Em relação aos demais caracteres agronômicos 0 número de vagens por planta foi o de maior heterose, e o número de sementes por vagem e tamanho de sementes não apresentaram heteroses significativas. Heterose significativa e de mesma magnitude da expressa para produtividade foi verificada em relação à altura de plantas. A análise dialélica foi desenvolvida de acordo com a metodologia de Griffing, e efeitos significativos para capacidade geral de combinação ocorreram para todos os caracteres estudados. Efeitos significativos para capacidade específica de combinação ocorreram para os caracteres tamanho de sementes, dias para a maturação, e altura de plantas.

BHATADE et al. (1977) analisaram um cruzamento dialélico envolvendo seis parentais, entre variedades americanas e indianas de soja. A análise foi efetuada segundo a metodologia de Griffing, método 2 e modelo 1 , 
sendo utilizada a geração $F_{2}$ para tomada de dados e análise. Os efeitos da capacidade geral de combinação foram elevados e significativos para todos os caracteres avaliados, com exceção do número de ramificações primárias. As proporções entre as somas de quadrados das capacidades geral e específica de combinação foram de $4: 1$ para produtividade, $7: 1$ para número de vagens por planta, e 38 : 1 para altura de plantas. Efeitos significativos para capacidade específica de combinação foram relatados para os caracteres produtividade e número de vagens por planta.

Com o propósito de estimar parâmetros genéticos visando a escolha de parentais para o início de um programa de melhoramento SRIVASTAVA et al. (1978), sintetizaram um cruzamento dialélico entre sete parentais, incluindo variedades americanas e germoplasma exótico. A análise da tabela dialélica se baseou na metodologia de Griffing, método 2 modelo 1, e os resultados indicaram efeitos significativos das capacidades geral e específica de combinação para todos os caracteres estudados, com exceção do caráter dias para o florescimento, que não apresentou efeito significativo para capacidade específica de combinação. Para produtividade de grãos os efeitos das capacidades geral e específica de combinação foram significativos e de mesma magnitude, indicando que efeitos aditivos e não aditivos têm a mesma ordem de importância, sendo sugerido a formação de uma população multi-parental o que seria o procedimento mais indicado para exploração da variabilidade genética potencial. Todavia os autores não se atentaram, em suas discussões, para as restrições impostas ao modelo de análise dialélica, que tem por pressuposto distribuição aleatória dos genes nos parentais e ausência de epistase. 
KAW \& MENON (1979) utilizando um cruzamento dialélico entre dez linhagens de soja envolvendo materiais americanos, indianos e exóticos, estudaram a heterose expressa para diversos caracteres. Os autores relataram heterose em relação ao pai superior de $4,3 \%$ para produtividade de grãos, e atribuíram este fato aos efeitos gênicos de sobredominância e epistáticos, além da divergência genética entre os parentais, que também era grande. Ainda utilizando os dados relativos ao mesmo dialélico, KAW \& MENON (1981) realizaram a análise de acordo com a metodologia de Griffing, método 2 e modelo 1, e obtiveram efeitos significativos para capacidades geral e específica de combinação para todos os caracteres estudados. As proporções entre as somas de quadrados das capacidades geral e específica de combinação foram altas para todos os caracteres, sendo a menor proporção de 6,7 : 1 para produtividade de grãos. Os autores estimaram ainda um coeficiente de correlação entre o desempenho de cada variedade "per se" e a capacidade geral de combinação, e o índice estimado se aproximou muito de um, para todos os caracteres estudados, sendo a estimativa deste parâmetro altamente significativa, o que indica mais uma vez que os efeitos aditivos dos genes seriam os mais importantes. Causa surpresa novamente o fato dos autores associarem, no primeiro trabalho, heterose em relação ao pai superior à efeitos de sobredominância e epistáticos, e na análise dialélica os efeitos aditivos dos genes aparecerem como os mais importantes, e com proporções altas em relação aos efeitos de dominância. Novamente os autores ignoraram as restrições impostas ao modelo de análise dialélica, principalmente no que se refere à presença de epistase.

O primeiro exemplo de utilização da metodologia de Gardner \& Eberhart para análise dialélica em soja surgiu com $o$ trabalho de PALUDZYSZYN FILHO (1982), que avaliou um cruzamento dialélico entre oito 
parentais utilizando a geração $F_{1}$ para tomada de dados. Para os três caracteres avaliados, produtividade de grãos, número de dias para o florescimento, e maturação, foram detectados efeitos significativos para as capacidades geral e específica de combinação, e as proporções entre as somas de quadrados destes efeitos foram de 1,9 : 1 para produtividade de grãos, 19,6 : 1 para dias para florescimento, e 19,7 : 1 para dias para maturação, indicando novamente que os efeitos aditivos dos genes aparecem como os mais importantes.

Com o propósito de estudar heterose e capacidade de combinação em cruzamentos KUNTA et al. (1985) efetuaram um cruzamento em esquema dialélico entre quatro parentais representando variedades americanas de soja. A análise dialélica foi efetuada segundo a metodologia de Gardner \& Eberhart, método III, sendo também utilizada a metodologia de Griffing, método 4 e modelo 1 para que fosse possível a estimativa das capacidades geral e específica de combinação a partir da geração $F_{1}$. Os autores relataram heteroses significativas para todos os demais caracteres estudados, entre eles a produtividade de grãos $(24,6 \%)$, com exceção apenas do caráter número de sementes por vagem $(0,4 \%)$. Efeitos significativos para as capacidades geral e específica de combinação foram obtidos para os caracteres número de vagens por planta, e índice de colheita. Os efeitos da capacidade geral de combinação foram também significativos para número de sementes por vagem, tamanho de sementes e altura de plantas. Efeitos de capacidade específica de combinação foram significativos para produtividade e altura de plantas, concordando com os estudos de heterose.

Em relação aos teores de óleo e proteína nos grãos em soja, o primeiro estudo de análise dialélica foi condurido por SABBOUH \& EDWARDS 
(1985), através da síntese de um cruzamento dialélico entre quatro cultivares americanas. A metodologia de Griffing, método 4 e modelo 1 foi utilizada nas gerações $F_{1}$ e $F_{2}$. As análises de variância mostraram diferenças significativas para os teores de proteína e óleo nos grãos, na a geração $F_{1}$ e para teor de proteína na geração $F_{2}$, indicando a existência de variabilidade genética para estes caracteres. Efeitos significativos da capacidade geral de combinação foram observados para os teores de óleo e proteína na geração $F_{1}$ e somente para o teor de proteína na geração $F_{2}$.

CRUZ et al. (1987) realizaram um cruzamento dialélico entre quatro parentais em soja, efetuando também os cruzamentos recíprocos, e utilizaram a metodologia de Griffing, método 1, modelo 1 para análise. Foram estimados efeitos altamente significativos para as capacidades geral e específica de combinação para todos os caracteres analisados, sendo: período vegetativo, período reprodutivo, altura de plantas e produtividade de grãos. As relações entre as somas de quadrados devido às capacidades geral e específica de combinação foram de $34: 1,16,5: 1,1,4: 1$ e $1,4: 1$, respectivamente para os mesmos caracteres. $\mathrm{O}$ autor relatou ainda efeitos altamente significativos para cruzamentos recíprocos.

VERMA \& RAM (1987) estudando a herança da impermeabilidade do tegumento das sementes em soja, efetuaram um cruzamento dialélico envolvendo seis parentais, sendo três deles materiais cultivados comercialmente, uma introdução de germoplasma exótico e dois representados por espécies selvagens afins à soja, Glycine formosana e Glycine soja, que possuem tegumento impermeável. Os autores utilizaram a análise gráfica de Hayman na geração $F_{1}$ para estudar a distribuição de genes dominantes e recessivos nos 
parentais, para o caráter impermeabilidade de tegumento da semente. A interpretação da análise gráfica revelou que a impermeabilidade está diretamente relacionada à presença de genes dominantes nos parentais.

Cruzamentos interespecíficos em soja começaram a receber maior atenção como possibilidade de introgressão de germoplasma exótico com interesse principalmente relacionado ao teor de proteína das sementes. Neste sentido WENBIN \& JINLING (1988) efetuaram um cruzamento descrito como dialélico cruzando um grupo de parentais com outro grupo diferente, onde os efeitos de parentais foram decompostos em capacidade geral de combinação, segundo metodologia similar a de dialélico parcial. No entanto, a metodologia utilizada pelos autores para análise, não é usual no estudo de cruzamentos dialélicos.

FREIRE FILHO (1988), a partir de um cruzamento dialélico entre dez parentais do grupo precoce em soja, avaliou dez caracteres envolvendo a produtividade de grãos e caracteres relacionados ao valor agronômico do material, sendo a análise efetuada segundo as metodologias de Hayman e Griffing. $\mathrm{O}$ autor discute que para a maioria dos caracteres as restrições impostas aos modelos de análise dialélica não puderam ser atendidas. A análise gráfica de Hayman evidenciou a presença de sobredominância para todos os caracteres estudados, não sendo possível estimar os limites teóricos de seleção. $O$ autor relata ainda efeitos significativos da variância aditiva para todos os caracteres estudados, sendo os efeitos da variância de dominância significativos para dias para 0 florescimento e maturação, número de internódios, altura da planta na maturação, valor agronômico e produtividade de grãos. Novamente, estes parâmetros discutidos pelo autor evidenciam que a participação dos efeitos aditivos dos genes 
são os mais importantes. Ainda segundo o autor a metodologia de Griffing revelou efeitos significativos das capacidades geral e específica de combinação para todos os caracteres estudados, no entanto a participação destes efeitos foram muito variáveis segundo os caracteres estudados.

NASS (1989) interessado na potencialidade de genótipos de soja para cultivo de inverno em região tropical, efetuou um cruzamento dialélico entre oito parentais envolvendo cultivares comerciais e germoplasma exótico de soja. A metodologia utilizada para análise foi a de Griffing, método 2 e modelo 1, e os resultados evidenciaram efeitos altamente significativos para capacidade geral de combinação em oito dos nove caracteres estudados, excetuando-se apenas a resistência ao acamamento. Para capacidade específica de combinação não foram detectados efeitos significativos para nenhum dos caracteres considerados, indicando a importância dos efeitos aditivos dos genes para tais características. $\mathrm{O}$ autor ressalta ainda que devido a magnitude das relações encontradas entre as capacidades geral e específica de combinação, epistasia do tipo aditivo $\mathrm{x}$ aditivo deve estar presente, o que contraria uma das restrições impostas ao modelo de análise dialélica.

LOISELLE et al. (1990), realizaram um cruzamento dialélico entre onze parentais pertencentes aos gnupos de maturação precoce e semi-precoce de soja, cultivados comercialmente nos Estados Unidos da América e Canadá. A metodologia de análise foi a descrita por Gardner \& Eberhart, método II e modelo 2, utilizando a geração $F_{2}$ para a coleta de dados. Efeitos significativos para variedades foram observados para todos os caracteres analisados, e a heterose média foi significativa para altura de plantas e produtividade de grãos. $\mathrm{O}$ teor de proteína não apresentou efeito signifcativo para heterose média, e efeitos de 
heterose de variedades foram significativos para todos os demais caracteres com exceção somente do número de dias para o florescimento. Heterose específica foi significativa para todos os caracteres estudados. Os parâmetros estimados indicam que efeitos aditivos dos genes são importantes na determinação de todos os caracteres avaliados, e ainda para os caracteres produtividade de grãos, dias para maturação e altura de plantas, efeitos de dominância são também importantes, 0 que justifica a heterose ocomida para tais caracteres.

PIMENTEL (1991), interessado em avaliar parentais para o início de um programa de melhoramento em soja, com ênfase no teor de proteína e produtividade de grãos, efetuou um cruzamento dialélico envolvendo oito linhagens, sendo três introduções de germoplasma exótico oriundo dos Estados Unidos da América, e cinco selecionadas do banco de germoplasma do Departamento de Genética da Escola Superior de Agronomia "Luiz de Queiroz". O método utilizado para análise foi o de Griffing, método 2 e modelo 1 , e a geração $F_{2}$ foi utilizada para a coleta de dados, sendo avaliados os caracteres: teor de proteína nos grãos, produtividade de grãos, e uma série de outros caracteres relacionados ao valor agronômico do material em estudo. Os resultados indicaram valores significativos dos efeitos devidos às capacidades geral e específica de combinação, para todos os caracteres avaliados, com exceção do valor agronômico que não apresentou efeito significativo da capacidade específica de combinação. As relações entre capacidade geral e específica de combinação foram sempre altas para todos os caracteres, excetuando-se o valor agronômico, 0 que indica a importância dos efeitos aditivos dos genes na determinação dos caracteres avaliados. 
SHARMA et al. (1993) descreveu a análise de um cruzamento dialélico em soja entre seis cultivares utilizados comercialmente na Índia. A metodologia de análise utilizada foi a de Griffing, método 2 e modelo 1 , e a geração utilizada para a coleta de dados foi a $F_{2}$. $O$ experimento foi avaliado em dois sistemas de cultivo, cultivo puro e em consórcio com milho (a cada duas linhas de soja, uma linha de milho). Os efeitos de capacidade geral de combinação foram significativos para todos os caracteres avaliados, entre eles produtividade de grãos e demais caracteres de interesse agronômico, e nos dois sistemas de cultivo. Os efeitos da capacidade específica de combinação foram significativos para os demais caracteres, com exceção do número de ramificações e número de vagens por nó, em sistema de cultivo único, e produtividade de grãos em sistema de consórcio. Os autores, comparando a magnitude das relações entre as capacidades geral e específica de combinação, concluem haver substancial preponderância dos efeitos aditivos dos genes em relação aos efeitos de dominância para a maioria dos caracteres estudados, e nos dois sistemas de cultivo.

SPEHAR (1995 a), trabalhando com genótipos adaptados à região central do Brasil, efetuou um cruzamento dialélico entre nove parentais sendo oito cultivados comercialmente nesta região do país, e uma introdução de germoplasma americano. A análise foi feita com base no modelo de Hayman, e a geração utilizada para coleta de dados foi a $F_{2}$. Os caracteres analisados foram a acumulação de diversos elementos minerais nos grãos produridos, com ênfase em alumínio, uma vez que os solos desta região do país são ricos neste elemento. As relações entre as variâncias e covariâncias estimadas nesta análise, demonstraram que o modelo aditivo-dominante foi suficiente para explicar as diferenças apresentadas pelos parentais para os elementos cálcio, magnésio, alumínio e 
manganês. Para os demais elementos considerados na análise a herança segue um modelo aparentemente mais complexo. SPEHAR (1995 b) analisou os mesmos cruzamentos, descritos acima, com base no modelo de Griffing, método 1 e modelo 1, sendo também avaliados os mesmos caracteres. Considerando o conjunto de elementos minerais avaliados nos grãos, pôde-se concluir, baseado nas relações entre capacidade geral e específica de combinação, que os efeitos aditivos dos genes tiveram importância relativa maior do que os efeitos de dominância. Vale ressaltar que os dados relativos a teores de alumínio se referem à acumulação deste elemento nos grãos de soja, e não à sensibilidade dos genótipos estudados à presença deste elemento no solo, o que seria de maior utilidade do ponto de vista agrícola.

\subsection{Análise Dialélica em Gerações Avançadas}

A maioria dos estudos envolvendo análise dialélica e capacidade combinatória têm sido efetuados utilizando-se como material experimental as gerações $F_{1}$ ou $F_{2}$ do cruzamento entre linhagens homozigóticas. Trabalhos desta natureza, envolvendo gerações com alta endogamia, próximas à homozigose, não têm sido relatados com freqüência.

O primeiro registro encontrado de um trabalho com este objetivo foi descrito por BUSCH et al. (1974). Os autores utilizaram um esquema dialélico envolvendo quatro parentais com baixa produtividade e quatro com alta, e avaliaram 25 cruzamentos para análise combinatória utilizando 21 linhagens $F_{5}$ derivadas de plantas $F_{2}$, o que permitiu que fossem obtidas estimativas 
significativas das capacidades geral e específica de combinação. Os efeitos da capacidade específica de combinação foram associados aos efeitos genéticos epistáticos do tipo aditivo $\mathrm{x}$ aditivo, uma vez que os efeitos de dominância $\mathrm{e}$ efeitos epistáticos envolvendo dominância deveriam ser de pequena magnitude, já que as linhagens avaliadas tinham elevado grau de homozigose.

Interessados em predizer o comportamento de progênies segregantes através do desempenho dos parentais, STUTHMAN \& STUCKER (1975) estimaram os efeitos das capacidades geral e específica de combinação utilizando um cruzamento dialélico entre doze cultivares de aveia. Dez plantas $F_{2}$ tomadas ao acaso para cada combinação híbrida foram avançadas à $F_{4}$ através do método de "Single Seed Descent", a partir de então linhas $F_{5}$ foram colhidas separadamente dando origem ao material experimental avaliado nas gerações $F_{6} e$ $\mathrm{F}_{7}$ em dois anos sucessivos. Os dados experimentais permitiram que fossem estimadas variâncias para as capacidades geral e específica de combinação bem como os efeitos da interação de cruzamentos por anos e as variâncias genéticas aditiva e epistática tipo aditiva por aditiva, para o caráter produtividade de grãos. Todos os efeitos do modelo, incluindo os efeitos de interações com anos foram significativos, e os efeitos da capacidade específica de combinação foram assumidos como sendo devidos à interações epistáticas do tipo aditivo $\mathrm{x}$ aditivo ou superiores. Os autores discutem, com base na magnitude dos efeitos estimados, que o desempenho médio dos pais não é um bom indicador do desempenho das progênies sempre que os efeitos epistáticos do tipo aditivo $\mathrm{x}$ aditivo forem importantes. Afirmam também que seleção em gerações precoces, para caracteres que apresentem interações epistáticas significativas, deve ser pouco efetiva, mesmo para caracteres com alta herdabilidade. 
CHOO et al. (1979) efetuaram análise dialélica utilizando como material experimental um conjunto de linhagens homozigóticas, obtidas por duplicação de haplóides, representantes de cada cruzamento. Através da decomposição da variância de tratamentos foi possível estimar as variâncias genética aditiva e epistática do tipo aditiva por aditiva. Os autores recomendam então que os cruzamentos mais promissores sejam escolhidos com base nas magnitudes das variâncias genética aditiva e também na epistática tipo aditiva por aditiva, uma vez que a interação epistática pode acrescentar desvios ao comportamento esperado dos cruzamentos previstos com base somente nas estimativas da variância genética aditiva.

CHOO (1981) discute as implicações dos efeitos epistáticos e da ligação gênica nas análises dialélicas, uma vez que a ausência de tais efeitos é premissa para utilização desta metodologia. $O$ autor ressalta que na presença de ligação as estimativas das variâncias genética aditiva e epistática aditiva por aditiva serão tendenciosas, e apresenta metodologia para obtenção destas variâncias livres dos efeitos de ligação, e portanto não tendenciosas.

Metodologia para estimativas das variâncias genéticas aditiva e espistática tipo aditiva $\mathrm{x}$ aditiva ou superiores foi apresentada também por $\mathrm{CHOO}$ \& REINBERGS (1982), baseada em estatísticas de terceiro grau. Este tipo de metodologia, embora tenha sido descrita no começo do século, não tem sido usual nos estudos teóricos em genética quantitativa, mas se constitui em uma ferramenta interessante para este propósito. Os autores demonstraram ser possível, com base nas estimativas de variância obtidas através desta metodologia, e utilizando-se um conjunto de linhas haplóides duplicados representantes de cada cruzamento, 
selecionar cruzamentos com maior potencial para obtenção de linhagens superiores.

O uso de haplóides duplicados como material experimental para análise dialélica foi postulado por $\mathrm{CHOO}$ et al. (1986) como uma excelente ferramenta para se escolher parentais em programas de seleção recorrente, para espécies em que a obtenção de plantas haplóides seja viável. Os autores avaliaram linhagens homozigóticas de aveia, obtidas por duplicação de haplóides, para 0 caráter produtividade de grãos, utilizando um esquema dialélico onde cada cruzamento esteve representado por um conjunto de vinte linhagens. A metodologia utilizada permitiu que fossem obtidas estimativas das variâncias genéticas aditiva e espistática tipo aditiva por aditiva. Foram também estimadas as frequêencias de linhagens superiores e inferiores de cada cruzamento e as estimativas correlacionadas com o comportamento dos parentais. A magnitude da estimativa da variância aditiva foi pequena, quando comparada à variância epistática para o conjunto de caracteres avaliados, no entanto, os autores ressaltam que o progresso esperado com seleção das linhagens haplóides duplicadas deverá ser considerável, uma vez que metade dos efeitos epistáticos são transmitidos às progênies, e tais efeitos apresentaram estimativas significativas.

A interpretação dos trabalhos em que análise dialélica foi efetuada a partir de conjuntos de linhagens homozigóticas representantes de cada cruzamento, evidenciou que neste caso estimativas mais realistas das variâncias genéticas podem ser obtidas, e que previsões a respeito do comportamento das progênies obtidas de cada cruzamento devam ser mais precisas. Estes trabalhos, no entanto, foram realizados com espécies em que a obtenção de plantas 
haplóides para produção de linhagens homozigóticas é viável e relativamente usual. Esta metodologia não é aplicável ainda para a maioria das culturas agrícolas de interesse, onde a obtenção de haplóides é um processo moroso, e algumas vezes inviável.

\subsection{Predição do Potencial de Cruzamentos para Freqüência de Obtenção de Linhagens Superiores}

A escolha de genitores para o início de um programa de melhoramento genético representa um dos maiores desafios do melhorista, uma vez que desta etapa depende o sucesso do programa a ser desenvolvido. Muitos esforços têm sido feitos para o desenvolvimento de metodologias, com base nos princípios de genética quantitativa, que permitam obter estimativas precisas do potencial dos parentais para obtenção de segregantes transgressivos. Para atender a este objetivo podemos citar, como exemplo, previsões baseadas nos coeficientes de parentesco entre parentais, previsões efetuadas a partir das estimativas de diferentes distâncias genéticas $\left(\mathrm{D}^{2}\right.$ de Mahalanobis, componentes principais, dentre outras) e também a técnica de cruzamentos dialélicos, que embora trabalhosa, fornece estimativas precisas sobre o potencial de diferentes materiais em um grupo de cruzamentos.

MATHER (1949) desenvolveu as bases teóricas para predição da resposta esperada à seleção a partir das estimativas das variâncias genéticas e ambientais; todavia foi a partir dos estudos de MATHER \& JNKS (1971) que a 
teoria para predições de segregantes de cruzamentos de linhas puras foi desenvolvida.

JINKS \& PERKINS (1972) utilizando as estimativas da variância genética aditiva, de dominância e epistáticas obtidas em vários experimentos, em que foi avaliada a altura de plantas em Nicotiana rustica, realizaram predições dos fenótipos esperados a partir de autofecundações de plantas $F_{2}$. Os valores preditos foram comparados aos observados após endogamia, e os resultados foram coincidentes, muito embora, os autores alertem para o fato de que se efeitos genéticos epistáticos e de ligação forem significativos, devem ocorrer desvios nos comportamentos esperados dos cruzamentos.

A influência dos efeitos da interação de genótipos com ambientes, epistáticos e de ligação, e as sugestões de como minimizar tais interferências na metodologia para predição do comportamento de cruzamentos após autofecundação, foram apresentados por JINKS \& POONI (1976). Os autores discutem, com base em dados de avaliação de altura de plantas e dias para florescimento em Nicotiana rustica repetidos em três locais e por vinte e cinco anos, resultados de predições do comportamento de cruzamentos, que quando comparados aos resultados observados se mostraram absolutamente concordantes, revelando o potencial desta metodologia para os programas de melhoramento. Interpretações a respeito dos efeitos epistáticos e de ligação são apresentadas para que se possa compreender a interferência de tais efeitos sobre as predições efetuadas.

POONI et al. (1977) associaram a ausência de distribuição normal das linhas puras obtidas de plantas $F_{2}$, através do método de "Single Seed 
Descent", aos efeitos epistáticos lineares e interações genótipo por microambientes. Os autores advertem que, para caracteres de alta herdabilidade e na presença de efeitos epistáticos significativos, a ausência de normalidade das linhagens pode interferir de maneira indesejada nas predições efetuadas. Os autores utilizaram parâmetros estatísticos de terceiro grau para corrigir os desvios à normalidade, estimando a partir das gerações parentais, $F_{1}, F_{2} e$ retrocruzamentos os coeficientes de simetria e curtose. Na prática esta correção se mostrou eficiente para corrigir os desvios de predição onde os efeitos epistáticos apareceram como significativos e de alta magnitude. A distribuição normal das linhagens recombinantes a partir do cruzamento entre duas linhas puras é condição assumida como verdadeira para efeito das predições, através desta metodologia.

POONI \& JINKS (1978) apresentaram metodologia para previsão do comportamento de linhagens homozigóticas recombinantes obtidas por cruzamento entre duas linhas puras, considerando dois ou três caracteres simultaneamente. Os autores adicionaram ao modelo já detalhado, o parâmetro referente à correlação genética aditiva obtida a partir de um triplo "test-cross", de onde foram estimados os demais parâmetros necessários à predição. A comparação entre a proporção esperada e observada de linhagens homozigóticas acima do parental superior, apesar de uma grande coincidência, evidenciou que para se assegurar a acurácia das previsões efetuadas é necessário que sejam utilizadas amostras grandes de famílias homozigóticas, maiores que as oitenta famílias $F_{11}$ utilizadas neste estudo, para se computar a proporção observada de linhagens superiores. 
JINKS \& POONI (1980) utilizaram famílias $\mathrm{F}_{3}$ para predição da freqüência esperada de linhagens homozigóticas superiores, assumindo que a porção da variância de dominância estimada a partir da variância genética de famílias $F_{3}$ era nula. Os autores compararam os resultados de predição obtidos a partir de famílias $\mathrm{F}_{3}$ e os obtidos através do triplo "test-cross", e os resultados evidenciaram que o fato de se assumir o componente de dominância como nulo, para a variância genética estimada em $\mathrm{F}_{3}$, não interferiu de maneira significativa nas predições efetuadas, e que tanto as predições realizadas a partir de famílias $\mathrm{F}_{3}$, quanto a partir do triplo "test-cross" não diferiram estatisticamente das proporções de linhagens superiores observadas em $\mathrm{F}_{7}$. Para um dos caracteres avaliados neste estudo a interação com ambientes proporcionou desvio nas predições efetuadas, ressaltando a importância de serem obtidas estimativas de variâncias livres de tais efeitos. A predição da proporção de linhagens esperadas com base na avaliação de famílias $F_{3}$ se mostrou uma ferramenta de grande interesse, uma vez que os parâmetros para predição podem ser obtidos de maneira menos trabalhosa quando comparada ao "test-cross".

TOLEDO et al. (1984) adaptaram a metodologia, descrita nos trabalhos anteriores, para predição de híbridos de segundo ciclo obtidos pelo intercruzamento das linhagens homozigóticas selecionadas, derivadas do cruzamento entre duas linhas homozigóticas. $O$ intercruzamento de linhagens de primeiro ciclo deve proporcionar o aparecimento de recombinantes superiores às melhores linhagens selecionadas, e a predição do comportamento de híbridos de segundo ciclo, nas fases iniciais do programa de melhoramento, é defendida pelo autor como ferramenta extremamente útil ao melhorista, permitindo que os esforços efetuados nos programas de melhoramento sejam dosados de acordo com as possibilidades de progresso a serem alcançados. Os valores preditos, quando 
comparados aos observados de primeiro e segundo ciclos, mostraram alto grau de concordância, demonstrando que esta metodologia é bastante robusta.

POONI et al. (1985) realizaram predições a respeito das propriedades genotípicas e fenotípicas dos híbridos de segundo ciclo para dois cruzamentos de Nicotiana rustica envolvendo uma série grande de caracteres de alta e baixa herdabilidades. O número de linhagens superiores de segundo ciclo predito foi comparado ao número observado através do cruzamento entre as linhagens de primeiro ciclo selecionadas e a geração $F_{1}$ do cruzamento original, que na ausência de desequilíbrio de ligação deve ser igual ao resultado do cruzamento dialélico entre as linhagens selecionadas de primeiro ciclo. Com raras exceções, os valores preditos foram bastante próximos aos esperados considerando a ampla gama de caracteres avaliados nos dois cruzamentos.

POWELL et al. (1985) utilizaram haplóides duplicados e famílias $F_{3}$ para estimar a variância genética aditiva, com o objetivo de comparar predições de comportamento de cruzamentos efetuados a partir de diferentes tipos de progênies em aveia, para caracteres relacionados ao conteúdo de amido. $\mathrm{O}$ número de linhagens homozigóticas transgressivas ao pai superior, obtidas através do método de "Single Seed Descent", pôde ser previsto com boa precisão a partir das estimativas da variância genética estimada para os dois tipos de progênies, 0 que indica que a porção da variância genética de dominância considerada como nula nas famílias $F_{3}$ para efeitos de predição, não foi suf́ciente para causar desvios de predição para os caracteres avaliados, e para esta espécie.

CALIGARI et al. (1985) também utilizaram haplóides duplicados e famílias $\mathrm{F}_{3}$ para realizar predições do comportamento de cruzamentos em aveia, 
com o objetivo de comparar as predições efetuadas com as proporções observadas de linhagens superiores obtidas pelo método de "Single Seed Descent" e avaliados em $\mathrm{F}_{7}$. Foram utilizadas, para as estimativas da média e da variância aditiva de cada um dos cinco cruzamentos, vinte linhagens haplóides duplicadas, vinte famílias $F_{3}$ e 40 linhagens $F_{7}$ homozigóticas. As predições efetuadas a partir dos dois tipos de famílias, haplóides duplicados ou famílias $\mathrm{F}_{3}$, apresentaram razoável grau de exatidão quando comparadas às proporções observadas de linhagens transgressivas, todavia as predições efetuadas a partir de haplóides duplicados, considerando o conjunto de caracteres avaliados, estiveram mais próximos às proporções observadas. Os autores concluem que a porção da variância genética de dominância estimada utilizando-se famílias $F_{3}$, considerada como nula para realização das predições, deve ter ocasionado os desvios de predição observados com maior freqüência neste tipo de família. Predições efetuadas com parâmetros obtidos a partir do triplo "test-cross" se mostraram claramente influenciadas pela interação de genótipos com ambientes, comum para este tipo de delineamento experimental.

Em soja, a metodologia para predição de cruzamentos e híbridos de segundo ciclo foi apresentada por TOLEDO (1987). O autor utilizou médias e variâncias das gerações $F_{2}$ e $F_{3}$, estimadas para vinte e oito cruzamentos envolvendo oito cultivares de soja, para demonstrar o potencial preditivo da metodologia utilizada, e discute com detalhes as possibilidades de uso de tais predições para que esforços sejam concentrados nos cruzamentos de maior interesse nos programas de melhoramento. 


\section{MATERIAL E MÉTODOS}

\subsection{Caracterização do Ambiente Experimental e Genótipos Utilizados}

A síntese de todas as gerações utilizadas neste trabalho, bem como a coleta dos dados experimentais foram efetuadas na área experimental do Setor de Genética Aplicada às Espécies Autógamas do Departamento de Genética da Escola Superior de Agricultura "Luiz de Queiroz", Universidade de São Paulo. A área experimental está localizada no município de Piracicaba, Estado de São Paulo, a $22^{\circ} 42^{\prime} 31^{\prime \prime}$ de latitude sul, 47³8'01' ' de longitude oeste, e a 540 metros acima do nível do mar.

Os genótipos utilizados foram caracterizados e descritos por PIMENTEL (1991), sendo compostos por linhagens de soja [Glycine max (L.) Merrill]. Foram utilizados oito parentais para a elaboração de um cruzamento dialélico, a partir dos quais foram obtidos vinte e oito cruzamentos, excetuando-se os recíprocos.

As linhagens utilizadas como parentais para a realização do cruzamento dialélico foram: Gaúcha, La-4910-215, OC-79230, BR-80-8858 e BR-80-14853, que apresentaram um elevado teor de proteína nos grãos aliados a um nível de produtividade semelhante aos materiais utilizados comercialmente no 
Estado de São Paulo, e avaliados como controle nos ensaios de produtividade. Além de outros três parentais PI-123439, PI-165896 e PI-239235, que foram cedidos pela EMBRAPA - Centro Nacional de Pesquisas de Soja, sendo introduções de germoplasma americano caracterizados pelo alto teor de proteína nos grãos, mas com níveis considerados baixos de produtividade. Estes parentais foram escolhidos em função do interesse em se iniciar um programa de melhoramento genético com a cultura da soja, visando aumentar o teor de proteína nos grãos, mantendo-se níveis de produtividade compatíveis aos níveis dos cultivares comerciais.

As características principais dos parentais utilizados estão relacionadas a seguir, e a descrição completa encontra-se em PIMENTEL (1991):

- Gaúcha: material brasileiro, utilizado comercialmente em pequena escala, apresenta um período vegetativo de 60 dias até o florescimento, hábito de crescimento indeterminado, flores brancas, cor do tegumento das sementes amarelo, hilo e pubescência marrons.

- La-4910-215: linhagem norte americana, com origem na Luisiania, tem período vegetativo de 60 dias até o florescimento, hábito de crescimento semideterminado, flores roxas, cor do tegumento das sementes amarelo, hilo e pubescência cinzas.

- OC-79230: linhagem brasileira, com origem na OCEPAR, apresenta período vegetativo de 60 dias até o florescimento, hábito de crescimento determinado, flores brancas, cor do tegumento das sementes amarelo, hilo marrom e pubescência cinza. 
- BR-80-8858: linhagem brasileira, proveniente da EMBRAPA CNPSoja, tem ciclo de 53 dias até o florescimento, hábito de crescimento indeterminado, flores roxas, cor do tegumento das sementes amarelo, hilo e pubescência cinzas.

- BR-80-14853: linhagem brasileira, proveniente da EMBRAPA CNPSoja, tem ciclo de 51 dias até o florescimento, hábito de crescimento indeterminado, flores roxas, cor do tegumento das sementes verde, hilo preto e pubescência marrom.

- PI-123439: linhagem norte americana, com origem na Luisiania, tem ciclo de 51 dias até o florescimento, hábito de crescimento determinado, flores roxas, cor do tegumento das sementes amarelo, hilo e pubescência cinzas.

- PI-165896: linhagem norte americana, com origem na Luisiania, tem ciclo de 47 dias até o florescimento, hábito de crescimento determinado, flores roxas, cor do tegumento das sementes preta, hilo preto e pubescência marrom.

- PI-239235: linhagem norte americana, com origem na Luisiania, tem ciclo de 55 dias até o florescimento, hábito de crescimento indeterminado, flores brancas, cor do tegumento das sementes amarelo, hilo cinza e pubescência cinza.

A relação dos cruzamentos avaliados na geração $F_{2}$ por PIMENTEL (1991) e nos quatro anos agrícolas de avaliação das linhagens na geração $F_{2: n}$, bem como as respectivas descrições de cada cruzamento são apresentadas na Tabela 1. 
Tabela 1. Relação dos cruzamentos avaliados na geração $F_{2}$ e em $F_{2: n}$ nos quatro anos agrícolas de experimentação, e as respectivas descrições.

\begin{tabular}{|c|c|c|c|}
\hline $\begin{array}{l}\text { Parental / } \\
\text { Cruzarm. }\end{array}$ & Descrição & $\begin{array}{l}\text { Parental / } \\
\text { Cruzam. }\end{array}$ & Descrição \\
\hline 1 & Gaúcha & $2 \times 6$ & La-4910-215 x PI 123439 \\
\hline 2 & $\mathrm{La}-4910-215$ & $2 \times 7$ & La-4910-215 x PI 165896 \\
\hline 3 & OC 79230 & $2 \times 8$ & La-4910-215 x PI 239235 \\
\hline 4 & BR 80-8858 & $3 \times 4$ & OC 79230 x BR 80-8858 \\
\hline 5 & BR 80-14853 & $3 \times 5$ & OC $79230 \times$ BR 80-14853 \\
\hline 6 & PI 123439 & $3 \times 6$ & OC $79230 \times$ PI 123439 \\
\hline 7 & PI 165896 & $3 \times 7$ & OC 79230 x PI 165896 \\
\hline 8 & PI 239235 & $3 \times 8$ & OC $79230 \times$ PI 239235 \\
\hline $1 \times 2$ & Gaúcha $\times$ La-4910-215 & $4 \times 5$ & BR 80-8858 x BR 80-14853 \\
\hline $1 \times 3$ & Gaúcha x OC 79230 & $4 \times 6$ & BR 80-8858 x PI 123439 \\
\hline $1 \times 4$ & Gaúcha x BR 80-8858 & $4 \times 7$ & BR 80-8858 x PI 165896 \\
\hline $1 \times 5$ & Gaúcha x BR 80-14853 & $4 \times 8$ & BR 80-8858 x PI 239235 \\
\hline $1 \times 6$ & Gaúcha x PI 123439 & $5 \times 6$ & BR 80-14853 x PI 123439 \\
\hline $1 \times 7$ & Gaúcha x PI 165896 & $5 \times 7$ & BR 80-14853 x PI 165896 \\
\hline $1 \times 8$ & Gaúcha x PI 239235 & $5 \times 8$ & BR 80-14853 x PI 239235 \\
\hline $2 \times 3$ & $\mathrm{La}-4910-215$ x OC 79230 & $6 \times 7$ & PI $123439 \times$ PI 165896 \\
\hline $2 \times 4$ & La-4910-215 x BR 80-8858 & $6 \times 8$ & PI $123439 \times$ PI 239235 \\
\hline $2 \times 5$ & La-4910-215 x BR 80-14853 & $7 \times 8$ & PI $165896 \times$ PI 239235 \\
\hline
\end{tabular}

PIMENTEL (1991) adverte que em dois dos cruzamentos efetuados a identificação de autofecundações não foi possível devido ao pequeno tamanho das sementes $F_{1}$ obtidas. Neste caso, optou-se por manter os cruzamentos e avaliar a respectiva progênie $F_{2}$ em campo, para deteç̧ão de autofecundação. Durante a condução do experimento e coleta de dados na geração $F_{2}$ foi possível constatar que um dos cruzamentos era na realidade autofecundação, sendo este cruzamento eliminado para efeito de análise do dialelo, que foi efetuada com 27 cruzamentos, dos 28 originais.

O experimento para coleta de dados e análise do dialelo na geração $\mathrm{F}_{2}$ foi instalado em campo em dezembro de 1987 , sendo utilizado delineamento de blocos casualizados com sete repetições. As parcelas foram formadas por uma fileira de plantas com três metros de comprimento, espaçada em um metro, contendo trinta plantas, correspondendo a um espaçamento entre plantas de 
aproximadamente dez centímetros. Cada repetição foi constituída por 40 tratamentos, sendo 28 cruzamentos, oito parentais, e quatro testemunhas, além de serem alocados sistematicamente dois controles, IAC Foscarin 31, e IAC - 12, representando os materiais comerciais mais plantados no Estado de São Paulo na ocasião da instalação do experimento, para que fosse possível estimar variações ambientais dentro das repetições. Os caracteres avaliados nesta etapa do trabalho por PIMENTEL (1991), e que foram comparados aos resultados de análise em gerações avançadas, referem-se à Altura da Planta na Maturação, avaliada em centímetros, do solo ao último internódio por ocasião da maturação fisiológica, e Produtividade de Grãos, correspondente ao peso médio em gramas por planta, avaliado em plantas individuais.

Neste experimento foram colhidas plantas individuais da geração $F_{2: 3}$, onde cada cruzamento foi representado por 20 progênies $F_{2: 3}$. A geração $F_{2: 3}$ foi avançada, até a geração $F_{2: 8}$ utilizando-se um "bulk" de sementes de cada progênie $F_{2: 3}$ original, em cada geração de autofecundação. Nestas etapas de autofecundações, cada progênie representante de um cruzamento foi formada por 30 plantas colhidas em "bulk". Durante a condução das gerações segregantes foram descartados mais dois cruzamentos devido à baixa percentagem de germinação das sementes no campo, restando 25 cruzamentos dos 28 originais.

Em dezembro de 1992 foi instalado um experimento em campo, com a geração $F_{2: 8}$ de 25 dos 28 cruzamentos originais do dialelo. Como as progênies na geração $F_{2: 8}$ estavam na realidade muito próximas à homozigose, desta geração em diante passaram a ser denominadas de progênies $F_{2: n}$. Cada cruzamento estava representado nesta geração por 20 "bulks" $F_{2: n}$, com exceção do cruzamento Gaúcha $x$ BR 80-8858 que contava com apenas treze. Os 
tratamentos foram instalados em campo em látice triplo de $5 \times 5$ com três repetições, e os 20 "bulks" representantes de cada cruzamento foram alocados hierarquicamente dentro do respectivo cruzamento. As parcelas foram constituídas por uma fileira de um metro de comprimento, espaçada da parcela seguinte em um metro, e com número variável de plantas, com estande ideal de 17 plantas.

Os caracteres avaliados nesta geração e nas demais avaliações da geração $F_{2: n}$ foram: Altura da Planta na Maturação, avaliada em centímetros do solo ao último internódio por ocasião da maturação fisiológica, e Produtividade de Grãos, correspondendo ao peso em gramas total da parcela, independentemente do número de plantas.

Após as avaliações em campo e maturação, as parcelas foram colhidas em "bulk" por progênie, por tratamento. Com estas sementes foi possível repetir o experimento no ano seguinte, sendo instalado em campo um experimento exatamente nos mesmos moldes do anterior no início do mês de dezembro de 1993, tendo como a única diferença o espaçamento entre parcelas, que neste ano e nos demais foi de 60 centímetros, ao invés de um metro. Neste ano foram também avaliados os caracteres Altura da Planta na Maturação e Produtividade de Grãos.

Nos anos de 1994/95 e 1995/96 os experimentos foram instalados também nos mesmos moldes do ano de 1993/94, em látice triplo e com o mesmo tamanho e distribuição de parcelas. Nestes experimentos foram também avaliados os caracteres Altura da Planta na Maturação e Produtividade de Grãos. 


\subsection{Análises de Variância dos Dados Experimentais}

As análises efetuadas para os cruzamentos na geração $F_{2: n}$ referemse a médias de parcelas para o caráter Altura da Planta na Maturação, avaliadas em cm por planta, muito embora tenham sido avaliadas cinco plantas representativas da parcela para este caráter. Para Produtividade de Grãos os dados representam totais da parcela, em gramas. Os caracteres avaliados foram submetidos a teste de homocedasticidade, para se verificar a distribuição normal.

As análises de variância ao nível dos cruzamentos da tabela dialélica, para os dados coletados nos quatro anos de avaliação das linhagens na geração $F_{2: n}$, foram realizadas segundo o delineamento de látice, de acordo com a metodologia descrita por COCHRAN \& COX (1957), tomando-se como unidade experimental a média dos 20 "bulks" representantes de cada cruzamento, alocados hierarquicamente no respectivo cruzamento de origem. $O$ teste de significância foi efetuado utilizando-se o erro efetivo da análise de variância segundo delineamento de látice. As comparações de médias de tratamentos foram realizadas utilizando-se as diferenças mínimas significativas calculadas para os níveis de significância de 1 e $5 \%$ de probabilidade. $O$ coeficiente de variação experimental foi obtido da maneira usual, calculando-se a percentagem do desvio padrão do erro intrabloco da análise de variância, segundo o delineamento de látice, em relação à média experimental do caráter avaliado.

Foram também efetuadas análises de variância individuais para cada cruzamento, em cada ano de avaliação bem como a análise conjunta para as quatro avaliações, considerando como unidade experimental, neste caso, os 20 "bulks" representantes de cada cruzamento. As análises foram efetuadas segundo 
delineamento hierárquico, com três repetições. Os parâmetros genéticos puderam ser estimados através das esperanças dos quadrados médios de cada fonte de variação, obtidos de acordo com a metodologia de GAYLOR et al. (1970). Foram estimadas a variância de progênies $\left(\sigma_{\mathrm{p}}^{2}\right)$, a variância da interação entre progênies e anos $\left(\sigma_{\mathrm{pa}}^{2}\right)$, e a variância fenotipica entre médias de progênies $\left(\sigma_{f}^{2}\right)$, utilizadas para se calcular o coeficiente de herdabilidade a nível de médias de "bulks", e o coeficiente de variação genética, segundo VENCOVSKY \& BARRIGA (1992). O intervalo de confiança da variância de progênies foi obtido de acordo com metodologia descrita por BARBIN (1993), isto é:

$$
\mathrm{IC}=\left[\frac{n t \sigma_{\mathrm{p}}^{2}}{\chi_{(\mathrm{nt}, 0,075)}^{2}} \leq \sigma_{\mathrm{P}}^{2} \leq \frac{n t \sigma_{\mathrm{p}}^{2}}{\chi_{(\mathrm{n} ; 0,025)}^{2}}\right]=0,95
$$

Onde os $n t$ graus de liberdade podem ser calculados, para análises individuais, de acordo com:

$$
n t=\frac{\left(\mathrm{QM}_{\mathrm{p}}-\mathrm{QM}_{\mathrm{e}}\right)^{2}}{\frac{\left(\mathrm{QM}_{\mathrm{p}}\right)^{2}}{\mathrm{fp}}+\frac{\left(\mathrm{QM}_{\mathrm{e}}\right)^{2}}{\mathrm{fe}}}
$$

Onde:

$\mathrm{QM}_{\mathrm{p}}=$ quadrado médio de progênies;

$\mathrm{QM}_{\mathrm{e}}=$ quadrado médio do erro;

$\mathrm{fp}$ = graus de liberdade associados à fonte de variação progênies;

$\mathrm{fe}=$ graus de liberdade associados à fonte de variação erro;

$\chi_{\mathrm{nt}}^{2}=$ valor de qui-quadrado com $\mathrm{nt}$ graus de liberdade; 
Para as análises conjuntas os $n t$ graus de liberdade, são estimados, segundo:

$$
n t=\frac{\left(\mathrm{QM}_{\mathrm{p}}-\mathrm{QM}_{\mathrm{pa}}\right)^{2}}{\frac{(\mathrm{QM})^{2}}{\mathrm{fp}}+\frac{\left(\mathrm{QM}_{\mathrm{pa}}\right)^{2}}{\mathrm{fpa}}}
$$

Onde:

$\mathrm{QM}_{\mathrm{p}}=$ quadrado médio de progênies;

$\mathrm{QM}_{\mathrm{pa}}=$ quadrado médio da interação progênies por anos;

$\mathrm{fp}=$ graus de liberdade associados à fonte de variação progênies;

fpa $=$ graus de liberdade associados à fonte de variação da interação entre progênies por anos;

Os intervalos de confiança para os coeficientes de herdabilidade foram obtidos de acordo com a metodologia descrita por KNAPP, et al. (1985). Para as análises individuais este intervalo é calculado de acordo com a seguinte expressão:

$\mathrm{p}\left\{1-\left[\frac{\left(\mathrm{QM}_{\mathrm{p}}\right)}{\left(\mathrm{QM}_{\mathrm{e}}\right)} \mathrm{F}_{(0,975 ; \text { glp }, \text { gle })}\right]^{-1} \leq \mathrm{h}^{2} \leq 1-\left[\frac{\left(\mathrm{QM}_{\mathrm{p}}\right)}{\left(\mathrm{QM}_{\mathrm{e}}\right)} \mathrm{F}_{(0,025 ; \text { glp, gle })}\right]^{-1}\right\}=0,95$

Onde:

$\mathrm{QM}_{\mathrm{p}}=$ Quadrado médio de progênies;

$\mathrm{QM}_{\mathrm{e}}=$ Quadrado médio do erro;

$\mathrm{gl}_{\mathrm{p}}=$ graus de liberdade associados à fonte de variação progênies;

$\mathrm{gl}_{\mathrm{e}}=$ graus de liberdade associados à fonte de variação erro; 
Para as análises conjuntas o intervalo é calculado pela expressão:

$\mathrm{p}\left\{1-\left[\frac{\left(\mathrm{QM}_{\mathrm{p}}\right)}{\left(\mathrm{QM}_{\mathrm{pa}}\right)} \mathrm{F}_{(0,975 ; \text { glp, glpa) }}\right]^{-1} \leq \mathrm{h}^{2} \leq 1-\left[\frac{\left(\mathrm{QM}_{\mathrm{p}}\right)}{\left(\mathrm{QM}_{\mathrm{pa}}\right)} \mathrm{F}_{(0,025 ; \text { glp, glpa) }}\right]^{-1}\right\}=0,95$

Onde:

$\mathrm{QM}_{\mathrm{p}}=$ quadrado médio de progênies;

$\mathrm{QM}_{\mathrm{pa}}=$ quadrado médio da interação progênies por anos;

$\mathrm{gl}_{\mathrm{p}}=$ graus de liberdade associados à fonte de variação progênies;

$\mathrm{gl}_{\mathrm{pa}}=$ graus de liberdade associados à fonte de variação da interação entre progênies por anos;

\subsection{Análise Dialélica}

As análises das tabelas dialélicas para as gerações $F_{2}$ e $F_{2: n}$ nos quatro anos de avaliação foram efetuadas de acordo com o modelo de GRIFFING (1956), sendo utilizado o método 4, modelo misto II, que faz uso de meia tabela dialélica, correspondendo a todos os cruzamentos entre um grupo de linhagens, excluindo-se os parentais e os cruzamentos recíprocos. Os parâmetros do modelo escolhido foram considerados fixos, com exceção do erro experimental, para todas as análises, uma vez que a escolha dos parentais foi efetuada com base em caracteres criteriosamente selecionados. 
A metodologia proposta por GRIFFING (1956) permite a análise da capacidade de combinação decompondo-se os efeitos de cruzamentos, obtidos da análise de variância segundo o delineamento de látice, em efeitos devido à capacidade geral (CGC) e capacidade específica (CEC) de combinação, segundo o modelo:

$$
\bar{Y}_{i j .}=\mu+g_{i}+g_{j}+s_{i j}+\bar{e}_{i j}
$$

Onde:

$\overline{\mathrm{Y}}_{\mathrm{ij} .}=$ média de $\mathrm{k}$ repetições do cruzamento entre o parental $\mathrm{i}$ e o parental j;

$\mu=$ média geral da tabela dialélica;

$\mathrm{g}_{\mathrm{i}}=$ efeito devido à capacidade geral de combinação do parental $\mathrm{i}$;

$\mathrm{g}_{\mathrm{j}}=$ efeito devido à capacidade geral de combinação do parental $\mathrm{j}$;

$\mathrm{s}_{\mathrm{ij}}=$ efeito devido à capacidade específica de combinação para o cruzamento entre os parentais i e j;

$\overline{\mathrm{e}_{\mathrm{ijj}}}$ = erro médio obtido da análise de variância segundo o delineamento utilizado, dividindo-se o resíduo pelo número de repetições;

O modelo estatístico-genético impõe as seguintes restrições para que as estimativas dos parâmetros do modelo sejam válidas:

$\overline{\mathrm{e}}_{\mathrm{ijk} \mathrm{k}}=\mathrm{o}$ erro médio deve ser independente, com distribuição normal, média zero e variância $\sigma^{2}$;

$\sum_{i=1}^{n} g_{i(j)}=0 ;$

$\sum_{j=1}^{n} s_{i j}=0$ (para cada $\left.\mathrm{i}\right) ;$ 
Os efeitos da média e das capacidades geral e específica de combinação foram estimados através do método de mínimos quadrados, e as somas de quadrado dos efeitos do modelo foram obtidas através das reduções do modelo completo.

Através das estimativas dos parâmetros do modelo foram compostas médias de cruzamentos, que para efeito de comparação foram estimadas a partir do modelo reduzido em $\mathrm{F}_{2}$, incluindo os efeitos da média e da capacidade geral de combinação e comparadas às médias experimentais observadas nas avaliações da geração $F_{2: n}$ através do coeficiente de correlação de Spearman, para que se pudesse avaliar a eficiência da seleção de parentais com base nos efeitos da capacidade geral de combinação estimados em gerações com baixo nível de endogamia.

Para que fosse possível a realização da análise dialélica conjunta, para os quatro anos de experimentação, as médias dos três cruzamentos perdidos foram estimadas, para os dois caracteres, através da fórmula proposta por ECKHARDT (1952), pela qual a média de um determinado cruzamento pode ser estimada através da seguinte expressão:

$a \times b=\frac{(n-1)\left(T^{\prime} a+T ' b\right)-2 T}{n^{2}-5 n+6}$

Onde:

a $\times$ b = estimativa do cruzamento para determinado caráter;

n = número de parentais;

$\mathrm{T}$ 'a = somatório da linha do parental "a" em uma tabela dialélica, excluindo-se o valor do cruzamento $\mathrm{a} \mathbf{x} \mathrm{b}$; 
$\mathrm{T}$ 'b = somatório da linha do parental " $\mathrm{b}$ " em uma tabela dialélica, excluindo-se o valor a $\mathrm{x}$ b;

$2 \mathrm{~T}^{\prime}=$ somatório geral da tabela dialélica menos $2 \mathrm{ab}$;

A fórmula descrita não utiliza os parentais para estimativa do cruzamento perdido.

A análise conjunta foi efetuada utilizando-se adaptações às fórmulas originalmente propostas por GRIFFING (1956), considerando no modelo os efeitos de anos, as interações entre cruzamentos por anos, e suas decomposições, de acordo com:

$$
\bar{Y}_{i j k .}=\mu+a_{k}+g_{i}+g_{j}+s_{i j}+g a_{i k}+g a_{j k}+s a_{i j k}+\bar{e}_{i j k}
$$

Onde, além dos efeitos já descritos para o modelo nas análises individuais, temse:

$\mathbf{a}=$ efeito do ano $\mathrm{k}$;

$\mathrm{ga}_{\mathrm{ik}}=$ efeito da interação entre capacidade geral de combinação do parental i com k anos;

$\mathrm{ga}_{\mathrm{jk}}=$ efeito da interação entre capacidade geral de combinação do parental $\mathbf{j}$ com k anos;

$s a_{\mathrm{ijk}}=$ efeito da interação entre a capacidade específica de combinação dos parentais i e j com $\mathrm{k}$ anos;

Para que a análise conjunta pudesse ser efetuada foram também admitidas as seguintes restrições: 


$$
\begin{aligned}
& \sum_{i=1}^{n} g_{i}=\sum_{j=1}^{n} g_{j}=\sum_{a=1}^{n} a_{k}=\sum_{i} g a_{i k}=\sum_{j} g a_{j k}=0 ; \\
& \sum_{j=1}^{n} s_{i j}=\sum_{j=1}^{n} s a_{i j k}=0 \quad(\text { para cada } i) ;
\end{aligned}
$$

As estimativas das capacidades geral e específica de combinação obtidas nas análises dialélicas em gerações avançadas de endogamia foram comparadas às estimativas obtidas na geração $F_{2}$. Os parâmetros obtidos na geração $F_{2}$ foram estimados a partir das médias de cruzamentos apresentadas por PIMENTEL (1991), que analisou dados coletados na geração $F_{2}$, para o mesmo dialelo. Com base nestas comparações espera-se discutir as implicações existentes, do ponto de vista do melhoramento genético, na utilização da metodologia de análise dialélica em gerações com baixo e alto níveis de homozigose, para espécies que como a soja utilizem como material comercial linhagens endogâmicas.

\subsection{Predição da Proporção de Linhagens Superiores por Cruzamento}

A proporção de linhagens superiores a um determinado padrão, para cada um dos 25 cruzamentos da tabela dialélica, foi calculada através da metodologia descrita por TOLEDO (1987), de acordo com:

$$
\mathrm{PS}=\frac{\mathrm{PD}-\overline{\mathrm{F}}_{\mathrm{n}}}{\left(\sigma_{\mathrm{A}}^{2}\right)^{1 / 2}}
$$


Onde:

$\mathrm{PS}=$ proporção de linhagens superiores ao padrão PD a serem obtidas após endogamia;

$\mathrm{PD}=$ padrão adotado como limite para obtenção de linhagens superiores. Foram considerados como padrão a média de todos os cruzamentos, e a média mais um desvio padrão, para as gerações $F_{2}$ e $F_{2: n}$, segundo os quatro anos de avaliação e análise conjunta;

$\overline{\mathrm{F}}_{\mathrm{n}}=$ média da geração em que foram estimados os parâmetros para a predição. Foram utilizadas a média da geração $F_{2} \mathrm{e}$ da geração $F_{2: n}$, nos quatro anos de avaliação e análise conjunta;

$\sigma_{A}^{2}=$ variância genética aditiva. Sendo:

$\sigma_{A}^{2}=\sigma_{F 2}^{2}-(1 / 2)\left(\sigma_{P A}^{2}+\sigma_{P B}^{2}\right)$ para a geração $F_{2}$ no cruzamento A x B, admitindo que a porção da variância de dominância, e a variância epistática do tipo aditivo $\mathrm{x}$ dominante ou superiores sejam de pequena magnitude em relação aos efeitos aditivos dos genes.

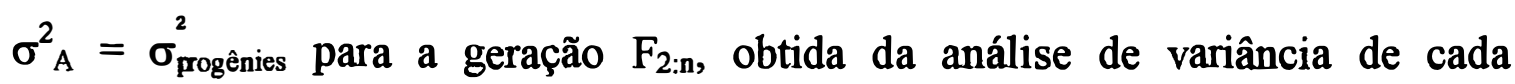
cruzamento. 


\section{RESULTADOS E DISCUSSÃO}

\subsection{Análises de Variância ao Nível dos Cruzamentos da Tabela Dialélica}

Os resultados das análises de variância à nível de cruzamentos, avaliados na geração $F_{2: n}$, para os caracteres Altura da Planta na Maturação e Produtividade de Grãos, segundo o delineamento de látice, bem como as médias experimentais, amplitudes de variação e coeficientes de variação são apresentados nas Tabelas 2 e 3 respectivamente, para os quatro anos de avaliação.

Os dois caracteres avaliados apresentaram valores significativos do teste F para tratamentos ajustados, nos quatro anos de avaliação, demonstrando haver variabilidade entre médias de cruzamentos para estes caracteres, o que pode ser confirmado pelas grandes amplitudes de variação observadas, que para 0 caráter Altura da Planta na Maturação atingiu valores ao redor de metade da média experimental, e para Produtividade de Grãos alcançou valores próximos à própria média, considerando o conjunto das quatro avaliações. Ao mesmo tempo em que os coeficientes de variação assumiram valores baixos, variando de 3,32 a $5,36 \%$ para o caráter Altura da Planta na Maturação e 6,40 a 10,68 \% para Produtividade de Grãos, o que demonstra boa precisão experimental. A boa precisão experimental, evidenciada pelos baixos valores obtidos para os coeficientes de variação, pode ser atribuída ao fato de que cada cruzamento esteve 
representado pela média de 20 "bulks" $\mathrm{F}_{2: \mathrm{n}}$, alocados hierarquicamente dentro de cruzamentos, com exceção do cruzamento Gaúcha x BR 80-8858 que contava com apenas 13 "bulks".

Tabela 2. Análises de variância para os caracteres Altura da Planta na Maturação (cm / planta) e Produtividade de Grãos (gramas / parcela), na geração $\mathrm{F}_{2: n}$, e nos quatro anos de avaliação, considerando a média dos "bulks" $\mathrm{F}_{2: \mathrm{n}}$ como unidade experimental.

\begin{tabular}{|c|c|c|c|c|c|c|c|c|}
\hline \multicolumn{9}{|c|}{ Altura da Planta na Maturação } \\
\hline & \multicolumn{2}{|c|}{$\mathrm{F}_{2 \mathrm{n}}$ ano $1992 / 93$} & \multicolumn{2}{|c|}{$F_{2 \text { n }}$ ano $1993 / 94$} & \multicolumn{2}{|c|}{$F_{2, n}$ ano $1994 / 95$} & \multicolumn{2}{|c|}{$F_{2: n}$ ano $1995 / 96$} \\
\hline F. Variação & $\mathrm{Gl}$ & $\mathrm{QM}$ & $\mathrm{Gl}$ & $\mathrm{QM}$ & $\mathrm{Gl}$ & $\overline{\mathrm{QM}}$ & $\mathrm{Gl}$ & QM \\
\hline Repetições & 2 & 214,01 & 1 & 35,82 & 2 & 105,47 & 2 & 67,68 \\
\hline Blocos (aj.) & 12 & 7,77 & 8 & 17,79 & 12 & 11,17 & 12 & 12,88 \\
\hline Tratam. (n.aj.) & 24 & 254,99 & 24 & 391,97 & 24 & 212,79 & 24 & 275,44 \\
\hline Tratam. (aj.) & 24 & $244,77^{* *}$ & 24 & $349,57^{* *}$ & 24 & $212,79^{* *}$ & 24 & $268,29^{* *}$ \\
\hline Erro Intrabloco & 36 & 5,97 & 16 & 10,05 & 36 & 17,09 & 36 & 9,65 \\
\hline Total & 74 & 92,65 & 49 & 198,90 & 74 & 81,99 & 74 & 97,94 \\
\hline $\mathrm{CV} \%$ & & 3,32 & & 3,75 & & 5,36 & & 4,68 \\
\hline Erro Efetivo & & 6,32 & & 11,50 & & 17,09 & & 10,25 \\
\hline Precisão / Bloc. & & 101,65 & & 109,76 & & 91,34 & & 101,98 \\
\hline
\end{tabular}

\begin{tabular}{|c|c|c|c|c|c|c|c|c|}
\hline \multicolumn{9}{|c|}{ Produtividade de Grãos } \\
\hline & \multicolumn{2}{|c|}{$F_{2: n}$ ano $1992 / 93$} & \multicolumn{2}{|c|}{$F_{2 n}$ ano $1993 / 94$} & \multicolumn{2}{|c|}{$\mathrm{F}_{2 \mathrm{n}}$ ano $1994 / 95$} & \multicolumn{2}{|c|}{$\mathrm{F}_{2 \mathrm{n}}$ ano $1995 / 96$} \\
\hline F. Variação & Gl & $\mathrm{QM}$ & $\mathrm{Gl}$ & QM & Gl & $\mathrm{QM}$ & Gl & QM \\
\hline Repetições & 2 & 5432,46 & 1 & 7518,05 & 2 & 1970,87 & 2 & 2812,00 \\
\hline Blocos (aj.) & 12 & 2890,82 & 8 & 406,86 & 12 & 536,22 & 12 & 259,48 \\
\hline Tratam. (n.aj.) & 24 & 9019,22 & 24 & 3075,68 & 24 & 4063,82 & 24 & 3385,28 \\
\hline Tratam. (aj.) & 24 & $6278,66^{* *}$ & 24 & $2887,89^{* *}$ & 24 & $3713,75^{* *}$ & 24 & $2780,40^{* *}$ \\
\hline Erro Intrabloco & 36 & 447,33 & 16 & 190,07 & 36 & 270,80 & 36 & 82,24 \\
\hline Total & 74 & 3758,38 & 49 & 1788,38 & 74 & 1589,96 & 74 & 1256,02 \\
\hline CV \% & & 8,17 & & 6,57 & & 10,68 & & 6,40 \\
\hline Erro Efetivo & & 541,86 & & 223,83 & & 304,31 & & 96,29 \\
\hline Precisão / Bloc. & & 195,29 & & 117,20 & & 110,79 & & 131,43 \\
\hline
\end{tabular}


Tabela 3. Médias de cruzamentos para os caracteres Altura da Planta na Maturação (cm / planta) e Produtividade de Grãos (gramas / parcela), na geração $F_{2: n}$, nos quatro anos de avaliação, considerando a média dos "bulks" $F_{2: n}$ como unidade experimental.

\begin{tabular}{|c|c|c|c|c|c|c|c|c|}
\hline \multirow[b]{2}{*}{$\begin{array}{l}\text { Cruza- } \\
\text { mento }\end{array}$} & \multicolumn{2}{|c|}{$\mathrm{F}_{2 \mathrm{n}}$ ano $1992 / 93$} & \multicolumn{2}{|c|}{$\mathrm{F}_{2: \mathrm{n}}$ ano $1993 / 94$} & \multicolumn{2}{|c|}{$F_{2 n}$ ano $1994 / 95$} & \multicolumn{2}{|c|}{$\mathrm{F}_{2 \mathrm{n}}$ ano $1995 / 96$} \\
\hline & $\begin{array}{c}\text { Altura na } \\
\text { Maturação }\end{array}$ & $\begin{array}{l}\text { Produção } \\
\text { de Grãos }\end{array}$ & $\begin{array}{l}\text { Altura na } \\
\text { Maturação }\end{array}$ & $\begin{array}{l}\text { Produção } \\
\text { de Grãos }\end{array}$ & $\begin{array}{c}\text { Altura na } \\
\text { Maturação }\end{array}$ & $\begin{array}{l}\text { Produção } \\
\text { de Grãos }\end{array}$ & $\begin{array}{c}\text { Altura na } \\
\text { Maturação }\end{array}$ & $\begin{array}{l}\text { Produção } \\
\text { de Grãos }\end{array}$ \\
\hline $1 \times 2$ & 77,13 & 247,66 & 86,22 & 243,90 & 86,50 & 188,36 & 70,27 & 150,88 \\
\hline $1 \times 3$ & 63,14 & 279,00 & 75,17 & 263,22 & 70,33 & 200,88 & 62,44 & 182,65 \\
\hline $1 \times 4$ & 59,48 & 305,33 & 58,60 & 245,91 & 65,26 & 232,14 & 55,32 & 187,82 \\
\hline $1 \times 6$ & 60,25 & 136,58 & 67,02 & 151,53 & 65,17 & 101,88 & 50,83 & 88,03 \\
\hline $1 \times 7$ & 74,02 & 236,88 & 86,51 & 159,30 & 79,92 & 113,04 & 68,08 & 112,70 \\
\hline $1 \times 8$ & 75,70 & 267,00 & 89,69 & 181,33 & 81,33 & 159,83 & 65,84 & 146,86 \\
\hline $2 \times 3$ & 76,54 & 293,21 & 84,02 & 257,42 & 78,17 & 202,38 & 66,49 & 174,51 \\
\hline $2 \times 4$ & 80,85 & 296,27 & 93,70 & 255,10 & 81,95 & 160,25 & 78,26 & 176,10 \\
\hline $2 \times 5$ & 79,44 & 275,99 & 85,62 & 247,32 & 75,16 & 137,82 & 71,03 & 162,86 \\
\hline $2 \times 6$ & 75,49 & 165,79 & 91,78 & 193,52 & 79,21 & 115,97 & 66,28 & 105,42 \\
\hline $2 \times 8$ & 97,89 & 275,34 & 115,20 & 190,97 & 98,81 & 147,66 & 92,21 & 154,49 \\
\hline $3 \times 5$ & 64,07 & 288,23 & 71,63 & 272,46 & 67,42 & 177,99 & 60,60 & 197,65 \\
\hline $3 \times 6$ & 67,87 & 233,99 & 71,57 & 194,73 & 70,75 & 172,62 & 56,23 & 127,21 \\
\hline $3 \times 7$ & 69,89 & 258,27 & 85,27 & 211,13 & 78,99 & 164,07 & 64,22 & 132,97 \\
\hline $3 \times 8$ & 78,90 & 316,50 & 99,13 & 230,59 & 82,52 & 206,75 & 74,68 & 173,30 \\
\hline $4 \times 5$ & 66,27 & 373,86 & 70,16 & 278,18 & 70,17 & 213,21 & 58,48 & 196,13 \\
\hline $4 \times 6$ & 60,20 & 196,82 & 64,78 & 155,66 & 64,17 & 126,01 & 52,37 & 116,89 \\
\hline $4 \times 7$ & 80,43 & 302,60 & 91,04 & 210,54 & 82,75 & 146,47 & 71,29 & 124,20 \\
\hline $4 \times 8$ & 83,14 & 320,03 & 92,84 & 231,88 & 84,00 & 175,20 & 72,71 & 162,98 \\
\hline $5 \times 6$ & 66,45 & 218,17 & 71,16 & 208,12 & 67,58 & 137,39 & 55,64 & 116,64 \\
\hline $5 \times 7$ & 67,69 & 224,34 & 77,23 & 173,58 & 74,25 & 106,96 & 66,04 & 118,55 \\
\hline $5 \times 8$ & 77,85 & 283,65 & 93,97 & 201,30 & 79,42 & 137,52 & 70,76 & 143,34 \\
\hline $6 \times 7$ & 72,53 & 213,96 & 80,83 & 175,72 & 74,34 & 106,90 & 59,64 & 86,93 \\
\hline $6 \times 8$ & 79,41 & 239,18 & 96,74 & 174,84 & 82,59 & 112,49 & 65,27 & 111,79 \\
\hline $7 \times 8$ & 87,01 & 226,99 & 113,89 & 141,19 & 89,43 & 109,48 & 83,14 & 94,31 \\
\hline Média & 73,67 & 259,03 & 84,55 & 209,98 & 77,21 & 154,13 & 66,33 & 141,81 \\
\hline$\sigma$ Padrão & 9,24 & 51,81 & 14,11 & 40,61 & 8,42 & 38,37 & 9,63 & 34,09 \\
\hline Menor & 59,48 & 136,58 & 58,60 & 141,19 & 64,17 & 101,88 & 50,83 & 86,93 \\
\hline Maior & 97,89 & 373,86 & 115,20 & 278,18 & 98,81 & 232,14 & 92,21 & 197,65 \\
\hline Amplit. & 38,41 & 237,28 & 56,60 & 136,99 & 34,64 & 130,25 & 41,38 & 110,73 \\
\hline$\overline{\operatorname{DMS}}(0,01)$ & 5,55 & 46,96 & 9,26 & 40,27 & 8,65 & 36,54 & 7,08 & 20,14 \\
\hline DMS $(0,05)$ & 4,16 & 35,02 & 6,72 & 29,23 & 6,49 & 27,25 & 5,31 & 15,02 \\
\hline
\end{tabular}

A precisão em relação a blocos casualizados, para o caráter Altura da Planta na Maturação, não ultrapassou aos $10 \%$, sendo nula para o ano de 1994/95, indicando que este caráter não é sensível a variações ambientais de pequena magnitude, capazes de justificar o controle local dentro de blocos. 
Todavia, para o caráter Produtividade de Grãos as magnitudes da eficiência do delineamento de látice foram sempre elevadas, demonstrando que este caráter é bastante sensível às pequenas variações no ambiente experimental, e que o controle local dentro de blocos se mostra necessário e eficiente.

A média geral experimental para o caráter Altura da Planta na Maturação revela um melhor desenvolvimento vegetativo no ano de 1993/94, bem como uma maior amplitude de variação, indicando que neste ano as condições de experimentação permitiram melhor expressão do potencial genético das progênies de cada cruzamento. Para Produtividade de Grãos os maiores valores da média experimental e amplitude de variação ocorreram em 1992/93; todavia é necessário ressaltar que neste ano agrícola as parcelas, embora contivessem o mesmo formato e com o mesmo número médio de plantas, eram espaçadas em um metro, ao contrário dos demais anos de avaliação em que o espaçamento utilizado foi de 60 centímetros.

As maiores médias de cruzamentos para o caráter Altura da Planta na Maturação foram obtidas em cruzamentos onde participaram os parentais PI 239235, La-4910-215 e PI 165896, indicando que estas linhagens contribuíram para aumentar a altura média das progênies $F_{2: n}$ nos cruzamentos em que participaram, sendo uma delas de crescimento indeterminado, uma de crescimento intermediário e uma de crescimento determinado. Por outro lado, os parentais Gaúcha, BR 80-14853 e PI 123439, contribuíram para reduzir a altura média dos cruzamentos em que foram utilizados como parentais, tendo duas destas linhagens crescimento indeterminado e a terceira crescimento determinado, o que evidencia que o hábito de crescimento não está diretamente relacionado com o incremento na altura média das progênies obtidas. 
Em relação ao caráter Produtividade de Grãos, os cruzamentos que apresentaram as maiores médias foram obtidos com a participação dos parentais OC 79230 e BR 80-8858, que são linhagens provenientes de programas de melhoramento conduzidos no País, sendo portanto materiais adaptados. Os cruzamentos de pior desempenho envolveram os parentais PI 123439 e PI 165896, que são introduções de germoplasma americano e que não manifestaram boa adaptação às condições de cultivo a que foram submetidos.

Os erros efetivos obtidos das análises de variância segundo 0 delineamento de látice, e que foram utilizados como resíduo nas análises de variância segundo modelo dialélico, variaram de 6,32 (cm / planta) ${ }^{2}$ em 1992/93 a $17,09$ (cm / planta $)^{2}$ em 1994/95 para o caráter Altura da Planta na Maturação, podendo ser considerados homogêneos uma vez que a razão entre a maior e a menor variância residual não atingiu o valor 7 , de acordo com o discutido por GOMES (1987). Para Produtividade de Grãos o menor valor obtido para o erro efetivo foi de 96,29 (gramas / parcela) ${ }^{2}$ no ano de 1995/96 e o maior valor foi de 541,86 (gramas / parcela) ${ }^{2}$ obtido em 1992/93, também demonstrando homogeneidade de resíduos para este caráter, muito embora a proporção entre resíduos tenha atingido o valor de 5,6 que é um valor elevado, mas justificável uma vez que no ano de 1992/93 o espaçamento entre parcelas era de um metro ao contrário dos demais, em que o espaçamento foi de 60 centímetros. A homogeneidade da variância residual possibilitou a realização das análises dialélicas conjuntas, entre os quatro anos de avaliação dos cruzamentos na geração $\mathrm{F}_{2: \mathrm{n}}$. 


\subsection{Análises de Variância ao Nível de Progênies}

Os resultados das análises de variância individuais na geração $F_{2: n}$ para cada cruzamento, bem como as análises conjuntas por cruzamento para os quatro anos de avaliação, efetuadas segundo delineamento hierárquico, são apresentados na LISTA DE TABELAS E FIGURAS nas Tabelas 10 a 35 para 0 caráter Altura da Planta na Maturação, e nas Tabelas 36 a 61 para Produtividade de Grãos, considerando os "bulks" $F_{2: n}$ dentro de cruzamentos como unidade experimental. As análises conjuntas puderam ser efetuadas para os dois caracteres avaliados e para todos os cruzamentos, uma vez que a razão entre o maior e o menor quadrado médio residual entre as avaliações de cada cruzamento foi sempre inferior a sete, demonstrando haver homogeneidade de variâncias residuais, conforme discute GOMES (1987), com exceção do cruzamento Gaúcha x La-4910-215 para o caráter Produtividade de Grãos, em que esta proporção atingiu 7,3 .

Os coeficientes de variação experimental para o caráter Altura da Planta na Maturação, nas análises individuais por cruzamento, mostraram-se elevados em relação à análise segundo o delineamento de látice, mas não atingiram $20 \%$, o que ainda é um valor bastante razoável em experimentação agrícola. Os valores obtidos para as amplitudes de variação situaram-se próximos a metade do valor da média experimental, para a maioria dos cruzamentos. Já para o caráter Produtividade de Grãos os coeficientes de variação experimental se mostraram elevados, atingindo em determinados anos, e para alguns cruzamentos, valores superiores a $40 \%$, o que certamente se refletiu em maiores erros associados às estimativas obtidas dos parâmetros genéticos. Para este caráter os valores das amplitudes de variação estiveram ao redor da média experimental, 
para a maioria dos cruzamentos, todavia puderam ser observadas amplitudes de variação superiores ao valor da média experimental, o que aliado a presença de variabilidade genética indica condições bastante favoráveis à seleção.

As médias experimentais e amplitudes de variação observadas revelam que para o caráter Altura da Planta na Maturação no ano de 1993/94 as progênies avaliadas apresentaram um melhor desenvolvimento vegetativo. Para 0 caráter Produtividade de Grãos o melhor desempenho ocorreu no ano de 1992/93, e as mesmas considerações da análise em delineamento de látice podem ser feitas.

Através das esperanças matemáticas dos quadrados médios puderam ser estimados parâmetros genéticos para cada cruzamento, individualmente em cada ano de experimentação e a partir da análise conjunta. Os parâmetros obtidos a partir da análise conjunta têm a vantagem de serem estimativas isentas dos efeitos da interação genótipos por ambientes, de acordo com as considerações de VENCOVSKY \& BARRIGA (1992), o que fica evidente quando se observa as menores amplitudes dos intervalos de confiança associados a estas estimativas quando obtidas na análise conjunta.

As estimativas das variâncias genéticas, entre progênies dentro de cruzamentos, se mostraram muito influenciadas pelo ano de experimentação, para os dois caracteres avaliados, e variando de acordo com o cruzamento considerado, o que demonstra que as progênies avaliadas evidenciaram seu potencial genético de maneira diferente, segundo os quatro anos de experimentação. Os intervalos de confiança associados às estimativas da variância genética de progênies apresentaram amplitudes elevadas para os dois caracteres avaliados, em especial para o caráter Produtividade de Grãos, em que para determinados cruzamentos e 
anos revelam total falta de precisão nas estimativas de variância obtidas, devendo neste caso ser desconsideradas.

As estimativas dos coeficientes de herdabilidade entre médias de "bulks", também se mostraram bastante variáveis em função do ano de experimentação, uma vez que são diretamente dependentes das estimativas da variância genética de progênies. De maneira geral, considerando os 25 cruzamentos avaliados nos quatro anos de experimentação e na análise conjunta, os coeficientes de herdabilidade estimados para o caráter Altura da Planta na Maturação mostraram valores elevados, apresentando média de 0,70 . As menores amplitudes dos intervalos de confiança das estimativas dos coeficientes de herdabilidade foram obtidas para os cruzamentos em que participaram os parentais La-4910-215 e PI 165896, muito embora estas amplitudes tenham se mostrado muito altas para a maioria dos cruzamentos.

Ainda em relação ao caráter Altura da Planta na Maturação, os cruzamentos em que foram obtidos os maiores valores dos coeficientes de herdabilidade, e com as menores amplitudes dos intervalos de confiança associados, foram os cruzamentos em que estavam envolvidos os parentais La4910-215 e PI 165896, que apresentaram também os maiores valores para os coeficientes de variação genética. Estes parentais também proporcionaram as melhores médias de "bulks" $F_{2: n}$, demonstrando haver condições bastante favoráveis a obtenção de ganhos genéticos com seleção, muito embora em determinadas populações seja mais interessante a seleção no sentido de se reduzir a altura média das progênies, especialmente nos casos onde haja associação positiva entre a altura de plantas e acamamento. 
Em relação à Produtividade de Grãos, os valores obtidos para os coeficientes de herdabilidade, apresentaram média de 0,55 , o que para as condições experimentais existentes neste trabalho representam valores de herdabilidade média, havendo no entanto determinados cruzamentos onde os valores obtidos para este parâmetro foram sempre altos, nos quatro anos de experimentação e análise conjunta, principalmente nos cruzamentos em que estavam envolvidos os parentais BR 80-8858 e PI 123439. As amplitudes dos intervalos de confiança das estimativas dos coeficientes de herdabilidade, para os cruzamentos em que participaram estes dois parentais, foram de menor magnitude quando comparados aos demais cruzamentos, todavia analisando-se o conjunto dos cruzamentos avaliados estas amplitudes foram sempre elevadas, também para este caráter.

Nos cruzamentos em que participou o parental PI 123439, muito embora os coeficientes de herdabilidade tenham se mostrado ligeiramente mais elevados do que para os demais, para o caráter Produtividade de Grãos, as médias experimentais apresentaram valores inferiores, em relação ao parental BR 808858. Os parentais BR 80-8858 e PI 123439 foram também responsáveis pelos maiores valores obtidos para o coeficiente de variação genética, indicando haver maiores possibilidades de ganhos com seleção para estes cruzamentos. Particularmente nos cruzamentos em que participou o parental BR 80-8858 as condições para ganhos com seleção são as mais efetivas, uma vez que nestes cruzamentos as médias são de maneira geral elevadas, os coeficientes de herdabilidade também são altos, e os valores do coeficiente de variação genética são os maiores obtidos. 
Os valores dos coeficientes de variação genética obtidos para 0 caráter Altura da Planta na Maturação foram mais expressivos para os cruzamentos em que participaram os parentais La-4910-215, PI 165896 e PI 239235 , atingindo valores ao redor de $15 \%$, ao mesmo tempo em que os valores do quociente entre os coeficientes de variação genética e ambiental, estiveram sempre próximos ou superiores a 1 , indicando uma situação bastante favorável à obtenção de progressos com seleção, conforme discutido por VENCOVSKY \& BARRIGA (1992).

É interessante ressaltar que para o caráter Altura da Planta na Maturação os parentais La-4910-215, PI 165896 e PI 239235 contribuíram para aumentar a altura média das progênies nos cruzamentos em que participaram, conforme discutido anteriormente, proporcionando também os cruzamentos com as maiores variâncias, o que indica uma situação bastante favorável à seleção de progênies com maior Altura da Planta na Maturação. Todavia, os parentais Gaúcha, BR 80-14853 e PI 123439, responsáveis pelos cruzamentos com menores médias, foram também responsáveis pelas menores variâncias observadas entre os cruzamentos avaliados, revelando que a seleção para redução da altura da planta deve conduzir a progressos com seleção de maneira mais lenta, quando comparado à seleção no sentido contrário. 


\subsection{Análises Dialélicas}

As análises de variância segundo o modelo de GRIFFING (1956) método 4, parâmetros do modelo estimados, e médias experimentais e estimadas a partir dos parâmetros do modelo, para as gerações $F_{2}$ e $F_{2: n}$ nas quatro avaliações e análise conjunta, para os caracteres Altura da Planta na Maturação e Produtividade de Grãos são apresentadas na LISTA DE TABELAS E FIGURAS nas Tabelas 62 a 72 . A Tabela 4 apresenta um resumo das análises de variância individuais nas gerações $F_{2}$ e $F_{2: n}$ nos quatro anos de experimentação e análise conjunta, para o caráter Altura da Planta na Maturação.

Tabela 4. Resumo das análises de variância das tabelas dialélicas, segundo o modelo de Griffing (1956) método 4, para o caráter Altura da Planta na Maturação (cm / planta), nas gerações $F_{2}$, e $F_{2: n}$ nos quatro anos de avaliação e análise conjunta das quatro avaliações.

\begin{tabular}{|c|c|c|c|c|c|c|c|c|c|c|c|c|}
\hline \multirow[t]{2}{*}{ Fonte de Variação } & \multicolumn{2}{|r|}{ F2 } & \multicolumn{2}{|c|}{$1992 / 93$} & \multicolumn{2}{|c|}{$1993 / 94$} & \multicolumn{2}{|c|}{$1994 / 95$} & \multicolumn{2}{|c|}{$1995 / 96$} & \multicolumn{2}{|c|}{ Anál. Conjunta } \\
\hline & $\mathrm{Gl}$ & $\overline{\mathrm{QM}}$ & 1 & $\overline{Q M}$ & $\mathrm{Gl}$ & $\mathrm{QM}$ & 1 & $\overline{\mathrm{QM}}$ & $\mathrm{Gl}$ & $\mathrm{QM}$ & $\mathrm{Gl}$ & QM \\
\hline Cruze & 26 & $135,13^{* *}$ & 24 & ** & 24 & 19 & 24 & $70,93^{* *}$ & 24 & $92,63^{* *}$ & $\begin{array}{c}3 \\
24\end{array}$ & $\begin{array}{r}1505.77^{* *} \\
517,91^{* *}\end{array}$ \\
\hline C. & - & $449,51^{* *}$ & 7 & 265, & 7 & 629 & -6 & $219,05^{* *}$ & 7 & $285,65^{* *}$ & 7 & $1842,75^{* *}$ \\
\hline C.E.C. & 19 & $19,30^{* *}$ & 17 & $11,16^{* *}$ & 17 & $21,80^{* *}$ & 17 & $9,94^{\text {ns }}$ & 17 & $13,15^{* *}$ & 17 & $54,22^{* *}$ \\
\hline$A \times C$ & & & & & & & & & & & 72 & $14,92^{* *}$ \\
\hline C.G. & & & & & & & & & & & 21 & $43,94^{* *}$ \\
\hline C.E.C. $\times \mathrm{A}$ & & & & & & & & & & & 1 & $4,77^{\mathrm{ns}}$ \\
\hline Erro & 156 & 6,12 & 36 & 2,11 & 16 & 5,75 & 36 & 5,70 & 36 & 3,42 & 124 & 4,24 \\
\hline
\end{tabular}

Os resultados apresentados na Tabela 4 revelam que existe variação significativa entre as médias de cruzamentos para as gerações $F_{2}$ e $F_{2: n}$ nas quatro avaliações e análise conjunta. $O$ efeito de cruzamentos foi decomposto nas capacidades geral e específica de combinação, sendo os efeitos da capacidade geral de combinação associados aos efeitos aditivos e de dominância dos genes, e a capacidade específica de combinação atribuída aos efeitos de dominância e epistáticos do tipo aditivo $\mathrm{x}$ aditivo, aditivo $\mathrm{x}$ dominante, dominante $\mathrm{x}$ dominante 
ou superiores para a geração $F_{2}$. Para a geração $F_{2: n}$ os efeitos da capacidade geral de combinação foram associados somente aos efeitos aditivos dos genes, e os efeitos da capacidade específica de combinação, nesta geração, associados aos efeitos epistáticos tipo aditivo $\mathrm{x}$ aditivo ou superiores, de acordo com STUTHMAN \& STUCKER (1975) e CHOO et al. (1986), uma vez que os cruzamentos estavam representados por um conjunto de "bulks" em homozigose. Os efeitos da capacidade geral de combinação foram sempre significativos, e as somas de quadrados deste efeito apresentaram magnitude muito superior em relação às somas de quadrados da capacidade específica de combinação, o que evidencia a importância dos efeitos aditivos dos genes na determinação deste caráter.

Efeitos da capacidade específica de combinação, foram significativos para $F_{2}$ e $F_{2: n}$ em três das quatro avaliações e também na análise conjunta. $\mathrm{Na}$ geração $\mathrm{F}_{2}$ os efeitos da capacidade específica de combinação podem ser atribuídos, entre outros efeitos, aos desvios de dominância gênica, que neste caso se mostraram importantes, uma vez que apresentaram valores para o teste $\mathrm{F}$ altamente significativos. $\mathrm{O}$ modelo reduzido, excluindo-se o efeito devido a capacidade específica de combinação, nesta geração, apresenta coeficiente de determinação de 0,9 , indicando que este efeito foi responsável por $10 \%$ da variabilidade entre as médias da tabela dialélica, e que portanto não pode ser desconsiderado, muito embora os efeitos da capacidade geral de combinação tenham sido responsáveis por $90 \%$ da variabilidade das médias, conforme descrito na Tabela 62, da LISTA DE TABELAS E FIGURAS.

$\mathrm{Na}$ geração $\mathrm{F}_{2: \mathrm{n}}$ os efeitos da capacidade específica de combinação foram também sempre altamente significativos, com exceção do ano agrícola de 
1994/95, e os coeficientes de determinação dos modelos reduzidos, eliminando-se este efeito, variaram de 0,90 a 0,92 , de acordo com as Tabelas 64, 66, 68 e 70 da LISTA DE TABELAS E FIGURAS. Fica evidente que os efeitos epistáticos tipo aditivo $\mathrm{x}$ aditivo ou superiores se mostraram importantes para explicar a variação entre médias de cruzamentos da tabela dialélica, sendo responsáveis por no mínimo oito porcento desta variação.

Muito embora os efeitos aditivos dos genes tenham sido sempre de maior magnitude em relação aos efeitos epistáticos, a análise dialélica tem por pressuposto a ausência de efeitos epistáticos, conforme discutido por $\mathrm{CHOO}$ et al. (1988). Os efeitos epistáticos devem interferir na classificação dos parentais com base nos efeitos da capacidade geral de combinação, estimados a partir das gerações $F_{1}$ ou $F_{2}$, com o propósito de seleção de cruzamentos de maior potencial para extração de linhagens puras, como acontece com cultivares de soja.

$O$ efeito de anos também se mostrou altamente significativo na análise dialélica conjunta entre as quatro avaliações dos "bulks" $F_{2: n}$, revelando que as condições experimentais não se mantiveram constantes ao longo das quatro avaliações. Da mesma forma as interações entre anos $\mathrm{x}$ cruzamentos, e anos $\mathbf{x}$ efeitos da capacidade geral de combinação, também foram altamente significativas, indicando que os efeitos da capacidade geral de combinação obtidos a partir da análise conjunta devem ser melhor estimados, uma vez que as interações entre anos e cruzamentos, bem como suas decomposições podem ser isoladas na análise conjunta. Efeitos da interação entre capacidade específica de combinação $\mathrm{x}$ anos não se mostraram significativos, todavia é necessário ressaltar que a magnitude deste efeito é muito pequena em relação aos demais, principalmente em relação ao resíduo experimental. 
O resumo das análises de variância individuais das médias das tabelas dialélicas, nas gerações $F_{2}$, e $F_{2: n}$ nos quatro anos de avaliação e análise conjunta das quatro avaliações de $\mathrm{F}_{2: n}$; para o caráter Produtividade de Grãos, é apresentado na Tabela 5. O efeito de cruzamentos se mostrou sempre altamente significativo, nas gerações $F_{2}$ e $F_{2: n}$ nas quatro avaliações e análise conjunta, confirmando que existe variabilidade entre médias de cruzamentos das tabelas dialélicas também para este caráter.

Tabela 5. Resumo das análises de variância das tabelas dialélicas, segundo o modelo de Griffing (1956) método 4, para o caráter Produtividade de Grãos (gramas / parcela), nas gerações $F_{2}$ e $F_{2: n}$ nas quatro avaliações e análise conjunta.

\begin{tabular}{|c|c|c|c|c|c|c|c|c|c|c|c|c|}
\hline \multirow[t]{2}{*}{ Fonte de Var. } & \multicolumn{2}{|r|}{$\mathrm{F} 2$} & \multicolumn{2}{|c|}{$1992 / 93$} & \multicolumn{2}{|c|}{$1993 / 94$} & \multicolumn{2}{|c|}{$1994 / 95$} & \multicolumn{2}{|c|}{$1995 / 96$} & \multicolumn{2}{|c|}{ Anál. Conjunta } \\
\hline & Gl & $\mathrm{QM}$ & $\mathrm{Gl}$ & $\mathrm{QM}$ & $\mathrm{Gl}$ & $\mathrm{QM}$ & $\mathrm{Gl}$ & $\mathrm{OM}$ & Gl & $\mathrm{QM}$ & $\mathrm{Gl}$ & $\overline{\mathrm{QM}}$ \\
\hline $\begin{array}{l}\text { Anos (A) } \\
\text { Cruzamen. (C) } \\
\text { C.G.C. } \\
\text { C.E.C. } \\
\text { A x C } \\
\text { C.G.C. } \times \text { A } \\
\text { C.E.C. } \times \text { A } \\
\end{array}$ & $\begin{array}{c}26 \\
7 \\
19\end{array}$ & $\begin{array}{r}19,50^{* *} \\
57,65^{* *} \\
3,57^{\text {ns }}\end{array}$ & $\begin{array}{c}24 \\
7 \\
17\end{array}$ & $\begin{array}{c}2683,74^{* *} \\
7412,31^{* *} \\
736,68\end{array}$ & $\begin{array}{c}24 \\
7 \\
17\end{array}$ & $\begin{array}{r}1649,26^{*} \\
4584,05^{*} \\
440,82^{*}\end{array}$ & $\begin{array}{c}24 \\
7 \\
17\end{array}$ & $\begin{array}{r}1471,87^{*} \\
4046,82^{*} \\
411,60^{*}\end{array}$ & $\begin{array}{c}24 \\
7 \\
17\end{array}$ & $\begin{array}{r}1161,79^{* *} \\
3696,23^{* *} \\
118,19^{* *}\end{array}$ & $\begin{array}{c}3 \\
24 \\
7 \\
17 \\
72 \\
21 \\
51 \\
\end{array}$ & $\begin{array}{r}84298,99^{* *} \\
7690,55^{* *} \\
25301,79^{* *} \\
1526,62^{* *} \\
371,64^{* *} \\
992,16^{* *} \\
154,46^{*}\end{array}$ \\
\hline Erro & 156 & 3,41 & 36 & 180,62 & 16 & 111,92 & 36 & 101,44 & 36 & 32,10 & 124 & 106,52 \\
\hline
\end{tabular}

As decomposições do efeito de cruzamentos comprovam, que também para este caráter, os efeitos aditivos dos genes foram sempre importantes, uma vez que apresentaram efeitos altamente significativos para todas as avaliações e análise conjunta. Efeitos devidos à capacidade específica de combinação também se mostraram bastante importantes, uma vez que apresentaram quadrados médios altamente significativos para a geração $F_{2: n} \mathrm{em}$ todas as avaliações e análise conjunta. $\mathrm{Na}$ geração $\mathrm{F}_{2}$ os efeitos da capacidade específica de combinação não foram significativos, devendo-se ressaltar novamente que a magnitude deste efeito é pequena, e portanto a significância depende diretamente da magnitude do resíduo, ou seja das condições 
experimentais. Este fato também foi discutido por PIMENTEL (1991) para os mesmos cruzamentos, e utilizando o mesmo modelo, todavia o autor empregou para análise o método 2 , ao invés do método 4 preferido neste trabalho.

Os modelos reduzidos, eliminando-se os efeitos devido à capacidade específica de combinação, apresentaram coeficientes de determinação variando entre 0,80 na geração $F_{2}$ e 0,93 na geração $F_{2: n}$ no ano agrícola de 1995/96, conforme apresentado na LISTA DE TABELAS E FIGURAS, nas Tabelas 62, 64, 66,68 e 70 demonstrando que os efeitos aditivos dos genes são os preponderantes na determinação do caráter Produtividade de Grãos. Todavia os efeitos da capacidade específica de combinação foram responsáveis por no mínimo oito porcento da variação entre médias de cruzamentos da tabela dialélica, não podendo portanto serem desconsiderados. Os mesmos comentários efetuados em relação ao pressuposto de ausência de efeitos epistáticos para análise dialélica podem ser feitos também para este caráter.

$\mathrm{Na}$ análise dialélica conjunta entre os quatro anos de avaliação da geração $F_{2: n}$, apresentada na Tabela 72 da LISTA DE TABELAS E FIGURAS, 0 efeito de anos mostrou-se altamente significativo, revelando desvios no comportamento dos cruzamentos em relação às avaliações também para este caráter. Os efeitos de cruzamentos e suas decomposições apresentaram valores para o teste $\mathrm{F}$ altamente significativos, e as interações com anos foram sempre significativas, para todas as decomposições apresentadas, comprovando que os parâmetros obtidos a partir da análise conjunta devam ser melhor estimados, estando isentos das interações com anos, o que resulta em maiores informações para seleção de genitores. 
Interações significativas entre as capacidades geral e específica de combinação por anos foram relatadas por KUNTA et al. (1985) e PASCHAL \& WILCOX (1975), sendo de pequena magnitude comparada aos demais efeitos, como também evidenciam os resultados apresentados neste trabalho. Muito embora a magnitude das interações tenha sido inferior em relação aos demais efeitos, estas apresentaram quadrados médios significativos, não podendo ser desprezadas como propõe PIMENTEL (1991). Tais interações devem causar pequenos desvios na classificação dos parentais com base nos parâmetros do modelo de análise dialélica, principalmente no grupo de cruzamentos intermediários.

RAMALHO et al. (1988), avaliaram um dialélico entre 12 cultivares de feijão, utilizando para análise as gerações, $F_{2}, F_{3}$ e $F_{4}$, em três locais. Foram obtidas interações significativas entre os efeitos da capacidade geral de combinação por locais, enquanto as interações entre capacidade geral de combinação por gerações se mostraram não significativas e de pequena magnitude para todos os caracteres avaliados, evidenciando que a avaliação das populações utilizando-se diferentes gerações é viável, no entanto os cruzamentos devem ser avaliados nos ambientes mais representativos das condições de cultivo da espécie estudada. Estas considerações vêm de encontro aos resultados obtidos neste trabalho, todavia é preciso ressaltar que a magnitude dos efeitos da capacidade específica de combinação foi muito inferior quando comparada aos efeitos da capacidade geral de combinação, e aos efeitos de locais.

Os parâmetros estimados segundo o modelo de GRIFFING (1956), método 4, para os dois caracteres avaliados nas gerações $F_{2}$ e $F_{2: n}$, nas quatro avaliações e na análise conjunta, são apresentados na Tabela 6. 
Tabela 6. Parâmetros estimados segundo o modelo de GRIFFING (1956) método 4, para os caracteres Altura da Planta na Maturação (cm / planta) e Produtividade de Grãos (gramas / planta), nas gerações $F_{2}$ e $F_{2: n}$ nos quatro anos de experimentação e análise conjunta.

\begin{tabular}{|c|c|c|c|c|c|c|c|c|c|c|c|c|}
\hline \multirow[t]{2}{*}{$\begin{array}{l}\text { Parâm } \\
\text { Estim. }\end{array}$} & \multicolumn{2}{|c|}{$\begin{array}{l}\text { Geração } F_{2} \\
\left(u, g_{i}, g_{i}, s_{i j}\right)\end{array}$} & \multicolumn{2}{|c|}{$\begin{array}{c}\text { Geração } F_{2 \cdot n} \\
1992 / 93 \\
\left(\mu, g_{i, 2} \xi_{j i}, s_{i j}\right)\end{array}$} & \multicolumn{2}{|c|}{$\begin{array}{c}\text { Geração } F_{2: n} \\
1993 / 94 \\
\left(u, g_{i}, g_{i}, S_{i j}\right)\end{array}$} & \multicolumn{2}{|c|}{$\begin{array}{c}\text { Geração } F_{2 \cdot n} \\
1994 / 95 \\
\left(\mu, g_{i} g_{i j}, S_{i j}\right)\end{array}$} & \multicolumn{2}{|c|}{$\begin{array}{c}\text { Geração } F_{2: n} \\
1995 / 96 \\
\left(\mu, g_{2} g_{\left.i, S_{i i}\right)}\right.\end{array}$} & \multicolumn{2}{|c|}{$\begin{array}{c}\text { Geração } F_{2: n} \\
\text { Análise Conj. }\end{array}$} \\
\hline & Altura & Prod. & Altura & Prod. & Altura & Prod. & Altura & Prod. & Altura & Prod. & Altura & Prod. \\
\hline$\mu$ & 76,81 & 169,50 & 73,44 & 261,18 & 84,10 & 212,43 & 77,05 & 155,86 & 66,31 & 143,61 & 75,60 & 196,23 \\
\hline$g_{1}$ & $-5,78$ & $-10,26$ & $-7,23$ & $-15,67$ & $-10,07$ & $-1,69$ & $-4,06$ & 11,69 & $-5,86$ & 4,58 & $-7,53$ & 0,51 \\
\hline$g_{2}$ & 6,69 & 14,16 & 10,18 & $-7,01$ & 12,08 & 15,21 & 8,53 & $-4,25$ & 10,33 & 5,04 & 11,81 & $-0,39$ \\
\hline$g_{3}$ & $-7,51$ & 15,18 & $-4,64$ & 30,77 & $-5,10$ & 36,57 & $-3,53$ & 44,40 & $-3,14$ & 30,65 & $-4,47$ & 40,89 \\
\hline$g_{4}$ & \begin{tabular}{|c|}
$-7,67$ \\
\end{tabular} & 16,44 & $-2,98$ & 51,72 & $-7,71$ & 27,85 & $-3,51$ & 32,50 & $-2,51$ & 26,62 & $-4,54$ & 39,97 \\
\hline$g_{5}$ & $-2,99$ & 11,40 & $-5,22$ & 16,30 & $-8,98$ & 20,94 & $-6,48$ & $-2,52$ & $-4,23$ & 15,62 & $-6,96$ & 13,37 \\
\hline$g_{6}$ & $-6,77$ & $-32,76$ & $-5,31$ & $-70,63$ & $-7,47$ & $-38,81$ & $-5,93$ & $-36,30$ & $-9,65$ & $-42,06$ & $-7,52$ & $-50,40$ \\
\hline$g_{7}$ & 11,36 & $-19,56$ & 4.23 & -22.21 & 8,46 & $-37,58$ & 5,18 & $-38,50$ & 4,98 & $-37,40$ & 7,24 & $-36,56$ \\
\hline$g_{8}$ & 12,67 & 5,46 & 10,97 & 16,74 & 18,80 & $-22,49$ & 9,79 & $-7,02$ & 10,08 & $-3,04$ & 11,97 & $-7,40$ \\
\hline$s_{12}$ & $-4,98$ & $-28,74$ & 0,74 & 9.16 & 0,11 & 17,95 & 4,97 & 25,06 & $-0,51$ & $-2,35$ & 0,16 & 11,34 \\
\hline$s_{13}$ & $-3,22$ & 34,98 & 1,57 & 2,73 & 6,24 & 15,91 & 0,87 & $-11,07$ & 5,13 & 3,82 & 4,17 & $-6,19$ \\
\hline$s_{14}$ & $-9,60$ & $-17,82$ & $-3,75$ & 8,10 & $-7,71$ & 7,32 & $-4,23$ & 32,09 & $-2,62$ & 13,01 & $-3,86$ & 6,09 \\
\hline$s_{15}$ & & - & 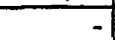 & & & & & & & & $-0,69$ & 20,89 \\
\hline$s_{16}$ & 2,80 & $-20,46$ & $-0,65$ & $-38,31$ & 0,46 & $-20,39$ & $-1,90$ & $-29,37$ & 0,03 & $-18,10$ & 0,28 & $-26,84$ \\
\hline$s_{17}$ & 4,05 & 16,08 & 3,58 & 13,58 & 4,03 & $-13,86$ & 1,74 & $-16,01$ & 2,65 & 1,91 & 1,83 & $-4,71$ \\
\hline$s_{18}$ & 10,96 & 16,02 & $-1,49$ & 4,73 & $-3,13$ & $-6,93$ & $-1,45$ & $-0,70$ & $-4,69$ & 1,71 & $-1,90$ & $-0,59$ \\
\hline$S_{23}$ & $-1,32$ & 20,22 & $-2,45$ & 8,27 & $-7,06$ & $-6,79$ & $-3,89$ & 6,36 & $-7,01$ & $-4,79$ & $-6,64$ & $-4,86$ \\
\hline $\mathrm{S}_{24}$ & 4,66 & 24,48 & 0,21 & $-9,62$ & 5,24 & $-0,40$ & $-0,12$ & $-23,87$ & 4,13 & 0,83 & 0,82 & $-13,88$ \\
\hline $\mathrm{s}_{25}$ & 6,44 & 7,38 & 1,04 & 5,53 & $-1,58$ & $-1,26$ & $-3,96$ & $-11,27$ & $-1,38$ & $-1,40$ & $-2,64$ & $-3,21$ \\
\hline $\mathrm{S}_{26}$ & 7,94 & $-6,90$ & $-2,83$ & $-17,75$ & 3,07 & 4,69 & $-0,45$ & 0,65 & $-0,72$ & $-1,17$ & $-1,70$ & $-0,27$ \\
\hline$S_{27}$ & \begin{tabular}{|l|}
$-18,59$ \\
\end{tabular} & $-29,88$ & & & & & & & & & 8,34 & 7,20 \\
\hline $\mathrm{S}_{28}$ & 5,86 & 13,44 & 3,29 & 4,43 & 0,23 & $-14,19$ & 3,44 & 3,07 & 5,49 & 8,88 & 1,65 & 3,67 \\
\hline $\mathbf{s}_{34}$ & $-1,72$ & $-8,34$ & & & - & -1 & & & - & - & 0,79 & 38,92 \\
\hline $\mathrm{s}_{35}$ & $-0,26$ & $-51,78$ & 0,49 & $-20,02$ & 1,61 & 2,53 & 0,37 & $-19,75$ & 1,66 & 7,78 & 1,75 & $-16,40$ \\
\hline$s_{36}$ & 9,82 & 22,74 & 4,39 & 12,68 & 0,04 & $-15,45$ & 3,15 & 8,65 & 2,72 & $-4,99$ & 3,00 & $-4,58$ \\
\hline$S_{37}$ & 4,53 & $-16,44$ & $-3,14$ & $-11,47$ & $-2,18$ & $-0,29$ & 0,29 & 2,30 & $-3,92$ & $-3,90$ & $-3,78$ & $-8,95$ \\
\hline$S_{38}$ & $-7,82$ & $-1,38$ & $-0,87$ & 7,82 & 1,34 & 4,08 & $-0,79$ & 13,50 & 1,43 & 2,08 & 0,70 & 2,07 \\
\hline$S_{45}$ & 0,82 & 27,42 & 1,03 & 44,66 & 2,75 & 16,96 & 3,10 & 27,36 & $-1,09$ & 10,29 & 2,17 & 15,78 \\
\hline$S_{46}$ & $-6,36$ & $-34,62$ & $-4,94$ & $-45,44$ & $-4,13$ & $-45,80$ & $-3,44$ & $-26,05$ & $-1,78$ & $-11,28$ & $-3,15$ & $-36,95$ \\
\hline$S_{47}$ & 14,81 & 21,96 & 5,75 & 11,91 & 6,20 & 7,84 & 4,03 & $-3,39$ & 2,51 & $-8,63$ & 3,09 & $-3,69$ \\
\hline$S_{48}$ & $-2,60$ & $-13,08$ & 1,71 & $-9,60$ & $-2,34$ & 14,08 & 0,67 & $-6,14$ & $-1,16$ & $-4,22$ & 0,14 & $-6,27$ \\
\hline$S_{56}$ & $-12,58$ & $-6,54$ & 3,54 & 11,32 & 3.51 & 13,57 & 2,93 & 20,34 & 3,22 & $-0,52$ & 4,09 & 10,88 \\
\hline$s_{57}$ & 4,45 & 8,76 & $-4,75$ & $-30,93$ & $-6,34$ & $-22,20$ & $-1,50$ & $-7,88$ & $-1,02$ & $-3,28$ & $-4,57$ & $-17,18$ \\
\hline$S_{58}$ & 1,12 & 14,82 & $-1,34$ & $-10,56$ & 0,05 & $-9,59$ & $-0,95$ & $-8,80$ & $-1,39$ & $-12,86$ & $-0,12$ & $-10,75$ \\
\hline$S_{67}$ & $-1,67$ & 37,56 & 0,18 & 45,62 & $-4,26$ & 39,69 & $-1,97$ & 25,84 & $-1,99$ & 22,77 & $-3,48$ & 36,60 \\
\hline$S_{68}$ & 0,06 & 8,16 & 0,31 & 31,89 & 1,32 & 23,71 & 1,68 & $-0,06$ & $-1,47$ & 13,28 & 0,96 & 21,14 \\
\hline$S_{78}$ & $-7,56$ & $-38,04$ & $-1,62$ & $-28,71$ & 2,54 & $-11,17$ & $-2,59$ & $-0,86$ & 1,78 & $-8,87$ & $-1,44$ & $-9,28$ \\
\hline$\sigma \mu$ & 0,47 & 2,10 & 0,28 & 2,54 & $\overline{0,45}$ & 2,00 & 0,45 & 1,90 & 0,35 & 1,07 & 0,39 & 1,95 \\
\hline$\sigma g_{i}$ & 0,95 & 4,26 & 0,56 & 5,13 & 0,92 & 4,04 & 0,91 & 3,84 & 0,71 & 2,16 & 0,78 & 3,94 \\
\hline$\sigma \mathrm{S}_{\mathrm{ii}}$ & 2,09 & $\overline{9,36}$ & 1,23 & 11,36 & 2,03 & 8,94 & 2,02 & 8,51 & 1,56 & 4,79 & 1,74 & 8,72 \\
\hline
\end{tabular}

Nota: os parâmetros estimados para o caráter Produtividade de Grãos na geração $\mathrm{F}_{2}$ foram multiplicadas por 6 para que fosse obtida equivalência com as demais parcelas. 
O comportamento dos efeitos das capacidades gerais de combinação ( $\mathrm{g}_{\mathrm{i}}$ 's) podem ser melhor compreendidos observando-se as Figuras 1 e 2 da LISTA DE TABELAS E FIGURAS, que apresentam sob a forma de gráfico estes efeitos, estimados para as gerações $F_{2}$ e $F_{2: n}$ nas quatro avaliações e análise conjunta. Os resultados apresentados nesta figura evidenciam que os parentais PI 239235, La4910-215 e PI 165896 formam um grupo de parentais que contribuem para aumentar a altura das progênies nos cruzamentos em que participam, uma vez que apresentam os maiores valores para $g_{i}$ 's nas duas gerações e nas quatro avaliações de $F_{2: n}$. Em contrapartida, os demais parentais devem contribuir para reduzir a altura das progênies dos cruzamentos de que fazem parte, pois consistentemente apresentaram os menores valores de $g_{i}$. Pode-se também observar que os efeitos da interação com anos foram suficientes para promover inversões na ordem de classificação dos valores de $\mathrm{g}_{\mathrm{i}}$ 's algumas vezes, principalmente no grupo de parentais que contribuem para reduzir a altura média das progênies.

As interações dos efeitos dos $g_{i}$ 's com a geração utilizada para obtenção das estimativas pode ser justificada pelo efeito de anos e também pelos efeitos de dominância e epistáticos dos genes, presentes em proporções diferentes segundo a geração utilizada para análise. Tanto os efeitos de dominância, quanto os epistáticos foram de pequena magnitude, sendo esta mais uma razão para as interações obtidas terem sido de pequena magnitude.

Muito embora a interação com anos e com a geração utilizada para a análise tenha interferido na classificação dos parentais, para este caráter, ficam muito bem definidos os grupos de parentais que concorrem para aumentar ou diminuir a altura média das progênies nos cruzamentos em que participam. Desta forma a seleção de parentais, baseada nos valores estimados dos gi's é viável para 
atender aos propósitos dos programas de melhoramento, a despeito dos efeitos epistáticos do tipo aditivo $\mathrm{x}$ aditivo e aditivo $\mathrm{x}$ dominante ou superiores presentes na geração $F_{2}$, e das interações de parâmetros com anos, que acabaram por provocar alguma inversão de classificação dos parentais, entre as gerações e anos de avaliação. Estes desvios na classificação dos parentais ocorreram no grupo de cruzamentos intermediários, não sendo suficientes para interferir nos grupos de parentais, que se mantiveram sempre muito bem definidos.

Para o caráter Produtividade de Grãos, a Figura 2 ilustra uma situação semelhante, formando os parentais OC 79230 e BR 80-8858 um grupo de parentais que concorre para aumentar a produtividade das progênies dos cruzamentos em que participam, e os parentais PI 123439 e PI 165896 para diminuir. Para este caráter também ocorreram interações entre anos e gerações de avaliação e as estimativas dos $\mathrm{g}_{\mathrm{i}}$ 's obtidas, que acabaram por interferir na ordem de classificação dos parentais, com base nestes efeitos, para os quatro anos de experimentação. No entanto, novamente neste caso as interações não foram suficientemente pronunciadas para alterar a ordem de classificação dos parentais que concorrem para aumentar ou diminuir a produtividade, entre os grupos, e ocorreram também principalmente nos cruzamentos do grupo intermediário.

Em relação aos efeitos das capacidades específicas de combinação, observa-se nas Figuras 3 e 4 da LISTA DE TABELAS E FIGURAS que ocorreram interações mais pronunciadas entre as estimativas e as avaliações em que estas estimativas foram obtidas, para os dois caracteres avaliados, o que aliado aos erros de estimativa acabou impossibilitando que este parâmetro pudesse ser considerado para a classificação de cruzamentos, para a maioria dos cruzamentos avaliados. 
É preciso ressaltar que em alguns cruzamentos, como por exemplo nos cruzamentos BR 80-8858 x BR 80-14853, BR 80-8858 x PI 123439, PI 123439 x PI 165896 e PI 165896 x PI 239235 para o caráter Produtividade de Grãos, e cruzamentos Gaúcha x BR 80-8858, Gaúcha x PI 165896, La-4910-215 x OC 79230, La-4910-215 x PI 239235, BR 80-8858 x PI 123439 e BR 80-8858 x PI 165896 para Altura da Planta na Maturação, houve consistência entre as estimativas dos efeitos da capacidade específica de combinação obtidas nas duas gerações utilizadas para avaliação, e entre as quatro avaliações e análise conjunta da geração $F_{2: n}$, sendo estes provavelmente os cruzamentos responsáveis pela significância dos efeitos da capacidade específica de combinação obtidas nas análises de variância das tabelas dialélicas. Estas estimativas foram destacadas com traços mais fortes nas Figuras 3 e 4 da LISTA DE TABELAS E FIGURAS para facilitar a visualização.

Em alguns cruzamentos, como 1Gaúcha x 2La-4910-215 e Gaúcha x PI 123439 para o caráter Produtividade de Grãos, e BR 80-14853 x PI 123439 e BR 80-14853 x PI 165896 para Altura da Planta na Maturação, a consistência entre as estimativas dos $s_{i j}$ 's foi obtida apenas nas quatro avaliações e análise conjunta da geração $F_{2: n}$, revelando que na geração $F_{2}$ a estimativa destes parâmetros estavam influenciadas pelos efeitos de dominância dos genes, novamente evidenciando que os efeitos da capacidade específica de combinação não devem ser levados em consideração para a classificação de parentais.

A falta de consistência nas estimativas dos efeitos das capacidades específicas de combinação pode ser atribuída, para a maioria dos cruzamentos, além das interações com anos aos erros associados às estimativas destes parâmetros, uma vez que em média, $90 \%$ da variação entre médias de 
cruzamentos da tabela dialélica puderam ser explicadas com base nos efeitos da capacidade geral de combinação, restando ao redor de $10 \%$ desta variação que pode ser atribuída aos efeitos da capacidade específica de combinação.

Para melhor avaliar a consistência entre as estimativas dos efeitos da capacidade geral de combinação ( $\left.g_{i}{ }^{\prime} s\right)$ obtidas a partir das gerações $F_{2}$ e $F_{2: n}$ nas quatro avaliações e análise conjunta, foram estimados coeficientes de correlação entre as estimativas deste parâmetro, cujos valores estão apresentados na Tabela 7. Com o mesmo propósito foram também estimados os coeficientes de correlação entre os efeitos devidos à capacidade específica de combinação $\left(\mathrm{s}_{\mathrm{ij}}{ }^{\prime} \mathbf{s}\right)$, apresentados na Tabela 8.

Tabela 7.Coeficientes de correlação entre os efeitos da capacidade geral de combinação ( $\mathrm{g}_{\mathrm{i}}$ 's), estimados para o modelo de GRIFFING (1956), método 4, para os caracteres Altura da Planta na Maturação e Produtividade de Grãos nas gerações $F_{2}$ e $F_{2: n}$ nos quatro anos de experimentação e análise conjunta.

\begin{tabular}{|c|c|c|c|c|c|c|c|c|c|c|}
\hline & \multicolumn{2}{|c|}{$\begin{array}{c}\text { Geração } F_{n} \\
\text { ano } 1992 / 1993 \\
\text { Modelo Compl. }\end{array}$} & \multicolumn{2}{|c|}{$\begin{array}{c}\text { Geração } F_{2 \pi} \\
\text { ano 1993/94 } \\
\text { Modelo Compl. }\end{array}$} & \multicolumn{2}{|c|}{$\begin{array}{c}\text { Geração } \mathrm{F}_{2: \mathrm{n}} \\
\text { ano 1994/95 } \\
\text { Modelo Compl. }\end{array}$} & \multicolumn{2}{|c|}{$\begin{array}{c}\text { Geraçăo } F_{2: n} \\
\text { ano 1995/96 } \\
\text { Modelo Compl. }\end{array}$} & \multicolumn{2}{|c|}{$\begin{array}{c}\text { Geração } F_{2 \pi} \\
\text { Análise Conjunta } \\
\text { Modelo Compl. }\end{array}$} \\
\hline & $\begin{array}{l}\text { Altura } \\
\text { Matur. }\end{array}$ & $\begin{array}{l}\text { Prod. } \\
\text { Grãos }\end{array}$ & $\begin{array}{l}\text { Altura } \\
\text { Matur. }\end{array}$ & $\begin{array}{l}\text { Prod. } \\
\text { Grãos }\end{array}$ & $\begin{array}{l}\text { Altura } \\
\text { Matur. }\end{array}$ & $\begin{array}{l}\text { Prod. } \\
\text { Grãos }\end{array}$ & $\begin{array}{l}\text { Altura } \\
\text { Matur. }\end{array}$ & $\begin{array}{l}\text { Prod. } \\
\text { Grãos }\end{array}$ & $\begin{array}{l}\text { Altura } \\
\text { Matur. }\end{array}$ & $\begin{array}{l}\text { Prod. } \\
\text { Grãos }\end{array}$ \\
\hline $\begin{array}{c}\text { Geração } F_{2} \\
\text { Modelo Comp. }\end{array}$ & $0,57 \mathrm{~s}^{\prime}$ & $0,91 \mathrm{~s}$ & $0,60 \mathrm{~s}$ & $0,93 \mathrm{~s}$ & $0,52 \mathrm{~s}$ & $0,79 \mathrm{~s}$ & $0,55 \mathrm{~s}$ & $0,93 \mathrm{~s}$ & $0,60 \mathrm{~s}$ & $0,86 \mathrm{~s}$ \\
\hline $\begin{array}{c}\text { Geração } F_{2: n} \\
\text { ano } 1992 / 1993 \\
\text { Modelo Compl. }\end{array}$ & & & $0,88 \mathrm{~s}$ & $0,83 \mathrm{~s}$ & $0,90 \mathrm{~s}$ & $0,74 \mathrm{~s}$ & $0,95 \mathrm{~s}$ & $0,83 \mathrm{~s}$ & $0,98 \mathrm{~s}$ & $0,81 \mathrm{~s}$ \\
\hline $\begin{array}{c}\text { Geração } F_{2 \pi} \\
\text { ano 1993/94 } \\
\text { Modelo Compl. }\end{array}$ & & & & & $0,83 \mathrm{~s}$ & $0,91 \mathrm{~s}$ & $0,79 \mathrm{~s}$ & $1,00 \mathrm{~s}$ & $0,93 \mathrm{~s}$ & $0,98 \mathrm{~s}$ \\
\hline $\begin{array}{c}\text { Geração } F_{2: n} \\
\text { ano 1994/95 } \\
\text { Modelo Compl. }\end{array}$ & & & & & & & $0,91 \mathrm{~s}$ & $0,91 \mathrm{~s}$ & $0,88 \mathrm{~s}$ & $0,95 \mathrm{~s}$ \\
\hline $\begin{array}{c}\text { Geração } F_{2 n} \\
\text { ano 1995/96 } \\
\text { Modelo Compl. }\end{array}$ & & & & & & & & & $0,93 \mathrm{~s}$ & $0,97 \mathrm{~s}$ \\
\hline
\end{tabular}

Nota: $\mathbf{s}=$ coeficiente de correlação de Spearman. 
A magnitude das correlações obtidas revela a boa consistência nas estimativas dos efeitos da capacidade geral de combinação, a despeito da geração utilizada ou ano de avaliação para as progênies na geração $F_{2: n}$, muito embora já se tenha discutido a respeito das interações destas estimativas com anos. Fica evidente mais uma vez que as estimativas dos efeitos da capacidade geral de combinação, obtidas na geração $F_{2}$, são seguras para fins de classificação de parentais com o objetivo de serem obtidas progênies superiores com cruzamento, desde que os efeitos de dominância gênica e epistáticos presentes não sejam de magnitude semelhante aos efeitos aditivos dos genes, o que torna a seleção de cruzamentos possível em gerações precoces. Os dois caracteres avaliados neste trabalho apresentaram efeitos aditivos dos genes de magnitude muito superior quando comparado aos efeitos de dominância e ou epistáticos, possibilitando a utilização da análise dialélica, para fins de seleção de parentais, de forma segura mesmo em gerações precoces como $\mathrm{F}_{2}$.

Em relação aos efeitos da capacidade específica de combinação, conforme apresentado na Tabela 8, as correlações obtidas entre os efeitos estimados na geração $F_{2}$ e $F_{2: n}$ foram de pequena magnitude, revelando não haver suficiente consistência entre as estimativas obtidas em diferentes gerações. Além das somas de quadrado para efeitos da capacidade específica de combinação terem apresentados valores muito inferiores, quando comparados aos valores obtidos para os efeitos da capacidade geral de combinação, a falta de consistência nas estimativas destes efeitos obtidas em diferentes gerações impede que a classificação de parentais leve também em consideração os efeitos da capacidade específica de combinação, para os dois caracteres avaliados neste trabalho. É importante ressaltar que a pequena magnitude dos efeitos da capacidade específica de combinação é exatamente o fator que permite a seleção de parentais 
em gerações precoces, como em $\mathrm{F}_{2}$ por exemplo, o que caso contrário não seria possível.

Tabela 8. Coeficientes de correlação entre os efeitos da capacidade específica de combinação ( $\mathrm{s}_{\mathrm{ij}}$ 's), estimados para o modelo de GRIFFING (1956), método 4, para os caracteres Altura da Planta na Maturação e Produtividade de Grãos nas gerações $F_{2}$ e $F_{2: n}$ nos quatro anos de experimentação e análise conjunta.

\begin{tabular}{|c|c|c|c|c|c|c|c|c|c|c|}
\hline & \multicolumn{2}{|c|}{$\begin{array}{c}\text { Geração } F_{2: n} \\
\text { ano 1992/ } 1993 \\
\text { Modelo Compl. }\end{array}$} & \multicolumn{2}{|c|}{$\begin{array}{c}\text { Geração } F_{2 n} \\
\text { ano 1993/94 } \\
\text { Modelo Compl. }\end{array}$} & \multicolumn{2}{|c|}{$\begin{array}{c}\text { Geração } F_{2: n} \\
\text { ano 1994/95 } \\
\text { Modelo Compl. }\end{array}$} & \multicolumn{2}{|c|}{$\begin{array}{c}\text { Geração } F_{2 n} \\
\text { ano 1995/96 } \\
\text { Modelo Compl. }\end{array}$} & \multicolumn{2}{|c|}{$\begin{array}{c}\text { Geração } \mathrm{F}_{2 \mathrm{n}} \\
\text { Análise Conjunta } \\
\text { Modelo Compl. }\end{array}$} \\
\hline & $\begin{array}{l}\text { Altura } \\
\text { Matur. }\end{array}$ & $\begin{array}{l}\text { Prod. } \\
\text { Grãos }\end{array}$ & $\begin{array}{l}\text { Altura } \\
\text { Matur. }\end{array}$ & $\begin{array}{l}\text { Prod. } \\
\text { Grãos }\end{array}$ & $\begin{array}{l}\text { Altura } \\
\text { Matur. }\end{array}$ & $\begin{array}{l}\text { Prod. } \\
\text { Grãos }\end{array}$ & $\begin{array}{l}\text { Altura } \\
\text { Matur. }\end{array}$ & $\begin{array}{l}\text { Prod. } \\
\text { Grãos }\end{array}$ & $\begin{array}{l}\text { Altura } \\
\text { Matur. }\end{array}$ & $\begin{array}{l}\text { Prod. } \\
\text { Grãos }\end{array}$ \\
\hline $\begin{array}{c}\text { Geração } F_{2} \\
\text { Modelo Comp. }\end{array}$ & $0,21 \mathrm{~s}$ & $0,57 \mathrm{~s}$ & $0,10 \mathrm{~s}$ & $0,18 \mathrm{~s}$ & $0,21 \mathrm{~s}$ & $0,16 \mathrm{~s}$ & $0,07 \mathrm{~s}$ & $0,29 \mathrm{~s}$ & $-0,06 \mathrm{~s}$ & $0,19 \mathrm{~s}$ \\
\hline $\begin{array}{c}\text { Geração } \text { F2:n } \\
\text { ano 1992/ } 1993 \\
\text { Modelo Compl. }\end{array}$ & & & $0,54 \mathrm{~s}$ & $0,56 \mathrm{~s}$ & $0,74 \mathrm{~s}$ & $0,62 \mathrm{~s}$ & $0,64 \mathrm{~s}$ & $0,51 \mathrm{~s}$ & $0,82 \mathrm{~s}$ & $0,81 \mathrm{~s}$ \\
\hline $\begin{array}{c}\text { Geração } \mathrm{F}_{2: \mathrm{n}} \\
\text { ano 1993/94 } \\
\text { Modelo Compl. }\end{array}$ & & & & & $0,57 \mathrm{~s}$ & $0,50 \mathrm{~s}$ & $0,76 \mathrm{~s}$ & $0,56 \mathrm{~s}$ & $0,81 \mathrm{~s}$ & $0,68 s$ \\
\hline $\begin{array}{c}\text { Geração } F_{2: n} \\
\text { ano 1994/95 } \\
\text { Modelo Compl. }\end{array}$ & & & & & & & $0,58 \mathrm{~s}$ & $0,42 \mathrm{~s}$ & $0,78 \mathrm{~s}$ & $0,80 \mathrm{~s}$ \\
\hline $\begin{array}{c}\text { Geração } F_{2: n} \\
\text { Safra 1995/96 } \\
\text { Modelo Compl. }\end{array}$ & & & & & & & & & $0,78 \mathrm{~s}$ & $0,66 \mathrm{~s}$ \\
\hline
\end{tabular}

Nota: $\mathbf{s}=$ coeficiente de correlação de Spearman.

Através das estimativas dos parâmetros do modelo reduzido $\left(\mu, \mathrm{g}_{\mathrm{i}}\right)$, as médias de cruzamentos para a geração $\mathrm{F}_{2}$ puderam ser compostas, e são comparadas às médias experimentais observadas para os cruzamentos nas quatro avaliações da geração $F_{2: n}$ e análise conjunta, através dos coeficientes de correlação apresentados na Tabela 9, para os dois caracteres avaliados. 
Tabela 9. Médias estimadas a partir dos parâmetros do modelo de GRIFFING (1956) método 4, na gerações $F_{2}$, e médias experimentais observadas da geração $F_{2: n}$ nas quatro avaliações e análise conjunta, para os caracteres Altura da Planta na Maturação (cm / planta) e Produtividade de Grãos (gramas / parcela).

\begin{tabular}{|c|c|c|c|c|c|c|c|c|c|c|c|c|}
\hline \multirow[t]{2}{*}{$\begin{array}{l}\text { Cruza- } \\
\text { mento }\end{array}$} & \multicolumn{2}{|c|}{$\begin{array}{c}\text { Geração } F_{2} \\
\text { Modelo Reduz. } \\
\mu, g_{i}\end{array}$} & \multicolumn{2}{|c|}{\begin{tabular}{|c|} 
Geração $\mathrm{F}_{2 \mathrm{n}}$ \\
Safra 1992/1993 \\
Médias \\
Observadas
\end{tabular}} & \multicolumn{2}{|c|}{$\begin{array}{c}\text { Geração } F_{2 n} \\
\text { Safra 1993/1994 } \\
\text { Médias } \\
\text { Observadas }\end{array}$} & \multicolumn{2}{|c|}{$\begin{array}{c}\text { Geração } F_{2 \cdot n} \\
\text { Safra 1994/1995 } \\
\text { Médias } \\
\text { Observadas }\end{array}$} & \multicolumn{2}{|c|}{\begin{tabular}{|c|} 
Geração $F_{2: n}$ \\
Safra 1995/1996 \\
Médias \\
Observadas \\
\end{tabular}} & \multicolumn{2}{|c|}{ 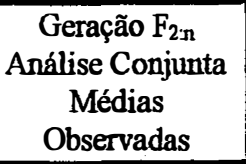 } \\
\hline & Altura & Prod. & Altura & Prod. & Altura & Prod. & Altura & Prod. & Altura & Prod. & Altura & Prod. \\
\hline $\bar{x}$ & 772 & $\overline{3,40}$ & 772 & & 8622 & & & & 7 & & 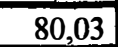 & \\
\hline & & & & & & & & & & & & \\
\hline$\times 4$ & & & & & & & & & & & 9,67 & \\
\hline$\times 5$ & & & & & & & & & & &, 42 & \\
\hline $1 \times 6$ & & 126,48 & 25 & 58 & 67,02 & & & & & & 82 & \\
\hline $1 \times 7$ & 39 & 139,68 & 1,02 & & 86,51 & & & & & &, 13 & \\
\hline $1 \times 8$ & 70 & 164,70 &, 70 & & 89,69 & & & & & & 8,14 & \\
\hline $2 \times 3$ & 99 & 198,78 & 54 & & 84,02 & & & & & & 5,30 & \\
\hline$\overline{x 4}$ & 83 & 00,04 & & & & & & & & & & \\
\hline$\overline{x 5}$ & & $\overline{6}$ & 44 & & 2 & & & & & & & \\
\hline$\overline{x 6}$ & 6,73 & 84 &, 49 & &, 78 & & & & 0,28 & & 5,19 & \\
\hline$\times 7$ & & & & & & & & & & & ( & \\
\hline 8 & & & 97,89 & & 5,20 & & & & & & & \\
\hline & & & & & & & & & & & & \\
\hline 5 & & 8 & 07 & 23 & 1,63 & & & & 60 & 65 & 93 & \\
\hline$\times 6$ & 53 & 15 & 87 & & 71,57 & & & & & & 61 & \\
\hline $3 \times 7$ & 66 & 165,12 & 9,89 & & 85,27 & & 99 & & & & 4,59 & \\
\hline $3 \times 8$ & 97 & 190,14 & 78,90 & & 99,13 & & & & 88 & &, 8 & \\
\hline $4 \times 5$ & 66,15 & 197,34 & 66,27 & & 70,16 & & & & & & 0,2 & \\
\hline $4 \times 6$ & 62,37 &, 12 &, 20 & &, 78 & & & & & & 00,30 & \\
\hline $4 \times 7$ & 50 & 166,38 &, 43 & & 4 & & & & & & 38 & \\
\hline $4 \times 8$ & & 10 & & & 34 & & & & & &, 18 & \\
\hline$\overline{x 6}$ & & &, 45 & & 1,16 & & & & & &, 21 & \\
\hline $5 \times 7$ & & & $\overline{67,69}$ & & 77,23 & & & & & & , & \\
\hline $5 \times 8$ & & & 77,85 & & 93,97 & & & & & & 0,50 & \\
\hline $6 \times 7$ & & & $\overline{72,53}$ & & 80,83 & & & & & & 71,83 & \\
\hline $6 \times 8$ & 82,71 & 142,20 & 79,41 & & 96,74 & & 59 & & 27 & & 1,00 & 57 \\
\hline $7 \times 8$ & 00,84 & 155,46 & 87,01 & 226,99 & 113,89 & & 43 & & 83,14 & $84, \mathrm{~J}$ & 93,37 & 2,99 \\
\hline & & & 0,62 & 0,84 & 0,79 & 0,80 & 0,74 & 0,74 & 0,69 & 0,90 & 0,76 & 0,88 \\
\hline
\end{tabular}

Nota: $\mathbf{s}=$ as médias de cruzamentos para o caráter Produtividade de Grãos na geração $F_{2}$ foram multiplicadas por 6 para que fosse obtida equivalência com as demais parcelas.

Os coeficientes de correlação de Spearman entre as médias de cruzamentos, estimadas na geração $F_{2}$ com base nos parâmetros do modelo reduzido e observadas nas quatro avaliações e análise conjunta da geração $F_{2: n}$, 
apresentaram-se variando de medianos a elevados, estando situados entre 0,62 em 1992/93 e 0,79 em 1993/94 para o caráter Altura da Planta na Maturação, e entre 0,74 em 1994/95 e 0,90 em 1995/96 para Produtividade de Grãos. Correlações de magnitude elevada entre as médias estimadas com base na capacidade geral de combinação em $F_{2}$ e as médias experimentais observadas na geração $F_{2: n}$ indicam uma vez mais que os efeitos da capacidade geral de combinação podem ser utilizados com segurança para classificação dos cruzamentos já na geração $F_{2}$.

A classificação das médias de cruzamentos em relação aos caracteres Altura da Planta na Maturação e Produtividade de Grãos, nas gerações $\mathrm{F}_{2}$ e $\mathrm{F}_{2: \mathrm{n}}$ nos quatro anos agrícolas de experimentação, pode ser melhor entendida observando-se as Figuras 5 e 6 da LISTA DE TABELAS E FIGURAS. A partir da análise destas figuras pode-se perceber que a classificação dos cruzamentos com base nas médias, observadas em diferentes gerações e anos de avaliação, se manteve razoavelmente constante, havendo alterações de classificação em alguns casos, mas que não chegaram a ser alterações pronunciadas, e que ocorreram principalmente no grupo de cruzamentos intermediários.

\subsection{Predição da Freqüência de Linhagens Superiores por Cruzamento}

Através das estimativas da variância genética aditiva, obtidas das análises de variância a nível de progênies, puderam ser calculadas as proporções esperadas de linhagens superiores para cada cruzamento. As médias das progênies $F_{2}$ e dos "bulks" $F_{2: n}$, e respectivos desvios padrão, que foram utilizadas como limite para as predições efetuadas, são apresentadas na LISTA DE TABELAS E 
FIGURAS na Tabela 73, para os dois caracteres avaliados e para as gerações $F_{2} e$ $F_{2: n}$ nos quatro anos de avaliação e análise conjunta.

As proporções esperadas e observadas de linhagens superiores ao valor da média dos cruzamentos, utilizadas como limite para estimativa das freqüências de linhagens superiores, para as gerações $F_{2}$ e $F_{2: n}$ nos quatro anos de experimentação e análise conjunta, são apresentadas nas Tabelas 74 e 75 da LISTA DE TABELAS E FIGURAS, para os caracteres Altura da Planta na Maturação e Produtividade de Grãos, respectivamente. Ainda nas Tabelas 74 e 75 são apresentados os valores dos coeficientes de correlação entre as freqüências observadas e esperadas de linhagens superiores, para cada avaliação dos cruzamentos.

Os valores dos coeficientes de correlação entre as freqüências observadas e esperadas de linhagens superiores, obtidos para o caráter Altura da Planta na Maturação, variaram de 0,73 em $\mathrm{F}_{2}$ a 0,98 em $\mathrm{F}_{2: n}$, no ano de 1995/96, para o coeficiente de Spearman. A magnitude dos coeficientes de correlação estimados indicam que as freqüências de linhagens esperadas com base na avaliação dos cruzamentos na geração $F_{2}$ apresentaram boa consistência com as freqüências observadas de linhagens superiores em $F_{2: n}$, na análise conjunta, o que indica que os efeitos genéticos de dominância, que compõe a variância genética estimada na geração $F_{2}$, em conjunto com os efeitos genéticos epistáticos, foram suficientes para provocar desvios nas estimativas das freqüências preditas, todavia estes desvios não foram capazes de promover alterações pronunciadas de classificação dos cruzamentos efetuada nesta geração, quando comparados à classificação obtida em $\mathrm{F}_{2: \mathrm{n}} \mathrm{na}$ análise conjunta. Deve-se alertar para o fato de que 
os efeitos de dominância ou epistáticos presentes na geração $F_{2}$ foram de pequena magnitude, para este caráter.

Com relação às freqüências estimadas a partir da geração $F_{2: n}$ a magnitude dos coeficientes de correlação, entre as proporções observadas e estimadas de linhagens superiores, revelam que seleção de cruzamentos com base nas freqüências esperadas de linhagens superiores é viável e confiável. Os cruzamentos onde podem ser obtidas as maiores freqüências de linhagens superiores para o caráter Altura da Planta na Maturação, no sentido de serem selecionadas progênies de maior altura média, são os cruzamentos La-4910-215 x PI 239235 e PI 165896 x PI 239235, além dos cruzamentos em que participaram estes parentais, sendo estes exatamente os mesmos parentais que apresentaram os maiores valores para os efeitos de capacidade geral de combinação $\mathrm{g}_{\mathrm{i}}$ 's nas análises dialélicas, para este caráter. Vale ressaltar, uma vez mais, que em certas populações a seleção para redução da altura média das progênies seria mais interessante, especialmente para as populações que apresentem associação positiva entre a altura de plantas e o acamamento.

Para o caráter Produtividade de Grãos os valores obtidos para os coeficientes de correlação entre freqüências esperadas e observadas de linhagens superiores variaram de 0,79 em $F_{2}$ a 0,98 em $F_{2: n}$ no ano de 1994/95, para 0 coeficiente de Spearman. Também para este caráter as magnitudes dos coeficientes de correlação estimados revelam que as freqüências de linhagens esperadas em $\mathrm{F}_{2}$ apresentaram boa consistência com as freqüências observadas de linhagens superiores em $F_{2: n}$, na análise conjunta, e as mesmas considerações discutidas em relação ao caráter Altura da Planta na Maturação podem ser efetuadas. 
Também para Produtividade de Grãos, a magnitude dos coeficientes de correlação entre as proporções observadas e estimadas na geração $F_{2: n}$ nos quatro anos agrícolas de experimentação indicam que seleção de cruzamentos com base nas freqüências esperadas de linhagens superiores também é possível e igualmente confiável. Os cruzamentos em que podem ser obtidas as maiores freqüências de linhagens superiores para o caráter Produtividade de Grãos, são os cruzamentos Gaúcha x OC 79230, La-4910-215 x OC 79230 e BR 80-8858 x BR 80-14853, além dos demais cruzamentos em que participaram os parentais OC 79230 e BR 80-8858, sendo também estes os mesmos parentais que apresentaram os maiores valores para os efeitos de capacidade geral de combinação ( $g_{i}$ 's) nas análises dialélicas.

Para melhor visualização dos cruzamentos com maiores possibilidades de serem obtidas progênies superiores foram também calculadas as freqüências esperadas e observadas de progênies superiores ao limite seletivo de uma vez a média dos "bulks" $F_{2: n}$ mais um desvio padrão, e os resultados estão apresentados na LISTA DE TABELAS E FIGURAS, nas Tabelas 76 e 77. Neste caso, pode-se observar mais claramente que os cruzamentos onde podem ser obtidas as maiores freqüências de progênies superiores são exatamente os cruzamentos onde participaram os parentais La-4910-215, PI 165896 e PI 239235 para o caráter Altura da Planta na Maturação, no sentido de se aumentar a altura média das progênies, e OC 79230 e BR 80-8858 para Produtividade de Grãos, conforme discutido anteriormente.

As comparações entre os cruzamentos onde podem ser obtidas as maiores freqüências de linhagens superiores, com os efeitos das capacidades geral de combinação dos parentais destes cruzamentos, revelam que existe 
concordância entre estas duas metodologias no sentido de seleção de parentais para programas de melhoramento. Com este propósito, a seleção de parentais a partir das estimativas dos parâmetros do modelo de análise dialélica, tem a vantagem de que a escolha dos parentais pode ser feita a partir da geração $F_{2}$, para espécies autógamas onde a produção de sementes $F_{1}$ é limitada e ou difícil como é o caso da soja. A seleção de parentais, ou cruzamentos, com base na freqüência de linhagens superiores a serem obtidas na homozigose se mostrou possível a partir da geração $F_{2}$, todavia os efeitos de dominância para os dois caracteres avaliados neste trabalho foram de pequena magnitude.

TOLEDO (1987) alerta que esta metodologia deve ser mais eficiente a partir da geração $F_{3}$, uma vez que neste caso teríamos apenas metade dos efeitos gênicos de dominância presentes em $\mathrm{F}_{2}$, que podem ser desconsiderados para efeitos de predição. Neste caso as predições efetuadas a partir da geração $F_{3}$, com o propósito de seleção de cruzamentos mais promissores, têm a desvantagem de demandar um maior tempo e esforço do melhorista quando comparado à metodologia de análise dialélica. 


\section{CONCLUSÕES}

De acordo com os resultados discutidos nos capítulos anteriores pode-se estabelecer as seguintes conclusões:

a) A escolha de parentais através da metodologia de análise dialélica, mostrou-se possível na geração $\mathrm{F}_{2}$, evidenciando que a capacidade geral de combinação pode ser um indicador seguro para a seleção de parentais mesmo em gerações precoces. A metodologia de predição das freqüências de linhagens superiores apresentou concordância, com a análise dialélica.

b) Os efeitos da capacidade geral de combinação, foram sempre os mais importantes para a determinação dos dois caracteres considerados neste trabalho. Os efeitos das capacidades específicas de combinação, estimados nas gerações $F_{2}$ e $F_{2: n}$, foram significativos para os dois caracteres avaliados, mas de menor magnitude se comparado aos efeitos da capacidade geral de combinação.

c) Os parentais PI 239235, La-4910-215 e PI 165896 devem contribuir para aumentar a Altura da Planta na Maturação, uma vez que apresentaram os 
maiores valores de $\mathrm{g}_{\mathrm{i}}$ 's para este caráter. Os parentais que devem contribuir para a redução deste caráter são Gaúcha, OC 79230, BR 80-8858, BR 8014853 e PI 123439 uma vez que apresentaram valores de $g_{i}$ 's negativos. Para maior Produtividade de Grãos os maiores valores dos $\mathrm{g}_{\mathrm{i}}$ 's foram obtidos para os parentais OC 79230 e BR 80-8858. Os cruzamentos BR 80-8858 x PI 165896, La-4910-215 x PI 239235 e Gaúcha x BR 80-8858 apresentaram os maiores valores da capacidade específica de combinação para o caráter Altura da Planta na Maturação. Para maior Produtividade de Grãos os cruzamentos de melhor capacidade específica de combinação foram: BR 80-8858 x BR 8014853, BR 80-8858 x PI 123439, PI 123439 x PI 165896 e PI 123439 x PI 239235.

d) Os efeitos da interação entre as capacidades geral e específica de combinação com anos foram significativos para as análises na geração $F_{2: n}$, para o caráter Produtividade de Grãos, indicando que tais interações podem causar desvios, de pequena magnitude, nos parâmetros estimados. Apesar da presença de interações foi possível estabelecer grupos de parentais capazes de promover aumentos ou reduções nos dois caracteres avaliados. 


\section{REFERÊNCIAS BIBLIOGRÁFICAS}

ARUNACHALAM, V. Evaluation of diallel crosses by graphical and combining ability methods. Indian Journal of Genetics and Plant Breeding, New Delhi, 36 (3): 358-66, 1976.

BAKER, R. J. Issues in diallel analysis. Crop Science, Madison, 18 (4): 533-6, 1978.

BARBIN, D. Componentes de variância. Piracicaba, Depto. de Matemática e Estatística - ESALQ / USP, 1993. 108p.

BECKER, W. A. Manual of quantitative genetics. Pullman, Students Book, 1975. $170 \mathrm{p}$.

BHATADE, S. S.; SINGH, C. B.; TIWAR, A. S. Diallel analysis of yield and its components in soybean. Indian Journal of Agricultural Sciences, Delhi, 47 (7): 322-4, 1977. 
BUSCH, R. H.; JANKE, J. C.; FROBERG, R. C. Evaluation of crosses among high and low yielding parents of spring whet (Triticum aestivum L.) and bulk prediction of line performance. Crop Science, Madison, 14 (1): 47-50, 1974.

CALIGARI, P. D. S.; POWELL, W.; JINKS, J. L. The use of doubled haploids in barley breeding 2 . An assessment of univariate cross prediction methods. Heredity, Edinburgh, 54 (3): 353-8, 1985.

CHOO, T. M. Double haploids for estimating mean and variance of recombination values. Genetics, Baltimore, 97 (1): 165-72, 1981.

CHOO, T. M. \& REINBERGS, E. Analysis of skewness and kurtosis for detecting gene interaction in a double haploid population. Crop Science, Madison, 22 (2): 231-5, 1982.

CHOO, T. M.; REINBERGS, E. ; JUI, P. Y. Comparison of $F_{2}$ and $F_{\infty}$ diallel analysis in barley. Genome, Ottawa, 30 (4): 865-9, 1988.

CHOO, T. M.; CHRISTIE, B. R.; REINBERGS, E. Double haploids for estimating genetic variances and a scheme for population improvement in self-pollinating crops. Theoretical and Applied Genetics, Berlin, 54 (2): 267-71, 1979.

CHOO, T. M.; KOTECHA, A.; REINGERGS, E.; SONG, L. S. P.; FEJER, S. O. Diallel analysis of grain yield in barley using doubled-haploid lines. Plant Breeding, Berlin, 97 (2): 129-37, 1986. 
COCHRAN, W. G. \& COX, W. G. Experimental designs. New York, John Willey \& Sons, 1957. $611 \mathrm{p}$.

CRUZ, C. D. \& VENCOVSKY, R. Comparação de alguns métodos de análise dialélica. Revista Brasileira de Genética, Ribeirão Preto, 12 (2): 425-38, 1989.

CRUZ, C. D.; SEDIYAMA, C. S.; SEDIYAMA, T. Capacidade combinatória e efeitos recíprocos de alguns caracteres em soja ( Glycine max (L.) Merrill). Revista Ceres, Viçosa, 34 (194): 432-9, 1987.

ECKHARDT, R. C. Predicting yields of missing single crosses of corn. Agronomy Journal, Madison, 44 (2): 215-6, 1952.

FEHR, W. R. Principles of cultivar development. New York, Macmillan, 1987. v.1, 525p.

FERREIRA, P. E. On Jinks-Hyman's analysis of half diallels. Revista Brasileira de Genética, Ribeirão Preto, 8 (1): 149-55, 1985.

FREIRE FILHO, F. R. Análise genética de um dialelo entre genótipos precoces de soja (Glycine max (L.) Merrill). Piracicaba, 1988. 224 p. (Doutorado Escola Superior de Agricultura "Luiz de Queiroz" / USP)

GARDNER, C. O. Simplified methods for estimating constants and computing sums of squares for a diallel cross analysis. Fitotecnia Latinoamericana, San Jose, 4 (1): 1-12, 1967. 
GARDNER, C. O. \& EBERHART, S. A. Analysis and interpretation of the variety cross diallel and related population. Biometrics, Raleigh, 22 (3): 439-52, 1966.

GAYLOR , D. W.; LUCAS, H. L.; ANDERSON, R. L. Calculation of expected mean squares by abbreviated Doolittle and square root methods. Biometrics, Raleigh, 26 (4): 641-55, 1970.

GOMES, F. P. Curso de estatística experimental. Piracicaba, Nobel, 1987. $467 p$.

GRIFFING, B. Concept of general and specific combining ability in relation to diallel crossing sistems. Australian Journal of Biological Sciences, Melbourne, 9: 463-93, 1956.

HAYES, H. K. \& JOHNSON, I. S. The breeding of improved selfed lines of corn. Journal of the American Society of Agronomy, Madison, 31 (8): 711-24, 1939.

HAYMAN, B. I. The analysis of variance of diallel tables. Biometrics, Raleigh, 10 (2): 235-44, 1954a.

HAYMAN, B. I. The theory and analysis of diallel crosses. Genetics, Baltimore, 39 (6): 789-809, $1954 \mathrm{~b}$. 
HAYMAN, B. I. The theory and analysis of diallel crosses II. Genetics, Baltimore, 43 (1): 63-85, 1958.

JINKS, J. L. The analysis of continous variation in a diallel cross of Nicotiana rustica varieties. Genetics, Baltimore, 39 (6): 767-88, 1954.

JINKS, J. L. The $F_{2}$ and backcross generation from a set of diallel crosses. Heredity, Edinburg, 10 (1): 1-30, 1956.

JINKS, J. L. \& HAYMAN, B. I. The analysis of diallel crosses. Maize Genetics Cooperation Newsletter, Ithaca, 27 : 48-54, 1953.

JINKS, J. L. \& PERKINS, J. M. Predicting the range of inbred lines. Heredity, Edinburgh, 28 (3): 399-403, 1972.

JINKS, J. L. \& POONI, H. S. Predicting the properties of recombinant inbred lines derived by single seed descent. Heredity, Edinburgh, 38 (2): 253-66, 1976.

JINKS, J. L. \& POONI, H. S. Comparing predictions of mean performance and environmental sensitivity of recombinant inbred lines based upon $F_{3}$ and triple test-cross families. Heredity, Edinburgh, 45 (3): 305-12, 1980.

JOHNSON, L. P. V. Aplication of the diallel cross thecniques to plant breeding. In: HANSON, W. D. \& ROBINSON, H. F. Statistical genetics and plant breeding. Washington, National Academic of Sciences, 1963. p.561-70. 
JONES, R. M. Analysis of variance of the half diallel table. Heredity, Edinburgh, 20 (1): 117-21, 1965.

KAW, R. N. \& MENON, M. Heterosis in a ten-parent diallel cross in soybean. Indian Journal of Agricultural Sciences, Dehli, 49 (5): 322-4, 1979.

KAW, R. N. \& MENON, M. Combining ability for developmental traits in soybean. The Indian Journal of Genetics and Plant Breeding, New Dehli, 41 (3): 303-8, 1981.

KEMPTHORNE, O. \& CURNOW, R. N. The partial diallel cross. Biometrics, Raleigh, 17 (2): 229-50, 1961.

KEARSEY, M. J. Biometrical analysis of a random mating population. A comparison of five experimental designs. Heredity, Edinburgh, 20 (2): 20535, 1965.

KNAPP, S. J.; STROUP, W. W.; ROSS, W. M. Exact confidence intervals for heritability on a progeny mean basis. Crop Science, Madison, 25 (1): 1924, 1985.

KUNTA, T.; EDWARDS, L. H.; McNEW, R. W.; DINKINS, R. Heterosis performance and combining ability in soybeans. Soybeans Genetics Newsletter, Ames, 12: 97-9, 1985.

LEFFEL, R. C. \& WEISS, M. G. Analysis of diallel crosses among ten varieties of soybeans. Agronomy Journal, Madison, 50 (9): 528-34, 1958. 
LOISElle, F.; VOLDENG, H. D.; TURCOTTE, P.; ST-PIERRE, C. A. Analysis of agronomic characters for an eleven-parent diallel of earlymaturing soybean genotypes in Eastern Canada. Canadian Journal of Plant Sciences, Ottawa, 70 (1): 107-15, 1990.

MATHER, K. Biometrical genetics. London, Methuen, 1949. 162p.

MATHER, K. \& JINKS, J. L. Biometrical genetics. London, Chapman Hall, 1971. 382p.

MATZINGER, D. F.; SPRAGUE , G. F.; COCKERHAM, C. C. Diallel cross of maize in experiments repeated over locations and years. Agronomy Journal, Madison, 51 (6): 346-50, 1959.

MIRANDA FILHO, J. B. \& GERALDI, I. O. An adapted model for the analysis of partial diallel crosses. Revista Brasileira de Genética, Ribeirão Preto, 7 (4): 677-88, 1984.

MURTY, B. R. \& ANAND, I. J. Combining ability and genetic diversity in some varieties of Linum usitatissimum. Indian Journal of Genetics and Plant Breeding, New Dehli, 26 (1): 21-36, 1966.

NASS, L. L. Potencialidade de genótipos de soja (Glycine max (L.) Merrill) para cultivo de inverno através de cruzamentos dialélicos. Piracicaba, 1989. 112p. (Mestrado - Escola Superior de Agricultura "Luiz de Queiroz" / USP). 
NASSAR, R. F. Effect of correlated gene distribution due to sampling on the diallel analysis. Genetics, Baltimore, 52 (1): 9-20, 1965.

PALUDZYSZYN FILHO, E. Análise do potencial genético de cultivares de soja [ Glycine max (L.) Merrill] através de cruzamentos dialélicos. Piracicaba, 1982. 94 p. (Mestrado - Escola Superior de Agricultura "Luiz de Queiroz" / USP)

PASCHAL, E. H. \& WILCOX, J. R. Heterosis and combining ability in exotic soybean germplasm. Crop Science, Madison, 15 (3):344-9, 1975.

PIMENTEL, A. M. Cruzamentos dialélicos em soja com ênfase em teor de proteína e produção de grãos. Piracicaba, 1991. 150 p. (Mestrado - Escola Superior de Agricultura "Luiz de Queiroz" / USP).

POONI, H. S. \& JINKS, J. L. Predicting the properties of recombinant inbred lines derived by single seed descent for two or more characters simultaneously. Heredity, Edinburgh, 40 (3): 349-61, 1978.

POONI, H. S.; JINKS, J. L.; CORNISH, M. A. The causes and consequences of non-normality in predicting the properties of recombinant inbred lines. Heredity, Edinburgh, 38 (3): 329-38, 1977.

POONI, H. S.; JINKS, J. L.; TOLEDO, J. F. F. Predicting and observing the properties of second cycle hybrids using basic generations and inbred line $\mathrm{x}$ $F_{1}$ crosses. Heredity, Edinburgh, 54 (1): 121-9, 1985. 
POWELL, W.; CALIGARI, P. D. S.; SWANSTON, J. S.; JINKS, J. L. Genetical investigations into $\beta$-glucan content in barley. Theoretical and Applied Genetics, Berlin, 71 (3): 461-6, 1985.

RAMALHO, M. A. P.; SANTOS, J. B.; PEREIRA FILHO, I. Choice of parents for dry bean (Phaseolus vulgaris L.) breeding I. Interaction of mean components by generation and by location. Revista Brasileira de Genética, Ribeirão Preto, 11 (2): 391-400, 1988.

RAMALHO, M. A. P.; SANTOS, J. B.; ZIMMERMANN, M. J. Genética quantitativa em plantas autógamas: aplicações ao melhoramento do feijoeiro. Goiânia, Universidade Federal de Goiás, 1993. 271p.

ROBINSON, H. F.; COMSTOCK, R. E.; HARVEY, P. H. Estimates of heritability and the degree of dominance in corn. Agronomy Journal, Madison, 41 (3): 353-9, 1949.

SABBOUH, M. Y. \& EDWARDS, L. H. Combining ability for seed protein and oil content in soybeans. Soybean Genetics Newsletter, Ames, 12: 99-100, 1985.

SHARMA, S. K.; MEHTA, H.; SOOD, V. K. Effect of cropping systems on combining ability and gene action for grain yield and its components in soybean. Field Crops Research, Amsterdan, 34 (1): 15-22, 1993. 
SPEHAR, C. R. Genetic differences in the acumulation of mineral elements in seeds of tropical soybeans Glycine $\max$ (L.) Merrill. Pesquisa Agropecuária Brasileira, Brasília, 30 (1): 89-94, 1995 a.

SPEHAR, C. R. Diallel analysis for mineral element absorption in tropical adapted soybeans [Glycine $\max (\mathrm{L}$.$) Merrill]. Theoretical and Applied$ Genetics, Berlin, 90 (5): 707-13, 1995 b.

SPRAGUE, G. F. \& TATUM, L. A. General vs specific combining ability in single crosses of corn. Journal of the American Society of Agronomy, Washington, 34 (3): 923-32, 1942.

SRIVASTAVA, R. L.; SAXENA, J. K.; AHAMAD, Z; BHATIA, R. S. Genetics of yield and yield components traits in soybean. Indian Journal of Genetics and Plant Breeding, New Dehli, 38 (1): 7-10, 1978.

STUTHMAN, D. D. \& STUCKER, R. E. Combining ability analysis of nearhomozygous lines derived from a 12-parent diallel cross in oats. Crop Science, Madison, 15 (6): 800-3, 1975.

TOLEDO, J. F. F. Predicting the inbreeding and the outcrossing potential of soybean (Glycine $\max$ L. Merrill) varieties. Revista Brasileira de Genética, Ribeirão Preto, 10 (3): 543-58, 1987.

TOLEDO, J. F. F.; POONI, H. S.; JINKS, J. L. Predicting the properties of second cycle hybrids produced by intercrossing random samples of recombinant inbred lines. Heredity, Edinburgh, 53 (2): 283-92, 1984. 
VENCOVSKY, R. \& BARRIGA, P. Genética biométrica no fitomelhoramento. Ribeirão Preto, Revista Brasileira de Genética, 1992. 496p.

VERMA, V. D. \& RAM, H. H. Genetics of seed impermeability in soya bean. Journal of Agricultural Sciences, Cambridge, 108 (2): 305-10, 1987.

WEBER, C. R.; EMPIG, L. T.; THORNE, J. C. Heterotic performance and combining ability of two-way $\mathrm{F}_{1}$ soybean hybrids. Crop Science, Madison, 10 (1): 159-60, 1970.

WENBIN, L. \& JNLING, W. An analysis of diallel crosses between the lines of interespecific hybrids and cultivars in soybean. I. Overcoming small seed trait of wild and semi-wild soybeans. Soybean Genetics Newsletter, Ames, 15: 36-40, 1988.

YATES, F. Analysis of data from all possible reciprocal crosses between a set of parental lines. Heredity, Edinburgh, 1 (2): 287-301, 1947. 
LISTA DE TABELAS E FIGURAS 
Tabela 10. Análise de variância dos cruzamentos da tabela dialélica para o caráter Altura da Planta na Maturação (cm / planta), na geração $F_{2: n}$, nas quatro avaliações e análise conjunta.

\begin{tabular}{|c|c|c|c|c|c|c|c|c|c|c|}
\hline & \multicolumn{2}{|c|}{$1992 / 93$} & \multicolumn{2}{|c|}{$1993 / 94$} & \multicolumn{2}{|c|}{$1994 / 95$} & \multicolumn{2}{|c|}{$1995 / 96$} & \multicolumn{2}{|c|}{ Conjunta } \\
\hline F. Variação & Gl & $\overline{Q M}$ & G1 & $\overline{\mathrm{QM}}$ & $\overline{\mathrm{Gl}}$ & $\overline{\mathrm{QM}}$ & Gl & $\overline{Q M}$ & Gl & $\overline{\mathrm{QM}}$ \\
\hline Repet. / Anos & & & & & & & & & 7 & $2217,32^{* *}$ \\
\hline Repetições & 2 & $4241,33^{* *}$ & 1 & $694,05^{* *}$ & 2 & $1949,89^{* *}$ & 2 & $1344,46^{* *}$ & & \\
\hline $\operatorname{Anos}(A)$ & & & & & & & & & 3 & $71607,70^{* *}$ \\
\hline Cruzam. (C) & 24 & $4875,90^{* *}$ & 24 & $7283,92^{* *}$ & 24 & $4111,37^{* *}$ & 24 & $5357,63^{* *}$ & 24 & $19911,62 *$ \\
\hline$A \times C$ & & & & & & & & & 72 & $597,05^{* *}$ \\
\hline Erro (parcel.) & 48 & $128,10^{\text {ns }}$ & 24 & $244,56^{* *}$ & 48 & $286,97^{* *}$ & 48 & $204,28^{* *}$ & 168 & $216,32^{* *}$ \\
\hline Prog. ( P ) / C & 468 & $370,01^{* *}$ & 468 & $456,58^{* *}$ & 468 & $319,21^{* *}$ & 466 & $412,23^{* *}$ & 468 & $1087,93^{* *}$ \\
\hline $\operatorname{Prog}(\mathrm{C} 1 \times 2)$ & 19 & $507,01^{* *}$ & 19 & $500,00^{* *}$ & 19 & $363,95^{* *}$ & 18 & $591,56^{* *}$ & 19 & $1340,32^{* *}$ \\
\hline $\operatorname{Prog}(C 1 \times 3)$ & 19 & $212,50^{\mathrm{ns}}$ & 19 & $114,00^{*}$ & 19 & $147,02^{* *}$ & 19 & $306,23^{* *}$ & 19 & $490,01^{* *}$ \\
\hline $\operatorname{Prog}\left(C_{1} \times 4\right)$ & 12 & $282,30^{*}$ & 12 & $168,21^{*}$ & 12 & $216,45^{*}$ & 12 & $225,67^{\text {ns }}$ & 12 & $524,15^{* *}$ \\
\hline $\operatorname{Prog}(C 1 \times 6)$ & 19 & $128,06^{\mathrm{ns}}$ & 19 & $216,81^{*}$ & 19 & $298,00^{* * *}$ & 19 & $239,92^{* *}$ & 19 & $419,93^{* *}$ \\
\hline $\operatorname{Prog}(C 1 \times 7)$ & 19 & $219,43^{\text {ns }}$ & 19 & $390,04^{* *}$ & 19 & $255,68^{*}$ & 19 & $514,61^{* *}$ & 19 & $904,06^{* *}$ \\
\hline $\operatorname{Prog}(C 1 \times 8)$ & 19 & $294,96^{*}$ & 19 & $231,72^{\text {ns }}$ & 19 & $148,77^{* *}$ & 19 & $140,97^{\mathrm{ns}}$ & 19 & $396,94^{* *}$ \\
\hline $\operatorname{Prog}(C 2 \times 3)$ & 19 & $468,75^{* *}$ & 19 & $667,31^{* *}$ & 19 & $342,02^{* *}$ & 19 & $458,31^{* *}$ & 19 & $1517,74^{* *}$ \\
\hline $\operatorname{Prog}(C 2 \times 4)$ & 19 & $787,28^{* *}$ & 19 & $666,28^{* *}$ & 19 & $503,80^{* *}$ & 19 & $573,25^{* *}$ & 19 & $1969,01^{* *}$ \\
\hline $\operatorname{Prog}(C 2 \times 5)$ & 19 & $929,89^{* *}$ & 19 & $795,50^{* *}$ & 19 & $537,22^{* *}$ & 19 & $636,17^{* *}$ & 19 & $2509,62^{* *}$ \\
\hline $\operatorname{Prog}(C 2 \times 6)$ & 19 & $256,40^{\mathrm{ns}}$ & 19 & $321,94^{*}$ & 19 & $394,14^{* *}$ & 19 & $444,86^{* *}$ & 19 & $925,78^{* *}$ \\
\hline $\operatorname{Prog}(C 2 \times 8)$ & 19 & $444,04^{* *}$ & 19 & $312,71^{* *}$ & 19 & $391,32^{* *}$ & 19 & $963,92^{* *}$ & 19 & $1168,14^{* *}$ \\
\hline $\operatorname{Prog}(C 3 \times 5)$ & 19 & $246,23^{* *}$ & 19 & $152,13^{*}$ & 19 & $203,92^{* *}$ & 19 & $146,89^{*}$ & 19 & $452,97^{* *}$ \\
\hline $\operatorname{Prog}(C 3 \times 6)$ & 19 & $322,44^{* *}$ & 19 & $213,04^{\mathrm{ns}}$ & 19 & $226,73^{* *}$ & 19 & $178,70^{\text {ns }}$ & 19 & $669,72^{* *}$ \\
\hline $\operatorname{Prog}(C 3 \times 7)$ & 19 & $563,74^{* *}$ & 19 & $919,18^{* *}$ & 19 & $487,06^{* *}$ & 19 & $522,82^{* *}$ & 19 & $2052,33^{* *}$ \\
\hline $\operatorname{Prog}(C 3 \times 8)$ & 19 & $363,65^{* *}$ & 19 & $440,92^{* *}$ & 19 & $314,42^{* *}$ & 18 & $296,59^{*}$ & 19 & $1062,15^{* *}$ \\
\hline $\operatorname{Prog}(\mathrm{C} 4 \times 5)$ & 19 & $179,81^{* *}$ & 19 & $109,30^{*}$ & 19 & $120,96^{*}$ & 19 & $160,44^{\mathrm{ns}}$ & 19 & $317,79^{* *}$ \\
\hline $\operatorname{Prog}(C 4 \times 6)$ & 19 & $414,50^{* *}$ & 19 & $613,08^{* *}$ & 19 & $436,10^{* *}$ & 19 & $457,76^{* *}$ & 19 & $1551,37^{* *}$ \\
\hline $\operatorname{Prog}(\mathrm{C} 4 \times 7)$ & 19 & $606,33^{* *}$ & 19 & $556,22^{* *}$ & 19 & $306,38^{*}$ & 19 & $558,24^{* *}$ & 19 & $1632,46^{* *}$ \\
\hline $\operatorname{Prog}(\mathrm{C} 4 \times 8)$ & 19 & $217,35^{*}$ & 19 & $326,70^{*}$ & 19 & $163,51^{*}$ & 19 & $183,77^{\text {ns }}$ & 19 & $583,87^{* *}$ \\
\hline $\operatorname{Prog}(C 5 \times 6)$ & 19 & $89,80^{\text {ns }}$ & 19 & $105,45^{\mathrm{ns}}$ & 19 & $159,19^{* *}$ & 19 & $137,23^{*}$ & 19 & $239,55^{* *}$ \\
\hline $\operatorname{Prog}(\mathrm{C} 5 \times 7)$ & 19 & $476,16^{* *}$ & 19 & $848,67^{* *}$ & 19 & $582,87^{* *}$ & 19 & $427,17^{* *}$ & 19 & $1598,54^{* *}$ \\
\hline $\operatorname{Prog}(\mathrm{C} 5 \times 8)$ & 19 & $188,72^{\text {ns }}$ & 19 & $737,28^{* *}$ & 19 & $359,01^{* *}$ & 19 & $422,37^{* *}$ & 19 & $1073,39^{* *}$ \\
\hline $\operatorname{Prog}(C 6 \times 7)$ & 19 & $372,05^{* *}$ & 19 & $548,13^{* *}$ & 19 & $512,48^{* *}$ & 19 & $724,98^{* *}$ & 19 & $1534,52^{* *}$ \\
\hline $\operatorname{Prog}(\mathrm{C} 6 \times 8)$ & 19 & $242,77^{\text {ns }}$ & 19 & $695,15^{* *}$ & 19 & $247,98^{*}$ & 19 & $407,97^{* *}$ & 19 & $1068,06^{* *}$ \\
\hline $\operatorname{Prog}(C 7 \times 8)$ & 19 & $403,64^{* * *}$ & 19 & $658,48^{* *}$ & 19 & $223,48^{\text {ns }}$ & 19 & $520,09^{* *}$ & 19 & $988,10^{* *}$ \\
\hline A x Prog / Cruz. & & & & & & & & & 1402 & $156,34^{* *}$ \\
\hline Епо & 932 & 120,09 & 464 & 89,97 & 917 & 95,48 & 929 & 96,13 & 3242 & 101,95 \\
\hline Total & 1474 & 283,06 & 981 & 446,14 & 1459 & 242,18 & 1469 & 288,20 & 5386 & 342,82 \\
\hline
\end{tabular}


Tabela 11. Análise de variância das progênies do cruzamento Gaúcha x La-4910215 para o caracter Altura da Planta na Maturação (cm / planta), na geração $F_{2: n}$, nas quatro avaliações e análise conjunta.

\begin{tabular}{|c|c|c|c|c|c|c|c|c|c|c|}
\hline & \multicolumn{2}{|c|}{$1992 / 93$} & \multicolumn{2}{|c|}{ 1993/94 } & \multicolumn{2}{|c|}{$1994 / 95$} & \multicolumn{2}{|c|}{$1995 / 96$} & \multicolumn{2}{|c|}{ Conjunta } \\
\hline F. Variação & $\mathrm{Gl}$ & $\mathrm{QM}$ & $\mathrm{Gl}$ & $\mathrm{QM}$ & Gl & $\mathrm{QM}$ & $\mathrm{Gl}$ & $\overline{\mathrm{QM}}$ & Gl & $\mathrm{QM}$ \\
\hline $\begin{array}{l}\text { Repet. / Anos } \\
\text { Repetições } \\
\text { Progênies (P) } \\
\text { Anos (A) } \\
\text { P x A } \\
\text { Emo }\end{array}$ & $\begin{array}{c}2 \\
19 \\
\\
38\end{array}$ & $\begin{array}{c}271,62 \\
507,01^{* * *} \\
90,35\end{array}$ & $\begin{array}{c}1 \\
19\end{array}$ & $\begin{array}{c}218,70 \\
500,00^{* *} \\
82,16\end{array}$ & $\begin{array}{c}2 \\
19 \\
\\
\\
38\end{array}$ & $\begin{array}{c}113,75 \\
363,95^{* *} \\
94,01\end{array}$ & $\begin{array}{c}2 \\
18 \\
\\
\\
35\end{array}$ & $\begin{array}{c}594,96 \\
591,57^{* *} \\
70,95\end{array}$ & \begin{tabular}{|c|}
7 \\
\\
19 \\
3 \\
56 \\
130
\end{tabular} & $\begin{array}{c}311,34 \\
1340,32^{* *} \\
3061,71^{* *} \\
200,54^{* *} \\
85,00\end{array}$ \\
\hline Total & 59 & 230,68 & 39 & 289,23 & 59 & 181,61 & 55 & 260,39 & 215 & 247,94 \\
\hline Média & & 77,03 & & 85,75 & & 86,50 & & 70,71 & & 79,64 \\
\hline Desv. Padrão & & 13,00 & & 15,85 & & 11,01 & & 14,07 & & 11,65 \\
\hline Menor Valor & & 49,67 & & 51,70 & & 65,00 & & 45,00 & & 53,84 \\
\hline Maior Valor & & 96,67 & & 108,20 & & 103,33 & & 88,33 & & 92,88 \\
\hline Amplitude & & 47,00 & & 56,50 & & 38,33 & & 43,33 & & 39,04 \\
\hline $\mathrm{CVe}$ & & 12,34 & & 10,57 & & 11,21 & & 11,91 & & 11,58 \\
\hline$\sigma_{\mathrm{p}}^{2}$ & & 138,89 & & 208,92 & & 89,98 & & 176,81 & & 105,27 \\
\hline IC $\sigma_{\mathrm{p}}^{2}-\mathrm{LI}$ & & 72,56 & & 109,74 & & 44,12 & & 94,68 & & 56,14 \\
\hline IC $\sigma_{\mathrm{p}}^{2}-\mathrm{LS}$ & & 368,18 & & 545,57 & & 275,55 & & 444,59 & & 266,87 \\
\hline IC $\sigma_{\mathrm{p}}^{2}(\mathrm{LS}-\mathrm{LI})$ & & 295,62 & & 435,83 & & 231,43 & & 349,91 & & 210,73 \\
\hline$\sigma^{2}$ & & 90,35 & & 82,16 & & 94,01 & & 70,95 & & 85,00 \\
\hline$\sigma_{\mathrm{pa}}^{2}$ & & & & & & & & & & 42,64 \\
\hline$\sigma_{\mathrm{f}}^{2}$ & & 169,01 & & 250,00 & & 121,32 & & 200,91 & & 128,88 \\
\hline$h_{x}^{2}$ & & 0,82 & & 0,84 & & 0,74 & & 0,88 & & 0,82 \\
\hline IC $h_{x}^{2}-L I$ & & 0,58 & & 0,58 & & 0,39 & & 0,71 & & 0,66 \\
\hline IC $h_{x}^{2}-$ LS & & 0,92 & & 0,93 & & 0,88 & & 0,94 & & 0,92 \\
\hline IC $h_{\mathrm{x}}^{2}(\mathrm{LS}-\mathrm{LI})$ & & 0,34 & & 0,35 & & 0,49 & & 0,23 & & 0,26 \\
\hline $\mathrm{CVg}$ & & 15,30 & & 16,86 & & 10,97 & & 18,80 & & 12,88 \\
\hline $\mathrm{CVg} / \mathrm{CVe}$ & & 1,24 & & 1,60 & & 0,98 & & 1,58 & & 1,11 \\
\hline
\end{tabular}


Tabela 12. Análise de variância das progênies do cruzamento Gaúcha x OC 79230 para o caracter Altura da Planta na Maturação (cm / planta), na geração $F_{2: n}$, nas quatro avaliações e análise conjunta.

\begin{tabular}{|c|c|c|c|c|c|c|c|c|c|c|}
\hline & \multicolumn{2}{|c|}{$1992 / 93$} & \multicolumn{2}{|c|}{$1993 / 94$} & \multicolumn{2}{|c|}{$1994 / 95$} & \multicolumn{2}{|c|}{$1995 / 96$} & \multicolumn{2}{|c|}{ Conjunta } \\
\hline F. Variação & $\mathrm{Gl}$ & $\mathrm{QM}$ & Gl & $\mathrm{QM}$ & $\mathrm{Gl}$ & $\overline{\mathrm{QM}}$ & $\overline{\mathrm{Gl}}$ & $\overline{Q M}$ & Gl & $\widehat{\mathrm{QM}}$ \\
\hline $\begin{array}{l}\text { Repet. / Anos } \\
\text { Repetiçōes } \\
\text { Progênies (P) } \\
\text { Anos (A) } \\
\text { P x A } \\
\text { Erro } \\
\end{array}$ & $\begin{array}{c}2 \\
19\end{array}$ & $\begin{array}{l}318,95 \\
212,51^{\mathrm{ns}} \\
119,11\end{array}$ & $\begin{array}{c}1 \\
19 \\
\\
19 \\
\end{array}$ & $\begin{array}{c}302,50 \\
114,00\end{array}$ & $\begin{array}{c}2 \\
19 \\
\\
\\
38\end{array}$ & $\begin{array}{c}107,92 \\
147,02^{* *} \\
46,95\end{array}$ & $\begin{array}{c}2 \\
19 \\
\\
\\
38\end{array}$ & $\begin{array}{c}300,42 \\
306,23 \\
\end{array}$ & \begin{tabular}{|c|}
7 \\
19 \\
3 \\
57 \\
133 \\
\end{tabular} & $\begin{array}{c}251,01 \\
490,01^{* *} \\
1837,78^{* *} \\
96,58^{\text {ns }} \\
80,41\end{array}$ \\
\hline Total & 59 & 155,96 & 39 & 82,16 & 59 & 81,24 & 59 & 170,65 & 219 & 149,68 \\
\hline Média & & 63,20 & & 75,60 & & 70,33 & & 62,83 & & 67,30 \\
\hline Desv. Padrão & & 8,42 & & 7,55 & & 7,00 & & 10,10 & & 6,59 \\
\hline Menor Valor & & 48,33 & & 56,90 & & 48,33 & & 48,33 & & 50,48 \\
\hline Maior Valor & & 84,67 & & 89,10 & & 80,00 & & 85,00 & & 80,28 \\
\hline Amplitude & & 36,34 & & 32,20 & & 31,67 & & 36,67 & & 29,81 \\
\hline $\mathrm{CVe}$ & & 17,27 & & 8,23 & & 9,74 & & 15,60 & & 13,32 \\
\hline$\sigma_{\mathrm{p}}^{2}$ & & 31,13 & & 37,65 & & 33,36 & & 70,07 & & 35,72 \\
\hline $\mathrm{IC} \sigma_{\mathrm{p}}^{2}-\mathrm{LI}$ & & 10,16 & & 8,94 & & 6,46 & & 32,70 & & 18,40 \\
\hline IC $\sigma_{p}^{2}-L S$ & & 376,71 & & 148,67 & & 117,17 & & 245,38 & & 96,77 \\
\hline IC $\sigma_{\mathrm{p}}^{2}$ (LS-LI) & & 366,55 & & 139,73 & & 110,71 & & 212,68 & & 78,37 \\
\hline$\sigma^{2}$ & & 119,11 & & 38,71 & & 46,95 & & 96,03 & & 80,41 \\
\hline$\sigma_{p a}^{2}$ & & & & & & & & & & 5,93 \\
\hline$\sigma_{f}^{2}$ & & 70,84 & & 57,00 & & 49,00 & & 102,08 & & 45,20 \\
\hline$h_{x}^{2}$ & & 0,44 & & 0,66 & & 0,68 & & 0,69 & & 0,79 \\
\hline $\mathrm{IC} \mathrm{h}_{\mathrm{x}}^{2}-\mathrm{LI}$ & & $-0,31$ & & 0,14 & & 0,25 & & 0,27 & & 0,55 \\
\hline IC $h_{x}^{2}-L S$ & & 0,60 & & 0,87 & & 0,84 & & 0,84 & & 0,83 \\
\hline IC $h_{x}^{2}$ (LS-LI) & & 0,91 & & 0,73 & & 0,59 & & 0,57 & & 0,28 \\
\hline $\mathrm{CVg}$ & & 8,83 & & 8,12 & & 8,21 & & 13,32 & & 8,88 \\
\hline $\mathrm{CVg} / \mathrm{CVe}$ & & 0,51 & & 0,99 & & 0,84 & & 0,85 & & 0,67 \\
\hline
\end{tabular}


Tabela 13. Análise de variância das progênies do cruzamento Gaúcha x BR 808858 para o caracter Altura da Planta na Maturação (cm / planta), na geração $F_{2: n}$, nas quatro avaliações e análise conjunta.

\begin{tabular}{|c|c|c|c|c|c|c|c|c|c|c|}
\hline & \multicolumn{2}{|c|}{$1992 / 93$} & \multicolumn{2}{|c|}{$1993 / 94$} & \multicolumn{2}{|c|}{$1994 / 95$} & \multicolumn{2}{|c|}{$1995 / 96$} & \multicolumn{2}{|c|}{ Conjunta } \\
\hline F. Variação & $\mathrm{Gl}$ & $\mathrm{QM}$ & $\mathrm{Gl}$ & $\overline{Q M}$ & $\mathrm{Gl}$ & $\overline{Q M}$ & $\mathrm{Gl}$ & $\overline{\mathrm{QM}}$ & Gl & $\overline{Q M}$ \\
\hline $\begin{array}{l}\text { Repet. / Anos } \\
\text { Repetições } \\
\text { Progênies (P) } \\
\text { Anos (A) } \\
\text { P x A } \\
\text { Erro }\end{array}$ & $\begin{array}{c}2 \\
12 \\
\\
24\end{array}$ & $\begin{array}{l}196,64 \\
282,30^{*} \\
118,28\end{array}$ & $\begin{array}{c}1 \\
12 \\
\\
11\end{array}$ & $\begin{array}{r}23,69 \\
168,21^{*} \\
\\
52,44\end{array}$ & $\begin{array}{c}2 \\
12 \\
\\
24\end{array}$ & $\begin{array}{c}12,18 \\
216,45\end{array}$ & $\begin{array}{c}2 \\
12 \\
24\end{array}$ & $\begin{array}{c}69,26 \\
225,67^{\text {ns }} \\
117,17\end{array}$ & $\begin{array}{c}7 \\
12 \\
3 \\
36 \\
83\end{array}$ & $\begin{array}{l}82,83 \\
524,15^{* *} \\
652,89^{* *} \\
122,83^{\text {ns }} \\
102,45\end{array}$ \\
\hline Total & 38 & 174,20 & 24 & 109,13 & 38 & 128,88 & 38 & 148,91 & 141 & 154,28 \\
\hline Média & & 59,56 & & 57,51 & & 65,26 & & 55,67 & & 59,70 \\
\hline Desv. Padrão & & 9,70 & & 9,18 & & 8,49 & & 8,67 & & 6,93 \\
\hline Menor Valor & & 42,00 & & 48,57 & & 51,67 & & 47,00 & & 49,76 \\
\hline Maior Valor & & 74,33 & & 75,70 & & 81,67 & & 80,00 & & 68,93 \\
\hline Amplitude & & 32,33 & & 27,14 & & 30,00 & & 33,00 & & 19,17 \\
\hline $\mathrm{CVe}$ & & 18,26 & & 12,59 & & 14,92 & & 19,45 & & 16,96 \\
\hline$\sigma_{p}^{2}$ & & 54,67 & & 60,40 & & 40,55 & & 36,17 & & 36,68 \\
\hline $\mathrm{IC} \sigma_{\mathrm{p}}^{2}-\mathrm{LI}$ & & 19,17 & & 23,88 & & 13,66 & & 10,59 & & 15,98 \\
\hline IC $\sigma_{p}^{2}-L S$ & & 515,97 & & 357,04 & & 413,73 & & 861,75 & & 154,25 \\
\hline IC $\sigma_{\mathrm{p}}^{2}$ (LS-LI) & & 496,80 & & 336,16 & & 400,07 & & 851,16 & & 138,27 \\
\hline$\sigma^{2}$ & & 118,28 & & 52,44 & & 94,82 & & 117,17 & & 102,45 \\
\hline$\sigma_{\mathrm{pa}}^{2}$ & & & & & & & & & & 7,55 \\
\hline$\sigma_{f}^{2}$ & & 94,10 & & 87,76 & & 72,15 & & 75,22 & & 48,86 \\
\hline$h_{x}^{2}$ & & 0,58 & & 0,69 & & 0,56 & & 0,48 & & 0,75 \\
\hline IC $h_{x}^{2}-L I$ & & $-0,26$ & & $-0,04$ & & $-0,32$ & & $-0,57$ & & 0,31 \\
\hline IC $h_{x}^{2}-L S$ & & 0,73 & & 0,91 & & 0,83 & & 0,80 & & 0,78 \\
\hline IC $h_{x}^{2}(\mathrm{LS}-\mathrm{LI})$ & & 0,99 & & 0,95 & & 1,15 & & 1,37 & & 0,47 \\
\hline $\mathrm{CVg}$ & & 12,41 & & 13,51 & & 9,76 & & 10,80 & & 10,15 \\
\hline $\mathrm{CVg} / \mathrm{CVe}$ & & 0,68 & & 1,07 & & 0,65 & & 0,56 & & 0,60 \\
\hline
\end{tabular}


Tabela 14. Análise de variância das progênies do cruzamento Gaúcha x PI 123439 para o caracter Altura da Planta na Maturação (cm / planta), na geração $F_{2: n}$, nas quatro avaliações e análise conjunta.

\begin{tabular}{|c|c|c|c|c|c|c|c|c|c|c|}
\hline & \multicolumn{2}{|c|}{$1992 / 93$} & \multicolumn{2}{|c|}{$1993 / 94$} & \multicolumn{2}{|c|}{$1994 / 95$} & \multicolumn{2}{|c|}{$1995 / 96$} & \multicolumn{2}{|c|}{ Conjunta } \\
\hline F. Variação & Gl & $\overline{Q M}$ & Gl & $\mathrm{QM}$ & $\mathrm{Gl}$ & $\overline{\mathrm{QM}}$ & $\mathrm{Gl}$ & $\overline{\mathrm{QM}}$ & G1 & $\overline{Q M}$ \\
\hline $\begin{array}{l}\text { Repet. / Anos } \\
\text { Repetições } \\
\text { Progênies (P) } \\
\text { Anos (A) } \\
\text { P x A } \\
\text { Erro } \\
\end{array}$ & $\begin{array}{c}2 \\
19 \\
\\
36\end{array}$ & $\begin{array}{c}50,47 \\
128,06^{\text {ns }} \\
105,22\end{array}$ & $\begin{array}{c}1 \\
19\end{array}$ & $\begin{array}{r}373,02 \\
216,81^{*} \\
\\
82,26 \\
\end{array}$ & $\begin{array}{c}2 \\
19 \\
\\
\\
36\end{array}$ & $\begin{array}{c}200,56 \\
298,00^{* *} \\
87,72\end{array}$ & $\begin{array}{c}2 \\
19 \\
\\
\\
37\end{array}$ & $\begin{array}{c}97,70 \\
239,92^{* *} \\
62,96\end{array}$ & \begin{tabular}{|c|}
7 \\
\\
19 \\
3 \\
57 \\
128
\end{tabular} & $\begin{array}{c}152,92 \\
\\
419,93^{* *} \\
2723,00^{* *} \\
154,29^{* *} \\
84,67\end{array}$ \\
\hline Total & 57 & 110,91 & 39 & 155,27 & 57 & 161,77 & 58 & 122,12 & 214 & 172,20 \\
\hline Média & & 59,97 & & 67,21 & & 65,26 & & 51,25 & & 60,35 \\
\hline Desv. Padrão & & 6,64 & & 10,42 & & 10,05 & & 9,25 & & 6,27 \\
\hline Menor Valor & & 48,33 & & 45,63 & & 50,00 & & 38,33 & & 47,66 \\
\hline Maior Valor & & 70,22 & & 95,70 & & 86,67 & & 73,33 & & 73,34 \\
\hline Amplitude & & 21,89 & & 50,08 & & 36,67 & & 35,00 & & 25,69 \\
\hline $\mathrm{CVe}$ & & 17,11 & & 13,50 & & 14,35 & & 15,48 & & 15,25 \\
\hline$\sigma_{\mathrm{p}}^{2}$ & & 7,91 & & 67,28 & & 72,64 & & 60,04 & & 24,50 \\
\hline $\mathrm{IC} \sigma_{\mathrm{p}}^{2}-\mathrm{LI}$ & & - & & 28,54 & & 34,55 & & 29,31 & & 10,82 \\
\hline $\mathrm{IC} \sigma_{\mathrm{p}}^{2}-\mathrm{LS}$ & & - & & 304,50 & & 243,36 & & 184,60 & & 97,23 \\
\hline IC $\sigma_{\mathrm{p}}^{2}(\mathrm{LS}-\mathrm{LI})$ & & - & & 275,96 & & 208,81 & & 155,29 & & 86,41 \\
\hline$\sigma^{2}$ & & 105,22 & & 82,26 & & 87,72 & & 62,96 & & 84,67 \\
\hline$\sigma_{\mathrm{pa}}^{2}$ & & & & & & & & & & 26,20 \\
\hline$\sigma_{f}^{2}$ & & 44,32 & & 108,41 & & 102,95 & & 85,40 & & 42,25 \\
\hline$h_{x}^{2}$ & & 0,18 & & 0,62 & & 0,71 & & 0,74 & & 0,58 \\
\hline $\mathrm{IC} \mathrm{h}_{\mathrm{x}}^{2}-\mathrm{LI}$ & & $-0,93$ & & 0,04 & & 0,31 & & 0,38 & & 0,16 \\
\hline $\mathrm{IC} \mathrm{h}_{\mathrm{x}}^{2}-\mathrm{LS}$ & & 0,85 & & 0,85 & & 0,86 & & 0,88 & & 0,81 \\
\hline $\mathrm{IC} \mathrm{h}_{\mathrm{x}}^{2}(\mathrm{LS}-\mathrm{LI})$ & & 1,78 & & 0,81 & & 0,55 & & 0,50 & & 0,65 \\
\hline $\mathrm{CVg}$ & & 4,67 & & 12,20 & & 13,06 & & 15,12 & & 8,20 \\
\hline $\mathrm{CVg} / \mathrm{CVe}$ & & 0,27 & & 0,90 & & 0,91 & & 0,98 & & 0,54 \\
\hline
\end{tabular}


Tabela 15. Análise de variância das progênies do cruzamento Gaúcha x PI 165896 para o caracter Altura da Planta na Maturação (cm / planta), na geração $F_{2: n}$, nas quatro avaliações e análise conjunta.

\begin{tabular}{|c|c|c|c|c|c|c|c|c|c|c|}
\hline & \multicolumn{2}{|c|}{$1992 / 93$} & \multicolumn{2}{|c|}{$1993 / 94$} & \multicolumn{2}{|c|}{$1994 / 95$} & \multicolumn{2}{|c|}{$1995 / 96$} & \multicolumn{2}{|c|}{ Conjunta } \\
\hline F. Variação & $\mathrm{Gl}$ & $\overline{Q M}$ & Gl & $\mathrm{QM}$ & $\overline{\mathrm{Gl}}$ & $\mathrm{QM}$ & $\mathrm{Gl}$ & QM & Gl & QM \\
\hline $\begin{array}{l}\text { Repet. / Anos } \\
\text { Repetições } \\
\text { Progênies (P) } \\
\text { Anos (A) } \\
\text { P x A } \\
\text { Erro } \\
\end{array}$ & $\begin{array}{c}2 \\
19\end{array}$ & $\begin{array}{c}387,49 \\
219,43^{\text {ns }} \\
\\
211,28 \\
\end{array}$ & $\begin{array}{c}1 \\
19 \\
\\
19 \\
\end{array}$ & $\begin{array}{l}234,16 \\
390,04^{* *} \\
114,47\end{array}$ & $\begin{array}{c}2 \\
19 \\
\\
\\
38\end{array}$ & $\begin{array}{l}271,67 \\
255,68^{*} \\
\\
113,77 \\
\end{array}$ & $\begin{array}{c}2 \\
19 \\
\\
38\end{array}$ & $\begin{array}{c}405,07 \\
514,61^{* *} \\
64,65\end{array}$ & \begin{tabular}{|c|}
7 \\
19 \\
3 \\
57 \\
132 \\
\end{tabular} & $\begin{array}{c}337,52 \\
904,06^{* *} \\
2997,53^{* *} \\
158,57^{\text {ns }} \\
127,06\end{array}$ \\
\hline Total & 58 & 220,03 & 39 & 251,79 & 59 & 164,82 & 59 & 221,09 & 218 & 249,28 \\
\hline Média & & 74,20 & & 86,34 & & 79,92 & & 68,22 & & 76,34 \\
\hline Desv. Padrão & & 8,64 & & 13,97 & & 9,23 & & 13,10 & & 9,39 \\
\hline Menor Valor & & 58,33 & & 55,90 & & 60,00 & & 45,00 & & 59,64 \\
\hline Maior Valor & & 88,67 & & 106,60 & & 93,33 & & 93,33 & & 91,32 \\
\hline Amplitude & & 30,33 & & 50,70 & & 33,33 & & 48,33 & & 31,68 \\
\hline $\mathrm{CVe}$ & & 19,59 & & 12,39 & & 13,35 & & 11,79 & & 14,77 \\
\hline$\sigma_{p}^{2}$ & & 2,77 & & 137,79 & & 47,30 & & 149,99 & & 68,00 \\
\hline $\mathrm{IC} \sigma_{\mathrm{p}}^{2}-\mathrm{LI}$ & & - & & 64,76 & & 18,91 & & 81,06 & & 35,76 \\
\hline $\mathrm{IC} \sigma_{\mathrm{p}}^{2}-\mathrm{LS}$ & & - & & 473,46 & & 265,87 & & 367,60 & & 177,96 \\
\hline IC $\sigma_{\mathrm{p}}^{2}$ (LS-LI) & & - & & 408,70 & & 246,96 & & 286,54 & & 142,20 \\
\hline$\sigma^{2}$ & & 211,28 & & 114,47 & & 113,77 & & 64,65 & & 127,06 \\
\hline$\sigma_{\mathrm{pa}}^{2}$ & & & & & & & & & & 11,61 \\
\hline$\sigma_{f}^{2}$ & & 74,45 & & 195,02 & & 85,23 & & 171,54 & & 83,89 \\
\hline$h_{x}^{2}$ & & 0,04 & & 0,71 & & 0,56 & & 0,87 & & 0,81 \\
\hline $\mathrm{IC} \mathrm{h}_{\mathrm{x}}^{2}-\mathrm{LI}$ & & $-1,26$ & & 0,26 & & $-0,04$ & & 0,71 & & 0,60 \\
\hline $\mathrm{IC} \mathrm{h}_{\mathrm{x}}^{2}-\mathrm{LS}$ & & 0,55 & & 0,88 & & 0,79 & & 0,94 & & 0,91 \\
\hline IC $h_{x}^{2}(L S-L I)$ & & 1,81 & & 0,62 & & 0,83 & & 0,23 & & 0,31 \\
\hline $\mathrm{cVg}$ & & 2,24 & & 13,60 & & 8,61 & & 17,95 & & 10,80 \\
\hline $\mathrm{CVg} / \mathrm{CVe}$ & & 0,11 & & 1,10 & & 0,64 & & 1,52 & & 0,73 \\
\hline
\end{tabular}


Tabela 16. Análise de variância das progênies do cruzamento Gaúcha x PI 239235 para o caracter Altura da Planta na Maturação (cm / planta), na geração $F_{2: n}$, nas quatro avaliações e análise conjunta.

\begin{tabular}{|c|c|c|c|c|c|c|c|c|c|c|}
\hline & \multicolumn{2}{|c|}{$1992 / 93$} & \multicolumn{2}{|c|}{$1993 / 94$} & \multicolumn{2}{|c|}{$1994 / 95$} & \multicolumn{2}{|c|}{$1995 / 96$} & \multicolumn{2}{|c|}{ Conjunta } \\
\hline F. Variacão & $\mathrm{Gl}$ & $\mathrm{QM}$ & $\mathrm{Gl}$ & $\widehat{\mathrm{QM}}$ & $\overline{\mathrm{Gl}}$ & $\overline{\mathrm{QM}}$ & $\overline{\mathrm{Gl}}$ & $\widehat{\mathrm{QM}}$ & G1 & $\overline{\mathrm{QM}}$ \\
\hline $\begin{array}{l}\text { Repet. / Anos } \\
\text { Repetições } \\
\text { Progênies (P) } \\
\text { Anos (A) } \\
\text { P x A } \\
\text { Erro } \\
\end{array}$ & $\begin{array}{c}2 \\
19\end{array}$ & $\begin{array}{c}331,32 \\
294,96^{*} \\
132,21\end{array}$ & $\begin{array}{c}1 \\
19 \\
\\
19\end{array}$ & $\begin{array}{c}6,64 \\
231,72^{\text {ns }} \\
142,72\end{array}$ & $\begin{array}{c}2 \\
19 \\
\\
\\
38\end{array}$ & $\begin{array}{c}52,92 \\
148,77^{* *} \\
55,55\end{array}$ & $\begin{array}{c}2 \\
19 \\
\\
\\
37\end{array}$ & $\begin{array}{c}5,01 \\
140,97^{\text {ns }} \\
136,55\end{array}$ & \begin{tabular}{|c|}
7 \\
19 \\
3 \\
57 \\
132 \\
\end{tabular} & $\begin{array}{c}112,16 \\
\\
396,94^{* *} \\
4990,71^{* *} \\
139,83^{\text {ns }} \\
112,87\end{array}$ \\
\hline Total & 59 & 191,37 & 39 & 182,59 & 59 & 85,48 & 58 & 133,46 & 218 & 211,78 \\
\hline Média & & 75,87 & & 89,57 & & 81,33 & & 65,76 & & 77,15 \\
\hline Desv. Padrão & & 9,92 & & 10,76 & & 7,04 & & 6,86 & & 6,14 \\
\hline Menor Valor & & 56,33 & & 65,00 & & 65,00 & & 53,33 & & 65,02 \\
\hline Maior Valor & & 92,33 & & 103,50 & & 91,67 & & 81,67 & & 87,28 \\
\hline Amplitude & & 36,00 & & 38,50 & & 26,67 & & 28,33 & & 22,27 \\
\hline CVe & & 15,16 & & 13,34 & & 9,16 & & 17,77 & & 13,77 \\
\hline$\sigma_{p}^{2}$ & & 54,25 & & 44,50 & & 31,08 & & 1,50 & & 23,40 \\
\hline IC $\sigma_{p}^{2}-L I$ & & 21,40 & & 12,26 & & 13,54 & & - & & 10,58 \\
\hline IC $\sigma_{p}^{2}-L S$ & & 300,97 & & 1785,66 & & 128,26 & & - & & 90,48 \\
\hline IC $\sigma_{p}^{2}(\mathrm{LS}-\mathrm{LI})$ & & 279,57 & & 1773,40 & & 114,72 & & - & & 79,90 \\
\hline$\sigma^{2}$ & & 132,21 & & 142,72 & & 55,55 & & 136,55 & & 112,87 \\
\hline$\sigma_{p a}^{2}$ & & & & & & & & & & 9,93 \\
\hline$\sigma_{\mathrm{f}}^{2}$ & & 98,32 & & 115,86 & & 49,59 & & 47,83 & & 37,37 \\
\hline$h_{x}^{2}$ & & 0,55 & & 0,38 & & 0,63 & & 0,03 & & 0,63 \\
\hline$I C h_{x}^{2}-L I$ & & $-0,05$ & & $-0,56$ & & 0,13 & & $-1,27$ & & 0,20 \\
\hline IC $h_{x}^{2}-L S$ & & 0,79 & & 0,76 & & 0,82 & & 0,54 & & 0,82 \\
\hline IC $h_{x}^{2}(\mathrm{LS}-\mathrm{LI})$ & & 0,84 & & 1,38 & & 0,69 & & 1,81 & & 1,02 \\
\hline $\mathrm{CVg}$ & & 9,70 & & 7,45 & & 6,85 & & 1,86 & & 6,27 \\
\hline $\mathrm{CVg} / \mathrm{CVe}$ & & 0,64 & & 0,56 & & 0,75 & & 0,10 & & 0,46 \\
\hline
\end{tabular}


Tabela 17. Análise de variância das progênies do cruzamento La-4910-215 x OC 79230 para o caracter Altura da Planta na Maturação (cm / planta), na geração $F_{2: n}$, nas quatro avaliações e análise conjunta.

\begin{tabular}{|c|c|c|c|c|c|c|c|c|c|c|}
\hline & \multicolumn{2}{|c|}{$1992 / 93$} & \multicolumn{2}{|c|}{$1993 / 94$} & \multicolumn{2}{|c|}{$1994 / 95$} & \multicolumn{2}{|c|}{$1995 / 96$} & \multicolumn{2}{|c|}{ Conjunta } \\
\hline F. Variação & Gl & $\overline{Q M}$ & Gl & $\overline{\mathrm{QM}}$ & $\mathrm{Gl}$ & $\overline{Q M}$ & $\mathrm{Gl}$ & $\overline{Q M}$ & $\mathrm{Gl}$ & $\overline{Q M}$ \\
\hline $\begin{array}{l}\text { Repet. / Anos } \\
\text { Repetições } \\
\text { Progênies (P) } \\
\text { Anos (A) } \\
\text { P x A } \\
\text { Erro }\end{array}$ & $\begin{array}{c}2 \\
19 \\
\\
\\
38\end{array}$ & $\begin{array}{l}607,02 \\
468,75^{* *} \\
108,68\end{array}$ & $\begin{array}{c}1 \\
19\end{array}$ & $\begin{array}{c}883,60 \\
667,31^{* * *} \\
90,29\end{array}$ & $\begin{array}{c}2 \\
19 \\
\\
\\
38\end{array}$ & $\begin{array}{c}21,67 \\
342,02^{* * *} \\
76,49\end{array}$ & $\begin{array}{c}2 \\
19 \\
\\
\\
38\end{array}$ & $\begin{array}{c}195,00 \\
458,31^{* *} \\
62,98\end{array}$ & \begin{tabular}{|c|}
7 \\
\\
19 \\
3 \\
57 \\
133
\end{tabular} & $\begin{array}{c}361,57 \\
1517,74^{* *} \\
2846,58^{* *} \\
139,55^{*} \\
83,80\end{array}$ \\
\hline Total & 59 & 241,53 & 39 & 391,75 & 59 & 160,14 & 59 & 194,77 & 219 & 269,44 \\
\hline Média & & 76,72 & & 84,80 & & 78,17 & & 66,75 & & 75,86 \\
\hline Desv. Padrão & & 12,50 & & 17,88 & & 10,68 & & 11,94 & & 12,03 \\
\hline Menor Valor & & 46,67 & & 61,60 & & 60,00 & & 45,00 & & 53,33 \\
\hline Maior Valor & & 91,33 & & 114,00 & & 96,67 & & 86,67 & & 95,25 \\
\hline Amplitude & & 44,67 & & 52,40 & & 36,67 & & 41,67 & & 41,92 \\
\hline $\mathrm{CVe}$ & & 13,59 & & 11,21 & & 11,19 & & 11,89 & & 12,07 \\
\hline$\sigma_{p}^{2}$ & & 120,02 & & 289,27 & & 88,51 & & 131,78 & & 125,16 \\
\hline IC $\sigma_{\mathrm{p}}^{2}-\mathrm{LI}$ & & 60,17 & & 155,33 & & 44,53 & & 70,66 & & 68,95 \\
\hline IC $\sigma_{\mathrm{p}}^{2}-\mathrm{LS}$ & & 348,68 & & 725,03 & & 251,50 & & 327,80 & & 292,10 \\
\hline IC $\sigma_{\mathrm{p}}^{2}$ (LS-LI) & & 288,51 & & 569,70 & & 206,97 & & 257,14 & & 223,15 \\
\hline$\sigma^{2}$ & & 108,68 & & 90,30 & & 76,49 & & 62,98 & & 83,80 \\
\hline$\sigma_{\mathrm{pa}}^{2}$ & & & & & & & & & & 20,47 \\
\hline$\sigma_{f}^{2}$ & & 156,25 & & 334,54 & & 114,01 & & 152,77 & & 140,30 \\
\hline$h_{x}^{2}$ & & 0,77 & & 0,87 & & 0,78 & & 0,86 & & 0,89 \\
\hline IC $h_{x}^{2}-L I$ & & 0,46 & & 0,66 & & 0,48 & & 0,68 & & 0,79 \\
\hline IC $h_{x}^{2}-L S$ & & 0,89 & & 0,95 & & 0,89 & & 0,93 & & 0,95 \\
\hline IC $h_{x}^{2}(\mathrm{LS}-\mathrm{LI})$ & & 0,43 & & 0,29 & & 0,41 & & 0,25 & & 0,16 \\
\hline $\mathrm{CVg}$ & & 14,28 & & 20,01 & & 12,04 & & 17,20 & & 14,75 \\
\hline $\mathrm{CVg} / \mathrm{CVe}$ & & 1,05 & & 1,79 & & 1,08 & & 1,45 & & 1,22 \\
\hline
\end{tabular}


Tabela 18. Análise de variância das progênies do cruzamento La-4910-215 x BR 80-8858 para o caracter Altura da Planta na Maturação (cm / planta), na geração $F_{2: n}$, nas quatro avaliações e análise conjunta.

\begin{tabular}{|c|c|c|c|c|c|c|c|c|c|c|}
\hline & \multicolumn{2}{|c|}{$1992 / 93$} & \multicolumn{2}{|c|}{$1993 / 94$} & \multicolumn{2}{|c|}{$1994 / 95$} & \multicolumn{2}{|c|}{$1995 / 96$} & \multicolumn{2}{|c|}{ Conjunta } \\
\hline F. Variação & Gl & $\mathrm{QM}$ & Gl & $\mathrm{QM}$ & $\mathrm{Gl}$ & $\mathrm{QM}$ & Gl & $\mathrm{QM}$ & Gl & $\mathrm{QM}$ \\
\hline $\begin{array}{l}\text { Repet. / Anos } \\
\text { Repetições } \\
\text { Progênies (P) } \\
\text { Anos (A) } \\
\text { P x A } \\
\text { Erro }\end{array}$ & $\begin{array}{c}2 \\
19\end{array}$ & $\begin{array}{c}264,95 \\
787,28^{* *} \\
96,46\end{array}$ & $\begin{array}{c}1 \\
19 \\
\\
19 \\
\end{array}$ & $\begin{array}{l}698,06 \\
666,28^{* *} \\
89,23\end{array}$ & $\begin{array}{c}2 \\
19 \\
\\
37\end{array}$ & $\begin{array}{c}1055,65 \\
503,81^{* *} \\
159,39\end{array}$ & $\begin{array}{c}2 \\
19 \\
\\
38\end{array}$ & $\begin{array}{c}84,35 \\
573,25^{* *} \\
89,79\end{array}$ & \begin{tabular}{c|}
7 \\
19 \\
3 \\
37 \\
57 \\
132
\end{tabular} & $\begin{array}{c}489,71 \\
1969,01^{* *} \\
1864,56^{* *} \\
187,20^{* *} \\
111,14\end{array}$ \\
\hline Total & 59 & 324,64 & 39 & 385,97 & 58 & 301,74 & 59 & 245,29 & 218 & 329,24 \\
\hline Média & & 80,85 & & 93,00 & & 81,95 & & 78,40 & & 82,70 \\
\hline Desv. Padrão & & 16,20 & & 18,25 & & 13,16 & & 13,82 & & 13,71 \\
\hline Menor Valor & & 52,33 & & 55,00 & & 55,00 & & 51,67 & & 54,40 \\
\hline Maior Valor & & 100,67 & & 115,40 & & 98,33 & & 95,00 & & 97,71 \\
\hline Amplitude & & 48,33 & & 60,40 & & 43,33 & & 43,33 & & 43,31 \\
\hline $\mathrm{CVe}$ & & 12,15 & & 10,16 & & 15,41 & & 12,09 & & 12,75 \\
\hline$\sigma_{\mathrm{p}}^{2}$ & & 230,27 & & 288,52 & & 116,86 & & 161,15 & & 162,52 \\
\hline IC $\sigma_{p}^{2}-L I$ & & 124,74 & & 154,66 & & 54,96 & & 85,07 & & 89,50 \\
\hline IC $\sigma_{p}^{2}-L S$ & & 562,53 & & 717,65 & & 391,88 & & 409,40 & & 382,94 \\
\hline IC $\sigma_{\mathrm{p}}^{2}(\mathrm{LS}-\mathrm{LI})$ & & 437,79 & & 562,99 & & 336,92 & & 324,33 & & 293,44 \\
\hline$\sigma^{2}$ & & 96,46 & & 89,23 & & 159,39 & & 89,79 & & 111,14 \\
\hline$\sigma_{\mathrm{pa}}^{2}$ & & & & & & & & & & 28,03 \\
\hline$\sigma_{\mathrm{f}}^{2}$ & & 262,43 & & 333,14 & & 170,93 & & 191,08 & & 183,01 \\
\hline$h_{x}^{2}$ & & 0,88 & & 0,87 & & 0,68 & & 0,84 & & 0,89 \\
\hline $\mathrm{IC} \mathrm{h}_{\mathrm{x}}^{2}-\mathrm{LI}$ & & 0,71 & & 0,66 & & 0,26 & & 0,63 & & 0,78 \\
\hline $\mathrm{IC} \mathrm{h}_{\mathrm{x}}^{2}-\mathrm{LS}$ & & 0,94 & & 0,95 & & 0,85 & & 0,90 & & 0,95 \\
\hline IC h $\mathrm{h}_{\mathrm{x}}^{2}$ (LS-LI) & & 0,23 & & 0,29 & & 0,59 & & 0,27 & & 0,17 \\
\hline $\mathrm{CVg}$ & & 18,77 & & 18,26 & & 13,19 & & 16,19 & & 15,42 \\
\hline $\mathrm{CVg} / \mathrm{CVe}$ & & 1,54 & & 1,80 & & 0,85 & & 1,34 & & 1,21 \\
\hline
\end{tabular}


Tabela 19. Análise de variância das progênies do cruzamento La-4910-215 x BR 80-14853 para o caracter Altura da Planta na Maturação (cm / planta), na geração $\mathrm{F}_{2: \mathrm{n}}$, nas quatro avaliações e análise conjunta.

\begin{tabular}{|c|c|c|c|c|c|c|c|c|c|c|}
\hline & \multicolumn{2}{|c|}{$1992 / 93$} & \multicolumn{2}{|c|}{$1993 / 94$} & \multicolumn{2}{|c|}{$1994 / 95$} & \multicolumn{2}{|c|}{$1995 / 96$} & \multicolumn{2}{|c|}{ Conjunta } \\
\hline F. Variação & Gl & QM & Gl & $\mathrm{QM}$ & Gl & QM & G1 & $\mathrm{QM}$ & Gl & QM \\
\hline $\begin{array}{l}\text { Repet. / Anos } \\
\text { Repetições } \\
\text { Progênies (P) } \\
\text { Anos (A) } \\
\text { P x A } \\
\text { Erro }\end{array}$ & $\begin{array}{c}2 \\
19\end{array}$ & $\begin{array}{l}262,87 \\
929,89^{* *} \\
182,34\end{array}$ & $\begin{array}{c}1 \\
19\end{array}$ & $\begin{array}{c}51,53 \\
795,50^{* *} \\
61,69\end{array}$ & $\begin{array}{c}2 \\
19 \\
\\
32\end{array}$ & $\begin{array}{c}1235,08 \\
537,22 * * \\
117,80\end{array}$ & $\begin{array}{c}2 \\
19 \\
\\
\\
38\end{array}$ & $\begin{array}{c}22,32 \\
636,17^{* *} \\
\\
91,79\end{array}$ & $\begin{array}{c}7 \\
\\
19 \\
3 \\
57 \\
127\end{array}$ & $\begin{array}{c}441,72 \\
2509,62^{* *} \\
1941,15^{* *} \\
129,72^{\text {ns }} \\
120,93\end{array}$ \\
\hline Total & 59 & 425,81 & 39 & 418,93 & 53 & 310,32 & 59 & 264,74 & 213 & 372,54 \\
\hline Média & & 79,42 & & 86,17 & & 76,20 & & 71,03 & & 77,52 \\
\hline Desv. Padrão & & 17,61 & & 19,94 & & 14,05 & & 14,56 & & 15,55 \\
\hline Menor Valor & & 38,67 & & 42,30 & & 46,67 & & 41,67 & & 43,49 \\
\hline Maior Valor & & 99,00 & & 110,00 & & 96,31 & & 91,67 & & 97,24 \\
\hline Amplitude & & 60,33 & & 67,70 & & 49,64 & & 50,00 & & 53,75 \\
\hline $\mathrm{CVe}$ & & 17,00 & & 9,12 & & 14,24 & & 13,49 & & 14,19 \\
\hline$\sigma_{\mathrm{p}}^{2}$ & & 249,18 & & 366,91 & & 156,25 & & 181,46 & & 222,72 \\
\hline IC $\sigma_{\mathrm{p}}^{2}-\mathrm{LI}$ & & 128,64 & & 203,47 & & 78,73 & & 96,68 & & 125,94 \\
\hline IC $\sigma_{p}^{2}-L S$ & & 681,69 & & 845,64 & & 440,90 & & 453,99 & & 502,65 \\
\hline IC $\sigma_{\mathrm{p}}^{2}$ (LS-LI) & & 552,55 & & 642,17 & & 362,17 & & 357,31 & & 367,71 \\
\hline$\sigma^{2}$ & & 182,34 & & 61,69 & & 117,80 & & 91,79 & & 120,93 \\
\hline$\sigma_{\mathrm{pa}}^{2}$ & & & & & & & & & & 3,32 \\
\hline$\sigma_{f}^{2}$ & & 309,96 & & 397,75 & & 200,14 & & 212,06 & & 235,29 \\
\hline $\mathrm{h}_{\mathrm{x}}^{2}$ & & 0,80 & & 0,92 & & 0,78 & & 0,86 & & 0,95 \\
\hline IC $h_{x}^{2}-L I$ & & 0,54 & & 0,80 & & 0,48 & & 0,66 & & 0,88 \\
\hline IC $h_{x}^{2}-$ LS & & 0,91 & & 0,97 & & 0,90 & & 0,93 & & 0,97 \\
\hline IC $h_{x}^{2}$ (LS-LI) & & 0,37 & & 0,17 & & 0,42 & & 0,27 & & 0,09 \\
\hline $\mathrm{CVg}$ & & 19,88 & & 22,23 & & 16,40 & & 18,96 & & 19,25 \\
\hline $\mathrm{CVg} / \mathrm{CVe}$ & & 1,17 & & 2,44 & & 1,15 & & 1,41 & & 1,36 \\
\hline
\end{tabular}


Tabela 20. Análise de variância das progênies do cruzamento La-4910-215 x PI 123439 para o caracter Altura da Planta na Maturação (cm / planta), na geração $\mathrm{F}_{2: n}$, nas quatro avaliações e análise conjunta.

\begin{tabular}{|c|c|c|c|c|c|c|c|c|c|c|}
\hline & \multicolumn{2}{|c|}{$1992 / 93$} & \multicolumn{2}{|c|}{$1993 / 94$} & \multicolumn{2}{|c|}{$1994 / 95$} & \multicolumn{2}{|c|}{$1995 / 96$} & \multicolumn{2}{|c|}{ Conjunta } \\
\hline F. Variação & $\mathrm{Gl}$ & QM & $\mathrm{Gl}$ & $\mathrm{QM}$ & $\mathrm{Gl}$ & $\mathrm{QM}$ & $\mathrm{Gl}$ & $\overline{Q M}$ & Gl & $\mathrm{QM}$ \\
\hline $\begin{array}{l}\text { Repet. / Anos } \\
\text { Repetições } \\
\text { Progênies (P) } \\
\text { Anos (A) } \\
\text { P x A } \\
\text { Erro } \\
\end{array}$ & $\begin{array}{c}2 \\
19\end{array}$ & $\begin{array}{l}778,40 \\
256,40^{\text {ns }} \\
153,38\end{array}$ & $\begin{array}{c}1 \\
19\end{array}$ & $\begin{array}{l}77,48 \\
321,94^{*} \\
\\
133,16 \\
\end{array}$ & $\begin{array}{c}2 \\
19 \\
37 \\
\end{array}$ & $\begin{array}{l}116,13 \\
394,14^{* *} \\
100,54\end{array}$ & $\begin{array}{c}2 \\
19 \\
\\
\\
38 \\
\end{array}$ & $\begin{array}{l}100,52 \\
444,86^{* *} \\
88,68\end{array}$ & \begin{tabular}{|c|} 
\\
19 \\
3 \\
57 \\
132 \\
\end{tabular} & $\begin{array}{c}295,37 \\
\\
925,78^{* *} \\
5321,99^{* * *} \\
163,85^{\text {ns }} \\
117,03 \\
\end{array}$ \\
\hline Total & 59 & 207,75 & 39 & 223,70 & 58 & 197,25 & 59 & 203,78 & 218 & 277,12 \\
\hline Média & & 75,50 & & 91,95 & & 79,24 & & 66,52 & & 77,05 \\
\hline Desv. Padrão & & 9,25 & & 12,69 & & 11,59 & & 12,18 & & 9,28 \\
\hline Menor Valor & & 63,33 & & 74,34 & & 63,33 & & 43,33 & & 65,83 \\
\hline Maior Valor & & 93,33 & & 117,80 & & 98,33 & & 85,00 & & 93,78 \\
\hline Amplitude & & 30,00 & & 43,47 & & 35,00 & & 41,67 & & 27,96 \\
\hline $\mathrm{CVe}$ & & 16,43 & & 12,55 & & 12,65 & & 14,16 & & 14,04 \\
\hline$\sigma_{p}^{2}$ & & 34,34 & & 94,39 & & 99,62 & & 118,73 & & 69,45 \\
\hline IC $\sigma_{\mathrm{p}}^{2}-\mathrm{LI}$ & & 10,40 & & 38,13 & & 48,93 & & 61,13 & & 36,38 \\
\hline $\mathrm{IC} \sigma_{\mathrm{p}}^{2}-\mathrm{LS}$ & & 657,83 & & 492,71 & & 302,57 & & 326,40 & & 183,31 \\
\hline IC $\sigma_{\mathrm{p}}^{2}(\mathrm{LS}-\mathrm{LI})$ & & 647,43 & & 454,58 & & 253,64 & & 265,27 & & 146,93 \\
\hline$\sigma^{2}$ & & 153,38 & & 133,16 & & 100,54 & & 88,68 & & 117,03 \\
\hline$\sigma_{\mathrm{pa}}^{2}$ & & & & & & & & & & 17,26 \\
\hline$\sigma_{\mathrm{f}}^{2}$ & & 85,47 & & 160,97 & & 133,73 & & 148,29 & & 86,50 \\
\hline $\mathrm{h}_{\mathrm{x}}^{2}$ & & 0,41 & & 0,59 & & 0,75 & & 0,80 & & 0,80 \\
\hline $\mathrm{IC} \mathrm{h}_{\mathrm{x}}^{2}-\mathrm{LI}$ & & $-0,40$ & & $-0,04$ & & 0,40 & & 0,53 & & 0,71 \\
\hline $\mathrm{IC} \mathrm{h}_{\mathrm{x}}^{2}-\mathrm{LS}$ & & 0,72 & & 0,84 & & 0,88 & & 0,91 & & 0,94 \\
\hline $\mathrm{IC} \mathrm{h}_{\mathrm{x}}^{2}(\mathrm{LS}-\mathrm{LI})$ & & 1,12 & & 0,88 & & 0,48 & & 0,38 & & 0,23 \\
\hline $\mathrm{CVg}$ & & 7,76 & & 10,57 & & 12,60 & & 16,38 & & 10,82 \\
\hline $\mathrm{CVg} / \mathrm{CVe}$ & & 0,47 & & 0,84 & & 1,00 & & 1,16 & & 0,77 \\
\hline
\end{tabular}


Tabela 21. Análise de variância das progênies do cruzamento La-4910-215 x PI 239235 para o caracter Altura da Planta na Maturação ( $\mathrm{cm}$ / planta), na geração $F_{2: n}$, nas quatro avaliações e análise conjunta.

\begin{tabular}{|c|c|c|c|c|c|c|c|c|c|c|}
\hline & \multicolumn{2}{|c|}{$1992 / 93$} & \multicolumn{2}{|c|}{$1993 / 94$} & \multicolumn{2}{|c|}{$1994 / 95$} & \multicolumn{2}{|c|}{$1995 / 96$} & \multicolumn{2}{|c|}{ Conjunta } \\
\hline F. Variação & $\mathrm{Gl}$ & $\mathrm{QM}$ & $\mathrm{Gl}$ & $\mathrm{QM}$ & Gl & $\mathrm{OM}$ & $\mathrm{Gl}$ & $\mathrm{QM}$ & $\overline{G l}$ & $\mathrm{QM}$ \\
\hline $\begin{array}{l}\text { Repet. / Anos } \\
\text { Repetições } \\
\text { Progênies (P) } \\
\text { Anos (A) } \\
\text { P x A } \\
\text { Erro }\end{array}$ & $\begin{array}{c}2 \\
19\end{array}$ & $\begin{array}{l}269,52 \\
444,05^{* *} \\
122,90\end{array}$ & $\begin{array}{c}1 \\
19 \\
\\
19\end{array}$ & $\begin{array}{c}180,84 \\
312,71^{* *} \\
75,59\end{array}$ & $\begin{array}{c}2 \\
19 \\
\\
37 \\
\end{array}$ & $\begin{array}{c}1258,77 \\
391,32^{* *} \\
75,70\end{array}$ & $\begin{array}{c}2 \\
19 \\
\\
\\
38\end{array}$ & $\begin{array}{l}887,92 \\
963,93^{* * *} \\
151,95\end{array}$ & $\begin{array}{c}7 \\
\\
19 \\
3 \\
57 \\
132 \\
\end{array}$ & $\begin{array}{c}716,18 \\
1168,14^{* *} \\
4248,83^{* *} \\
314,62^{* *} \\
111,22 \\
\end{array}$ \\
\hline Total & 59 & 231,29 & 39 & 193,81 & 58 & 219,89 & 59 & 438,38 & 218 & 332,89 \\
\hline Média & & 97,62 & & 114,68 & & 98,90 & & 92,08 & & 99,56 \\
\hline Desv. Padrão & & 12,17 & & 12,50 & & 11,52 & & 17,93 & & 10,19 \\
\hline Menor Valor & & 80,00 & & 78,00 & & 76,67 & & 55,00 & & 75,33 \\
\hline Maior Valor & & 123,33 & & 133,80 & & 116,67 & & 121,67 & & 116,27 \\
\hline Amplitude & & 43,33 & & 55,80 & & 40,00 & & 66,67 & & 40,93 \\
\hline $\mathrm{CVe}$ & & 11,36 & & 7,58 & & 8,80 & & 13,39 & & 10,59 \\
\hline$\sigma_{p}^{2}$ & & 107,05 & & 118,56 & & 107,09 & & 270,66 & & 77,33 \\
\hline IC $\sigma_{p}^{2}-L I$ & & 51,48 & & 58,50 & & 55,32 & & 143,30 & & 37,66 \\
\hline IC $\sigma_{p}^{2}-\mathrm{LS}$ & & 338,67 & & 358,29 & & 290,95 & & 694,03 & & 239,99 \\
\hline IC $\sigma_{\mathrm{p}}^{2}(\mathrm{LS}-\mathrm{LI})$ & & 287,19 & & 299,79 & & 235,63 & & 550,73 & & 202,33 \\
\hline$\sigma^{2}$ & & 122,90 & & 75,59 & & 75,70 & & 151,95 & & 111,22 \\
\hline$\sigma_{\text {pa }}^{2}$ & & & & & & & & & & 74,96 \\
\hline$\sigma_{1}^{2}$ & & 148,02 & & 156,36 & & 132,77 & & 321,31 & & 115,11 \\
\hline$h_{x}^{2}$ & & 0,72 & & 0,76 & & 0,81 & & 0,84 & & 0,67 \\
\hline $\mathrm{IC} \mathrm{h}_{\mathrm{x}}^{2}-\mathrm{LI}$ & & 0,35 & & 0,39 & & 0,55 & & 0,63 & & 0,39 \\
\hline $\mathrm{IC} \mathrm{h}_{\mathrm{x}}^{2}-\mathrm{LS}$ & & 0,87 & & 0,90 & & 0,91 & & 0,93 & & 0,86 \\
\hline IC $h_{x}^{2}(\mathrm{LS}-\mathrm{LI})$ & & 0,52 & & 0,51 & & 0,36 & & 0,30 & & 0,47 \\
\hline $\mathrm{CVg}$ & & 10,60 & & 9,50 & & 10,46 & & 17,87 & & 8,83 \\
\hline $\mathrm{CVg} / \mathrm{CVe}$ & & 0,93 & & 1,25 & & 1,19 & & 1,33 & & 0,83 \\
\hline
\end{tabular}


Tabela 22. Análise de variância das progênies do cruzamento OC 79230 x BR 8014853 para o caracter Altura da Planta na Maturação (cm / planta), na geração $\mathrm{F}_{2: n}$, nas quatro avaliações e análise conjunta.

\begin{tabular}{|c|c|c|c|c|c|c|c|c|c|c|}
\hline & \multicolumn{2}{|c|}{$1992 / 93$} & \multicolumn{2}{|c|}{$1993 / 94$} & \multicolumn{2}{|c|}{$1994 / 95$} & \multicolumn{2}{|c|}{$1995 / 96$} & \multicolumn{2}{|c|}{ Conjunta } \\
\hline F. Variação & $\overline{\mathrm{Gl}}$ & $\mathrm{QM}$ & $\overline{\mathrm{Gl}}$ & $\overline{\mathrm{QM}}$ & $\overline{\mathrm{Gl}}$ & $\overline{\mathrm{QM}}$ & GI & $\overline{Q M}$ & $\mathrm{Gl}$ & $\overline{Q M}$ \\
\hline $\begin{array}{l}\text { Repet. / Anos } \\
\text { Repetições } \\
\text { Progênies (P) } \\
\text { Anos (A) } \\
\text { P x A } \\
\text { Erro }\end{array}$ & $\begin{array}{c}2 \\
19 \\
\\
\\
38\end{array}$ & $\begin{array}{c}494,32 \\
246,23 * * \\
50,35\end{array}$ & $\begin{array}{c}1 \\
19\end{array}$ & $\begin{array}{c}268,32 \\
152,13^{*} \\
53,90\end{array}$ & $\begin{array}{c}2 \\
19\end{array}$ & $\begin{array}{c}100,42 \\
203,93^{* *} \\
69,72\end{array}$ & $\begin{array}{c}2 \\
19 \\
\\
38\end{array}$ & $\begin{array}{r}25,82 \\
146,89^{*} \\
\\
66,05\end{array}$ & \begin{tabular}{|c|}
7 \\
\\
19 \\
3 \\
57 \\
133
\end{tabular} & $\begin{array}{c}215,63 \\
452,97^{* *} \\
1217,90^{* *} \\
98,74^{*} \\
60,88\end{array}$ \\
\hline Total & 59 & 128,48 & 39 & 107,25 & 59 & 113,98 & 59 & 90,71 & 219 & 125,54 \\
\hline Média & & 64,17 & & 72,01 & & 67,42 & & 60,28 & & 65,42 \\
\hline Desv. Padrão & & 9,10 & & 8,72 & & 8,25 & & 6,99 & & 6,47 \\
\hline Menor Valor & & 40,33 & & 49,00 & & 41,67 & & 45,00 & & 49,58 \\
\hline Maior Valor & & 79,33 & & 83,50 & & 80,00 & & 71,67 & & 77,04 \\
\hline Amplitude & & 39,00 & & 34,50 & & 38,33 & & 26,67 & & 27,46 \\
\hline $\mathrm{CVe}$ & & 11,06 & & 10,20 & & 12,39 & & 13,48 & & 11,93 \\
\hline$\sigma_{p}^{2}$ & & 65,40 & & 49,11 & & 44,74 & & 26,95 & & 32,09 \\
\hline IC $\sigma_{\mathrm{p}}^{2}-\mathrm{LI}$ & & 33,41 & & 21,85 & & 20,18 & & 10,70 & & 16,31 \\
\hline IC $\sigma_{\mathrm{p}}^{2}-\mathrm{LS}$ & & 179,77 & & 204,54 & & 167,31 & & 155,09 & & 90,66 \\
\hline IC $\sigma_{\mathrm{p}}^{2}(\mathrm{LS}-\mathrm{LI})$ & & 146,36 & & 182,69 & & 154,92 & & 144,39 & & 74,35 \\
\hline$\sigma^{2}$ & & 50,35 & & 53,90 & & 69,72 & & 66,05 & & 60,88 \\
\hline$\sigma_{\mathrm{pa}}^{2}$ & & & & & & & & & & 13,90 \\
\hline$\sigma_{f}^{2}$ & & 82,22 & & 76,06 & & 67,98 & & 48,96 & & 42,73 \\
\hline$h_{x}^{2}$ & & 0,80 & & 0,65 & & 0,66 & & 0,55 & & 0,75 \\
\hline IC $h_{x}^{2}-L I$ & & 0,52 & & 0,10 & & 0,20 & & $-0,05$ & & 0,50 \\
\hline IC $h_{x}^{2}-L S$ & & 0,90 & & 0,86 & & 0,84 & & 0,79 & & 0,89 \\
\hline IC $h_{x}^{2}$ (LS-LI) & & 0,38 & & 0,76 & & 0,64 & & 0,84 & & 0,38 \\
\hline $\mathrm{CVg}$ & & 12,60 & & 9,73 & & 9,92 & & 8,61 & & 8,66 \\
\hline $\mathrm{CVg} / \mathrm{CVe}$ & & 1,14 & & 0,95 & & 0,80 & & 0,64 & & 0,73 \\
\hline
\end{tabular}


Tabela 23. Análise de variância das progênies do cruzamento OC 79230 x PI 123439 para o caracter Altura da Planta na Maturação (cm / planta), na geração $F_{2: n}$, nas quatro avaliações e análise conjunta.

\begin{tabular}{|c|c|c|c|c|c|c|c|c|c|c|}
\hline & \multicolumn{2}{|c|}{$1992 / 93$} & \multicolumn{2}{|c|}{$1993 / 94$} & \multicolumn{2}{|c|}{$1994 / 95$} & \multicolumn{2}{|c|}{$1995 / 96$} & \multicolumn{2}{|c|}{ Coniunta } \\
\hline F. Variacão & $\mathrm{Gl}$ & $\mathrm{QM}$ & $\mathrm{Gl}$ & $\mathrm{QM}$ & G1 & $\mathrm{QM}$ & Gl & QM & GI & $\mathrm{QM}$ \\
\hline $\begin{array}{l}\text { Repet. / Anos } \\
\text { Repetições } \\
\text { Progênies (P) } \\
\text { Anos (A) } \\
\text { P x A } \\
\text { Erro }\end{array}$ & $\begin{array}{c}2 \\
19 \\
\\
38\end{array}$ & $\begin{array}{c}901,55 \\
322,44^{* *} \\
76,27\end{array}$ & $\begin{array}{c}1 \\
19 \\
19\end{array}$ & $\begin{array}{c}23,87 \\
213,04^{\text {ns }} \\
127,24\end{array}$ & $\begin{array}{c}2 \\
19 \\
\\
\\
38\end{array}$ & $\begin{array}{c}95,00 \\
226,73^{* *} \\
86,67\end{array}$ & $\begin{array}{c}2 \\
19 \\
\\
\\
38\end{array}$ & $\begin{array}{l}225,42 \\
178,70^{\text {ns }} \\
115,28\end{array}$ & \begin{tabular}{|c|}
7 \\
19 \\
3 \\
57 \\
133
\end{tabular} & $\begin{array}{c}352,54 \\
6092^{* *} \\
2737,65^{* *} \\
90,39^{\text {ns }} \\
97,67\end{array}$ \\
\hline Total & 59 & 183,52 & 39 & 166,39 & 59 & 132,06 & 59 & 139,43 & 219 & 189,71 \\
\hline Média & & 67,65 & & 70,47 & & 70,75 & & 56,08 & & 65,85 \\
\hline Desv. Padrão & & 10,37 & & 9,65 & & 8,69 & & 7,72 & & 7,97 \\
\hline Menor Valor & & 51,33 & & 56,50 & & 53,33 & & 42,67 & & 52,08 \\
\hline Maior Valor & & 95,00 & & 93,50 & & 85,00 & & 70,00 & & 84,58 \\
\hline Amplitude & & 43,67 & & 37,00 & & 31,67 & & 27,33 & & 32,50 \\
\hline $\mathrm{CVe}$ & & 12,91 & & 16,00 & & 13,16 & & 19,14 & & 15,01 \\
\hline$\sigma_{\mathrm{p}}^{2}$ & & 82,06 & & 42,90 & & 46,69 & & 21,14 & & 52,69 \\
\hline $\mathrm{IC} \sigma_{\mathrm{p}}^{2}-\mathrm{LI}$ & & 41,14 & & 12,19 & & 20,09 & & 5,68 & & 28,36 \\
\hline $\mathrm{IC} \sigma_{\mathrm{p}}^{2}-\mathrm{LS}$ & & 242,27 & & 1110,14 & & 197,65 & & 826,94 & & 130,83 \\
\hline IC $\sigma_{\mathrm{p}}^{2}(\mathrm{LS}-\mathrm{LI})$ & & 201,13 & & 1097,95 & & 177,56 & & 821,26 & & 102,47 \\
\hline$\sigma^{2}$ & & 76,27 & & 127,24 & & 86,67 & & 115,28 & & 97,67 \\
\hline$\sigma_{\mathrm{pa}}^{2}$ & & & & & & & & & & - \\
\hline$\sigma_{\mathrm{f}}^{2}$ & & 107,49 & & 106,52 & & 75,58 & & 59,57 & & 88,50 \\
\hline$h_{x}^{2}$ & & 0,76 & & 0,40 & & 0,62 & & 0,36 & & 0,60 \\
\hline $\mathrm{IC} \mathrm{h}_{\mathrm{x}}^{2}-\mathrm{LI}$ & & 0,45 & & $-0,51$ & & 0,10 & & $-0,51$ & & 0,69 \\
\hline $\mathrm{IC} \mathrm{h}_{\mathrm{x}}^{2}-\mathrm{LS}$ & & 0,89 & & 0,76 & & 0,82 & & 0,69 & & 0,93 \\
\hline IC h ${ }_{x}^{2}$ (LS-LI) & & 0,44 & & 1,27 & & 0,72 & & 1,20 & & 0,24 \\
\hline $\mathrm{CVg}$ & & 13,39 & & 9,29 & & 9,66 & & 8,20 & & 11,02 \\
\hline $\mathrm{CVg} / \mathrm{CVe}$ & & 1,04 & & 0,58 & & 0,73 & & 0,43 & & 0,73 \\
\hline
\end{tabular}


Tabela 24. Análise de variância das progênies do cruzamento OC 79230 x PI 165896 para o caracter Altura da Planta na Maturação (cm / planta), na geração $F_{2: n}$, nas quatro avaliações e análise conjunta.

\begin{tabular}{|c|c|c|c|c|c|c|c|c|c|c|}
\hline & \multicolumn{2}{|c|}{$1992 / 93$} & \multicolumn{2}{|c|}{$1993 / 94$} & \multicolumn{2}{|c|}{$1994 / 95$} & \multicolumn{2}{|c|}{$1995 / 96$} & \multicolumn{2}{|c|}{ Conjunta } \\
\hline F. Variação & $\mathrm{GI}$ & $\overline{\mathrm{QM}}$ & $\mathrm{Gl}$ & $\overline{\mathrm{QM}}$ & Gl & $\overline{\mathrm{QM}}$ & $\mathrm{Gl}$ & $\overline{\mathrm{QM}}$ & $\mathrm{Gl}$ & $\overline{Q M}$ \\
\hline $\begin{array}{l}\text { Repet. / Anos } \\
\text { Repetições } \\
\text { Progênies (P) } \\
\text { Anos (A) } \\
\text { P x A } \\
\text { Erro }\end{array}$ & $\begin{array}{c}2 \\
19 \\
\\
37\end{array}$ & $\begin{array}{l}146,96 \\
563,74 \\
\\
187,61\end{array}$ & $\begin{array}{c}1 \\
19 \\
\\
19\end{array}$ & $\begin{array}{c}24,49 \\
919,19^{* *} \\
94,11\end{array}$ & $\begin{array}{c}2 \\
19 \\
\\
36\end{array}$ & $\begin{array}{c}96,49 \\
487,07^{* *} \\
82,66\end{array}$ & $\begin{array}{c}2 \\
19 \\
\\
38 \\
\end{array}$ & $\begin{array}{c}294,82 \\
522,82^{* *} \\
86,36\end{array}$ & \begin{tabular}{|c|}
7 \\
19 \\
3 \\
57 \\
130 \\
\end{tabular} & $\begin{array}{c}157,29 \\
2052,33^{* *} \\
4671,78^{* *} \\
146,83^{\text {ns }} \\
115,28\end{array}$ \\
\hline Total & 58 & 309,42 & 39 & 494,28 & 57 & 217,94 & 59 & 233,98 & 216 & 358,64 \\
\hline Média & & 69,42 & & 85,42 & & 79,05 & & 63,87 & & 73,41 \\
\hline Desv. Padrão & & 14,19 & & 21,44 & & 12,76 & & 13,20 & & 14,31 \\
\hline Menor Valor & & 47,33 & & 56,50 & & 55,00 & & 43,33 & & 52,66 \\
\hline Maior Valor & & 96,81 & & 120,00 & & 100,00 & & 85,00 & & 99,20 \\
\hline Amplitude & & 49,47 & & 63,50 & & 45,00 & & 41,67 & & 46,54 \\
\hline $\mathrm{CVe}$ & & 19,73 & & 11,36 & & 11,50 & & 14,55 & & 14,63 \\
\hline$\sigma_{p}^{2}$ & & 127,61 & & 412,54 & & 139,71 & & 145,49 & & 175,65 \\
\hline IC $\sigma_{p}^{2}-L I$ & & 58,24 & & 226,24 & & 73,29 & & 76,41 & & 97,74 \\
\hline IC $\sigma_{\mathrm{p}}^{2}-\mathrm{LS}$ & & 468,52 & & 987,94 & & 364,33 & & 374,86 & & 400,61 \\
\hline IC $\sigma_{\mathrm{p}}^{2}$ (LS-LI) & & 410,28 & & 761,70 & & 291,04 & & 298,45 & & 302,87 \\
\hline$\sigma^{2}$ & & 187,61 & & 94,11 & & 82,66 & & 86,36 & & 115,28 \\
\hline$\sigma_{\mathrm{pa}}^{2}$ & & & & & & & & & & 11,74 \\
\hline$\sigma_{f}^{2}$ & & 191,27 & & 459,59 & & 168,26 & & 174,27 & & 190,65 \\
\hline$h_{x}^{2}$ & & 0,67 & & 0,90 & & 0,83 & & 0,84 & & 0,92 \\
\hline IC $h_{x}^{2}-L I$ & & 0,22 & & 0,74 & & 0,60 & & 0,61 & & 0,84 \\
\hline IC $h_{x}^{2}-L S$ & & 0,84 & & 0,96 & & 0,92 & & 0,92 & & 0,96 \\
\hline IC $h_{x}^{2}$ (LS-LI) & & 0,62 & & 0,22 & & 0,32 & & 0,31 & & 0,12 \\
\hline $\mathrm{CVg}$ & & 16,27 & & 23,78 & & 14,95 & & 18,89 & & 18,05 \\
\hline $\mathrm{CVg} / \mathrm{CVe}$ & & 0,82 & & 2,09 & & 1,30 & & 1,30 & & 1,23 \\
\hline
\end{tabular}


Tabela 25. Análise de variância das progênies do cruzamento OC 79230 x PI 239235 para o caracter Altura da Planta na Maturação (cm / planta), na geração $F_{2: n}$, nas quatro avaliações e análise conjunta.

\begin{tabular}{|c|c|c|c|c|c|c|c|c|c|c|}
\hline & \multicolumn{2}{|c|}{$1992 / 93$} & \multicolumn{2}{|c|}{$1993 / 94$} & \multicolumn{2}{|c|}{$1994 / 95$} & \multicolumn{2}{|c|}{$1995 / 96$} & \multicolumn{2}{|c|}{ Conjunta } \\
\hline F. Variação & Gl & $\mathrm{QM}$ & $\overline{G l}$ & QM & $\mathrm{Gl}$ & $\mathrm{QM}$ & $\mathrm{Gl}$ & $\mathrm{QM}$ & $\mathrm{Gl}$ & $\mathrm{QM}$ \\
\hline $\begin{array}{l}\text { Repet. / Anos } \\
\text { Repetições } \\
\text { Progênies (P) } \\
\text { Anos (A) } \\
\text { P x A } \\
\text { Erro } \\
\end{array}$ & $\begin{array}{c}2 \\
19 \\
\\
38 \\
\end{array}$ & $\begin{array}{c}261,95 \\
363,65^{* *} \\
75,58\end{array}$ & $\begin{array}{c}1 \\
19 \\
\\
19\end{array}$ & $\begin{array}{c}260,10 \\
440,92^{* *} \\
72,33\end{array}$ & $\begin{array}{c}2 \\
19\end{array}$ & $\begin{array}{c}62,35 \\
314,42^{* *} \\
72,16\end{array}$ & $\begin{array}{c}2 \\
18 \\
\\
36 \\
\end{array}$ & $\begin{array}{l}345,18 \\
296,59\end{array}$ & \begin{tabular}{|c|}
7 \\
\\
19 \\
3 \\
56 \\
130 \\
\end{tabular} & $\begin{array}{c}228,44 \\
1062,15^{* *} \\
5122,51^{* *} \\
114,62^{\text {ns }} \\
89,30\end{array}$ \\
\hline Total & 59 & 174,67 & 39 & 256,71 & 58 & 151,18 & 56 & 191,46 & 215 & 256,63 \\
\hline Média & & 78,90 & & 98,90 & & 82,52 & & 74,30 & & 82,38 \\
\hline Desv. Padrão & & 11,01 & & 14,85 & & 10,24 & & 9,94 & & 10,42 \\
\hline Menor Valor & & 60,00 & & 71,90 & & 55,00 & & 56,67 & & 62,46 \\
\hline Maior Valor & & 100,00 & & 123,80 & & 96,67 & & 91,67 & & 101,42 \\
\hline Amplitude & & 40,00 & & 51,90 & & 41,67 & & 35,00 & & 38,96 \\
\hline $\mathrm{CVe}$ & & 11,02 & & 8,60 & & 10,29 & & 15,37 & & 11,47 \\
\hline$\sigma_{p}^{2}$ & & 96,02 & & 184,30 & & 82,20 & & 55,41 & & 87,74 \\
\hline $\mathrm{IC} \sigma_{\mathrm{p}}^{2}-\mathrm{LI}$ & & 48,91 & & 96,88 & & 41,18 & & 21,71 & & 47,84 \\
\hline $\mathrm{IC} \sigma_{\mathrm{p}}^{2}-\mathrm{LS}$ & & 265,21 & & 481,64 & & 236,59 & & 314,59 & & 208,89 \\
\hline IC $\sigma_{\mathrm{p}}^{2}(\mathrm{LS}-\mathrm{LI})$ & & 216,30 & & 384,76 & & 195,41 & & 292,88 & & 161,05 \\
\hline$\sigma^{2}$ & & 75,58 & & 72,33 & & 72,16 & & 130,36 & & 89,30 \\
\hline$\sigma_{\mathrm{pa}}^{2}$ & & & & & & & & & & 9,34 \\
\hline$\sigma_{\mathrm{f}}^{2}$ & & 121,22 & & 220,46 & & 106,68 & & 98,86 & & 99,46 \\
\hline $\mathrm{h}_{\mathrm{x}}^{2}$ & & 0,79 & & 0,84 & & 0,77 & & 0,56 & & 0,88 \\
\hline $\mathrm{IC} \mathrm{h} \mathrm{h}_{\mathrm{x}}^{2} \mathrm{LI}$ & & 0,51 & & 0,59 & & 0,46 & & $-0,06$ & & 0,75 \\
\hline $\mathrm{IC} \mathrm{h}_{\mathrm{x}}^{2}-\mathrm{LS}$ & & 0,90 & & 0,94 & & 0,89 & & 0,80 & & 0,95 \\
\hline IC h $h_{x}^{2}(\mathrm{LS}-\mathrm{LI})$ & & 0,39 & & 0,35 & & 0,43 & & 0,86 & & 0,20 \\
\hline $\mathrm{CVg}$ & & 12,42 & & 13,73 & & 10,99 & & 10,02 & & 11,37 \\
\hline $\mathrm{CVg} / \mathrm{CVe}$ & & 1,13 & & 1,60 & & 1,07 & & 0,65 & & 0,99 \\
\hline
\end{tabular}


Tabela 26. Análise de variância das progênies do cruzamento BR 80-8858 x BR 80-14853 para o caracter Altura da Planta na Maturação (cm / planta), na geração $\mathrm{F}_{2: \mathrm{n}}$, nas quatro avaliações e análise conjunta.

\begin{tabular}{|c|c|c|c|c|c|c|c|c|c|c|}
\hline & \multicolumn{2}{|c|}{$1992 / 93$} & \multicolumn{2}{|c|}{$1993 / 94$} & \multicolumn{2}{|c|}{$1994 / 95$} & \multicolumn{2}{|c|}{$1995 / 96$} & \multicolumn{2}{|c|}{ Conjunta } \\
\hline F. Variação & Gl & $\mathrm{QM}$ & $\overline{\mathrm{Gl}}$ & $\mathrm{QM}$ & $\mathrm{Gl}$ & $\mathrm{QM}$ & Gl & $\mathrm{QM}$ & G1 & $\mathrm{QM}$ \\
\hline $\begin{array}{l}\text { Repet. / Anos } \\
\text { Repetições } \\
\text { Progênies (P) } \\
\text { Anos (A) } \\
\text { P x A } \\
\text { Erro } \\
\end{array}$ & $\begin{array}{c}2 \\
19\end{array}$ & $\begin{array}{c}213,80 \\
179,81^{* *} \\
65,92\end{array}$ & $\begin{array}{c}1 \\
19 \\
\\
19 \\
\end{array}$ & $\begin{array}{c}262,50 \\
109,30 \\
\\
37,56\end{array}$ & $\begin{array}{c}2 \\
19 \\
\\
38\end{array}$ & $\begin{array}{c}67,92 \\
120,97^{*} \\
50,37\end{array}$ & $\begin{array}{c}2 \\
19 \\
\\
38 \\
\end{array}$ & $\begin{array}{c}40,42 \\
160,44^{\text {ns }} \\
93,93\end{array}$ & \begin{tabular}{|c|}
7 \\
19 \\
3 \\
57 \\
133 \\
\end{tabular} & $\begin{array}{c}129,54 \\
\\
317,79^{* *} \\
1890,26^{* *} \\
84,24^{\text {ns }} \\
65,43 \\
\end{array}$ \\
\hline Total & 59 & 107,61 & 39 & 78,28 & 59 & 73,70 & 59 & 113,53 & 219 & 119,27 \\
\hline Média & & 66,50 & & 70,83 & & 70,17 & & 58,17 & & 66,01 \\
\hline Desv. Padrão & & 7,74 & & 7,39 & & 6,35 & & 7,31 & & 5,46 \\
\hline Menor Valor & & 51,00 & & 55,00 & & 53,33 & & 50,00 & & 55,08 \\
\hline Maior Valor & & 89,33 & & 92,50 & & 81,67 & & 78,33 & & 80,46 \\
\hline Amplitude & & 38,33 & & 37,50 & & 28,33 & & 28,33 & & 25,38 \\
\hline $\mathrm{CVe}$ & & 12,21 & & 8,65 & & 10,12 & & 16,66 & & 12,25 \\
\hline$\sigma_{p}^{2}$ & & 37,96 & & 35,87 & & 23,53 & & 22,17 & & 21,18 \\
\hline $\mathrm{IC} \sigma_{\mathrm{p}}^{2}-\mathrm{LI}$ & & 16,77 & & 15,94 & & 9,70 & & 6,89 & & 10,37 \\
\hline IC $\sigma_{p}^{2}-L S$ & & 156,06 & & 143,24 & & 113,25 & & 355,94 & & 65,41 \\
\hline IC $\sigma_{\mathrm{p}}^{2}(\mathrm{LS}-\mathrm{LI})$ & & 139,29 & & 127,30 & & 103,55 & & 349,05 & & 55,04 \\
\hline$\sigma^{2}$ & & 65,92 & & 37,56 & & 50,37 & & 93,93 & & 65,43 \\
\hline$\sigma_{\mathrm{pa}}^{2}$ & & & & & & & & & & 6,90 \\
\hline$\sigma_{\mathrm{f}}^{2}$ & & 59,94 & & 54,65 & & 40,32 & & 53,48 & & 29,65 \\
\hline $\mathrm{h}_{\mathrm{x}}^{2}$ & & 0,63 & & 0,66 & & 0,58 & & 0,42 & & 0,71 \\
\hline $\mathrm{IC} \mathrm{h}_{\mathrm{x}}^{2}-\mathrm{LI}$ & & 0,14 & & 0,13 & & 0,02 & & $-0,37$ & & 0,40 \\
\hline $\mathrm{IC} \mathrm{h}_{\mathrm{x}}^{2}-\mathrm{LS}$ & & 0,83 & & 0,86 & & 0,80 & & 0,72 & & 0,87 \\
\hline $\mathrm{IC} \mathrm{h}_{\mathrm{x}}^{2}(\mathrm{LS}-\mathrm{LI})$ & & 0,69 & & 0,73 & & 0,78 & & 1,09 & & 0,47 \\
\hline $\mathrm{CVg}$ & & 9,27 & & 8,46 & & 6,91 & & 8,10 & & 6,97 \\
\hline $\mathrm{CVg} / \mathrm{CVe}$ & & 0,76 & & 0,98 & & 0,68 & & 0,49 & & 0,57 \\
\hline
\end{tabular}


Tabela 27. Análise de variância das progênies do cruzamento BR 80-8858 x PI 123439 para o caracter Altura da Planta na Maturação (cm / planta), na geração $F_{2: n}$, nas quatro avaliações e análise conjunta.

\begin{tabular}{|c|c|c|c|c|c|c|c|c|c|c|}
\hline & \multicolumn{2}{|c|}{$1992 / 93$} & \multicolumn{2}{|c|}{$1993 / 94$} & \multicolumn{2}{|c|}{$1994 / 95$} & \multicolumn{2}{|c|}{$1995 / 96$} & \multicolumn{2}{|c|}{ Conjunta } \\
\hline F. Variação & $\overline{\mathrm{Gl}}$ & $\overline{Q M}$ & GI & $\mathrm{QM}$ & $\mathrm{Gl}$ & $\overline{Q M}$ & G1 & $\overline{Q M}$ & $\mathrm{Gl}$ & $\mathrm{QM}$ \\
\hline $\begin{array}{l}\text { Repet. / Anos } \\
\text { Repetições } \\
\text { Progênies (P) } \\
\text { Anos (A) } \\
\text { P x A } \\
\text { Erro }\end{array}$ & $\begin{array}{c}2 \\
19\end{array}$ & $\begin{array}{l}107,22 \\
414,50^{* *} \\
108,06\end{array}$ & $\begin{array}{c}1 \\
19 \\
\\
18 \\
\end{array}$ & $\begin{array}{c}19,60 \\
613,08^{* *} \\
74,53\end{array}$ & $\begin{array}{c}2 \\
19 \\
\\
36 \\
\end{array}$ & $\begin{array}{c}217,96 \\
436,10^{* *} \\
50,94\end{array}$ & $\begin{array}{c}2 \\
19 \\
\\
38\end{array}$ & $\begin{array}{l}543,52 \\
457,76^{* *} \\
45,48\end{array}$ & \begin{tabular}{|c|}
7 \\
19 \\
3 \\
57 \\
130 \\
\end{tabular} & $\begin{array}{c}251,00 \\
1551,37^{* *} \\
1986,63^{* *} \\
123,36^{* *} \\
69,31 \\
\end{array}$ \\
\hline Total & 59 & 206,71 & 38 & 342,36 & 57 & 185,19 & 59 & 195,13 & 216 & 246,45 \\
\hline Média & & 60,38 & & 66,34 & & 64,07 & & 52,43 & & 60,24 \\
\hline Desv. Padrão & & 11,76 & & 17,95 & & 12,70 & & 12,35 & & 12,53 \\
\hline Menor Valor & & 43,33 & & 42,09 & & 43,28 & & 34,67 & & 43,90 \\
\hline Maior Valor & & 87,00 & & 107,00 & & 88,33 & & 81,67 & & 91,00 \\
\hline Amplitude & & 43,67 & & 64,91 & & 45,06 & & 47,00 & & 47,10 \\
\hline $\mathrm{CVe}$ & & 17,22 & & 13,01 & & 11,14 & & 12,86 & & 13,82 \\
\hline$\sigma_{p}^{2}$ & & 102,15 & & 276,55 & & 133,05 & & 137,43 & & 131,50 \\
\hline IC $\sigma_{p}^{2}-L I$ & & 50,09 & & 149,70 & & 72,30 & & 75,31 & & 72,89 \\
\hline IC $\sigma_{\mathrm{p}}^{2}-\mathrm{LS}$ & & 315,97 & & 678,90 & & 322,49 & & 326,54 & & 302,96 \\
\hline IC $\sigma_{\mathrm{p}}^{2}(\mathrm{LS}-\mathrm{LI})$ & & 265,88 & & 529,20 & & 250,19 & & 251,23 & & 230,07 \\
\hline$\sigma^{2}$ & & 108,06 & & 74,53 & & 50,94 & & 45,48 & & 69,31 \\
\hline$\sigma_{\text {pa }}^{2}$ & & & & & & & & & & 20,15 \\
\hline$\sigma_{t}^{2}$ & & 138,17 & & 314,83 & & 150,65 & & 152,59 & & 145,41 \\
\hline$h_{x}^{2}$ & & 0,74 & & 0,88 & & 0,88 & & 0,90 & & 0,90 \\
\hline IC $h_{x}^{2}-L I$ & & 0,39 & & 0,69 & & 0,73 & & 0,77 & & 0,82 \\
\hline $\mathrm{IC} h_{\mathrm{x}}^{2}-\mathrm{LS}$ & & 0,88 & & 0,95 & & 0,95 & & 0,95 & & 0,96 \\
\hline IC $h_{x}^{2}(\mathrm{LS}-\mathrm{LI})$ & & 0,49 & & 0,26 & & 0,22 & & 0,18 & & 0,14 \\
\hline $\mathrm{CVg}$ & & 16,74 & & 25,07 & & 18,00 & & 22,36 & & 19,04 \\
\hline $\mathrm{CVg} / \mathrm{CVe}$ & & 0,97 & & 1,93 & & 1,62 & & 1,74 & & 1,38 \\
\hline
\end{tabular}


Tabela 28. Análise de variância das progênies do cruzamento BR 80-8858 x PI 165896 para o caracter Altura da Planta na Maturação (cm / planta), na geração $F_{2: n}$, nas quatro avaliações e análise conjunta.

\begin{tabular}{|c|c|c|c|c|c|c|c|c|c|c|}
\hline & \multicolumn{2}{|c|}{$1992 / 93$} & \multicolumn{2}{|c|}{$1993 / 94$} & \multicolumn{2}{|c|}{$1994 / 95$} & \multicolumn{2}{|c|}{$1995 / 96$} & \multicolumn{2}{|c|}{ Conjunta } \\
\hline F. Variação & Gl & $\overline{\mathrm{QM}}$ & Gl & $\overline{\mathrm{QM}}$ & $\mathrm{Gl}$ & $\overline{\mathrm{QM}}$ & $\mathrm{Gl}$ & $\overrightarrow{\mathrm{QM}}$ & Gl & $\overline{\mathrm{QM}}$ \\
\hline $\begin{array}{l}\text { Repet. / Anos } \\
\text { Repetições } \\
\text { Progênies (P) } \\
\text { Anos (A) } \\
\text { P x A } \\
\text { Enro }\end{array}$ & $\begin{array}{c}2 \\
19 \\
\\
38\end{array}$ & $\begin{array}{c}45,15 \\
606,33^{* *} \\
147,92\end{array}$ & $\begin{array}{c}1 \\
19 \\
\\
19\end{array}$ & $\begin{array}{c}9,41 \\
556,22^{* *} \\
81,34\end{array}$ & $\begin{array}{c}2 \\
19 \\
\\
\\
38\end{array}$ & $\begin{array}{c}248,75 \\
306,38^{*} \\
156,64\end{array}$ & $\begin{array}{c}2 \\
19 \\
\\
\\
38\end{array}$ & $\begin{array}{c}751,25 \\
558,25^{* *} \\
83,71\end{array}$ & \begin{tabular}{|c|}
7 \\
19 \\
3 \\
57 \\
133 \\
\end{tabular} & $\begin{array}{c}299,96 \\
1632,46^{* *} \\
3414,74^{* *} \\
131,57^{\text {ns }} \\
122,56\end{array}$ \\
\hline Total & 59 & 292,06 & 39 & 310,84 & 59 & 207,99 & 59 & 259,15 & 219 & 306,67 \\
\hline Média & & 80,65 & & 91,14 & & 82,75 & & 71,00 & & 80,50 \\
\hline Desv. Padrão & & 14,22 & & 16,68 & & 10,11 & & 13,29 & & 12,44 \\
\hline Menor Valor & & 54,00 & & 61,70 & & 63,33 & & 46,67 & & 62,76 \\
\hline Maior Valor & & 104,00 & & 116,90 & & 100,00 & & 98,33 & & 102,31 \\
\hline Amplitude & & 50,00 & & 55,20 & & 36,67 & & 51,67 & & 39,55 \\
\hline $\mathrm{CVe}$ & & 15,08 & & 9,90 & & 15,12 & & 12,89 & & 13,75 \\
\hline$\sigma_{p}^{2}$ & & 152,80 & & 237,44 & & 49,91 & & 158,18 & & 136,42 \\
\hline IC $\sigma_{\mathrm{p}}^{2}-\mathrm{LI}$ & & 76,00 & & 125,92 & & 17,98 & & 83,99 & & 75,79 \\
\hline IC $\sigma_{p}^{2}-L S$ & & 456,67 & & 598,53 & & 413,55 & & 399,24 & & 316,50 \\
\hline $\mathrm{IC} \sigma_{\mathrm{p}}^{2}(\mathrm{LS}-\mathrm{LI})$ & & 380,67 & & 472,61 & & 395,57 & 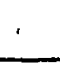 & 315,25 & & 240,71 \\
\hline$\sigma^{2}$ & & 147,92 & & 81,34 & & 156,65 & & 83,71 & & 122,56 \\
\hline$\sigma_{\text {pa }}^{2}$ & & & & & & & & & & 3,31 \\
\hline$\sigma_{f}^{2}$ & & 202,11 & & 278,11 & & 102,21 & & 186,08 & & 148,77 \\
\hline $\mathrm{h}_{\mathrm{x}}^{2}$ & & 0,76 & & 0,85 & & 0,49 & & 0,85 & & 0,92 \\
\hline $\mathrm{IC} \mathrm{h}_{\mathrm{x}}^{2}-\mathrm{LI}$ & & 0,43 & & 0,63 & & $-0,20$ & & 0,65 & & 0,82 \\
\hline IC $h_{x}^{2}-L S$ & & 0,88 & & 0,94 & & 0,76 & & 0,93 & & 0,96 \\
\hline IC $h_{x}^{2}$ (LS-LI) & & 0,45 & & 0,31 & & 0,96 & & 0,28 & & 0,14 \\
\hline $\mathrm{CVg}$ & & 15,33 & & 16,91 & & 8,54 & & 17,71 & & 14,51 \\
\hline $\mathrm{CVg} / \mathrm{CVe}$ & & 1,02 & & 1,71 & & 0,56 & & 1,37 & & 1,06 \\
\hline
\end{tabular}


Tabela 29. Análise de variância das progênies do cruzamento BR 80-8858 x PI 239235 para o caracter Altura da Planta na Maturação (cm / planta), na geração $F_{2: n}$, nas quatro avaliações e análise conjunta.

\begin{tabular}{|c|c|c|c|c|c|c|c|c|c|c|}
\hline & \multicolumn{2}{|c|}{$1992 / 93$} & \multicolumn{2}{|c|}{$1993 / 94$} & \multicolumn{2}{|c|}{$1994 / 95$} & \multicolumn{2}{|c|}{$1995 / 96$} & \multicolumn{2}{|c|}{ Conjunta } \\
\hline F. Variação & $\mathrm{Gl}$ & $\overline{\mathrm{QM}}$ & Gl & $\overline{\mathrm{QM}}$ & $\mathrm{Gl}$ & $\overline{Q M}$ & $\mathrm{Gl}$ & $\overline{Q M}$ & G1 & $\mathbf{Q M}$ \\
\hline $\begin{array}{l}\text { Repet. / Anos } \\
\text { Repetições } \\
\text { Progênies (P) } \\
\text { Anos (A) } \\
\text { P x A } \\
\text { Erro } \\
\end{array}$ & $\begin{array}{c}2 \\
19\end{array}$ & $\begin{array}{c}94,87 \\
217,35\end{array}$ & $\begin{array}{c}1 \\
19\end{array}$ & $\begin{array}{c}18,23 \\
326,70 * \\
131,59\end{array}$ & $\begin{array}{c}2 \\
19 \\
\\
38\end{array}$ & $\begin{array}{c}1235,00 \\
163,51\end{array}$ * & $\begin{array}{c}2 \\
19 \\
\\
38 \\
\end{array}$ & $\begin{array}{l}301,25 \\
183,77^{\text {ns }} \\
113,97\end{array}$ & $\begin{array}{c}7 \\
19 \\
3 \\
57 \\
133 \\
\end{array}$ & $\begin{array}{c}468,64 \\
\\
583,87^{* *} \\
3866,78^{* *} \\
102,49^{\text {ns }} \\
101,35 \\
\end{array}$ \\
\hline Total & 59 & 138,22 & 39 & 223,74 & 59 & 142,20 & 59 & 142,80 & 219 & 206,83 \\
\hline Média & & 82,98 & & 94,18 & & 84,00 & & 72,50 & & 82,44 \\
\hline Desv. Padrão & & 8,51 & & 12,78 & & 7,38 & & 7,71 & & 7,62 \\
\hline Menor Valor & & 69,67 & & 65,50 & & 63,33 & & 53,33 & & 66,29 \\
\hline Maior Valor & & 101,00 & & 114,50 & & 93,33 & & 85,00 & & 96,67 \\
\hline Amplitude & & 31,33 & & 49,00 & & 30,00 & & 31,67 & & 30,38 \\
\hline $\mathrm{CVe}$ & & 12,11 & & 12,18 & & 10,24 & & 14,73 & & 12,21 \\
\hline$\sigma_{p}^{2}$ & & 38,80 & & 97,55 & & 29,83 & & 23,27 & & 43,76 \\
\hline IC $\sigma_{\mathrm{p}}^{2}-\mathrm{LI}$ & & 15,07 & & 40,25 & & 11,69 & & 6,70 & & 22,87 \\
\hline IC $\sigma_{p}^{2}-L S$ & & 240,53 & & 493,71 & & 169,48 & & 609,43 & & 114,48 \\
\hline IC $\sigma_{\mathrm{p}}^{2}(\mathrm{LS}-\mathrm{LI})$ & & 225,46 & & 453,46 & & 157,79 & & 602,73 & & 91,61 \\
\hline$\sigma^{2}$ & & 100,94 & & 131,59 & & 74,04 & & 113,97 & & 101,35 \\
\hline$\sigma_{\text {pa }}^{2}$ & & & & & & & & & & 0,42 \\
\hline$\sigma_{f}^{2}$ & & 72,45 & & 163,35 & & 54,50 & & 61,26 & & 53,13 \\
\hline$h_{x}^{2}$ & & 0,54 & & 0,60 & & 0,55 & & 0,38 & & 0,82 \\
\hline $\mathrm{IC} \mathrm{h}_{\mathrm{x}}^{2}-\mathrm{LI}$ & & $-0,09$ & & $-0,02$ & & $-0,06$ & & $-0,45$ & & 0,60 \\
\hline $\mathrm{IC} \mathrm{h}_{\mathrm{x}}^{2}-\mathrm{LS}$ & & 0,78 & & 0,84 & & 0,79 & & 0,71 & & 0,91 \\
\hline $\mathrm{IC} \mathrm{h}_{\mathrm{x}}^{2}(\mathrm{LS}-\mathrm{LI})$ & & 0,87 & & 0,86 & & 0,85 & & 1,16 & & 0,31 \\
\hline $\mathrm{CVg}$ & & 7,51 & & 10,49 & & 6,50 & & 6,65 & & 8,02 \\
\hline $\mathrm{CVg} / \mathrm{CVe}$ & & 0,62 & & 0,86 & & 0,63 & & 0,45 & & 0,66 \\
\hline
\end{tabular}


Tabela 30. Análise de variância das progênies do cruzamento BR 80-14853 x PI 123439 para o caracter Altura da Planta na Maturação (cm / planta), na geração $F_{2: n}$, nas quatro avaliações e análise conjunta.

\begin{tabular}{|c|c|c|c|c|c|c|c|c|c|c|}
\hline & \multicolumn{2}{|c|}{$1992 / 93$} & \multicolumn{2}{|c|}{$1993 / 94$} & \multicolumn{2}{|c|}{$1994 / 95$} & \multicolumn{2}{|c|}{$1995 / 96$} & \multicolumn{2}{|c|}{ Conjunta } \\
\hline F. Variação & GI & $\mathrm{QM}$ & $\mathrm{Gl}$ & $\mathrm{QM}$ & $\mathrm{Gl}$ & $\mathrm{QM}$ & Gl & $\mathrm{QM}$ & $\mathrm{Gl}$ & $\mathrm{QM}$ \\
\hline $\begin{array}{l}\text { Repet. / Anos } \\
\text { Repetições } \\
\text { Progênies (P) } \\
\text { Anos (A) } \\
\text { P x A } \\
\text { Erro }\end{array}$ & $\begin{array}{c}2 \\
19\end{array}$ & $\begin{array}{c}59,72 \\
89,80^{\text {ns }} \\
108,61\end{array}$ & $\begin{array}{c}1 \\
19 \\
18\end{array}$ & $\begin{array}{l}440,94 \\
105,45^{\text {ns }} \\
54,03\end{array}$ & $\begin{array}{c}2 \\
19 \\
\\
\\
38\end{array}$ & $\begin{array}{c}15,42 \\
159,19^{* *} \\
50,50\end{array}$ & $\begin{array}{c}2 \\
19 \\
\\
\\
38\end{array}$ & $\begin{array}{c}327,92 \\
137,23 \\
\\
68,22\end{array}$ & \begin{tabular}{|c|}
7 \\
\\
19 \\
3 \\
57 \\
132 \\
\end{tabular} & $\begin{array}{c}178,15 \\
\\
239,55^{* *} \\
2688,92^{* *} \\
84,04^{\text {ns }} \\
72,81\end{array}$ \\
\hline Total & 59 & 100,90 & 38 & 89,92 & 59 & 84,31 & 59 & 99,24 & 218 & 129,66 \\
\hline Média & & 66,53 & & 72,04 & & 67,58 & & 55,33 & & 64,73 \\
\hline Desv. Padrão & & 5,47 & & 7,36 & & 7,28 & & 6,76 & & 4,76 \\
\hline Menor Valor & & 58,00 & & 59,50 & & 51,67 & & 43,33 & & 57,25 \\
\hline Maior Valor & & 76,33 & & 87,20 & & 83,33 & & 66,67 & & 74,77 \\
\hline Amplitude & & 18,33 & & 27,70 & & 31,67 & & 23,33 & & 17,52 \\
\hline $\mathrm{CVe}$ & & 15,66 & & 10,20 & & 10,52 & & 14,93 & & 13,18 \\
\hline$\sigma_{\mathrm{p}}^{2}$ & & - & & 26,41 & & 36,23 & & 23,00 & & 14,17 \\
\hline IC $\sigma_{p}^{2}-L I$ & & - & & 9,10 & & 16,85 & & 8,44 & & 6,38 \\
\hline IC $\sigma_{\mathrm{p}}^{2}-\mathrm{LS}$ & & - & & 275,70 & & 128,12 & & 169,22 & & 53,71 \\
\hline IC $\sigma_{\mathrm{p}}^{2}(\mathrm{LS}-\mathrm{LI})$ & & - & & 266,60 & & 111,27 & & 160,78 & & 47,33 \\
\hline$\sigma^{2}$ & & 108,61 & & 54,03 & & 50,50 & & 68,22 & & 72,81 \\
\hline$\sigma_{\text {pa }}^{2}$ & & & & & & & & & & 4,14 \\
\hline$\sigma_{i}^{2}$ & & 29,94 & & 54,15 & & 53,06 & & 45,74 & & 22,35 \\
\hline$h_{x}^{2}$ & & - & & 0,49 & & 0,68 & & 0,50 & & 0,63 \\
\hline $\mathrm{IC} \mathrm{h}_{\mathrm{x}}^{2}-\mathrm{LI}$ & & $-1,83$ & & $-0,30$ & & 0,26 & & $-0,16$ & & 0,20 \\
\hline $\mathrm{IC} h_{x}^{2}-\mathrm{LS}$ & & 0,43 & & 0,80 & & 0,85 & & 0,76 & & 0,82 \\
\hline IC h $h_{\mathrm{x}}^{2}(\mathrm{LS}-\mathrm{LI})$ & & 2,26 & & 1,10 & & 0,59 & & 0,92 & & 0,62 \\
\hline $\mathrm{CVg}$ & & - & & 7,13 & & 8,91 & & 8,67 & & 5,81 \\
\hline $\mathrm{CVg} / \mathrm{CVe}$ & & - & & 0,70 & & 0,85 & & 0,58 & & 0,44 \\
\hline
\end{tabular}


Tabela 31. Análise de variância das progênies do cruzamento BR 80-14853 x PI 165896 para o caracter Altura da Planta na Maturação (cm / planta), na geração $F_{2: n}$, nas quatro avaliações e análise conjunta.

\begin{tabular}{|c|c|c|c|c|c|c|c|c|c|c|}
\hline & \multicolumn{2}{|c|}{$1992 / 93$} & \multicolumn{2}{|c|}{$1993 / 94$} & \multicolumn{2}{|c|}{$1994 / 95$} & \multicolumn{2}{|c|}{$1995 / 96$} & \multicolumn{2}{|c|}{ Conjunta } \\
\hline F. Variação & $\mathrm{Gl}$ & $\mathrm{QM}$ & $\mathrm{Gl}$ & $\overline{Q M}$ & $\mathrm{Gl}$ & $\mathrm{QM}$ & $\mathrm{Gl}$ & $\mathrm{QM}$ & $\mathrm{Gl}$ & $\overline{Q M}$ \\
\hline $\begin{array}{l}\text { Repet. / Anos } \\
\text { Repetições } \\
\text { Progênies (P) } \\
\text { Anos (A) } \\
\text { P x A } \\
\text { Erro }\end{array}$ & $\begin{array}{c}2 \\
19 \\
\\
38 \\
\end{array}$ & $\begin{array}{l}273,15 \\
476,16^{* *} \\
123,69\end{array}$ & $\begin{array}{c}1 \\
19 \\
19\end{array}$ & $\begin{array}{c}1,89 \\
848,67^{* *} \\
\\
97,75\end{array}$ & $\begin{array}{c}2 \\
19 \\
\\
38 \\
\end{array}$ & $\begin{array}{c}31,25 \\
582,87^{* *} \\
102,74\end{array}$ & $\begin{array}{c}2 \\
19 \\
\\
38\end{array}$ & $\begin{array}{l}215,52 \\
427,18^{* *} \\
116,78\end{array}$ & \begin{tabular}{|c|}
7 \\
19 \\
3 \\
57 \\
133 \\
\end{tabular} & $\begin{array}{c}148,82 \\
1598,54^{* *} \\
1313,12^{* * *} \\
245,45^{* *} \\
112,03\end{array}$ \\
\hline Total & 59 & 242,27 & 39 & 461,13 & 59 & 254,94 & 59 & 220,08 & 219 & 293,35 \\
\hline Média & & 67,65 & & 76,39 & & 74,25 & & 65,98 & & 70,58 \\
\hline Desv. Padrão & & 12,60 & & 20,55 & & 13,94 & & 11,93 & & 12,65 \\
\hline Menor Valor & & 51,67 & & 43,95 & & 51,67 & & 45,00 & & 51,99 \\
\hline Maior Valor & & 95,00 & & 113,10 & & 100,00 & & 90,00 & & 90,11 \\
\hline Amplitude & & 43,33 & & 69,15 & & 48,33 & & 45,00 & & 38,12 \\
\hline $\mathrm{CVe}$ & & 16,44 & & 12,94 & & 13,65 & & 16,38 & & 15,00 \\
\hline$\sigma_{p}^{2}$ & & 117,49 & & 375,46 & & 160,04 & & 103,47 & & 122,60 \\
\hline $\mathrm{IC} \boldsymbol{\sigma}_{\mathrm{p}-\mathrm{LI}}^{2}$ & & 57,36 & & 203,55 & & 83,55 & & 49,91 & & 65,12 \\
\hline IC $\sigma_{p}^{2}-\mathrm{LS}$ & & 358,25 & & 907,94 & & 421,03 & & 324,81 & & 311,45 \\
\hline IC $\sigma_{\mathrm{p}}^{2}(\mathrm{LS}-\mathrm{L} \mathrm{I})$ & & 300,89 & & 704,39 & & 337,48 & & 274,90 & & 246,33 \\
\hline$\sigma^{2}$ & & 123,69 & & 97,75 & & 102,74 & & 116,78 & & 112,03 \\
\hline$\sigma_{\text {pa }}^{2}$ & & & & & & & & & & 48,92 \\
\hline$\sigma_{f}^{2}$ & & 158,72 & & 424,34 & & 194,29 & & 142,39 & & 150,73 \\
\hline $\mathrm{h}_{\mathrm{x}}^{2}$ & & 0,74 & & 0,89 & & 0,82 & & 0,73 & & 0,81 \\
\hline $\mathrm{IC} \mathrm{h}_{\mathrm{x}}^{2}-\mathrm{LI}$ & & 0,39 & & 0,71 & & 0,59 & & 0,36 & & 0,65 \\
\hline $\mathrm{IC} \mathrm{h}_{\mathrm{x}}^{2}-\mathrm{LS}$ & & 0,88 & & 0,95 & & 0,92 & & 0,87 & & 0,93 \\
\hline IC $h_{x}^{2}(\mathrm{LS}-\mathrm{LI})$ & & 0,49 & & 0,24 & & 0,33 & & 0,51 & & 0,28 \\
\hline $\mathrm{CVg}$ & & 16,02 & & 25,37 & & 17,04 & & 15,42 & & 15,69 \\
\hline $\mathrm{CVg} / \mathrm{CVe}$ & & 0,97 & & 1,96 & & 1,25 & & 0,94 & & 1,05 \\
\hline
\end{tabular}


Tabela 32. Análise de variância das progênies do cruzamento BR 80-14853 x PI 239235 para o caracter Altura da Planta na Maturação (cm / planta), na geração $F_{2: n}$, nas quatro avaliações e análise conjunta.

\begin{tabular}{|c|c|c|c|c|c|c|c|c|c|c|}
\hline & \multicolumn{2}{|c|}{$1992 / 93$} & \multicolumn{2}{|c|}{$1993 / 94$} & \multicolumn{2}{|c|}{$1994 / 95$} & \multicolumn{2}{|c|}{$1995 / 96$} & \multicolumn{2}{|c|}{ Conjunta } \\
\hline F. Variação & $\mathrm{Gl}$ & $\overline{\mathrm{QM}}$ & $\mathrm{Gl}$ & $\overline{Q M}$ & $\mathrm{Gl}$ & $\overline{Q M}$ & Gl & $\overline{Q M}$ & $\mathrm{Gl}$ & $\mathrm{QM}$ \\
\hline $\begin{array}{l}\text { Repet. / Anos } \\
\text { Repetições } \\
\text { Progênies (P) } \\
\text { Anos (A) } \\
\text { P x A } \\
\text { Eño } \\
\end{array}$ & $\begin{array}{c}2 \\
19 \\
\\
38 \\
\end{array}$ & $\begin{array}{l}158,87 \\
188,72^{\text {ns }} \\
129,24\end{array}$ & $\begin{array}{c}1 \\
19 \\
\\
19\end{array}$ & $\begin{array}{l}216,23 \\
737,28^{* *} \\
106,00\end{array}$ & $\begin{array}{c}2 \\
19 \\
\\
\\
38\end{array}$ & $\begin{array}{l}320,42 \\
359,01^{* *} \\
139,28\end{array}$ & $\begin{array}{c}2 \\
19 \\
\\
\\
38\end{array}$ & $\begin{array}{c}81,67 \\
422,37^{* *} \\
117,63\end{array}$ & \begin{tabular}{|c|}
7 \\
\\
19 \\
3 \\
57 \\
133 \\
\end{tabular} & $\begin{array}{c}191,16 \\
1073,39^{* *} \\
4350,05^{* *} \\
211,33^{* *} \\
125,47\end{array}$ \\
\hline Total & 59 & 149,40 & 39 & 416,37 & 59 & 216,18 & 59 & 214,55 & 219 & 290,03 \\
\hline Média & & 78,17 & & 94,03 & & 79,42 & & 70,83 & & 79,39 \\
\hline Desv. Padrão & & 7,93 & & 19,20 & & 10,94 & & 11,87 & & 10,49 \\
\hline Menor Valor & & 60,00 & & 64,50 & & 61,67 & & 50,00 & & 62,40 \\
\hline Maior Valor & & 91,67 & & 132,30 & & 108,33 & & 90,00 & & 100,58 \\
\hline Amplitude & & 31,67 & & 67,80 & & 46,67 & & 40,00 & & 38,18 \\
\hline $\mathrm{CVe}$ & & 14,54 & & 10,94 & & 14,86 & & 15,31 & & 14,11 \\
\hline$\sigma_{p}^{2}$ & & 19,83 & & 315,64 & & 73,25 & & 101,58 & & 78,11 \\
\hline $\mathrm{IC} \sigma_{\mathrm{p}}^{2}-\mathrm{LI}$ & & 4,83 & & 192,93 & & 31,50 & & 48,90 & & 40,25 \\
\hline IC $\sigma_{\mathrm{p}}^{2}-\mathrm{LS}$ & & 2312,55 & & 946,51 & & 322,39 & & 325,58 & & 211,72 \\
\hline IC $\sigma_{p}^{2}(\mathrm{LS}-\mathrm{LI})$ & & 2307,72 & & 753,58 & & 290,89 & & 275,78 & & 171,47 \\
\hline$\sigma^{2}$ & & 129,24 & & 106,00 & & 139,28 & & 117,63 & & 125,47 \\
\hline$\sigma_{\mathrm{pa}}^{2}$ & & & & & & & & & & 31,48 \\
\hline$\sigma_{\mathrm{f}}^{2}$ & & 62,91 & & 368,64 & & 119,67 & & 140,79 & & 101,06 \\
\hline$h_{x}^{2}$ & & 0,32 & & 0,86 & & 0,61 & & 0,72 & & 0,78 \\
\hline$I C h_{x}^{2}-L I$ & & $-0,60$ & & 0,64 & & 0,09 & & 0,35 & & 0,55 \\
\hline IC $h_{x}^{2}-L S$ & & 0,67 & & 0,94 & & 0,82 & & 0,87 & & 0,90 \\
\hline IC $h_{x}^{2}(\mathrm{LS}-\mathrm{LI})$ & & 1,27 & & 0,30 & & 0,73 & & 0,52 & & 0,35 \\
\hline $\mathrm{CVg}$ & & 5,70 & & 18,90 & & 10,78 & & 14,23 & & 11,13 \\
\hline $\mathrm{CVg} / \mathrm{CVe}$ & & 0,39 & & 1,73 & & 0,73 & & 0,93 & & 0,79 \\
\hline
\end{tabular}


Tabela 33. Análise de variância das progênies do cruzamento PI 123439 x PI 165896 para o caracter Altura da Planta na Maturação (cm / planta), na geração $F_{2: n}$, nas quatro avaliações e análise conjunta.

\begin{tabular}{|c|c|c|c|c|c|c|c|c|c|c|}
\hline & \multicolumn{2}{|c|}{$1992 / 93$} & \multicolumn{2}{|c|}{$1993 / 94$} & \multicolumn{2}{|c|}{$1994 / 95$} & \multicolumn{2}{|c|}{$1995 / 96$} & \multicolumn{2}{|c|}{ Conjunta } \\
\hline F. Variação & $\mathrm{Gl}$ & $\overline{\mathrm{QM}}$ & $\mathrm{Gl}$ & $\overline{\mathrm{QM}}$ & Gl & $\overline{\mathrm{QM}}$ & $\mathrm{Gl}$ & $\overline{\mathrm{QM}}$ & G1 & $\overline{\mathrm{QM}}$ \\
\hline $\begin{array}{l}\text { Repet. / Anos } \\
\text { Repetições } \\
\text { Progênies (P) } \\
\text { Anos (A) } \\
\text { P x A } \\
\text { Erro }\end{array}$ & \begin{tabular}{c|}
2 \\
19 \\
38
\end{tabular} & $\begin{array}{c}265,32 \\
372,05^{* *} \\
83,93\end{array}$ & $\begin{array}{c}1 \\
19 \\
\\
19 \\
\end{array}$ & $\begin{array}{c}32,76 \\
548,13^{* *} \\
35,91\end{array}$ & $\begin{array}{c}2 \\
19 \\
\\
36\end{array}$ & $\begin{array}{c}597,96 \\
512,48^{* *} \\
86,69\end{array}$ & $\begin{array}{c}2 \\
19 \\
\\
\\
38\end{array}$ & $\begin{array}{c}52,92 \\
724,98^{* *} \\
72,22\end{array}$ & \begin{tabular}{|c|}
7 \\
\\
19 \\
3 \\
57 \\
131 \\
\end{tabular} & $\begin{array}{c}266,45 \\
1534,52^{* *} \\
3661,86^{* *} \\
207,71^{* *} \\
74,33\end{array}$ \\
\hline Total & 59 & 182,86 & 39 & 285,37 & 57 & 246,56 & 59 & 281,77 & 217 & 293,01 \\
\hline Média & & 72,47 & & 79,41 & & 74,40 & & 59,92 & & 70,80 \\
\hline Desv. Padrão & & 11,14 & & 16,56 & & 13,36 & & 15,55 & & 12,11 \\
\hline Menor Valor & & 50,67 & & 58,60 & & 50,00 & & 36,67 & & 56,52 \\
\hline Maior Valor & & 95,00 & & 120,40 & & 103,33 & & 90,00 & & 96,02 \\
\hline Amplitude & & 44,33 & & 61,80 & & 53,33 & & 53,33 & & 39,50 \\
\hline $\mathrm{CVe}$ & & 12,64 & & 7,55 & & 12,52 & & 14,18 & & 12,18 \\
\hline$\sigma_{p}^{2}$ & & 96,04 & & 256,11 & & 147,09 & & 217,59 & & 121,35 \\
\hline $\mathrm{IC} \sigma_{\mathrm{p}}^{2}-\mathrm{LI}$ & & 48,38 & & 143,34 & & 77,27 & & 119,55 & & 65,31 \\
\hline $\mathrm{IC} \sigma_{\mathrm{D}}^{2}-\mathrm{LS}$ & & 275,55 & & 584,86 & & 383,35 & & 516,69 & & 299,55 \\
\hline IC $\sigma_{\mathrm{p}}^{2}(\mathrm{LS}-\mathrm{LI})$ & & 227,17 & & 441,52 & & 306,08 & & 397,14 & & 234,24 \\
\hline$\sigma^{2}$ & & 83,93 & & 35,91 & & 86,69 & & 72,22 & & 74,33 \\
\hline$\sigma_{\mathrm{pa}}^{2}$ & & & & & & & & & & 49,40 \\
\hline$\sigma_{f}^{2}$ & & 124,01 & & 274,06 & & 177,04 & & 241,66 & & 146,47 \\
\hline$h_{\mathrm{x}}^{2}$ & & 0,78 & & 0,94 & & 0,83 & & 0,90 & & 0,83 \\
\hline IC h $h_{x}^{2}-\mathrm{LI}$ & & 0,47 & & 0,83 & & 0,60 & & 0,77 & & 0,69 \\
\hline $\mathrm{IC} \mathrm{h} \mathrm{h}_{\mathrm{x}}^{2}-\mathrm{LS}$ & & 0,89 & & 0,97 & & 0,92 & & 0,95 & & 0,93 \\
\hline IC $h_{x}^{2}$ (LS-LI) & & 0,42 & & 0,14 & & 0,32 & & 0,18 & & 0,24 \\
\hline $\mathrm{CVg}$ & & 13,52 & & 20,15 & & 16,30 & & 24,62 & & 15,56 \\
\hline $\mathrm{CVg} / \mathrm{CVe}$ & & 1,07 & & 2,67 & & 1,30 & & 1,74 & & 1,28 \\
\hline
\end{tabular}


Tabela 34. Análise de variância das progênies do cruzamento PI 123439 x PI 239235 para o caracter Altura da Planta na Maturação (cm / planta), na geração $F_{2: n}$, nas quatro avaliações e análise conjunta.

\begin{tabular}{|c|c|c|c|c|c|c|c|c|c|c|}
\hline & \multicolumn{2}{|c|}{$1992 / 93$} & \multicolumn{2}{|c|}{$1993 / 94$} & \multicolumn{2}{|c|}{$1994 / 95$} & \multicolumn{2}{|c|}{ 1995/96 } & \multicolumn{2}{|c|}{ Conjunta } \\
\hline F. Variação & Gl & $\mathrm{QM}$ & G1 & $\mathrm{QM}$ & $\mathrm{Gl}$ & $\mathrm{QM}$ & $\overline{\mathrm{Gl}}$ & $\mathrm{QM}$ & $\mathrm{Gl}$ & $\mathrm{QM}$ \\
\hline $\begin{array}{l}\text { Repet. / Anos } \\
\text { Repetições } \\
\text { Progênies (P) } \\
\text { Anos (A) } \\
\text { P x A } \\
\text { Erro }\end{array}$ & $\begin{array}{c}2 \\
19 \\
38\end{array}$ & $\begin{array}{l}128,22 \\
242,77^{\text {ns }} \\
146,64\end{array}$ & $\begin{array}{c}1 \\
19 \\
\\
19 \\
\end{array}$ & $\begin{array}{l}431,65 \\
695,15^{* *} \\
120,42\end{array}$ & $\begin{array}{c}2 \\
19 \\
\\
37 \\
\end{array}$ & $\begin{array}{c}12,96 \\
247,98\end{array}$ * & $\begin{array}{c}2 \\
19 \\
\\
38 \\
\end{array}$ & $\begin{array}{c}55,85 \\
407,97^{* *} \\
136,11\end{array}$ & $\begin{array}{c}7 \\
\\
19 \\
3 \\
57 \\
132\end{array}$ & $\begin{array}{c}117,96 \\
1068,06^{* *} \\
8216,58^{* *} \\
175,27^{\text {ns }} \\
132,71 \\
\end{array}$ \\
\hline Total & 59 & 176,97 & 39 & 408,40 & 58 & 159,01 & 59 & 220,94 & 218 & 336,13 \\
\hline Média & & 79,33 & & 96,57 & & 82,58 & & 65,10 & & 79,46 \\
\hline Desv. Padrão & & 8,99 & & 18,64 & & 9,10 & & 11,66 & & 10,37 \\
\hline Menor Valor & & 60,67 & & 59,20 & & 58,33 & & 43,33 & & 55,63 \\
\hline Maior Valor & & 98,33 & & 123,50 & & 96,67 & & 83,33 & & 95,74 \\
\hline Amplitude & & 37,67 & & 64,30 & & 38,33 & & 40,00 & & 39,11 \\
\hline $\mathrm{CVe}$ & & 12,26 & & 11,36 & & 13,33 & & 17,92 & & 14,50 \\
\hline$\sigma_{p}^{2}$ & & 32,05 & & 287,37 & & 43,01 & & 90,62 & & 81,42 \\
\hline IC $\sigma_{\mathrm{p}}^{2}-\mathrm{LI}$ & & 9,62 & & 149,87 & & 16,08 & & 41,30 & & 42,83 \\
\hline $\mathrm{IC} \sigma_{\mathrm{p}}^{2}-\mathrm{LS}$ & & 680,73 & & 760,46 & & 309,32 & & 332,27 & & 208,77 \\
\hline IC $\sigma_{p}^{2}(\mathrm{LS}-\mathrm{LI})$ & & 671,11 & & 610,59 & & 293,24 & & 290,97 & & 165,94 \\
\hline$\sigma^{2}$ & & 146,64 & & 120,42 & & 121,21 & & 136,11 & & 132,71 \\
\hline$\sigma_{\mathrm{pa}}^{2}$ & & & & & & & & & & 15,69 \\
\hline$\sigma_{t}^{2}$ & & 80,92 & & 347,58 & & 84,14 & & 135,99 & & 99,32 \\
\hline$h_{x}^{2}$ & & 0,40 & & 0,83 & & 0,51 & & 0,67 & & 0,82 \\
\hline $\mathrm{IC} \mathrm{h} \mathrm{h}_{\mathrm{x}}^{2}-\mathrm{LI}$ & & $-0,42$ & & 0,56 & & $-0,15$ & & 0,22 & & 0,63 \\
\hline $\mathrm{IC} \mathrm{h}_{\mathrm{x}}^{2}-\mathrm{LS}$ & & 0,71 & & 0,93 & & 0,77 & & 0,84 & & 0,92 \\
\hline $\mathrm{IC} \mathrm{h}_{\mathrm{x}}^{2}(\mathrm{LS}-\mathrm{LI})$ & & 1,13 & & 0,37 & & 0,92 & & 0,62 & & 0,29 \\
\hline $\mathrm{CVg}$ & & 7,14 & & 17,56 & & 7,94 & & 14,62 & & 11,36 \\
\hline $\mathrm{CVg} / \mathrm{CVe}$ & & 0,58 & & 1,55 & & 0,60 & & 0,82 & & 0,78 \\
\hline
\end{tabular}


Tabela 35. Análise de variância das progênies do cruzamento PI 165896 x PI 239235 para o caracter Altura da Planta na Maturação (cm / planta), na geração $F_{2: n}$, nos quatro anos agrícolas de experimentação e análise conjunta.

\begin{tabular}{|c|c|c|c|c|c|c|c|c|c|c|}
\hline & \multicolumn{2}{|c|}{$1992 / 93$} & \multicolumn{2}{|c|}{ 1993/94 } & \multicolumn{2}{|c|}{$1994 / 95$} & \multicolumn{2}{|c|}{$1995 / 96$} & \multicolumn{2}{|c|}{ Conjunta } \\
\hline F. Variação & $\mathrm{Gl}$ & $\mathrm{QM}$ & $\mathrm{Gl}$ & $\overline{Q M}$ & $\mathrm{Gl}$ & $\mathrm{QM}$ & Gl & $\mathrm{QM}$ & $\mathrm{Gl}$ & QM \\
\hline $\begin{array}{l}\text { Repet. / Anos } \\
\text { Repetições } \\
\text { Progênies (P) } \\
\text { Anos (A) } \\
\text { P x A } \\
\text { Erro }\end{array}$ & $\begin{array}{c}2 \\
19 \\
\\
38 \\
\end{array}$ & $\begin{array}{l}352,32 \\
403,65^{* *} \\
160,05\end{array}$ & $\begin{array}{c}1 \\
19 \\
\\
18 \\
\end{array}$ & $\begin{array}{c}1646,53 \\
658,48 * * \\
186,26\end{array}$ & $\begin{array}{c}2 \\
19 \\
\\
38\end{array}$ & $\begin{array}{c}1730,52 \\
223,48^{\text {ns }} \\
221,31\end{array}$ & $\begin{array}{c}2 \\
19 \\
\\
\\
38 \\
\end{array}$ & $\begin{array}{l}237,92 \\
520,09^{* *} \\
131,34\end{array}$ & $\begin{array}{c}7 \\
19 \\
3 \\
57 \\
132 \\
\end{array}$ & $\begin{array}{c}898,29 \\
988,10^{* *} \\
7976,40^{* *} \\
272,53^{*} \\
172,99 \\
\end{array}$ \\
\hline Total & 59 & 245,02 & 38 & 460,80 & 59 & 273,16 & 59 & 260,14 & 218 & 400,74 \\
\hline Média & & 87,03 & & 113,17 & & 89,43 & & 83,17 & & 91,29 \\
\hline Desv. Padrão & & 11,60 & & 18,17 & & 8,63 & & 13,17 & & 9,95 \\
\hline Menor Valor & & 66,33 & & 83,30 & & 76,67 & & 61,67 & & 73,15 \\
\hline Maior Valor & & 111,00 & & 136,50 & & 106,67 & & 108,33 & & 107,11 \\
\hline Amplitude & & 44,67 & & 53,20 & & 30,00 & & 46,67 & & 33,96 \\
\hline $\mathrm{CVe}$ & & 14,54 & & 12,06 & & 16,63 & & 13,78 & & 14,41 \\
\hline$\sigma_{p}^{2}$ & & 81,20 & & 242,49 & & 0,72 & & 129,58 & & 65,01 \\
\hline $\mathrm{IC} \sigma_{\mathrm{p}}^{2}-\mathrm{LI}$ & & 34,54 & & 114,86 & & - & & 63,73 & & 31,51 \\
\hline IC $\sigma_{p}^{2}-\mathrm{LS}$ & & 368,58 & & 809,12 & & - & & 390,30 & & 205,09 \\
\hline IC $\sigma_{\mathrm{p}}^{2}(\mathrm{LS}-\mathrm{LI})$ & & 334,04 & & 694,26 & & - & & 326,57 & & 173,58 \\
\hline$\sigma^{2}$ & & 160,05 & & 186,26 & & 221,31 & & 131,34 & & 172,99 \\
\hline$\sigma_{\mathrm{pa}}^{2}$ & & & & & & & & & & 36,73 \\
\hline$\sigma_{\mathrm{f}}^{2}$ & & 134,55 & & 338,14 & & 74,49 & & 173,36 & & 94,36 \\
\hline$h_{x}^{2}$ & & 0,60 & & 0,72 & & 0,01 & & 0,75 & & 0,69 \\
\hline IC $h_{x}^{2}-L I$ & & 0,07 & & 0,28 & & $-1,32$ & & 0,41 & & 0,37 \\
\hline IC $h_{x}^{2}-L S$ & & 0,81 & & 0,89 & & 0,53 & & 0,88 & & 0,87 \\
\hline IC $h_{x}^{2}(L S-L I)$ & & 0,74 & & 0,61 & & 1,85 & & 0,47 & & 0,50 \\
\hline $\mathrm{CVg}$ & & 10,35 & & 13,76 & & 0,95 & & 13,69 & & 8,83 \\
\hline $\mathrm{CVg} / \mathrm{CVe}$ & & 0,71 & & 1,14 & & 0,06 & & 0,99 & & 0,61 \\
\hline
\end{tabular}


Tabela 36. Análise de variância dos cruzamentos da tabela dialélica para o caráter Produtividade de Grãos (gramas / parcela), na geração $F_{2: n}$, nas quatro avaliações e análise conjunta.

\begin{tabular}{|c|c|c|c|c|c|c|c|c|c|c|}
\hline & \multicolumn{2}{|c|}{$1992 / 93$} & \multicolumn{2}{|c|}{ 1993/94 } & \multicolumn{2}{|c|}{$1994 / 95$} & \multicolumn{2}{|c|}{$1995 / 96$} & \multicolumn{2}{|c|}{ Conjunta } \\
\hline F. Variação & $\mathrm{Gl}$ & $\mathrm{QM}$ & $\mathrm{Gl}$ & $\mathrm{QM}$ & $\mathrm{Gl}$ & $\overline{\mathrm{QM}}$ & Gl & $\overline{\mathrm{QM}}$ & $\mathrm{Gl}$ & $\mathrm{QM}$ \\
\hline Repet. / Anos & & & & & & & & & 8 & $132517,95^{* *}$ \\
\hline Repetições & 2 & $95609,27^{* *}$ & 2 & $284780,62^{\circ *}$ & 2 & $39127,63^{* *}$ & 2 & $52821,13^{* *}$ & & \\
\hline $\operatorname{Anos}(\mathrm{A})$ & & & & & & & & & 3 & $4115272,08^{* *}$ \\
\hline Cruzam. (C) & 24 & $173668,77^{\circ}$ & 24 & $80591,13^{\circ}$ & 24 & $75045,59^{\circ *}$ & 24 & $64137,75^{*}$ & 24 & $320560,56^{* *}$ \\
\hline$A \times C$ & & & & & & & & & 72 & $24968,30^{\circ "}$ \\
\hline Erro (parcel.) & 48 & $20491,59^{*}$ & 47 & $9692,41^{*}$ & 48 & $6642,45^{\circ *}$ & 48 & $2365,88^{\circ}$ & 191 & $9603,01^{\circ *}$ \\
\hline Prog. (P )/C & 468 & $11294,97^{* *}$ & 468 & $9694,51^{\circ *}$ & 468 & $6209,81^{\circ *}$ & 466 & $4160,09^{* *}$ & 468 & $17282,37^{* *}$ \\
\hline $\operatorname{Prog}(C 1 \times 2)$ & 19 & $11736,60^{\circ}$ & 19 & $8391,42^{\circ}$ & 19 & $5149,80^{\text {ns }}$ & 18 & $4343,40^{\circ *}$ & 19 & $8396,43 *$ \\
\hline Prog $(C 1 \times 3)$ & 19 & $9701,25^{n s}$ & 19 & $11717,54^{\circ}$ & 19 & $5425,32^{\circ}$ & 19 & $4693.39^{*}$ & 19 & $17659,54^{* *}$ \\
\hline $\operatorname{Prog}(C 1 \times 4)$ & 12 & $39823,78^{* *}$ & 12 & $24435,54^{\circ *}$ & 12 & $15300,59^{* *}$ & 12 & $7702,85^{\circ}$ & 12 & $51701,97^{* *}$ \\
\hline Prog $(C 1 \times 6)$ & 19 & $5039,35^{\text {ns }}$ & 19 & $6591,62{ }^{\circ *}$ & 19 & $6165,67^{* *}$ & 19 & $3571,55^{*}$ & 19 & $9827,70^{\circ *}$ \\
\hline $\operatorname{Prog}(\mathrm{C} 1 \times 7)$ & 19 & $4572,52^{n s}$ & 19 & $3577,59^{\text {ns }}$ & 19 & $2345,36^{\text {ns }}$ & 19 & $1463,91^{\text {ns }}$ & 19 & $4608,19^{* *}$ \\
\hline Prog $(C 1 \times 8)$ & 19 & $7855,09^{\text {ns }}$ & 19 & $7018,66^{\mathrm{ng}}$ & 19 & $3820,91^{\text {ns }}$ & 19 & $3491,30^{\text {ns }}$ & 19 & $7098,78^{\circ}$ \\
\hline $\operatorname{Prog}(C 2 \times 3)$ & 19 & $17255,24^{\circ *}$ & 19 & $9598,28^{\mathrm{ns}}$ & 19 & $3554,20^{\text {ns }}$ & 19 & $3049,14^{\text {ns }}$ & 19 & $16102,44^{* *}$ \\
\hline Prog (C $2 \times 4)$ & 19 & $12080,19^{* *}$ & 19 & $9389,33^{*}$ & 19 & $7862,78^{\circ}$ & 19 & $4913,59^{\circ}$ & 19 & $21444,08^{* *}$ \\
\hline $\operatorname{Prog}(C 2 \times 5)$ & 19 & $11876,61^{\circ}$ & 19 & $9488,26^{\mathrm{ns}}$ & 19 & $6042,98^{\circ}$ & 19 & $3914,42 *$ & 19 & $23186,43^{\circ \bullet}$ \\
\hline $\operatorname{Prog}(C 2 \times 6)$ & 19 & $9640,21^{* *}$ & 19 & $7418,03^{\circ *}$ & 19 & $4762,84^{\text {ns }}$ & 19 & $3884,99^{*}$ & 19 & $14018,71^{* *}$ \\
\hline Prog $(C 2 \times 8)$ & 19 & $6102,30^{\mathrm{ns}}$ & 19 & $6895,84^{\mathrm{ns}}$ & 19 & $7582,13^{* *}$ & 19 & $2781,58^{*}$ & 19 & $10034,43^{* *}$ \\
\hline Prog $(C 3 \times 5)$ & 19 & $11025,25^{\circ}$ & 19 & $13677,49^{\circ}$ & 19 & $8172,46^{\circ}$ & 19 & $4457,58^{\text {ns }}$ & 19 & $22794,56^{\circ *}$ \\
\hline $\operatorname{Prog}(C 3 \times 6)$ & 19 & $10971,55^{*}$ & 19 & $5026,23^{\circ}$ & 19 & $7974,78^{\circ}$ & 19 & $4308.85^{*}$ & 19 & $18972,94 *$ \\
\hline Prog (C $3 \times 7)$ & 19 & $12467,74^{\circ *}$ & 19 & $11881,38^{\circ *}$ & 19 & $6599,94^{\text {ns }}$ & 19 & $5406.23^{* *}$ & 19 & $25336,01^{* *}$ \\
\hline $\operatorname{Prog}(C 3 \times 8)$ & 19 & $6735,34^{\text {ns }}$ & 19 & $10516,51^{*}$ & 19 & $8326,36^{*}$ & 18 & $4563,35^{*}$ & 19 & $16799,99 *$ \\
\hline Prog (C $4 \times 5)$ & 19 & $17062,24^{* *}$ & 19 & $18713,00^{\circ}$ & 19 & $6178,46^{\circ}$ & 19 & $2169,32^{\text {ns }}$ & 19 & $21112,42 *$ \\
\hline Prog $(C 4 \times 6)$ & 19 & $21793,17^{* 4}$ & 19 & $13382,60^{\circ}$ & 19 & $5316,05^{* *}$ & 19 & $7136,87^{*}$ & 19 & $31721,21^{* *}$ \\
\hline $\operatorname{Prog}(\mathrm{C} 4 \times 7)$ & 19 & $8432,91^{\text {ns }}$ & 19 & $9654,48^{\circ}$ & 19 & $5104,79^{\mathrm{ns}}$ & 19 & $4056,41^{* *}$ & 19 & $13801,23^{* *}$ \\
\hline Prog (C $4 \times 8)$ & 19 & $6399,84^{\text {ns }}$ & 19 & $4521,03^{\text {ns }}$ & 19 & $4754,09^{\text {ns }}$ & 19 & $2641,83^{\text {ns }}$ & 19 & $4619,54^{\mathrm{ns}}$ \\
\hline Prog $(C 5 \times 6)$ & 19 & $12437,51^{* *}$ & 19 & $8927,13^{\text {ns }}$ & 19 & $10014,65^{* *}$ & 19 & $5993,34^{\circ *}$ & 19 & $20554,82^{\circ \bullet}$ \\
\hline Prog $(C 5 \times 7)$ & 19 & $7260,75^{*}$ & 19 & $5804,75^{\circ}$ & 19 & $4303,25^{\circ}$ & 19 & $5010,06^{\circ *}$ & 19 & $10216,27^{* *}$ \\
\hline Prog $(C 5 \times 8)$ & 19 & $5199,66^{\mathrm{ns}}$ & 19 & $6531,48^{\mathrm{ns}}$ & 19 & $3793,95^{\text {ns }}$ & 19 & $2082,00^{\text {ns }}$ & 19 & $8402,64 *$ \\
\hline Prog (C $6 \times 7)$ & 19 & $13404,69^{\circ *}$ & 19 & $17067,30^{* *}$ & 19 & $10780,13^{* *}$ & 19 & $4264.49^{\circ *}$ & 19 & $33052,92 *$ \\
\hline Prog $(C 6 \times 8)$ & 19 & $17015,26^{\circ}$ & 19 & $13584,38^{* *}$ & 19 & $5613,51^{* *}$ & 19 & $3408,90^{* *}$ & 19 & $22230,61^{* *}$ \\
\hline $\operatorname{Prog}(C 7 \times 8)$ & 19 & $6995,84^{\circ}$ & 19 & $3983,79^{\text {ns }}$ & 19 & $3649,58^{\text {ns }}$ & 19 & $6068,89^{\circ *}$ & 19 & $11046,23 *$ \\
\hline A x Prog. / Cruz. & & & & & & & & & 1402 & $4693,10^{* *}$ \\
\hline Erro & 920 & 4554,74 & 877 & 4714,62 & 902 & 2853,45 & 919 & 1558,71 & 3618 & 3408,33 \\
\hline Total & 1462 & 10176,93 & 1418 & 8245,53 & 1444 & 5298,19 & 1459 & 3538.93 & 5786 & 8940,64 \\
\hline
\end{tabular}


Tabela 37. Análise de variância das progênies do cruzamento Gaúcha x La-4910215 para o caracteres Produtividade de Grãos (gramas / parcela), na geração $F_{2: n}$, nas quatro avaliações e análise conjunta.

\begin{tabular}{|c|c|c|c|c|c|c|c|c|c|c|}
\hline & \multicolumn{2}{|c|}{$1992 / 93$} & \multicolumn{2}{|c|}{$1993 / 94$} & \multicolumn{2}{|c|}{$1994 / 95$} & \multicolumn{2}{|c|}{$1995 / 96$} & \multicolumn{2}{|c|}{ Conjunta } \\
\hline F. Variação & Gl & $\overline{\mathrm{QM}}$ & Gl & $\overline{Q M}$ & $\mathrm{Gl}$ & $\overline{\mathrm{OM}}$ & $\mathrm{Gl}$ & $\overline{Q M}$ & $\mathrm{Gl}$ & $\overline{O M}$ \\
\hline $\begin{array}{l}\text { Repet. / Anos } \\
\text { Repetições } \\
\text { Progênies (P) } \\
\text { Anos (A) } \\
\text { P x A } \\
\text { Erro }\end{array}$ & $\begin{array}{c}2 \\
19\end{array}$ & $\begin{array}{c}54326,60 \\
11736,60 * \\
6209,97\end{array}$ & $\begin{array}{c}2 \\
19 \\
\\
37\end{array}$ & $\begin{array}{l}2035,06 \\
8391,42 \\
3669,93\end{array}$ & $\begin{array}{c}2 \\
19\end{array}$ & $\begin{array}{l}7590,17 \\
5149,80^{\text {ns }} \\
3741,03\end{array}$ & $\begin{array}{c}2 \\
18 \\
\\
35\end{array}$ & $\begin{array}{c}3019,45 \\
4343,40 * * \\
849,09\end{array}$ & \begin{tabular}{c|}
8 \\
19 \\
3 \\
56 \\
147
\end{tabular} & \begin{tabular}{|r|}
16742,82 \\
\\
$8396,43^{* * *}$ \\
$116399,36^{* *}$ \\
$7123,71^{* *}$ \\
3672,81
\end{tabular} \\
\hline Total & 59 & 9220,80 & 58 & 5160.25 & 58 & 4335,25 & 55 & 2071,60 & 233 & 6786,92 \\
\hline Média & & 241,90 & & 240,92 & & 181,77 & & 151,65 & & 204,89 \\
\hline Desv. Padrão & & 62,55 & & 53,69 & & 42,13 & & 38,09 & & 27,35 \\
\hline Menor Valor & & 140,00 & & 129,70 & & 108,20 & & 91,52 & & 162,73 \\
\hline Maior Valor & & 345,33 & & 361,80 & & 260,74 & & 232,26 & & 261,67 \\
\hline Amplitude & & 205,33 & & 232,10 & & 152,55 & & 140,74 & & 98,94 \\
\hline $\mathrm{CVe}$ & & 32,58 & & 25,15 & & 33,65 & & 19,21 & & 29,58 \\
\hline$\sigma_{\mathrm{p}}^{2}$ & & 1842,21 & & 1601,93 & & 477,98 & & 1186,75 & & 107,42 \\
\hline IC $\sigma_{p}^{2}-L I$ & & 675,56 & & 642,85 & & 101,16 & & 602,94 & & - \\
\hline IC $\sigma_{p}^{2}-L S$ & & 14156,51 & & 8536,80 & & 271,43 & & 3349,00 & & - \\
\hline IC $\sigma_{\mathrm{p}}^{2}(\mathrm{LS}-\mathrm{LI})$ & & 13480,95 & & 7893,95 & & 170,27 & & 2746,06 & & - \\
\hline$\sigma^{2}$ & & 6209,97 & & 3669,93 & & 3741,03 & & 849,09 & & 3672,81 \\
\hline$\sigma_{\mathrm{pa}}^{2}$ & & & & & & & & & & 1167,35 \\
\hline$\sigma_{\mathrm{f}}^{2}$ & & 3912,20 & & 2847,08 & & 1747,24 & & 1475,12 & & 816,65 \\
\hline$h_{x}^{2}$ & & 0,47 & & 0,56 & & 0,27 & & 0,81 & & 0,13 \\
\hline $\mathrm{IC} \mathrm{h} \mathrm{h}_{\mathrm{x}}^{2}-\mathrm{LI}$ & & $-0,24$ & & $-0,03$ & & $-0,71$ & & 0,53 & & $-0,93$ \\
\hline IC $h_{x}^{2}-L S$ & & 0,75 & & 0,79 & & 0,66 & & 0,91 & & 0,57 \\
\hline IC h $h_{x}^{2}(\mathrm{LS}-\mathrm{LI})$ & & 0,99 & & 0,82 & & 1,37 & & 0,38 & & 1,50 \\
\hline $\mathrm{cVg}$ & & 17,74 & & 16,61 & & 12,03 & & 22,72 & & 5,06 \\
\hline $\mathrm{CVg} / \mathrm{CVe}$ & & 0,54 & & 0,66 & & 0,36 & & 1,18 & & 0,17 \\
\hline
\end{tabular}


Tabela 38. Análise de variância das progênies do cruzamento Gaúcha x OC 79230 para o caracter Produtividade de Grãos (gramas / parcela), na geração $\mathrm{F}_{\text {2:n }}$, nas quatro avaliações e análise conjunta.

\begin{tabular}{|c|c|c|c|c|c|c|c|c|c|c|}
\hline & \multicolumn{2}{|c|}{$1992 / 93$} & \multicolumn{2}{|c|}{$1993 / 94$} & \multicolumn{2}{|c|}{$1994 / 95$} & \multicolumn{2}{|c|}{$1995 / 96$} & \multicolumn{2}{|c|}{ Conjunta } \\
\hline F. Variaçăo & $\mathrm{Gl}$ & $\overline{\mathrm{QM}}$ & Gl & $\overline{\mathrm{QM}}$ & $\mathrm{Gl}$ & $\overline{\mathrm{QM}}$ & $\mathrm{Gl}$ & $\mathrm{QM}$ & G1 & QM \\
\hline $\begin{array}{l}\text { Repet. / Anos } \\
\text { Repetiçōes } \\
\text { Progênies (P) } \\
\text { Anos (A) } \\
\text { P x A } \\
\text { Erro }\end{array}$ & $\begin{array}{c}2 \\
19 \\
\\
38\end{array}$ & $\begin{array}{c}30189,07 \\
9701,25^{\text {ns }} \\
6600,58\end{array}$ & $\begin{array}{c}2 \\
19 \\
\\
37\end{array}$ & $\begin{array}{c}88886,61 \\
11717,54^{*} \\
5059,63\end{array}$ & $\begin{array}{c}2 \\
19\end{array}$ & $\begin{array}{r}12977,66 \\
5425,32 \\
2593,95\end{array}$ & $\begin{array}{c}2 \\
19 \\
\\
\\
38\end{array}$ & $\begin{array}{l}1025,91 \\
4693,39\end{array}$ & \begin{tabular}{|c|}
8 \\
\\
19 \\
3 \\
57 \\
149 \\
\end{tabular} & $\begin{array}{r}33269,81 \\
\\
17659,54^{* *} \\
139042,87^{* *} \\
4625,99^{\text {ns }} \\
3979,97\end{array}$ \\
\hline Total & 59 & 8398,71 & 58 & 10131,25 & 57 & 3902,08 & 59 & 2590,37 & 236 & 7947,10 \\
\hline Média & & 296,27 & & 231,80 & & 200,71 & & 188,42 & & 229,53 \\
\hline Desv. Padrão & & 56,87 & & 64,52 & . & 43,69 & & 39,55 & & 36,00 \\
\hline Menor Valor & & 154,67 & & 110,51 & & 118,96 & & 114,08 & & 135,61 \\
\hline Maior Valor & & 378,67 & & 369,23 & & 269,47 & & 264,28 & & 271,44 \\
\hline Amplitude & & 224,00 & & 258,72 & & 150,52 & & 150,20 & & 135,83 \\
\hline $\mathrm{CVe}$ & & 27,42 & & 30,69 & & 25,38 & & 21,37 & & 27,49 \\
\hline$\sigma_{p}^{2}$ & & 1033,56 & & 2258,94 & & 978,11 & & 1024,06 & & 1100,35 \\
\hline IC $\sigma_{\mathrm{p}}^{2}-\mathrm{LI}$ & & 250,41 & & 915,72 & & 542,34 & & 460,58 & & 539,73 \\
\hline IC $\sigma_{p}^{2}-$ LS & & 89144,41 & & 11832,92 & & 6598,63 & & 3876,98 & & 3370,79 \\
\hline IC $\sigma_{\mathrm{p}}^{2}(\mathrm{LS}-\mathrm{LI})$ & & 88894,00 & & 10917,20 & & 6056,29 & & 3416,40 & & 2831,06 \\
\hline$\sigma^{2}$ & & 6600,58 & & 5059,63 & & 2593,95 & & 1621,20 & & 3979,97 \\
\hline$\sigma_{p a}^{2}$ & & & & & & & & & & 218,47 \\
\hline$\sigma_{f}^{2}$ & & 3233,75 & & 3975,58 & & 1874,21 & & 1564,46 & & 1510,32 \\
\hline $\mathrm{h}_{\mathrm{x}}^{2}$ & & 0,32 & & 0,57 & & 0,52 & & 0,66 & & 0,73 \\
\hline IC $h_{x}^{2}-L I$ & & $-0,59$ & & $-0,01$ & & $-0,13$ & & 0,19 & & 0,40 \\
\hline $\mathrm{IC} \mathrm{h}_{\mathrm{x}}^{2}-\mathrm{LS}$ & & 0,68 & & 0,68 & & 0,68 & & 0,68 & & 0,87 \\
\hline IC $h_{x}^{2}$ (LS-LI) & & 1,27 & & 0,69 & & 0,81 & & 0,49 & & 0,47 \\
\hline $\mathrm{cVg}$ & & 10,85 & & 20,50 & & 15,58 & & 16,98 & & 14,45 \\
\hline $\mathrm{CVg} / \mathrm{CVe}$ & & 0,40 & & 0,67 & & 0,61 & & 0,79 & & 0,53 \\
\hline
\end{tabular}


Tabela 39. Análise de variância das progênies do cruzamento Gaúcha x BR 808858 para o caracter Produtividade de Grãos (gramas / parcela), na geração $F_{2: n}$, nas quatro avaliações e análise conjunta.

\begin{tabular}{|c|c|c|c|c|c|c|c|c|c|c|}
\hline & \multicolumn{2}{|c|}{$1992 / 93$} & \multicolumn{2}{|c|}{$1993 / 94$} & \multicolumn{2}{|c|}{$1994 / 95$} & \multicolumn{2}{|c|}{$1995 / 96$} & \multicolumn{2}{|r|}{ Conjunta } \\
\hline F. Variação & Gl & $\overline{Q M}$ & $\mathrm{Gl}$ & $\overline{\mathrm{QM}}$ & Gl & $\overline{\mathrm{QM}}$ & $\mathrm{Gl}$ & $\overline{\mathrm{QM}}$ & $\mathrm{Gl}$ & QM \\
\hline $\begin{array}{l}\text { Repet. / Anos } \\
\text { Repetições } \\
\text { Progênies (P) } \\
\text { Anos (A) } \\
\text { P x A } \\
\text { Erro }\end{array}$ & $\begin{array}{c}2 \\
12\end{array}$ & $\begin{array}{l}23270,15 \\
39823,78^{* *} \\
12510,60\end{array}$ & $\begin{array}{c}2 \\
12\end{array}$ & $\begin{array}{c}1974,16 \\
24435,54^{*} \\
6202,43\end{array}$ & $\begin{array}{c}2 \\
12 \\
\\
24\end{array}$ & $\begin{array}{c}3573,22 \\
15300,59\end{array}$ & $\begin{array}{c}2 \\
12\end{array}$ & $\begin{array}{r}3346,87 \\
7702,85 \\
2528,73\end{array}$ & $\begin{array}{c}8 \\
12 \\
3 \\
36 \\
93 \\
\end{array}$ & $\begin{array}{c}12484,10 \\
\\
51701,97^{* *} \\
1041336,41^{* *} \\
11853,60^{*} \\
6477,25\end{array}$ \\
\hline Total & 38 & 21702,11 & 36 & 13032,56 & 38 & 7849,20 & 37 & 4251,04 & 152 & 13568,55 \\
\hline Média & & 312,00 & & 220,65 & & 232,11 & & 190,10 & & 239,27 \\
\hline Desv. Padrão & & 115,22 & & 92,64 & & 71,42 & & 51,19 & & 66,45 \\
\hline Menor Valor & & 168,67 & & 78,50 & & 97,24 & & 112,17 & & 147,95 \\
\hline Maior Valor & & 500,00 & & 368,03 & & 367,43 & & 257,81 & & 354,17 \\
\hline Amplitude & & 331,33 & & 289,53 & & 270,19 & & 145,65 & & 206,22 \\
\hline $\mathrm{CVe}$ & & 35,85 & & 35,69 & & 28,84 & & 26,45 & & 33,64 \\
\hline$\sigma_{p}^{2}$ & & 9104,39 & & 6435,21 & & 3606,92 & & 1773,99 & & 3388,44 \\
\hline IC $\sigma_{\mathrm{p}}^{2}-\mathrm{LI}$ & & 3645,36 & & 2725,99 & & 1469,00 & & 699,68 & & 1482,44 \\
\hline IC $\sigma_{p}^{2}-L S$ & & 49600,85 & & 28479,33 & & 18018,34 & & 10462,97 & & 14047,25 \\
\hline IC $\sigma_{\mathrm{p}}^{2}(\mathrm{LS}-\mathrm{LI})$ & & 45955,49 & & 25753,34 & & 16549,34 & & 9763,29 & & 12564,81 \\
\hline$\sigma^{2}$ & & 12510,60 & & 6202,43 & & 4479,83 & & 2528,73 & & 6477,25 \\
\hline$\sigma_{\text {pa }}^{2}$ & & & & & & & & & & 1833,16 \\
\hline$\sigma_{f}^{2}$ & & 13274,59 & & 8624,57 & & 5100,20 & & 2640,97 & & 4564,75 \\
\hline$h_{x}^{2}$ & & 0,69 & & 0,75 & & 0,71 & & 0,67 & & 0,74 \\
\hline $\mathrm{IC} \mathrm{h}_{\mathrm{x}}^{2}-\mathrm{LI}$ & & 0,05 & & 0,23 & & 0,12 & & 0,01 & & 0,33 \\
\hline IC $h_{x}^{2}-L S$ & & 0,88 & & 0,88 & & 0,88 & & 0,87 & & 0,86 \\
\hline IC $h_{x}^{2}(L S-L I)$ & & 0,83 & & 0,65 & & 0,76 & & 0,86 & & 0,53 \\
\hline $\mathrm{CVg}$ & & 30,58 & & 36,36 & & 25,88 & & 22,16 & & 24,33 \\
\hline $\mathrm{CVg} / \mathrm{CVe}$ & & 0,85 & & 1,02 & & 0,90 & & 0,84 & & 0,72 \\
\hline
\end{tabular}


Tabela 40. Análise de variância das progênies do cruzamento Gaúcha x PI 123439 para o caracter Produtividade de Grãos (gramas / parcela), na geração $F_{2: n}$, nas quatro avaliações e análise conjunta.

\begin{tabular}{|c|c|c|c|c|c|c|c|c|c|c|}
\hline & \multicolumn{2}{|c|}{$1992 / 93$} & \multicolumn{2}{|c|}{$1993 / 94$} & \multicolumn{2}{|c|}{$1994 / 95$} & \multicolumn{2}{|c|}{$1995 / 96$} & \multicolumn{2}{|c|}{ Conjunta } \\
\hline F. Variação & Gl & $\overline{Q M}$ & Gl & $\overline{\mathrm{QM}}$ & Gl & $\overline{Q M}$ & G1 & $\overline{\mathrm{QM}}$ & $\mathrm{Gl}$ & QM \\
\hline $\begin{array}{l}\text { Repet. / Anos } \\
\text { Repetções } \\
\text { Progênies (P) } \\
\text { Anos (A) } \\
\text { P x A } \\
\text { Erro }\end{array}$ & $\begin{array}{c}2 \\
19 \\
\\
\\
34\end{array}$ & $\begin{array}{c}4966,31 \\
5039,35^{\text {ns }} \\
2699,54\end{array}$ & $\begin{array}{c}2 \\
19 \\
\\
\\
37\end{array}$ & $\begin{array}{r}34942,67 \\
6591,62^{* *} \\
1782,24\end{array}$ & $\begin{array}{c}2 \\
19 \\
\\
\\
36\end{array}$ & $\begin{array}{r}241,74 \\
6165,67 \\
1727,38\end{array}$ & $\begin{array}{c}2 \\
19 \\
\\
35 \\
\end{array}$ & $\begin{array}{l}9852,05 \\
3571,55^{* *} \\
1036,80\end{array}$ & \begin{tabular}{|c|}
8 \\
\\
19 \\
3 \\
57 \\
142
\end{tabular} & $\begin{array}{c}12500,64 \\
\\
9827,70^{* *} \\
28294,91^{* *} \\
3846,83^{* *} \\
1804,23\end{array}$ \\
\hline Total & 55 & 3590,26 & 58 & 4501,19 & 57 & 3154,68 & 56 & 2211,63 & 229 & 3699,07 \\
\hline Média & & 138,25 & & 128,86 & & 105,41 & & 89,19 & & 115,40 \\
\hline Desv. Padrão & & 43,23 & & 46,88 & & 46,31 & & 35,17 & & 29,37 \\
\hline Menor Valor & & 55,33 & & 20,27 & & 43,55 & & 44,78 & & 52,81 \\
\hline Maior Valor & & 215,10 & & 185,07 & & 203,22 & & 163,27 & & 162,19 \\
\hline Amplitude & & 159,77 & & 164,80 & & 159,67 & & 118,49 & & 109,38 \\
\hline $\mathrm{CVe}$ & & 37,58 & & 32,76 & & 39,43 & & 36,10 & & 36,81 \\
\hline$\sigma_{p}^{2}$ & & 840,39 & & 1631,76 & & 1533,23 & & 891,86 & & 518,84 \\
\hline IC $\sigma_{p}^{2}-L I$ & & 289,08 & & 793,48 & & 733,67 & & 422,52 & & 223,40 \\
\hline IC $\sigma_{\mathrm{p}}^{2}-\mathrm{LS}$ & & 8754,26 & & 5163,86 & & 4879,16 & & 2906,83 & & 2241,26 \\
\hline IC $\sigma_{\mathrm{p}}^{2}(\mathrm{LS}-\mathrm{LI})$ & & 8465,18 & & 4370,38 & & 4145,49 & & 2484,31 & & 2017,86 \\
\hline$\sigma^{2}$ & & 2699,54 & & 1782,24 & & 1727,38 & & 1036,80 & & 1804,23 \\
\hline$\sigma_{\text {pa }}^{2}$ & & & & & & & & & & 715,10 \\
\hline$\sigma_{f}^{2}$ & & 1740,24 & & 2236,44 & & 2129,97 & & 1256,66 & & 1212,84 \\
\hline$h_{x}^{2}$ & & 0,48 & & 0,73 & & 0,72 & & 0,71 & & 0,43 \\
\hline $\mathrm{IC} \mathrm{h}_{\mathrm{x}}^{2}-\mathrm{LI}$ & & $-0,27$ & & 0,37 & & 0,34 & & 0,32 & & 0,11 \\
\hline IC $h_{x}^{2}-L S$ & & 0,75 & & 0,87 & & 0,87 & & 0,86 & & 0,80 \\
\hline IC h $h_{\mathrm{x}}^{2}(\mathrm{LS}-\mathrm{LI})$ & & 1,02 & & 0,50 & & 0,53 & & 0,54 & & 0,69 \\
\hline $\mathrm{cVg}$ & & 20,97 & & 31,35 & & 37,15 & & 33,49 & & 19,74 \\
\hline $\mathrm{CVg} / \mathrm{CVe}$ & & 0,56 & & 0,96 & & 0,94 & & 0,93 & & 0,54 \\
\hline
\end{tabular}


Tabela 41. Análise de variância das progênies do cruzamento Gaúcha x PI 165896 para o caracter Produtividade de Grãos (gramas / parcela), na geração $\mathrm{F}_{2: \mathrm{n}}$, nas quatro avaliações e análise conjunta.

\begin{tabular}{|c|c|c|c|c|c|c|c|c|c|c|}
\hline & \multicolumn{2}{|c|}{$1992 / 93$} & \multicolumn{2}{|c|}{$1993 / 94$} & \multicolumn{2}{|c|}{$1994 / 95$} & \multicolumn{2}{|c|}{$1995 / 96$} & \multicolumn{2}{|r|}{ Conjunta } \\
\hline F. Variação & $\mathrm{Gl}$ & $\mathrm{QM}$ & $\mathrm{Gl}$ & $\overline{Q M}$ & $\mathrm{Gl}$ & $\overline{Q M}$ & Gl & $\overline{Q M}$ & Gl & $\overline{Q M}$ \\
\hline $\begin{array}{l}\text { Repet. / Anos } \\
\text { Repetições } \\
\text { Progênies (P) } \\
\text { Anos (A) } \\
\text { P x A } \\
\text { Erro }\end{array}$ & $\begin{array}{c}2 \\
19 \\
\\
36 \\
\end{array}$ & $\begin{array}{c}46654,59 \\
4572,52^{\text {ns }} \\
\\
2565,36\end{array}$ & $\begin{array}{c}2 \\
19 \\
\\
\\
36\end{array}$ & $\begin{array}{c}5176,65 \\
3577,59^{\text {ns }} \\
\\
3264,33\end{array}$ & $\begin{array}{c}2 \\
19 \\
37 \\
37\end{array}$ & $\begin{array}{c}2473,18 \\
2345,36^{\text {ns }} \\
1515,03\end{array}$ & $\begin{array}{c}2 \\
19 \\
37 \\
\end{array}$ & $\begin{array}{c}2439,38 \\
1463,91^{\text {ns }} \\
1124,78\end{array}$ & \begin{tabular}{|c|}
8 \\
19 \\
3 \\
57 \\
146 \\
\end{tabular} & $\begin{array}{c}14185,95 \\
\\
4608,19^{* *} \\
200647,11^{* *} \\
2450,39^{\text {ns }} \\
2106,45\end{array}$ \\
\hline Total & 57 & 4781,40 & 57 & 3435,85 & 58 & 1820,07 & 58 & 1281,21 & 233 & 5365,66 \\
\hline Média & & 240,04 & & 154,33 & & 115,30 & & 115,99 & & 156,07 \\
\hline Desv. Padrão & & 39,92 & & 34,66 & & 28,05 & & 22,41 & & 19,95 \\
\hline Menor Valor & & 179,30 & & 89,87 & & 63,55 & & 75,44 & & 127,04 \\
\hline Maior Valor & & 308,00 & & 208,70 & & 152,65 & & 172,00 & & 191,09 \\
\hline Amplitude & & 128,70 & & 118,83 & & 89,11 & & 96,56 & & 64,04 \\
\hline $\mathrm{CVe}$ & & 21,10 & & 37,02 & & 33,76 & & 28,92 & & 29,41 \\
\hline$\sigma_{p}^{2}$ & & 693,38 & & 108,22 & & 281,72 & & 115,06 & & 184,41 \\
\hline IC $\sigma_{\mathrm{P}}^{2}-\mathrm{LI}$ & & 228,32 & & - & & 74,89 & & 20,23 & & 65,04 \\
\hline IC $\sigma_{p}^{2}-L S$ & & 9129,25 & & - & & 10910,44 & & 600199,74 & & 1656,97 \\
\hline IC $\sigma_{p}^{2}$ (LS-LI) & & 8900,93 & & - & & 10835,55 & & 600179,51 & & 1591,93 \\
\hline$\sigma^{2}$ & & 2565,36 & & 3264,33 & & 1515,03 & & 1124,78 & & 2106,45 \\
\hline$\sigma_{\text {pa }}^{2}$ & & & & & & & & & & 18,01 \\
\hline$\sigma_{f}^{2}$ & & 1579,61 & & 1235,91 & & 795,74 & & 496,68 & & 917,26 \\
\hline$h_{x}^{2}$ & & 0,44 & & 0,09 & & 0,35 & & 0,23 & & 0,20 \\
\hline $\mathrm{IC} \mathrm{h}_{\mathrm{x}}^{2}-\mathrm{LI}$ & & $-0,32$ & & $-1,15$ & & $-0,52$ & & $-0,80$ & & $-0,21$ \\
\hline IC $h_{x}^{2}-L S$ & & 0,74 & & 0,57 & & 0,69 & & 0,64 & & 0,73 \\
\hline IC $h_{x}^{2}$ (LS-LI) & & 1,06 & & 1,72 & & 1,21 & & 1,44 & & 0,94 \\
\hline $\mathrm{CVg}$ & & 10,97 & & 6,74 & & 14,56 & & 9,25 & & 8,70 \\
\hline $\mathrm{CVg} / \mathrm{CVe}$ & & 0,52 & & 0,18 & & 0,43 & & 0,32 & & 0,30 \\
\hline
\end{tabular}


Tabela 42. Análise de variância das progênies do cruzamento Gaúcha x PI 239235 para o caracter Produtividade de Grãos (gramas / parcela), na geração $F_{2: n}$, nas quatro avaliações e análise conjunta.

\begin{tabular}{|c|c|c|c|c|c|c|c|c|c|c|}
\hline & \multicolumn{2}{|r|}{$1992 / 93$} & \multicolumn{2}{|c|}{$1993 / 94$} & \multicolumn{2}{|c|}{$1994 / 95$} & \multicolumn{2}{|c|}{$1995 / 96$} & \multicolumn{2}{|c|}{ Conjunta } \\
\hline F. Variação & $\mathrm{Gl}$ & $\overline{\mathrm{QM}}$ & $\mathrm{Gl}$ & $\overline{\mathrm{QM}}$ & $\mathrm{Gl}$ & $\mathrm{QM}$ & Gl & $\overline{\mathrm{QM}}$ & $\mathrm{Gl}$ & $\overline{Q M}$ \\
\hline $\begin{array}{l}\text { Repet. / Anos } \\
\text { Repetições } \\
\text { Progênies (P) } \\
\text { Anos (A) } \\
\text { P x A } \\
\text { Erro } \\
\end{array}$ & $\begin{array}{c}2 \\
19 \\
\\
37\end{array}$ & $\begin{array}{c}6825,92 \\
7855,09^{\text {ns }} \\
\\
5911,74\end{array}$ & $\begin{array}{c}2 \\
19 \\
\\
37 \\
\end{array}$ & $\begin{array}{c}4594,90 \\
7018,66^{\text {ns }} \\
\\
5698,10\end{array}$ & $\begin{array}{c}2 \\
19\end{array}$ & $\begin{array}{c}7316,17 \\
3820,92^{\text {ns }} \\
2528,17\end{array}$ & $\begin{array}{c}2 \\
19 \\
\\
37\end{array}$ & $\begin{array}{c}690,25 \\
3451,30^{\text {ns }} \\
\\
1846,07\end{array}$ & \begin{tabular}{|c|}
8 \\
19 \\
3 \\
57 \\
149 \\
\end{tabular} & $\begin{array}{c}4856,81 \\
\\
7098,78^{*} \\
198839,68^{* *} \\
5015,73^{\text {ns }} \\
3986,17 \\
\end{array}$ \\
\hline Total & 58 & 6579,88 & 58 & 6092,65 & 59 & 3106,78 & 58 & 2332,07 & 236 & 6991,89 \\
\hline Média & & 272,81 & & 176,53 & & 157,39 & & 145,19 & & 187,85 \\
\hline Desv. Padrão & & 52,93 & & 50,18 & & 35,69 & & 34,01 & & 25,66 \\
\hline Menor Valor & & 210,67 & & 111,13 & & 100,37 & & 82,38 & & 135,30 \\
\hline Maior Valor & & 378,67 & & 276,49 & & 250,43 & & 204,22 & & 235,47 \\
\hline Amplitude & & 168,00 & & 165,35 & & 150,06 & & 121,84 & & 100,17 \\
\hline $\mathrm{CVe}$ & & 28,18 & & 42,76 & & 31,95 & & 29,59 & & 33,61 \\
\hline$\sigma_{p}^{2}$ & & 659,35 & & 448,05 & & 430,92 & & 544,63 & & 175,48 \\
\hline IC $\sigma_{\mathrm{p}}^{2}-\mathrm{LI}$ & & 125,21 & & - & & 110,60 & & 186,94 & & 40,75 \\
\hline IC $\sigma_{p}^{2}-\mathrm{LS}$ & & 1414300,69 & & - & & 23990,94 & & 5328,51 & & 27347,61 \\
\hline IC $\sigma_{\mathrm{p}}^{2}(\mathrm{LS}-\mathrm{LI})$ & & 1414175,48 & & - & & 23880,34 & & 5141,57 & & 27306,86 \\
\hline$\sigma^{2}$ & & 5911,74 & & 5698,10 & & 2528,17 & & 1846,07 & & 3986,17 \\
\hline$\sigma_{\text {pa }}^{2}$ & & & & & & & & & & 348,18 \\
\hline$\sigma_{f}^{2}$ & & 2665,10 & & 2381,31 & & 1273,64 & & 1170,97 & & 629,85 \\
\hline$h_{x}^{2}$ & & 0,25 & & 0,19 & & 0,34 & & 0,47 & & 0,28 \\
\hline $\mathrm{IC} \mathrm{h}_{\mathrm{x}}^{2}-\mathrm{LI}$ & & $-0,77$ & & $-0,91$ & & $-0,55$ & & $-0,26$ & & $-0,61$ \\
\hline $\mathrm{IC} \mathrm{h}_{\mathrm{x}}^{2}-\mathrm{LS}$ & & 0,64 & & 0,62 & & 0,69 & & 0,75 & & 0,64 \\
\hline $\mathrm{IC} \mathrm{h}_{\mathrm{x}}^{2}(\mathrm{LS}-\mathrm{LI})$ & & 1,41 & & 0,81 & & 1,24 & & 1,01 & & 1,25 \\
\hline $\mathrm{CVg}$ & & 9,41 & & 11,99 & & 13,19 & & 16,07 & & 7,05 \\
\hline $\mathrm{CVg} / \mathrm{CVe}$ & & 0,33 & & 0,28 & & 0,41 & & 0,54 & & 0,21 \\
\hline
\end{tabular}


Tabela 43. Análise de variância das progênies do cruzamento La-4910-215 x OC 79230 para o caracter Produtividade de Grãos (gramas / parcela), na geração $F_{2: n}$, nas quatro avaliações e análise conjunta.

\begin{tabular}{|c|c|c|c|c|c|c|c|c|c|c|}
\hline & \multicolumn{2}{|c|}{$1992 / 93$} & \multicolumn{2}{|r|}{$1993 / 94$} & \multicolumn{2}{|c|}{$1994 / 95$} & \multicolumn{2}{|c|}{$1995 / 96$} & \multicolumn{2}{|r|}{ Conjunta } \\
\hline F. Variação & Gl & $\mathrm{QM}$ & $\mathrm{Gl}$ & $\overline{\mathrm{QM}}$ & $\mathrm{Gl}$ & $\overline{\mathrm{QM}}$ & $\mathrm{Gl}$ & $\overline{Q M}$ & $\mathrm{Gl}$ & $\overline{\mathrm{OM}}$ \\
\hline $\begin{array}{l}\text { Repet. / Anos } \\
\text { Repetições } \\
\text { Progenies (P) } \\
\text { Anos (A) } \\
\text { P x A } \\
\text { Erro } \\
\end{array}$ & $\begin{array}{c}2 \\
19\end{array}$ & $\begin{array}{r}33328,87 \\
17255,24^{* *} \\
4875,88 \\
\end{array}$ & $\begin{array}{c}2 \\
19 \\
\\
\\
37\end{array}$ & $\begin{array}{c}17677,73 \\
9598,28^{\text {ns }} \\
7377,98\end{array}$ & $\begin{array}{c}2 \\
19\end{array}$ & $\begin{array}{c}6645,09 \\
3554,20^{\text {ns }} \\
4507,17\end{array}$ & $\begin{array}{c}2 \\
19 \\
\\
38 \\
\end{array}$ & $\begin{array}{l}4824,55 \\
3049,14^{\text {ns }} \\
2815,54\end{array}$ & \begin{tabular}{|c|}
8 \\
19 \\
3 \\
57 \\
150 \\
\end{tabular} & $\begin{array}{c}15619,06 \\
\\
16102,44^{* *} \\
185116,37^{* *} \\
5784,80^{\text {ns }} \\
4880,16\end{array}$ \\
\hline Total & 59 & 9826,96 & 58 & 8460,48 & 58 & 4268,71 & 59 & 2958,87 & 237 & 8641,38 \\
\hline Média & & 297,47 & & 259,44 & & 196,21 & & 177,49 & & 232,69 \\
\hline Desv. Padrão & & 75,84 & & 57,70 & & 34,47 & & 31,88 & & 36,82 \\
\hline Menor Valor & & 157,33 & & 148,30 & & 143,42 & & 91,05 & & 160,09 \\
\hline Maior Valor & & 473,33 & & 343,70 & & 270,81 & & 236,61 & & 289,92 \\
\hline Amplitude & & 316,00 & & 195,40 & & 127,39 & & 145,56 & & 129,83 \\
\hline $\mathrm{CVe}$ & & 23,47 & & 33,11 & & 34,22 & & 29,90 & & 30,02 \\
\hline$\sigma_{\mathrm{p}}^{2}$ & & 4126,45 & & 754,66 & & - & & 77,87 & & 867,34 \\
\hline IC $\sigma_{\mathrm{p}}^{2}-\mathrm{LI}$ & & 2336,22 & & 132,30 & & - & & - & & 386,62 \\
\hline IC $\sigma_{\mathrm{p}}^{2}-\mathrm{LS}$ & & 13306,87 & & 3924341,20 & & - & & - & & 3359,99 \\
\hline IC $\sigma_{\mathrm{p}}^{2}(\mathrm{LS}-\mathrm{LI})$ & & 10970,65 & & 3924208,90 & & - & & - & & 2973,37 \\
\hline$\sigma^{2}$ & & 4875,88 & & 7377,98 & & 4507,17 & & 2815,54 & & 4880,16 \\
\hline$\sigma_{p a}^{2}$ & & & & & & & & & & 304,80 \\
\hline$\sigma_{f}^{2}$ & & 5751,75 & & 3262,39 & & - & & 1016,38 & & 1380,52 \\
\hline$h_{x}^{2}$ & & 0,72 & & 0,23 & & - & & 0,08 & & 0,63 \\
\hline IC $h_{x}^{2}-L I$ & & 0,34 & & $-0,80$ & & $-1,98$ & & $-1,16$ & & 0,18 \\
\hline IC $h_{x}^{2}-L S$ & & 0,87 & & 0,64 & & 0,40 & & 0,56 & & 0,82 \\
\hline IC $h_{x}^{2}$ (LS-LI) & & 0,53 & & 1,44 & & 2,38 & & 1,72 & & 0,64 \\
\hline $\mathrm{CVg}$ & & 21,59 & & 10,59 & & - & & 4,97 & & 12,66 \\
\hline $\mathrm{CVg} / \mathrm{CVe}$ & & 0,92 & & 0,32 & & - & & 0,17 & & 0,42 \\
\hline
\end{tabular}


Tabela 44. Análise de variância das progênies do cruzamento La-4910-215 x BR 80-8858 para o caracter Produtividade de Grãos (gramas / parcela), na geração $F_{2: n}$, nas quatro avaliações e análise conjunta.

\begin{tabular}{|c|c|c|c|c|c|c|c|c|c|c|}
\hline & \multicolumn{2}{|c|}{$1992 / 93$} & \multicolumn{2}{|c|}{$1993 / 94$} & \multicolumn{2}{|c|}{$1994 / 95$} & \multicolumn{2}{|c|}{$1995 / 96$} & \multicolumn{2}{|c|}{ Conjunta } \\
\hline F. Variação & Gl & $\overline{\mathrm{QM}}$ & $\mathrm{Gl}$ & $\overline{Q M}$ & $\mathrm{Gl}$ & $\overline{Q M}$ & $\mathrm{Gl}$ & $\mathrm{QM}$ & G1 & $\overline{Q M}$ \\
\hline $\begin{array}{l}\text { Repet. / Anos } \\
\text { Repetições } \\
\text { Progênies (P) } \\
\text { Anos (A) } \\
\text { P x A } \\
\text { Erro } \\
\end{array}$ & \begin{tabular}{c|}
2 \\
19 \\
37 \\
\end{tabular} & $\begin{array}{c}16964,98 \\
12080,19^{* *} \\
4788,68 \\
\end{array}$ & $\begin{array}{c}2 \\
19\end{array}$ & $\begin{array}{r}11650,46 \\
9389,33^{*} \\
\\
4524,35\end{array}$ & $\begin{array}{c}2 \\
19 \\
\\
\\
35\end{array}$ & $\begin{array}{r}23309,57 \\
7862,78^{*} \\
\\
3504,73\end{array}$ & $\begin{array}{c}2 \\
19 \\
\\
\\
38\end{array}$ & $\begin{array}{l}6847,28 \\
4913,60\end{array}$ & \begin{tabular}{|c|}
8 \\
19 \\
3 \\
57 \\
148 \\
\end{tabular} & $\begin{array}{c}14693,08 \\
\\
21444,08^{* *} \\
209802,96^{* *} \\
4267,27^{\text {ns }} \\
3522,87\end{array}$ \\
\hline Total & 58 & 7597,15 & 59 & 6332,60 & 56 & 5690,67 & 59 & 2665,35 & 235 & 8166,00 \\
\hline Média & & 291,05 & & 233,83 & & 159,53 & & 175,94 & & 215,47 \\
\hline Desv. Padrão & & 63,61 & & 55,94 & & 53,27 & & 40,47 & & 42,48 \\
\hline Menor Valor & & 127,33 & & 119,60 & & 59,72 & & 89,39 & & 112,76 \\
\hline Maior Valor & & 384,00 & & 385,67 & & 266,89 & & 261,52 & & 324,52 \\
\hline Amplitude & & 256,67 & & 266,07 & & 207,18 & & 172,13 & & 211,76 \\
\hline $\mathrm{CVe}$ & & 23,78 & & 28,77 & & 37,11 & & 20,54 & & 27,55 \\
\hline$\sigma_{p}^{2}$ & & 2473,91 & & 1621,66 & & 1533,39 & & 1202,66 & & 1456,55 \\
\hline $\mathrm{IC} \sigma_{\mathrm{p}}^{2}-\mathrm{LI}$ & & 1050,78 & & 609,15 & & 606,34 & & 585,12 & & 750,96 \\
\hline $\mathrm{IC} \sigma_{\mathrm{p}}^{2}-\mathrm{LS}$ & & 11211,66 & & 10827,90 & & 8526,60 & & 3729,05 & & 3979,49 \\
\hline $\mathrm{IC} \sigma_{\mathrm{p}}^{2}(\mathrm{LS}-\mathrm{LI})$ & & 10160,88 & & 10218,75 & & 7920,26 & & 3143,93 & & 3228,53 \\
\hline$\sigma^{2}$ & & 4788,68 & & 4524,35 & & 3504,73 & & 1305,61 & & 3522,87 \\
\hline$\sigma_{\mathrm{pa}}^{2}$ & & & & & & & & & & 252,98 \\
\hline$\sigma_{1}^{2}$ & & 4098,62 & & 3129,78 & & 2766,54 & & 1637,87 & & 1841,35 \\
\hline$h_{x}^{2}$ & & 0,60 & & 0,52 & & 0,55 & & 0,73 & & 0,79 \\
\hline $\mathrm{IC} \mathrm{h}_{\mathrm{x}}^{2}-\mathrm{LI}$ & & 0,07 & & $-0,13$ & & $-0,05$ & & 0,38 & & 0,55 \\
\hline $\mathrm{IC} h_{\mathrm{x}}^{2}-\mathrm{LS}$ & & 0,81 & & 0,77 & & 0,79 & & 0,87 & & 0,90 \\
\hline $\mathrm{ICh}_{\mathrm{x}}^{2}(\mathrm{LS}-\mathrm{LI})$ & & 0,74 & & 0,90 & & 0,84 & & 0,49 & & 0,35 \\
\hline $\mathrm{CVg}$ & & 17,09 & & 17,22 & & 24,55 & & 19,71 & & 17,71 \\
\hline $\mathrm{CVg} / \mathrm{CVe}$ & & 0,72 & & 0,60 & & 0,66 & & 0,96 & & 0,64 \\
\hline
\end{tabular}


Tabela 45. Análise de variância das progênies do cruzamento La-4910-215 x BR 80-14853 para o caracter Produtividade de Grãos (gramas / parcela), na geração $F_{2: n}$, nas quatro avaliações e análise conjunta.

\begin{tabular}{|c|c|c|c|c|c|c|c|c|c|c|}
\hline & \multicolumn{2}{|c|}{$1992 / 93$} & \multicolumn{2}{|c|}{$1993 / 94$} & \multicolumn{2}{|c|}{$1994 / 95$} & \multicolumn{2}{|c|}{$1995 / 96$} & \multicolumn{2}{|c|}{ Conjunta } \\
\hline F. Variação & $\overline{\mathrm{Gl}}$ & $\overline{\mathrm{QM}}$ & $\mathrm{Gl}$ & $\overline{\mathrm{QM}}$ & $\mathrm{Gl}$ & $\overline{\mathrm{QM}}$ & Gl & $\overline{\mathrm{QM}}$ & $\mathrm{Gl}$ & $\overline{Q M}$ \\
\hline $\begin{array}{l}\text { Repet. / Anos } \\
\text { Repetições } \\
\text { Progênies (P) } \\
\text { Anos (A) } \\
\text { P x A } \\
\text { Erro }\end{array}$ & $\begin{array}{c}2 \\
19 \\
\\
38\end{array}$ & $\begin{array}{c}2391,80 \\
11876,61^{*} \\
5500,15\end{array}$ & $\begin{array}{c}2 \\
19 \\
\\
\\
36\end{array}$ & $\begin{array}{c}16350,70 \\
9488,26^{\text {ns }} \\
6830,52\end{array}$ & $\begin{array}{c}2 \\
19 \\
\\
38 \\
\end{array}$ & $\begin{array}{c}28065,52 \\
6042,98 * \\
3146,88\end{array}$ & $\begin{array}{c}2 \\
19 \\
\\
\\
38\end{array}$ & 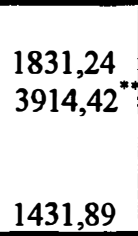 & \begin{tabular}{|c|}
8 \\
19 \\
3 \\
57 \\
150 \\
\end{tabular} & $\begin{array}{c}12159,82 \\
\\
23186,43^{* *} \\
257921,83^{* *} \\
2711,95^{\text {ns }} \\
4192,65\end{array}$ \\
\hline Total & 59 & 7448,22 & 57 & 8050,47 & 59 & 4924,22 & 59 & 2244,89 & 237 & 8839,94 \\
\hline Média & & 280,50 & & 236,49 & & 139,07 & & 161,49 & & 204,12 \\
\hline Desv. Padrão & & 62,92 & & 57,06 & & 44,88 & & 36,12 & & 44,16 \\
\hline Menor Valor & & 162,00 & & 142,57 & & 66,01 & & 103,10 & & 142,01 \\
\hline Maior Valor & & 408,00 & & 378,53 & & 255,36 & & 248,07 & & 311,03 \\
\hline Amplitude & & 246,00 & & 235,97 & & 189,36 & & 144,98 & & 169,02 \\
\hline $\mathrm{CVe}$ & & 26,44 & & 34,95 & & 40,34 & & 23,43 & & 31,72 \\
\hline$\sigma_{p}^{2}$ & & 2125,49 & & 918,13 & & 965,37 & & 827,51 & & 1721,71 \\
\hline $\mathrm{IC} \sigma_{\mathrm{p}}^{2}-\mathrm{LI}$ & & 829,98 & & 193,66 & & 343,68 & & 363,19 & & 937,70 \\
\hline $\mathrm{IC} \sigma_{\mathrm{p}}^{2}-\mathrm{LS}$ & & 13247,69 & & 302744,50 & & 8755,92 & & 3320,44 & & 4182,64 \\
\hline IC $\sigma_{\mathrm{p}}^{2}(\mathrm{LS}-\mathrm{LI})$ & & 12417,71 & & 302550,84 & & 8412,24 & & 2957,25 & & 3244,94 \\
\hline$\sigma^{2}$ & & 5500,15 & & 6830,52 & & 3146,88 & & 1431,89 & & 4192,56 \\
\hline$\sigma_{\mathrm{pa}}^{2}$ & & & & & & & & & & - \\
\hline$\sigma_{f}^{2}$ & & 3958,87 & & 3277,79 & & 2014,33 & & 1304,81 & & 3132,36 \\
\hline$h_{x}^{2}$ & & 0,54 & & 0,28 & & 0,48 & & 0,63 & & 0,55 \\
\hline $\mathrm{IC} \mathrm{h} \mathrm{h}_{\mathrm{x}}^{2} \mathrm{LI}$ & & $-0,08$ & & $-0,69$ & & $-0,22$ & & 0,14 & & 0,73 \\
\hline $\mathrm{IC} \mathrm{h}-\mathrm{LS}$ & & 0,78 & & 0,66 & & 0,75 & & 0,83 & & 0,94 \\
\hline IC $h_{x}^{2}$ (LS-LI) & & 0,86 & & 1,35 & & 0,97 & & 0,69 & & 0,21 \\
\hline $\mathrm{CVg}$ & & 16,44 & & 12,81 & & 22,34 & & 17,81 & & 20,33 \\
\hline $\mathrm{CVg} / \mathrm{CVe}$ & & 0,62 & & 0,37 & & 0,55 & & 0,76 & & 0,64 \\
\hline
\end{tabular}


Tabela 46. Análise de variância das progênies do cruzamento La-4910-215 x PI 123439 para o caracter Produtividade de Grãos (gramas / parcela), na geração $F_{2: n}$, nas quatro avaliações e análise conjunta.

\begin{tabular}{|c|c|c|c|c|c|c|c|c|c|c|}
\hline & \multicolumn{2}{|c|}{$1992 / 93$} & \multicolumn{2}{|c|}{$1993 / 94$} & \multicolumn{2}{|c|}{$1994 / 95$} & \multicolumn{2}{|c|}{$1995 / 96$} & \multicolumn{2}{|c|}{ Conjunta } \\
\hline F. Variação & $\mathrm{Gl}$ & $\overline{\mathrm{QM}}$ & $\mathrm{Gl}$ & $\overline{\mathrm{QM}}$ & $\mathrm{Gl}$ & $\overline{Q M}$ & $\mathrm{Gl}$ & $\overline{\mathrm{QM}}$ & $\mathrm{Gl}$ & $\overline{\mathrm{QM}}$ \\
\hline $\begin{array}{l}\text { Repet. / Anos } \\
\text { Repetições } \\
\text { Progênies (P) } \\
\text { Anos (A) } \\
\text { P x A } \\
\text { Erro } \\
\end{array}$ & $\begin{array}{c}2 \\
19\end{array}$ & $\begin{array}{r}12851,47 \\
9640,21^{* *} \\
2601,29\end{array}$ & $\begin{array}{c}2 \\
19\end{array}$ & $\begin{array}{r}18368,38 \\
7418,03^{* *} \\
2801,56\end{array}$ & $\begin{array}{c}2 \\
19 \\
\\
36\end{array}$ & $\begin{array}{l}2433,76 \\
4762,84^{\text {ns }} \\
2940,19\end{array}$ & $\begin{array}{c}2 \\
19 \\
\\
\\
38\end{array}$ & $\begin{array}{c}21,81 \\
3884,99^{* *} \\
1376,96\end{array}$ & \begin{tabular}{c|}
8 \\
19 \\
3 \\
57 \\
150 \\
\end{tabular} & $\begin{array}{c}8418,85 \\
14018,71^{* *} \\
62059,35^{* *} \\
3895,79{ }^{* *} \\
2423,20\end{array}$ \\
\hline Total & 59 & 5215,52 & 59 & 4815,91 & 57 & 3529,97 & 59 & 2138,69 & 237 & 4664,23 \\
\hline Média & & 151,03 & & 177,63 & & 115,70 & & 108,30 & & 138,35 \\
\hline Desv. Padrão & & 56,69 & & 49,73 & & 40,26 & & 35,99 & & 34,26 \\
\hline Menor Valor & & 80,00 & & 72,17 & & 65,56 & & 53,22 & & 77,68 \\
\hline Maior Valor & & 285,33 & & 272,93 & & 230,54 & & 192,62 & & 241,52 \\
\hline Amplitude & & 205,33 & & 200,77 & & 164,98 & & 139,40 & & 163,84 \\
\hline $\mathrm{CVe}$ & & 33,77 & & 29,80 & & 46,87 & & 34,27 & & 35,58 \\
\hline$\sigma_{\mathrm{p}}^{2}$ & & 2346,31 & & 1538,82 & & 629,64 & & 836,01 & & 805,64 \\
\hline IC $\sigma_{\mathrm{p}}^{2}-\mathrm{LI}$ & & 1135,65 & & 666,51 & & 182,44 & & 371,23 & & 388,14 \\
\hline $\mathrm{IC} \sigma_{\mathrm{p}}^{2}-\mathrm{LS}$ & & 7313,12 & & 6433,97 & & 16612,58 & & 3226,30 & & 2525,97 \\
\hline IC $\sigma_{\mathrm{p}}^{2}(\mathrm{LS}-\mathrm{LI})$ & & 6177,47 & & 5767,46 & & 16430,14 & & 2855,07 & & 2137,83 \\
\hline$\sigma^{2}$ & & 2601,29 & & 2801,56 & & 2940,19 & & 1376,96 & & 2423,20 \\
\hline$\sigma_{\mathrm{pa}}^{2}$ & & & & & & & & & & 495,61 \\
\hline$\sigma_{f}^{2}$ & & 3213,40 & & 2472,68 & & 1645,36 & & 1295,00 & & 1707,84 \\
\hline $\mathrm{h}_{\mathrm{x}}^{2}$ & & 0,73 & & 0,62 & & 0,38 & & 0,65 & & 0,50 \\
\hline $\mathrm{IC} \mathrm{h}_{\mathrm{x}}^{2}-\mathrm{LI}$ & & 0,37 & & 0,12 & & $-0,45$ & & 0,17 & & 0,37 \\
\hline $\mathrm{IC} \mathrm{h}_{\mathrm{x}}^{2}-\mathrm{LS}$ & & 0,87 & & 0,82 & & 0,71 & & 0,83 & & 0,86 \\
\hline IC $h_{x}^{2}$ (LS-LI) & & 0,50 & & 0,70 & & 1,16 & & 0,66 & & 0,49 \\
\hline $\mathrm{CVg}$ & & 32,07 & & 22,08 & & 21,69 & & 26,70 & & 21,08 \\
\hline $\mathrm{CVg} / \mathrm{CVe}$ & & 0,95 & & 0,74 & & 0,46 & & 0,78 & & 0,59 \\
\hline
\end{tabular}


Tabela 47. Análise de variância das progênies do cruzamento La-4910-215 x PI 239235 para o caracter Produtividade de Grãos (gramas / parcela), na geração $F_{2: n}$, nas quatro avaliações e análise conjunta.

\begin{tabular}{|c|c|c|c|c|c|c|c|c|c|c|}
\hline & \multicolumn{2}{|c|}{$1992 / 93$} & \multicolumn{2}{|c|}{$1993 / 94$} & \multicolumn{2}{|c|}{$1994 / 95$} & \multicolumn{2}{|c|}{$1995 / 96$} & \multicolumn{2}{|c|}{ Conjunta } \\
\hline F. Variação & $\mathrm{Gl}$ & $\mathrm{QM}$ & $\overline{\mathrm{Gl}}$ & $\mathrm{QM}$ & $\mathrm{Gl}$ & $\overline{Q M}$ & Gl & $\mathrm{QM}$ & $\mathrm{Gl}$ & QM \\
\hline $\begin{array}{l}\text { Repet. / Anos } \\
\text { Repetições } \\
\text { Progênies (P) } \\
\text { Anos (A) } \\
\text { P x A } \\
\text { Erro } \\
\end{array}$ & $\begin{array}{c}2 \\
19\end{array}$ & $\begin{array}{c}1740,07 \\
6102,30^{\text {ns }} \\
\\
3650,73 \\
\end{array}$ & $\begin{array}{c}2 \\
19 \\
\\
37 \\
\end{array}$ & $\begin{array}{r}22539,96 \\
6895,84^{\text {ns }} \\
6878,22 \\
\end{array}$ & $\begin{array}{c}2 \\
19 \\
\\
36\end{array}$ & $\begin{array}{l}3800,45 \\
7582,13 \\
\\
2276,78\end{array}$ & $\begin{array}{c}2 \\
19 \\
\\
38 \\
\end{array}$ & $\begin{array}{c}16240,47 \\
2781,58^{*} \\
1266,11\end{array}$ & \begin{tabular}{|c|}
8 \\
\\
19 \\
3 \\
57 \\
149 \\
\end{tabular} & $\begin{array}{c}11080,24 \\
10034,43^{* *} \\
152932,16^{* *} \\
4442,47^{\text {ns }} \\
3512,07\end{array}$ \\
\hline Total & 59 & 4375,45 & 58 & 7424,05 & 57 & 4098,69 & 59 & 2261,74 & 236 & 6417,84 \\
\hline Média & & 254,73 & & 186,18 & & 144,87 & & 149,96 & & 184,26 \\
\hline Desv. Padrão & & 45,10 & & 48,23 & & 52,96 & & 30,45 & & 29,58 \\
\hline Menor Valor & & 160,00 & & 106,40 & & 31,52 & & 85,81 & & 118,64 \\
\hline Maior Valor & & 313,33 & & 277,43 & & 224,55 & & 210,55 & & 223,22 \\
\hline Amplitude & & 153,33 & & 171,03 & & 193,03 & & 124,74 & & 104,59 \\
\hline $\mathrm{CVe}$ & & 23,72 & & 44,55 & & 32,94 & & 23,73 & & 32,16 \\
\hline$\sigma_{p}^{2}$ & & 817,19 & & 5,98 & & 1832,76 & & 505,16 & & 471,90 \\
\hline $\mathrm{IC} \sigma_{\mathrm{p}}^{2}-\mathrm{LI}$ & & 247,52 & & - & & 862,22 & & 198,63 & & 191,50 \\
\hline $\mathrm{IC} \sigma_{\mathrm{p}}^{2}-\mathrm{LS}$ & & 15650,11 & & - & & 6148,16 & & 2969,34 & & 2543,08 \\
\hline IC $\sigma_{p}^{2}(\mathrm{LS}-\mathrm{LI})$ & & 15402,59 & & - & & 5285,94 & & 2770,71 & & 2351,58 \\
\hline$\sigma^{2}$ & & 3650,73 & & 6878,22 & & 2276,78 & & 1266,11 & & 3512,07 \\
\hline$\sigma_{\text {pa }}^{2}$ & & & & & & & & & & 314,58 \\
\hline$\sigma_{f}^{2}$ & & 2034,10 & & 2339,63 & & 2619,29 & & 927,19 & & 874,84 \\
\hline $\mathrm{h}_{\mathrm{x}}^{2}$ & & 0,40 & & 0,00 & & 0,70 & & 0,55 & & 0,54 \\
\hline $\mathrm{IC} \mathrm{h}_{\mathrm{x}}^{2}-\mathrm{LI}$ & & $-0,40$ & & $-1,34$ & & 0,29 & & $-0,07$ & & $-0,01$ \\
\hline $\mathrm{ICh}_{\mathrm{x}}^{2}-\mathrm{LS}$ & & 0,72 & & 0,53 & & 0,86 & & 0,78 & & 0,78 \\
\hline IC $h_{x}^{2}($ LS-LI $)$ & & 1,12 & & 1,87 & & 0,57 & & 0,85 & & 0,79 \\
\hline $\mathrm{CVg}$ & & 11,22 & & 1,31 & & 29,55 & & 14,99 & & 11,79 \\
\hline $\mathrm{CVg} / \mathrm{CVe}$ & & 0,47 & & 0,03 & & 0,90 & & 0,63 & & 0,37 \\
\hline
\end{tabular}


Tabela 48. Análise de variância das progênies do cruzamento OC 79230 x BR 8014853 para o caracter Produtividade de Grãos (gramas / parcela), na geração $F_{2: n}$, nas quatro avaliações e análise conjunta.

\begin{tabular}{|l|c|c|c|c|c|c|c|c|c|c|}
\hline & \multicolumn{2}{|c|}{$1992 / 93$} & \multicolumn{2}{|c|}{$1993 / 94$} & \multicolumn{2}{|c|}{$1994 / 95$} & \multicolumn{2}{|c|}{$1995 / 96$} & \multicolumn{2}{c|}{ Conjunta } \\
\hline F. Variação & GI & QM & Gl & QM & Gl & QM & Gl & QM & Gl & QM \\
\hline Repet. / Anos & \multirow{2}{*}{} & & & & & & & & 8 & 32815,82 \\
Repetições & 2 & 67742,78 & 2 & 38011,82 & 2 & 13420,62 & 2 & 12088,05 & & \\
Progênies (P) & 19 & $11025,25^{* *}$ & 19 & 13677,49 & 19 & 8172,46 & 19 & $4457,58^{\text {ns }}$ & 19 & $22794,56^{* *}$ \\
Anos (A) & & & & & & & & & 3 & $171366,06^{* *}$ \\
Px A & & & & & & & & & 57 & $4846,07^{\text {ns }}$ \\
Erro & 37 & 2805,65 & 34 & 6961,34 & 38 & 4266,14 & 38 & 2691,28 & 147 & 4114,80 \\
\hline Total & 58 & 7737,49 & 55 & 10410,57 & 59 & 5834,43 & 59 & 3578,62 & 234 & 8935,14 \\
\hline
\end{tabular}

\begin{tabular}{|c|c|c|c|c|c|}
\hline Média & . $\quad 296,41$ & 249,39 & 177,94 & 195,75 & 229,26 \\
\hline Desv. Padrão & 60,59 & 70,38 & 52,19 & 38,55 & 44,34 \\
\hline Menor Valor & 150,00 & 145,43 & 75,66 & 107,92 & 129,42 \\
\hline Maior Valor & 409,33 & 394,23 & 280,28 & 258,26 & 307,72 \\
\hline Amplitude & 259,33 & 248,80 & 204,62 & 150,34 & 178,30 \\
\hline $\mathrm{CVe}$ & 17,87 & 33,46 & 36,71 & 26,50 & 27,98 \\
\hline$\sigma_{p}^{2}$ & 2793,78 & 2407,68 & 1302,11 & 588,77 & 1529,25 \\
\hline IC $\sigma_{p}^{2}-L I$ & 1374,61 & 864,67 & 460,86 & 177,01 & 779,34 \\
\hline IC $\sigma_{p}^{2}-L S$ & 8500,52 & 19890,42 & 11740,56 & 12523,18 & 4225,59 \\
\hline IC $\sigma_{\mathrm{p}}^{2}(\mathrm{LS}-\mathrm{LI})$ & 7125,91 & 19025,75 & 11279,70 & 12346,17 & 3446,25 \\
\hline$\sigma^{2}$ & 2805,65 & 6961,34 & 4266,14 & 2691,28 & 4114,80 \\
\hline$\sigma_{\text {pa }}^{2}$ & & & & & 250,02 \\
\hline$\sigma_{f}^{2}$ & 3747,40 & 4003,23 & 2724,15 & 1485,86 & 1965,46 \\
\hline$h_{x}^{2}$ & 0,75 & 0,49 & 0,48 & 0,40 & 0,78 \\
\hline IC $h_{x}^{2}-L I$ & 0,40 & $-0,20$ & $-0,22$ & $-0,41$ & 0,52 \\
\hline $\mathrm{IC} \mathrm{h}_{\mathrm{x}}^{2}-\mathrm{LS}$ & 0,88 & 0,76 & 0,75 & 0,71 & 0,89 \\
\hline $\mathrm{IC} \mathrm{h}_{\mathrm{x}}^{2}(\mathrm{LS}-\mathrm{LI})$ & 0,48 & 0,96 & 0,97 & 1,12 & 0,37 \\
\hline $\mathrm{CVg}$ & 17,83 & 19,67 & 20,28 & 12,40 & 17,06 \\
\hline $\mathrm{CVg} / \mathrm{CVe}$ & 1,00 & 0,59 & 0,55 & 0,47 & 0,61 \\
\hline
\end{tabular}


Tabela 49. Análise de variância das progênies do cruzamento OC 79230 x PI 123439 para o caracter Produtividade de Grãos (gramas / parcela), na geração $\mathrm{F}_{2: n}$, nas quatro avaliações e análise conjunta.

\begin{tabular}{|c|c|c|c|c|c|c|c|c|c|c|}
\hline & \multicolumn{2}{|c|}{$1992 / 93$} & \multicolumn{2}{|c|}{$1993 / 94$} & \multicolumn{2}{|c|}{$1994 / 95$} & \multicolumn{2}{|c|}{$1995 / 96$} & \multicolumn{2}{|c|}{ Conjunta } \\
\hline F. Variação & $\mathrm{Gl}$ & $\overline{Q M}$ & $\mathrm{Gl}$ & $\overline{\mathrm{QM}}$ & $\mathrm{Gl}$ & $\overline{\mathrm{QM}}$ & Gl & $\overline{Q M}$ & $\mathrm{Gl}$ & $\overline{\mathrm{QM}}$ \\
\hline $\begin{array}{l}\text { Repet. / Anos } \\
\text { Repetições } \\
\text { Progênies (P) } \\
\text { Anos (A) } \\
\text { P x A } \\
\text { Erro }\end{array}$ & $\begin{array}{c}2 \\
19 \\
38 \\
\end{array}$ & $\begin{array}{c}29883,47 \\
10971,55^{* *} \\
2013,01 \\
\end{array}$ & $\begin{array}{c}2 \\
19\end{array}$ & $\begin{array}{c}1417,62 \\
5026,23\end{array}$ * & $\begin{array}{c}2 \\
19\end{array}$ & $\begin{array}{r}2077,02 \\
7974,78 \\
\\
3487,39\end{array}$ & $\begin{array}{c}2 \\
19 \\
\\
\\
38\end{array}$ & $\begin{array}{l}5733,51 \\
4308,85^{* 1} \\
1691,69\end{array}$ & $\begin{array}{c}8 \\
\\
19 \\
3 \\
57 \\
148\end{array}$ & $\begin{array}{c}9777,90 \\
18972,94^{* *} \\
84057,29^{* *} \\
3102,82^{\text {ns }} \\
2437,74 \\
\end{array}$ \\
\hline Total & 59 & 5842,72 & 55 & 3378,54 & 59 & 4884,68 & 59 & 2671,52 & 235 & 5227,78 \\
\hline Média & & 207,77 & & 191,36 & & 166,04 & & 121,60 & & 171,36 \\
\hline Desv. Padrão & & 60,48 & & 42,88 & & 51,56 & & 37,90 & & 40,12 \\
\hline Menor Valor & & 84,00 & & 111,77 & & 72,57 & & 58,91 & & 94,66 \\
\hline Maior Valor & & 316,00 & & 250,47 & & 227,14 & & 200,43 & & 235,70 \\
\hline Amplitude & & 232,00 & & 138,70 & & 154,57 & & 141,52 & & 141,04 \\
\hline $\mathrm{CVe}$ & & 21,60 & & 26,51 & & 35,57 & & 33,82 & & 28,81 \\
\hline$\sigma_{\mathrm{p}}^{2}$ & & 2986,18 & & 879,42 & & 1495,80 & & 872,39 & & 1345,76 \\
\hline $\mathrm{IC} \sigma_{\mathrm{p}}^{2}-\mathrm{LI}$ & & 1547,59 & & 316,49 & & 601,77 & & 372,62 & & 708,90 \\
\hline$I C \sigma_{p}^{2}-L S$ & & 7907,99 & & 7652,47 & & 7991,32 & & 3892,84 & & 3455,45 \\
\hline $\mathrm{ICO}_{\mathrm{p}}^{2}(\mathrm{LS}-\mathrm{LI})$ & & 6360,40 & & 7335,98 & & 7389,55 & & 3520,22 & & 2746,55 \\
\hline$\sigma^{2}$ & & 2013,01 & & 2573,12 & & 3487,39 & & 1691,69 & & 2437,94 \\
\hline$\sigma_{\mathrm{pa}}^{2}$ & & & & & & & & & & 226,02 \\
\hline$\sigma_{f}^{2}$ & & 3657,18 & & 1801,85 & & 2658,26 & & 1436,28 & & 1629,35 \\
\hline$h_{x}^{2}$ & & 0,82 & & 0,49 & & 0,56 & & 0,61 & & 0,83 \\
\hline $\mathrm{ICh}_{\mathrm{x}}^{2}-\mathrm{LI}$ & & 0,57 & & $-0,21$ & & $-0,02$ & & 0,08 & & 0,63 \\
\hline $\mathrm{ICh}_{\mathrm{x}}^{2}-\mathrm{LS}$ & & 0,91 & & 0,76 & & 0,79 & & 0,81 & & 0,92 \\
\hline $\mathrm{ICh}_{\mathrm{x}}^{2}(\mathrm{LS}-\mathrm{LI})$ & & 0,34 & & 0,97 & & 0,81 & & 0,73 & & 0,29 \\
\hline $\mathrm{cVg}$ & & 26,30 & & 15,50 & & 23,29 & & 24,29 & & 21,41 \\
\hline $\mathrm{CVg} / \mathrm{CVe}$ & & 1,22 & & 0,58 & & 0,65 & & 0,72 & & 0,74 \\
\hline
\end{tabular}


Tabela 50. Análise de variância das progênies do cruzamento OC 79230 x PI 165896 para o caracter Produtividade de Grãos (gramas / parcela), na geração $F_{2: n}$, nas quatro avaliações e análise conjunta.

\begin{tabular}{|c|c|c|c|c|c|c|c|c|c|c|}
\hline & \multicolumn{2}{|c|}{$1992 / 93$} & \multicolumn{2}{|c|}{$1993 / 94$} & \multicolumn{2}{|c|}{$1994 / 95$} & \multicolumn{2}{|c|}{$1995 / 96$} & \multicolumn{2}{|r|}{ Conjunta } \\
\hline F. Variação & $\mathrm{Gl}$ & $\overline{\mathrm{QM}}$ & $\mathrm{Gl}$ & $\overline{\mathrm{QM}}$ & Gl & $\overline{\mathrm{QM}}$ & GI & $\overline{\mathrm{QM}}$ & Gl & $\overline{\mathrm{QM}}$ \\
\hline $\begin{array}{l}\text { Repet. / Anos } \\
\text { Repetições } \\
\text { Progênies (P) } \\
\text { Anos (A) } \\
\text { P x A } \\
\text { Erro }\end{array}$ & $\begin{array}{c}2 \\
19\end{array}$ & $\begin{array}{c}23654,80 \\
12467,75^{* *} \\
4613,81\end{array}$ & $\begin{array}{c}2 \\
19 \\
\\
37\end{array}$ & $\begin{array}{c}44904,60 \\
11881,38^{* *} \\
4186,69\end{array}$ & $\begin{array}{c}2 \\
19 \\
\\
36\end{array}$ & $\begin{array}{r}13045,97 \\
6599,94^{\text {ns }} \\
4508,37\end{array}$ & $\begin{array}{c}2 \\
19 \\
\\
\\
37\end{array}$ & $\begin{array}{l}7361,66 \\
5406,23\end{array}$ & \begin{tabular}{|c|}
8 \\
19 \\
3 \\
57 \\
146 \\
\end{tabular} & $\begin{array}{c}22241,76 \\
\\
25336,01^{* *} \\
133740,07^{* *} \\
3673,10^{\text {ns }} \\
3659,77\end{array}$ \\
\hline Total & 57 & 7899,90 & 58 & 8111,43 & 57 & 5505,12 & 58 & 2904,52 & 233 & 7743,48 \\
\hline Média & & 242,41 & & 183,05 & & 166,12 & & 127,34 & & 179,52 \\
\hline Desv. Padrão & & 65,82 & & 63,04 & & 47,58 & & 42,60 & & 46,47 \\
\hline Menor Valor & & 95,33 & & 60,93 & & 88,91 & & 75,02 & & 105,44 \\
\hline Maior Valor & & 368,67 & & 305,13 & & 236,41 & & 245,78 & & 255,99 \\
\hline Amplitude & & 273,33 & & 244,20 & & 147,50 & & 170,76 & & 150,55 \\
\hline $\mathrm{CVe}$ & & 28,02 & & 35,35 & & 40,42 & & 29,16 & & 33,70 \\
\hline$\sigma_{p}^{2}$ & & 2713,18 & & 2610,70 & & 722,54 & & 1366,41 & & 1854,02 \\
\hline IC $\sigma_{\mathrm{p}}^{2}-\mathrm{LI}$ & & 1191,40 & & 1165,65 & & 176,28 & & 671,15 & & 989,56 \\
\hline $\mathrm{IC} \sigma_{\mathrm{p}}^{2}-\mathrm{LS}$ & & 12289,41 & & 10130,35 & & 84385,10 & & 4150,34 & & 4646,71 \\
\hline IC $\sigma_{\mathrm{p}}^{2}(\mathrm{LS}-\mathrm{LI})$ & & 11098,23 & & 8964,70 & & 84208,82 & & 3479,19 & & 3657,15 \\
\hline$\sigma^{2}$ & & 4613,81 & & 4186,69 & & 4508,37 & & 1378,93 & & 3659,77 \\
\hline$\sigma_{\text {pa }}^{2}$ & & & & & & & & & & 4,57 \\
\hline$\sigma_{f}^{2}$ & & 4307,06 & & 4031,17 & & 2280,00 & & 1834,25 & & 3110,38 \\
\hline $\mathrm{h}_{\mathrm{x}}^{2}$ & & 0,63 & & 0,65 & & 0,32 & & 0,71 & & 0,60 \\
\hline IC $h_{x}^{2}-L I$ & & 0,13 & & 0,17 & & $-0,61$ & & 0,40 & & 0,67 \\
\hline IC $h_{x}^{2}-L S$ & & 0,83 & & 0,83 & & 0,68 & & 0,88 & & 0,93 \\
\hline $\mathrm{IC} \mathrm{h}_{\mathrm{x}}^{2}(\mathrm{LS}-\mathrm{LI})$ & & 0,70 & & 0,66 & & 1,29 & & 0,48 & & 0,26 \\
\hline $\mathrm{CVg}$ & & 21,49 & & 27,91 & & 16,18 & & 29,03 & & 23,99 \\
\hline $\mathrm{CVg} / \mathrm{CVe}$ & & 0,77 & & 0,79 & & 0,40 & & 1,00 & & 0,71 \\
\hline
\end{tabular}


Tabela 51. Análise de variância das progênies do cruzamento OC 79230 x PI 239235 para o caracter Produtividade de Grãos (gramas / parcela), na geração $F_{2: n}$, nas quatro avaliações e análise conjunta.

\begin{tabular}{|c|c|c|c|c|c|c|c|c|c|c|}
\hline & \multicolumn{2}{|c|}{$1992 / 93$} & \multicolumn{2}{|c|}{$1993 / 94$} & \multicolumn{2}{|c|}{$1994 / 95$} & \multicolumn{2}{|c|}{$1995 / 96$} & \multicolumn{2}{|c|}{ Conjunta } \\
\hline F. Variacão & $\mathrm{Gl}$ & $\mathrm{QM}$ & Gl & $\mathrm{QM}$ & $\mathrm{Gl}$ & $\mathrm{QM}$ & $\mathrm{Gl}$ & $\overline{\mathrm{QM}}$ & Gl & $\overline{\mathrm{QM}}$ \\
\hline $\begin{array}{l}\text { Repet. / Anos } \\
\text { Repetições } \\
\text { Progênies (P) } \\
\text { Anos (A) } \\
\text { P x A } \\
\text { Erro } \\
\end{array}$ & $\begin{array}{c}2 \\
19\end{array}$ & $\begin{array}{c}6005,07 \\
6735,34^{\text {ns }} \\
4354,19\end{array}$ & $\begin{array}{c}2 \\
19\end{array}$ & $\begin{array}{r}20532,83 \\
10516,51 \\
5390,95\end{array}$ & $\begin{array}{c}2 \\
19\end{array}$ & $\begin{array}{l}5180,78 \\
8326,36\end{array}$ & $\begin{array}{c}2 \\
18 \\
\\
\\
34 \\
\end{array}$ & $\begin{array}{l}6612,26 \\
4563,35^{*} \\
2090,17\end{array}$ & $\begin{array}{c}8 \\
19 \\
3 \\
56 \\
147\end{array}$ & $\begin{array}{r}9582,73 \\
\\
16799,99^{* *} \\
164862,51^{* *} \\
4445,12^{\text {ns }} \\
3635,18\end{array}$ \\
\hline Total & 59 & 5176,96 & 59 & 7554,84 & 58 & 4509,54 & 54 & 3082,05 & 233 & 7183,47 \\
\hline Média & & 296,77 & & 215,46 & & 206,37 & & 171,05 & & 223,58 \\
\hline Desv. Padrão & & 52,25 & & 59,21 & & 53,75 & & 40,34 & & 38,60 \\
\hline Menor Valor & & 190,67 & & 130,87 & & 108,43 & & 111,94 & & 154,25 \\
\hline Maior Valor & & 395,33 & & 352,53 & & 305,55 & & 247,78 & & 304,75 \\
\hline Amplitude & & 204,67 & & 121,67 & & 197,12 & & 135,84 & & 150,51 \\
\hline $\mathrm{CVe}$ & & 22,24 & & 34,08 & & 24,29 & & 26,73 & & 26,97 \\
\hline$\sigma_{p}^{2}$ & & 793,72 & & 1708,52 & & 1972,30 & & 856,10 & & 1057,05 \\
\hline IC $\sigma_{\mathrm{p}}^{2}-\mathrm{LI}$ & & 217,57 & & 611,63 & & 931,74 & & 325,87 & & 517,98 \\
\hline IC $\sigma_{p}^{2}-L S$ & & 38277,94 & & 14069,52 & & 6726,60 & & 5384,36 & & 3267,64 \\
\hline IC $\sigma_{\mathrm{p}}^{2}(\mathrm{LS}-\mathrm{LI})$ & & 38060,37 & & 13457,89 & & 5794,86 & & 5058,49 & & 2749,66 \\
\hline$\sigma^{2}$ & & 4354,19 & & 5390,95 & & 2513,26 & & 2090,17 & & 3635,18 \\
\hline$\sigma_{\mathrm{pa}}^{2}$ & & & & & & & & & & 273,98 \\
\hline$\sigma_{f}^{2}$ & & 2245,11 & & 3505,50 & & 2825,01 & & 1579,62 & & 1460,85 \\
\hline$h_{x}^{2}$ & & 0,35 & & 0,49 & & 0,70 & & 0,54 & & 0,72 \\
\hline IC $h_{x}^{2}-L I$ & & $-0,51$ & & $-0,20$ & & 0,29 & & $-0,11$ & & 0,40 \\
\hline IC $h_{x}^{2}-L S$ & & 0,69 & & 0,76 & & 0,86 & & 0,79 & & 0,87 \\
\hline IC $h_{x}^{2}(\mathrm{LS}-\mathrm{LI})$ & & 1,20 & & 0,96 & & 0,57 & & 0,90 & & 0,47 \\
\hline $\mathrm{CVg}$ & & 9,49 & & 19,18 & & 21,52 & & 17,11 & & 14,54 \\
\hline $\mathrm{CVg} / \mathrm{CVe}$ & & 0,43 & & 0,56 & & 0,89 & & 0,64 & & 0,54 \\
\hline
\end{tabular}


Tabela 52. Análise de variância das progênies do cruzamento BR 80-8858 x BR 80-14853 para o caracter Produtividade de Grãos (gramas / parcela), na geração $F_{2: n}$, nas quatro avaliações e análise conjunta.

\begin{tabular}{|c|c|c|c|c|c|c|c|c|c|c|}
\hline & \multicolumn{2}{|c|}{$1992 / 93$} & \multicolumn{2}{|c|}{$1993 / 94$} & \multicolumn{2}{|c|}{$1994 / 95$} & \multicolumn{2}{|c|}{$1995 / 96$} & \multicolumn{2}{|c|}{ Conjunta } \\
\hline F. Variação & $\mathrm{Gl}$ & $\mathrm{QM}$ & $\mathrm{Gl}$ & $\overline{Q M}$ & $\mathrm{Gl}$ & $\mathrm{QM}$ & Gl & $\overline{\mathrm{QM}}$ & Gl & $\overline{\mathrm{QM}}$ \\
\hline $\begin{array}{l}\text { Repet. / Anos } \\
\text { Repetições } \\
\text { Progênies (P) } \\
\text { Anos (A) } \\
\text { P x A } \\
\text { Erro }\end{array}$ & $\begin{array}{c}2 \\
19\end{array}$ & $\begin{array}{c}4318,07 \\
17062,24^{* *} \\
6530,56\end{array}$ & $\begin{array}{c}2 \\
19\end{array}$ & $\begin{array}{c}13308,71 \\
18713,00^{*} \\
7519,70\end{array}$ & $\begin{array}{c}2 \\
19 \\
\\
36\end{array}$ & $\begin{array}{l}4706,83 \\
6178,46^{*} \\
2717,12\end{array}$ & $\begin{array}{c}2 \\
19 \\
\\
38 \\
\end{array}$ & $\begin{array}{l}2363,24 \\
2169,32^{\text {ns }} \\
2285,05\end{array}$ & \begin{tabular}{|c|}
8 \\
19 \\
3 \\
57 \\
149 \\
\end{tabular} & $\begin{array}{c}6174,21 \\
\\
21112,42^{* *} \\
411010,51^{* *} \\
7670,20^{* *} \\
4772,07\end{array}$ \\
\hline Total & 59 & 9847,12 & 58 & 11386,09 & 57 & 3940,72 & 59 & 2250,43 & 236 & 11999,16 \\
\hline Média & & 378,63 & & 263,53 & & 213,30 & & 193,78 & & 262,72 \\
\hline Desv. Padrão & & 75,42 & & 79,13 & & 47,27 & & 26,89 & & 42,09 \\
\hline Menor Valor & & 257,33 & & 138,90 & & 116,05 & & 145,46 & & 209,14 \\
\hline Maior Valor & & 574,00 & & 384,93 & & 301,80 & & 233,46 & & 351,12 \\
\hline Amplitude & & 316,67 & & 246,03 & & 185,75 & & 88,00 & & 141,98 \\
\hline $\mathrm{CVe}$ & & 21,34 & & 32,91 & & 24,44 & & 24,67 & & 26,29 \\
\hline$\sigma_{p}^{2}$ & & 3510,56 & & 3797,73 & & 1195,74 & & - & & 1133,93 \\
\hline $\mathrm{IC} \sigma_{\mathrm{p}}^{2}-\mathrm{LI}$ & & 1522,87 & & 1597,51 & & 479,74 & & - & & 503,18 \\
\hline $\mathrm{IC} \sigma_{\mathrm{p}}^{2}-\mathrm{LS}$ & & 15277,98 & & 17418,15 & & 6552,76 & & - & & 4445,75 \\
\hline IC $\sigma_{p}^{2}(L S-L I)$ & & 13755,11 & & 15820,64 & & 6073,02 & & - & & 3942,57 \\
\hline$\sigma^{2}$ & & 6530,56 & & 7519,70 & & 2717,12 & & 2285,05 & & 4772,07 \\
\hline$\sigma_{\mathrm{pa}}^{2}$ & & & & & & & & & & 980,12 \\
\hline$\sigma_{f}^{2}$ & & 5687,41 & & 6349,03 & & 2134,39 & & - & & 1868,38 \\
\hline$h_{x}^{2}$ & & 0,62 & & 0,60 & & 0,56 & & - & & 0,61 \\
\hline $\mathrm{IC} \mathrm{h}_{\mathrm{x}}^{2}-\mathrm{LI}$ & & 0,10 & & 0,06 & & $-0,03$ & & $-1,47$ & & 0,17 \\
\hline $\mathrm{IC} \mathrm{h}_{\mathrm{x}}^{2}-\mathrm{LS}$ & & 0,82 & & 0,81 & & 0,79 & & 0,50 & & 0,82 \\
\hline IC h ${ }_{x}^{2}$ (LS-LI) & & 0,72 & & 0,75 & & 0,82 & & 1,97 & & 0,65 \\
\hline $\mathrm{CVg}$ & & 15,65 & & 23,39 & & 16,21 & & - & & 12,82 \\
\hline $\mathrm{CVg} / \mathrm{CVe}$ & & 0,73 & & 0,71 & & 0,66 & & - & & 0,49 \\
\hline
\end{tabular}


Tabela 53. Análise de variância das progênies do cruzamento BR 80-8858 x PI 123439 para o caracter Produtividade de Grãos (gramas / parcela), na geração $\mathrm{F}_{2: \mathrm{n}}$, nas quatro avaliações e análise conjunta.

\begin{tabular}{|c|c|c|c|c|c|c|c|c|c|c|}
\hline & \multicolumn{2}{|c|}{$1992 / 93$} & \multicolumn{2}{|c|}{$1993 / 94$} & \multicolumn{2}{|c|}{$1994 / 95$} & \multicolumn{2}{|c|}{$1995 / 96$} & \multicolumn{2}{|c|}{ Conjunta } \\
\hline F. Variação & $\mathrm{Gl}$ & $\overline{Q M}$ & $\mathrm{Gl}$ & $\overline{\mathrm{QM}}$ & $\mathrm{Gl}$ & $\overline{\mathrm{QM}}$ & $\mathrm{Gl}$ & $\overline{\mathrm{QM}}$ & $\mathrm{Gl}$ & $\overline{Q M}$ \\
\hline \begin{tabular}{|l|} 
Repet. / Anos \\
Repetições \\
Progênies (P) \\
Anos (A) \\
P x A \\
Erro
\end{tabular} & $\begin{array}{c}2 \\
19\end{array}$ & $\begin{array}{l}30252,30 \\
21793,17^{* *} \\
2829,49\end{array}$ & $\begin{array}{c}2 \\
19 \\
\\
\\
36\end{array}$ & $\begin{array}{c}8636,60 \\
13382,61^{*} \\
4538,03\end{array}$ & $\begin{array}{c}2 \\
19 \\
\\
36\end{array}$ & $\begin{array}{l}2660,42 \\
5316,05^{* *} \\
1869,33\end{array}$ & $\begin{array}{c}2 \\
19 \\
\\
\\
38\end{array}$ & $\begin{array}{c}7463,86 \\
7136,87^{* *} \\
900,81\end{array}$ & \begin{tabular}{|c|}
8 \\
19 \\
3 \\
57 \\
147 \\
\end{tabular} & $\begin{array}{c}12252,05 \\
31721,21^{* *} \\
95724,25^{* *} \\
5302,49^{* *} \\
2514,20\end{array}$ \\
\hline Total & 58 & 9987,35 & 57 & 7629,85 & 57 & 3045,99 & 59 & 3131,51 & 234 & 7092,83 \\
\hline Média & & 209,39 & & 154,20 & & 128,51 & & 120,16 & & 153,03 \\
\hline Desv. Padrão & & 85,24 & & 67,19 & & 45,49 & & 48,78 & & 52,13 \\
\hline Menor Valor & & 63,33 & & 46,43 & & 15,53 & & 47,29 & & 47,36 \\
\hline Maior Valor & & 387,33 & & 332,33 & & 204,12 & & 241,25 & & 278,79 \\
\hline Amplitude & & 324,00 & & 285,90 & & 188,59 & & 193,96 & & 231,43 \\
\hline $\mathrm{CVe}$ & & 25,40 & & 43,69 & & 33,64 & & 24,98 & & 32,77 \\
\hline$\sigma_{p}^{2}$ & & 6434,11 & & 3055,40 & & 1190,28 & & 2078,69 & & 2248,98 \\
\hline $\mathrm{IC} \sigma_{\mathrm{p}}^{2}-\mathrm{LI}$ & & 3458,97 & & 1387,27 & & 532,08 & & 1121,78 & & 1180,54 \\
\hline IC $\sigma_{\mathrm{p}}^{2}-\mathrm{LS}$ & & 15775,18 & & 11498,67 & & 4624,20 & & 5087,26 & & 5791,89 \\
\hline IC $\sigma_{\mathrm{p}}^{2}(\mathrm{LS}-\mathrm{LI})$ & & 12316,21 & & 10111,40 & & 4092,12 & & 3965,48 & & 4611,35 \\
\hline$\sigma^{2}$ & & 2829,49 & & 4538,03 & & 1869,33 & & 900,81 & & 2514,20 \\
\hline$\sigma_{\mathrm{pa}}^{2}$ & & & & & & & & & & 952,21 \\
\hline$\sigma_{f}^{2}$ & & 7394,10 & & 4623,10 & & 1836,46 & & 2378,96 & & 2788,38 \\
\hline$h_{x}^{2}$ & & 0,87 & & 0,66 & & 0,65 & & 0,87 & & 0,81 \\
\hline IC $h_{x}^{2}-L I$ & & 0,70 & & 0,20 & & 0,17 & & 0,70 & & 0,62 \\
\hline IC $h_{x}^{2}-L S$ & & 0,94 & & 0,84 & & 0,83 & & 0,94 & & 0,92 \\
\hline IC h $h_{x}^{2}($ LS-LI $)$ & & 0,24 & & 0,64 & & 0,66 & & 0,24 & & 0,30 \\
\hline $\mathrm{CVg}$ & & 38,40 & & 35,85 & & 26,85 & & 37,94 & & 30,99 \\
\hline $\mathrm{CVg} / \mathrm{CVe}$ & & 1,51 & & 0,82 & & 0,80 & & 1,52 & & 0,95 \\
\hline
\end{tabular}


Tabela 54. Análise de variância das progênies do cruzamento BR 80-8858 x PI 165896 para o caracter Produtividade de Grãos (gramas / parcela), na geração $F_{2: n}$, nas quatro avaliações e análise conjunta.

\begin{tabular}{|c|c|c|c|c|c|c|c|c|c|c|}
\hline & \multicolumn{2}{|r|}{$1992 / 93$} & \multicolumn{2}{|c|}{$1993 / 94$} & \multicolumn{2}{|c|}{$1994 / 95$} & \multicolumn{2}{|c|}{$1995 / 96$} & \multicolumn{2}{|c|}{ Conjunta } \\
\hline F. Variação & $\mathrm{Gl}$ & $\mathrm{QM}$ & Gl & $\overline{\mathrm{QM}}$ & $\mathrm{Gl}$ & $\overline{\mathrm{QM}}$ & GI & $\mathrm{QM}$ & Gl & $\overline{\mathrm{QM}}$ \\
\hline $\begin{array}{l}\text { Repet. / Anos } \\
\text { Repetições } \\
\text { Progênies (P) } \\
\text { Anos (A) } \\
\text { P x A } \\
\text { Erro }\end{array}$ & $\begin{array}{c}2 \\
19\end{array}$ & $\begin{array}{c}5445,80 \\
8432,91^{\text {ns }} \\
\\
6669,52\end{array}$ & $\begin{array}{c}2 \\
19 \\
\\
36\end{array}$ & $\begin{array}{r}11944,40 \\
9654,48 \\
5018,89\end{array}$ & $\begin{array}{c}2 \\
19 \\
\\
37\end{array}$ & $\begin{array}{c}972,42 \\
5104,80^{\text {ns }} \\
\\
3477,56\end{array}$ & $\begin{array}{c}2 \\
19 \\
\\
38\end{array}$ & $\begin{array}{l}4376,69 \\
4056,41^{*} \\
1229,40\end{array}$ & \begin{tabular}{c|}
8 \\
19 \\
3 \\
57 \\
149
\end{tabular} & $\begin{array}{c}5684,83 \\
\\
13801,23^{* *} \\
415396,71^{* *} \\
4482,45^{\text {ns }} \\
4090,66\end{array}$ \\
\hline Total & 59 & 7195,91 & 57 & 6807,08 & 58 & 3924,24 & 59 & 2246,48 & 236 & 10249,58 \\
\hline Média & & 310,70 & & 190,51 & & 149,77 & & 121,77 & & 193,39 \\
\hline Desv. Padrão & & 53,02 & & 57,16 & & 42,25 & & 36,77 & & 34,26 \\
\hline Menor Valor & & 236,00 & & 70,87 & & 81,32 & & 77,69 & & 141,55 \\
\hline Maior Valor & & 468,00 & & 329,83 & & 232,75 & & 200,58 & & 286,51 \\
\hline Amplitude & & 232,00 & & 258,97 & & 151,43 & & 122,89 & & 144,96 \\
\hline $\mathrm{CVe}$ & & 26,29 & & 37,19 & & 39,38 & & 28,79 & & 33,02 \\
\hline$\sigma_{\mathrm{p}}^{2}$ & & 587,80 & & 1601,39 & & 552,10 & & 942,34 & & 786,76 \\
\hline IC $\sigma_{\mathrm{p}}^{2}-\mathrm{LI}$ & & 97,88 & & 568,73 & & 132,32 & & 443,97 & & 363,07 \\
\hline IC $\sigma_{\mathrm{p}}^{2}-\mathrm{LS}$ & & 7199861,69 & & 14488,68 & & 47088,11 & & 3205,18 & & 2760,92 \\
\hline IC $\sigma_{\mathrm{p}}^{2}(\mathrm{LS}-\mathrm{L} \mathrm{I})$ & & 7199763,81 & & 13919,95 & & 46955,79 & & 2761,21 & & 2397,85 \\
\hline$\sigma^{2}$ & & 6669,52 & & 5018,89 & & 3477,56 & & 1229,40 & & 4090,66 \\
\hline$\sigma_{\mathrm{pa}}^{2}$ & & & & & & & & & & 132,50 \\
\hline$\sigma_{f}^{2}$ & & 2810,97 & & 3335,21 & & 1731,97 & & 1352,14 & & 1177,01 \\
\hline$h_{x}^{2}$ & & 0,21 & & 0,48 & & 0,32 & & 0,70 & & 0,67 \\
\hline IC $h_{x}^{2}-L I$ & & $-0,85$ & & $-0,22$ & & $-0,60$ & & 0,29 & & 0,26 \\
\hline IC $h_{x}^{2}-L S$ & & 0,62 & & 0,76 & & 0,68 & & 0,86 & & 0,84 \\
\hline IC $h_{\mathrm{x}}^{2}$ (LS-LI) & & 1,47 & & 0,98 & & 1,28 & & 0,57 & & 0,58 \\
\hline $\mathrm{CVg}$ & & 7,80 & & 21,01 & & 15,69 & & 25,21 & & 14,50 \\
\hline $\mathrm{CVg} / \mathrm{CVe}$ & & 0,30 & & 0,56 & & 0,40 & & 0,88 & & 0,44 \\
\hline
\end{tabular}


Tabela 55. Análise de variância das progênies do cruzamento BR 80-8858 x PI 239235 para o caracter Produtividade de Grãos (gramas / parcela), na geração $F_{2: n}$, nas quatro avaliações e análise conjunta.

\begin{tabular}{|c|c|c|c|c|c|c|c|c|c|c|}
\hline & \multicolumn{2}{|c|}{$1992 / 93$} & \multicolumn{2}{|c|}{$1993 / 94$} & \multicolumn{2}{|c|}{$1994 / 95$} & \multicolumn{2}{|c|}{$1995 / 96$} & \multicolumn{2}{|c|}{ Conjunta } \\
\hline F. Variação & Gl & $\overline{\mathrm{QM}}$ & $\mathrm{Gl}$ & QM & $\mathrm{Gl}$ & $\overline{\mathrm{QM}}$ & GI & $\overline{\mathrm{QM}}$ & $\mathrm{Gl}$ & $\overline{\mathrm{QM}}$ \\
\hline $\begin{array}{l}\text { Repet. / Anos } \\
\text { Repetições } \\
\text { Progênies (P) } \\
\text { Anos (A) } \\
\text { P x A } \\
\text { Erro }\end{array}$ & $\begin{array}{c}2 \\
19 \\
\\
\\
38\end{array}$ & $\begin{array}{r}28876,87 \\
6399,85^{\text {n }} \\
5329,29\end{array}$ & $\begin{array}{c}1 \\
19 \\
\\
18\end{array}$ & $\begin{array}{l}1922,76 \\
4521,03^{\mathrm{n}} \\
7294,91\end{array}$ & $\begin{array}{c}2 \\
19\end{array}$ & $\begin{array}{c}28443,16 \\
4754,09^{n s} \\
3345,80\end{array}$ & $\begin{array}{c}2 \\
19 \\
\\
36\end{array}$ & $\begin{array}{l}1409,00 \\
2641,83^{n} \\
3426,24\end{array}$ & \begin{tabular}{|c|}
7 \\
19 \\
3 \\
57 \\
129 \\
\end{tabular} & $\begin{array}{c}17034,40 \\
4619,54^{\text {ns }} \\
286408,90^{* *} \\
4565,75^{\text {ns }} \\
4503,57\end{array}$ \\
\hline Total & 59 & 6472,27 & 38 & 5766,59 & 58 & 4672,56 & 57 & 3093,99 & 215 & 8872,50 \\
\hline Média & & 314,07 & & 229,55 & & 175,82 & & 159,88 & & 219,64 \\
\hline Desv. Padrão & & 46,19 & & 48,41 & & 39,84 & & 29,97 & & 21,12 \\
\hline Menor Valor & & 221,33 & & 151,00 & & 91,21 & & 85,25 & & 180,47 \\
\hline Maior Valor & & 387,33 & & 316,35 & & 278,88 & & 205,57 & & 253,88 \\
\hline Amplitude & & 166,00 & & 165,35 & & 187,67 & & 120,32 & & 73,42 \\
\hline $\mathrm{CVe}$ & & 23,24 & & 37,21 & & 32,90 & & 36,61 & & 30,55 \\
\hline$\sigma_{p}^{2}$ & & 356,85 & & - & & 477,81 & & - & & 4,74 \\
\hline $\mathrm{IC} \sigma_{\mathrm{p}}^{2}-\mathrm{LI}$ & & - & & - & & 109,52 & & - & & - \\
\hline $\mathrm{IC} \sigma_{\mathrm{p}-\mathrm{LS}}^{2}$ & & - & & - & & 108564,19 & & - & & - \\
\hline IC $\sigma_{\mathrm{p}}^{2}(\mathrm{LS}-\mathrm{LI})$ & & - & & - & & 108454,67 & & - & & - \\
\hline$\sigma^{2}$ & & 5329,29 & & 7294,91 & & 3345,80 & & 3426,24 & & 4503,57 \\
\hline$\sigma_{p a}^{2}$ & & & & & & & & & & 23,30 \\
\hline$\sigma_{\mathrm{f}}^{2}$ & & 2133,28 & & - & & 1612,98 & & - & & 1694,32 \\
\hline$h_{x}^{2}$ & & 0,17 & & - & & 0,30 & & - & & 0,00 \\
\hline $\mathrm{IC} \mathrm{h} \mathrm{h}_{\mathrm{x}}^{2}-\mathrm{LI}$ & & $-0,95$ & & $-3,11$ & & $-0,65$ & & $-2,05$ & & $-1,25$ \\
\hline IC $h_{x}^{2}-L S$ & & 0,60 & & 0,37 & & 0,67 & & 0,39 & & 0,50 \\
\hline IC $h_{x}^{2}(\mathrm{LS}-\mathrm{LI})$ & & 1,55 & & 3,48 & & 1,32 & & 2,44 & & 1,75 \\
\hline $\mathrm{CVg}$ & & 6,02 & & - & & 12,43 & & - & & 0,99 \\
\hline $\mathrm{CVg} / \mathrm{CVe}$ & & 0,26 & & - & & 0,38 & & - & & 0,03 \\
\hline
\end{tabular}


Tabela 56. Análise de variância das progênies do cruzamento BR 80-14853 x PI 123439 para o caracter Produtividade de Grãos (gramas / parcela), na geração $F_{2: n}$, nas quatro avaliações e análise conjunta.

\begin{tabular}{|c|c|c|c|c|c|c|c|c|c|c|}
\hline & \multicolumn{2}{|c|}{$1992 / 93$} & \multicolumn{2}{|c|}{$1993 / 94$} & \multicolumn{2}{|c|}{$1994 / 95$} & \multicolumn{2}{|c|}{$1995 / 96$} & \multicolumn{2}{|c|}{ Conjunta } \\
\hline F. Variação & $\mathrm{Gl}$ & $\mathrm{QM}$ & Gl & $\mathrm{QM}$ & Gl & $\mathrm{QM}$ & Gl & $\mathrm{QM}$ & Gl & $\mathrm{QM}$ \\
\hline $\begin{array}{l}\text { Repet. / Anos } \\
\text { Repetições } \\
\text { Progênies (P) } \\
\text { Anos (A) } \\
\text { P x A } \\
\text { Erro }\end{array}$ & $\begin{array}{c}2 \\
19\end{array}$ & $\begin{array}{c}26421,80 \\
12437,51^{* *} \\
2075,34 \\
\end{array}$ & $\begin{array}{c}2 \\
19 \\
\\
36 \\
\end{array}$ & $\begin{array}{c}82432,55 \\
8927,13^{\text {ns }} \\
5164,66 \\
\end{array}$ & $\begin{array}{c}2 \\
19 \\
\\
\\
37\end{array}$ & $\begin{array}{r}3354,87 \\
10014,65^{* *} \\
2451,50\end{array}$ & $\begin{array}{c}2 \\
19 \\
\\
\\
38\end{array}$ & $\begin{array}{c}8480,57 \\
5993,34^{* *} \\
1027,05\end{array}$ & \begin{tabular}{|c|}
8 \\
19 \\
3 \\
57 \\
149 \\
\end{tabular} & $\begin{array}{c}30172,45 \\
20554,82^{* *} \\
97407,93^{* *} \\
5605,94^{* *} \\
2647,81 \\
\end{array}$ \\
\hline Total & 59 & 6237,62 & 57 & 9129,97 & 58 & 4960,23 & 59 & 2879,03 & 236 & 6941,56 \\
\hline Média & & 208,90 & & 176,10 & & 140,11 & & 117,10 & & 160,51 \\
\hline Desv. Padrão & & 64,39 & & 54,63 & & 57,78 & & 44,70 & & 41,23 \\
\hline Menor Valor & & 57,33 & & 78,63 & & 22,13 & & 57,70 & & 56,45 \\
\hline Maior Valor & & 292,67 & & 287,83 & & 262,23 & & 180,17 & & 243,06 \\
\hline Amplitude & & 235,34 & & 209,20 & & 240,11 & & 122,46 & & 186,61 \\
\hline $\mathrm{CVe}$ & & 21,81 & & 40,81 & & 35,34 & & 27,37 & & 32,06 \\
\hline$\sigma_{p}^{2}$ & & 3454,06 & & 1299,76 & & 2566,07 & & 1655,43 & & 1261,14 \\
\hline IC $\sigma_{p}^{2}-L I$ & & 1816,31 & & 406,96 & & 1272,55 & & 870,27 & & 612,45 \\
\hline IC $\sigma_{p}^{2}-L S$ & & 8969,83 & & 19199,40 & & 7644,83 & & 4355,75 & & 3943,80 \\
\hline IC $\sigma_{p}^{2}(\mathrm{LS}-\mathrm{LI})$ & & 7153,52 & & 18792,44 & & 6372,28 & & 3485,48 & & 3331,35 \\
\hline$\sigma^{2}$ & & 2075,34 & & 5164,66 & & 2451,50 & & 1027,05 & & 2647,81 \\
\hline$\sigma_{\mathrm{pa}}^{2}$ & & & & & & & & & & 1000,42 \\
\hline$\sigma_{f}^{2}$ & & 4145,84 & & 3083,94 & & 3397,82 & & 1997,78 & & 1823,06 \\
\hline$h_{x}^{2}$ & & 0,83 & & 0,42 & & 0,76 & & 0,83 & & 0,69 \\
\hline $\mathrm{IC} \mathrm{h}_{\mathrm{x}}^{2}-\mathrm{LI}$ & & 0,61 & & $-0,36$ & & 0,43 & & 0,60 & & 0,38 \\
\hline IC $h_{x}^{2}-L S$ & & 0,92 & & 0,73 & & 0,88 & & 0,92 & & 0,86 \\
\hline IC $h_{x}^{2}(\mathrm{LS}-\mathrm{LI})$ & & 0,31 & & 1,09 & & 0,45 & & 0,32 & & 0,48 \\
\hline $\mathrm{CVg}$ & & 28,13 & & 20,47 & & 36,16 & & 34,75 & & 22,13 \\
\hline $\mathrm{CVg} / \mathrm{CVe}$ & & 1,29 & & 0,50 & & 1,02 & & 1,27 & & 0,69 \\
\hline
\end{tabular}


Tabela 57. Análise de variância das progênies do cruzamento BR 80-14853 x PI 165896 para o caracter Produtividade de Grãos (gramas / parcela), na geração $F_{2: n}$, nas quatro avaliações e análise conjunta.

\begin{tabular}{|c|c|c|c|c|c|c|c|c|c|c|}
\hline & \multicolumn{2}{|c|}{$1992 / 93$} & \multicolumn{2}{|c|}{$1993 / 94$} & \multicolumn{2}{|c|}{$1994 / 95$} & \multicolumn{2}{|c|}{$1995 / 96$} & \multicolumn{2}{|c|}{ Conjunta } \\
\hline F. Variação & $\mathrm{Gl}$ & QM & G1 & $\mathrm{QM}$ & Gl & $\overline{\mathrm{QM}}$ & $\mathrm{Gl}$ & $\mathrm{QM}$ & $\mathrm{Gl}$ & $Q M$ \\
\hline $\begin{array}{l}\text { Repet. / Anos } \\
\text { Repetições } \\
\text { Progênies (P) } \\
\text { Anos (A) } \\
\text { P x A } \\
\text { Eño }\end{array}$ & $\begin{array}{c}2 \\
19\end{array}$ & $\begin{array}{r}15072,87 \\
7260,75 \\
3259,74\end{array}$ & $\begin{array}{c}2 \\
19 \\
\\
37\end{array}$ & $\begin{array}{r}15152,33 \\
5804,75^{*} \\
2766,60\end{array}$ & $\begin{array}{c}2 \\
19 \\
\\
\\
37\end{array}$ & $\begin{array}{l}7004,00 \\
4303,25^{*} \\
1973,15\end{array}$ & $\begin{array}{c}2 \\
19 \\
\\
38\end{array}$ & $\begin{array}{c}126,70 \\
5010,07 \\
\\
971,58\end{array}$ & $\begin{array}{c}19 \\
3 \\
57 \\
150\end{array}$ & $\begin{array}{r}9563,48 \\
\\
10216,27^{* *} \\
184943,57^{* *} \\
4054,18^{* * *} \\
2241,07\end{array}$ \\
\hline Total & 59 & 4948,65 & 58 & 4188,95 & 58 & 2940,90 & 59 & 2243.47 & 237 & 5876,36 \\
\hline Média & & 230,17 & & 164,84 & & 107,51 & & 119,15 & & 155,58 \\
\hline Desv. Padrão & & 49,20 & & 45,64 & & 37,89 & & 40,87 & & 29,51 \\
\hline Menor Valor & & 156,67 & & 73,20 & & 33,29 & & 62,48 & & 109,81 \\
\hline Maior Valor & & 366,00 & & 249,10 & & 178,56 & & 209,03 & & 202,10 \\
\hline Amplitude & & 209,33 & & 175,90 & & 145,27 & & 146,55 & & 92,30 \\
\hline $\mathrm{CVe}$ & & 24,81 & & 31,91 & & 41,32 & & 26,16 & & 30,43 \\
\hline$\sigma_{p}^{2}$ & & 1333,67 & & 1030,80 & & 790,57 & & 1346,16 & & 517,56 \\
\hline IC $\sigma_{\mathrm{p}}^{2}-\mathrm{LI}$ & & 531,12 & & 389,53 & & 309,75 & & 694,80 & & 220,82 \\
\hline IC $\sigma_{\mathrm{p}}^{2}-\mathrm{LS}$ & & 7696,72 & & 6671,11 & & 4782,04 & & 3654,51 & & 2260,14 \\
\hline IC $\sigma_{\mathrm{p}}^{2}(\mathrm{LS}-\mathrm{LI})$ & & 7165,60 & & 6281,58 & & 4472,29 & & 2959,71 & & 2039,32 \\
\hline$\sigma^{2}$ & & 3259,74 & & 2766,60 & & 1973,15 & & 971,58 & & 2241,07 \\
\hline$\sigma_{\text {pa }}^{2}$ & & & & & & & & & & 610,21 \\
\hline$\sigma_{\mathrm{f}}^{2}$ & & 2420,25 & & 1969,46 & & 1460,03 & & 1670,02 & & 911,33 \\
\hline$h_{x}^{2}$ & & 0,55 & & 0,52 & & 0,54 & & 0,81 & & 0,57 \\
\hline $\mathrm{IC} \mathrm{h}_{\mathrm{x}}^{2}-\mathrm{LI}$ & & $-0,05$ & & $-0,12$ & & $-0,08$ & & 0,55 & & 0,10 \\
\hline$I C h_{x}^{2}-L S$ & & 0,79 & & 0,77 & & 0,78 & & 0,91 & & 0,80 \\
\hline IC $h_{x}^{2}(L S-L I)$ & & 0,84 & & 0,89 & & 0,86 & & 0,36 & & 0,70 \\
\hline $\mathrm{CVg}$ & & 15,87 & & 19,48 & & 26,15 & & 30,79 & & 14,62 \\
\hline $\mathrm{CVg} / \mathrm{CVe}$ & & 0,64 & & 0,61 & & 0,63 & & 1,18 & & 0,48 \\
\hline
\end{tabular}


Tabela 58. Análise de variância das progênies do cruzamento BR 80-14853 x PI 239235 para o caracter Produtividade de Grãos (gramas / parcela), na geração $F_{2: n}$, nas quatro avaliações e análise conjunta.

\begin{tabular}{|c|c|c|c|c|c|c|c|c|c|c|}
\hline & \multicolumn{2}{|c|}{$1992 / 93$} & \multicolumn{2}{|c|}{$1993 / 94$} & \multicolumn{2}{|c|}{$1994 / 95$} & \multicolumn{2}{|c|}{$1995 / 96$} & \multicolumn{2}{|c|}{ Conjunta } \\
\hline F. Variação & $\overline{G l}$ & $\overline{Q M}$ & Gl & QM & $\mathrm{Gl}$ & QM & Gl & $\mathrm{QM}$ & Gl & $\mathrm{QM}$ \\
\hline $\begin{array}{l}\text { Repet. / Anos } \\
\text { Repetições } \\
\text { Progênies (P) } \\
\text { Anos (A) } \\
\text { P x A } \\
\text { Erro }\end{array}$ & $\begin{array}{c}2 \\
19\end{array}$ & $\begin{array}{c}50122,87 \\
5199,66^{\text {ns }} \\
5259,57\end{array}$ & $\begin{array}{c}2 \\
19\end{array}$ & $\begin{array}{l}4468,69 \\
6531,48^{\text {n }} \\
3884,09\end{array}$ & $\begin{array}{c}2 \\
19 \\
\\
\\
38\end{array}$ & $\begin{array}{l}6560,82 \\
3793,95^{\mathrm{n}} \\
2103,94\end{array}$ & $\begin{array}{c}2 \\
19 \\
\\
\\
38\end{array}$ & $\begin{array}{c}599,65 \\
2082,01^{n} \\
1837,10\end{array}$ & \begin{tabular}{|c|}
8 \\
\\
19 \\
3 \\
57 \\
152
\end{tabular} & $\begin{array}{c}15438,01 \\
\\
8402,64^{* *} \\
373625,65^{* *} \\
3068,15^{\text {ns }} \\
3271,18\end{array}$ \\
\hline Total & 59 & 6761,07 & 59 & 4756,46 & 59 & 2799,26 & 59 & 1874,02 & 239 & 8686,76 \\
\hline Média & & 311,47 & & 202,36 & & 140,20 & & 148,27 & & 200,57 \\
\hline Desv. Padrão & & 41,60 & & 46,66 & & 35,56 & & 26,34 & & 26,46 \\
\hline Menor Valor & & 248,00 & & 123,07 & & 95,38 & & 91,21 & & 154,69 \\
\hline Maior Valor & & 409,33 & & 327,60 & & 223,46 & & 181,77 & & 240,52 \\
\hline Amplitude & & 161,33 & & 204,53 & & 128,07 & & 90,56 & & 85,83 \\
\hline $\mathrm{CVe}$ & & 23,28 & & 30,80 & & 32,72 & & 28,91 & & 28,52 \\
\hline$\sigma_{p}^{2}$ & & - & & 882,46 & & 563,34 & & 81,63 & & 444,54 \\
\hline$I C \sigma_{p}^{2}-L I$ & & - & & 266,58 & & 185,92 & & - & & 197,86 \\
\hline IC $\sigma_{p}^{2}-L S$ & & - & & 15183,80 & & 6419,25 & & - & & 1777,93 \\
\hline$I C \sigma_{p}^{2}(\mathrm{LS}-\mathrm{LI})$ & & - & & 14917,22 & & 6233,33 & & - & & 1580,07 \\
\hline$\sigma^{2}$ & & 5259,57 & & 3884,09 & & 2103,94 & & 1837,10 & & 3271,18 \\
\hline$\sigma_{\mathrm{pa}}^{2}$ & & & & & & & & & & - \\
\hline$\sigma_{\mathrm{f}}^{2}$ & & - & & 2177,16 & & 1264,65 & & 694,00 & & 1534,93 \\
\hline$h_{x}^{2}$ & & - & & 0,41 & & 0,45 & & 0,12 & & 0,29 \\
\hline$I C h_{x}^{2}-L I$ & & $-1,37$ & & $-0,39$ & & $-0,30$ & & $-1,07$ & & 0,17 \\
\hline $\mathrm{ICh}_{\mathrm{x}}^{2}-\mathrm{LS}$ & & 0,52 & & 0,72 & & 0,74 & & 0,58 & & 0,82 \\
\hline IC $h_{x}^{2}(\mathrm{LS}-\mathrm{LI})$ & & 1,89 & & 1,11 & & 1,04 & & 1,65 & & 0,65 \\
\hline $\mathrm{CVg}$ & & - & & 14,68 & & 16,93 & & 6,09 & & 10,51 \\
\hline $\mathrm{CVg} / \mathrm{CVe}$ & & - & & 0,48 & & 0,52 & & 0,21 & & 0,37 \\
\hline
\end{tabular}


Tabela 59. Análise de variância das progênies do cruzamento PI 123439 x PI 165896 para o caracter Produtividade de Grãos (gramas / parcela), na geração $F_{2: n}$, nas quatro avaliações e análise conjunta.

\begin{tabular}{|c|c|c|c|c|c|c|c|c|c|c|}
\hline & \multicolumn{2}{|c|}{$1992 / 93$} & \multicolumn{2}{|c|}{$1993 / 94$} & \multicolumn{2}{|c|}{$1994 / 95$} & \multicolumn{2}{|c|}{$1995 / 96$} & \multicolumn{2}{|c|}{ Conjunta } \\
\hline F. Variação & $\mathrm{Gl}$ & $\mathrm{QM}$ & $\mathrm{Gl}$ & $\overline{\mathrm{QM}}$ & $\mathrm{Gl}$ & $\mathrm{QM}$ & $\mathrm{Gl}$ & $\overline{Q M}$ & $\mathrm{Gl}$ & $\overline{\mathrm{QM}}$ \\
\hline $\begin{array}{l}\text { Repet. / Anos } \\
\text { Repetições } \\
\text { Progênies (P) } \\
\text { Anos (A) } \\
\text { P x A } \\
\text { Erro } \\
\end{array}$ & $\begin{array}{c}2 \\
19\end{array}$ & $\begin{array}{c}35041,07 \\
13404,69 * * \\
4477,70\end{array}$ & $\begin{array}{c}2 \\
19\end{array}$ & $\begin{array}{c}28497,70 \\
17067,30 * \\
2280,59 \\
\end{array}$ & $\begin{array}{c}2 \\
19\end{array}$ & $\begin{array}{r}2081,96 \\
10780,13 \\
1950,06\end{array}$ & $\begin{array}{c}2 \\
19 \\
\\
38 \\
\end{array}$ & $\begin{array}{r}102,17 \\
4264,49^{* *} \\
722,07\end{array}$ & \begin{tabular}{|c|}
8 \\
\\
19 \\
3 \\
57 \\
144 \\
\end{tabular} & $\begin{array}{c}16410,72 \\
\\
33052,92 * * \\
189273,56=* \\
4154,57^{* *} \\
2375,66\end{array}$ \\
\hline Total & 59 & 8388,54 & 57 & 8129,39 & 53 & 5120,53 & 59 & 1841,84 & 231 & 8251,85 \\
\hline Média & & 216,27 & & 158,02 & & 109,95 & & 89,16 & & 144,09 \\
\hline Desv. Padrão & & 66,85 & & 78,15 & & 62,14 & & 37,69 & & 54,02 \\
\hline Menor Valor & & 106,00 & & 43,14 & & 18,97 & & 41,14 & & 68,26 \\
\hline Maior Valor & & 419,33 & & 389,90 & & 253,20 & & 187,39 & & 264,80 \\
\hline Amplitude & & 313,33 & & 346,76 & & 234,23 & & 146,26 & & 196,54 \\
\hline $\mathrm{CVe}$ & & 30,94 & & 30,22 & & 40,16 & & 30,14 & & 33,83 \\
\hline$\sigma_{p}^{2}$ & & 2975,66 & & 5108,14 & & 3289,64 & & 1180,81 & & 2493,11 \\
\hline IC $\sigma_{p}^{2}-L I$ & & 1354,44 & & 2748,65 & & 1711,29 & & 620,51 & & 1350,66 \\
\hline IC $\sigma_{p}^{2}-L S$ & & 10895,64 & & 12680,35 & & 8744,44 & & 3084,81 & & 6125,22 \\
\hline IC $\sigma_{\mathrm{p}}^{2}(\mathrm{LS}-\mathrm{LI})$ & & 9541,20 & & 9931,68 & & 7033,15 & & 2464,30 & & 4774,56 \\
\hline$\sigma^{2}$ & & 4477,70 & & 2280,59 & & 1950,06 & & 722,07 & & 2375,66 \\
\hline$\sigma_{p a}^{2}$ & & & & & & & & & & 607,19 \\
\hline$\sigma_{f}^{2}$ & & 4468,23 & & 5895,99 & & 4016,13 & & 1421,50 & & 2912,41 \\
\hline$h_{x}^{2}$ & & 0,67 & & 0,87 & & 0,82 & & 0,83 & & 0,86 \\
\hline $\mathrm{IC} \mathrm{h}_{\mathrm{x}}^{2}-\mathrm{LI}$ & & 0,22 & & 0,69 & & 0,57 & & 0,60 & & 0,71 \\
\hline IC $h_{x}^{2}-L S$ & & 0,84 & & 0,94 & & 0,92 & & 0,92 & & 0,94 \\
\hline IC $h_{x}^{2}(\mathrm{LS}-\mathrm{LI})$ & & 0,62 & & 0,25 & & 0,35 & & 0,32 & & 0,23 \\
\hline $\mathrm{CVg}$ & & 25,23 & & 45,23 & & 52,17 & & 38,54 & & 34,65 \\
\hline $\mathrm{CVg} / \mathrm{CVe}$ & & 0,82 & & 1,50 & & 1,30 & & 1,28 & & 1,02 \\
\hline
\end{tabular}


Tabela 60. Análise de variância das progênies do cruzamento PI 123439 x PI 239235 para o caracter Produtividade de Grãos (gramas / parcela), na geração $F_{2: n}$, nas quatro avaliações e análise conjunta.

\begin{tabular}{|c|c|c|c|c|c|c|c|c|c|c|}
\hline & \multicolumn{2}{|c|}{$1992 / 93$} & \multicolumn{2}{|c|}{$1993 / 94$} & \multicolumn{2}{|c|}{$1994 / 95$} & \multicolumn{2}{|c|}{$1995 / 96$} & \multicolumn{2}{|c|}{ Conjunta } \\
\hline F. Variação & Gl & $\overline{Q M}$ & $\mathrm{Gl}$ & $\overline{\mathrm{QM}}$ & $\overline{\mathrm{Gl}}$ & $\overline{\mathrm{QM}}$ & $\mathrm{Gl}$ & $\overline{\mathrm{QM}}$ & $\mathrm{Gl}$ & $\widehat{\mathrm{QM}}$ \\
\hline $\begin{array}{l}\text { Repet. / Anos } \\
\text { Repetições }\end{array}$ & 2 & 3099,84 & 2 & 3293,55 & 2 & 1015,27 & 2 & 745,17 & 8 & 2038,46 \\
\hline Progênies (P) & 19 & $17015,26^{*}$ & 19 & $13584,38^{*}$ & 19 & $5613,51=$ & 19 & $3408,90^{*}$ & 19 & $22230,61^{* *}$ \\
\hline Anos (A) & & & & & & & & & 3 & $262123,54^{* *}$ \\
\hline $\mathrm{PxA}$ & & & & & & & & & 57 & $5797,15^{* *}$ \\
\hline Erro & 34 & 5260,29 & 32 & 4951,19 & 37 & 1977,65 & 38 & 1187,50 & 141 & 3231,10 \\
\hline Total & 55 & 9242,54 & 53 & 7983,55 & 58 & 3135,52 & 59 & 1887,87 & 228 & 8820,54 \\
\hline Média & & 258,29 & & 171,99 & & 119,41 & & 111,12 & & 163,59 \\
\hline Desv. Padrão & & 77,17 & & 72,66 & & 43,41 & & 33,71 & & 44,50 \\
\hline Menor Valor & & 158,67 & & 85,57 & & 33,27 & & 46,71 & & 107,89 \\
\hline Maior Valor & & 409,33 & & 352,07 & & 189,47 & & 194,53 & & 261,34 \\
\hline Amplitude & & 250,67 & & 266,50 & & 156,20 & & 147,82 & & 153,45 \\
\hline $\mathrm{CVe}$ & & 28,08 & & 40,91 & & 37,24 & & 31,01 & & 34,75 \\
\hline$\sigma_{p}^{2}$ & & 4214,05 & & 3216,30 & & 1233,60 & & 740,47 & & 1434,90 \\
\hline IC $\sigma_{p}^{2}-L I$ & & 1968,21 & & 1415,08 & & 550,92 & & 332,69 & & 701,31 \\
\hline IC $\sigma_{\mathrm{p}}^{2}-\mathrm{LS}$ & & 14575,96 & & 13168,21 & & 4787,95 & & 2845,04 & & 4336,89 \\
\hline IC $\sigma_{\mathrm{p}}^{2}(\mathrm{LS}-\mathrm{LI})$ & & 12607,75 & & 11753,13 & & 4237,03 & & 2512,35 & & 3635,58 \\
\hline$\sigma^{2}$ & & 5260,29 & & 4951,19 & & 1977,65 & & 1187,50 & & 3231,10 \\
\hline$\sigma_{\mathrm{pa}}^{2}$ & & & & & & & & & & 902,68 \\
\hline$\sigma_{f}^{2}$ & & 6099,79 & & 5060,86 & & 1904,58 & & 1136,30 & & 2035,35 \\
\hline$h_{x}^{2}$ & & 0,69 & & 0,64 & & 0,65 & & 0,65 & & 0,71 \\
\hline IC $h_{x}^{2}-L I$ & & 0,27 & & 0,13 & & 0,17 & & 0,18 & & 0,41 \\
\hline $\mathrm{IC} \mathrm{h}_{\mathrm{x}}^{2}-\mathrm{LS}$ & & 0,85 & & 0,83 & & 0,83 & & 0,83 & & 0,87 \\
\hline IC $h_{x}^{2}(\mathrm{LS}-\mathrm{LI})$ & & 0,58 & & 0,70 & & 0,66 & & 0,65 & & 0,46 \\
\hline $\mathrm{CVg}$ & & 25,13 & & 32,98 & & 29,42 & & 24,49 & & 23,16 \\
\hline $\mathrm{CVg} / \mathrm{CVe}$ & & 0,90 & & 0,81 & & 0,79 & & 0,79 & & 0,67 \\
\hline
\end{tabular}


Tabela 61. Análise de variância das progênies do cruzamento PI 165896 x PI 239235 para o caracter Produtividade de Grãos (gramas / parcela), na geração $F_{2: n}$, nos quatro anos agrícolas de experimentação e análise conjunta.

\begin{tabular}{|c|c|c|c|c|c|c|c|c|c|c|}
\hline & \multicolumn{2}{|c|}{$1992 / 93$} & \multicolumn{2}{|c|}{$1993 / 94$} & \multicolumn{2}{|c|}{$1994 / 95$} & \multicolumn{2}{|c|}{$1995 / 96$} & \multicolumn{2}{|c|}{ Conjunta } \\
\hline F. Variação & Gl & $\mathrm{QM}$ & Gl & QM & $\mathrm{Gl}$ & $\mathrm{QM}$ & Gl & QM & Gl & QM \\
\hline $\begin{array}{l}\text { Repet. / Anos } \\
\text { Repetições } \\
\text { Progênies (P) } \\
\text { Anos (A) } \\
\text { P x A } \\
\text { Erro }\end{array}$ & $\begin{array}{c}2 \\
19 \\
\\
\\
38\end{array}$ & $\begin{array}{r}40831,67 \\
6995,85^{*} \\
\\
3134,83\end{array}$ & $\begin{array}{c}2 \\
19\end{array}$ & $\begin{array}{l}1120,80 \\
3983,79^{n} \\
3202,15\end{array}$ & $\begin{array}{c}2 \\
19 \\
\\
\\
36\end{array}$ & $\begin{array}{c}5806,17 \\
3649,58^{n} \\
2128,30\end{array}$ & $\begin{array}{c}2 \\
19 \\
\\
\\
37\end{array}$ & $\begin{array}{c}5063,90 \\
6068,89^{* 11} \\
735,73\end{array}$ & \begin{tabular}{|c|}
8 \\
19 \\
3 \\
57 \\
147 \\
\end{tabular} & $\begin{array}{c}13205,63 \\
11046,23^{* *} \\
178347,59^{* *} \\
3217,30^{\text {ns }} \\
2300,96\end{array}$ \\
\hline Total & 59 & 5656,06 & 57 & 3389,67 & 57 & 2764,44 & 58 & 2632,05 & 234 & 5864,07 \\
\hline Média & & 217,73 & & 148,38 & & 107,82 & & 96,70 & & 143,10 \\
\hline Desv. Padrão & & 48,29 & & 37,43 & & 35,71 & & 45,11 & & 30,80 \\
\hline Menor Valor & & 120,00 & & 94,58 & & 49,73 & & 51,02 & & 94,77 \\
\hline Maior Valor & & 296,00 & & 219,87 & & 166,84 & & 234,01 & & 214,33 \\
\hline Amplitude & & 176,00 & & 125,28 & & 117,12 & & 182,98 & & 119,56 \\
\hline $\mathrm{CVe}$ & & 25,72 & & 38,14 & & 42,79 & & 28,05 & & 33,52 \\
\hline$\sigma_{p}^{2}$ & & 1287,01 & & 270,02 & & 525,53 & & 1809,47 & & 666,40 \\
\hline IC $\sigma_{\mathrm{p}}^{2}-\mathrm{LI}$ & & 508,01 & & - & & 163,95 & & 978,04 & & 317,78 \\
\hline IC $\sigma_{\mathrm{p}}^{2}-\mathrm{LS}$ & & 7143,82 & & - & & 8472,10 & & 4386,47 & & 2161,28 \\
\hline IC $\sigma_{\mathrm{p}}^{2}(\mathrm{LS}-\mathrm{L})$ & & 6635,81 & & - & & 8311,15 & & 3408,43 & & 1843,50 \\
\hline$\sigma^{2}$ & & 3134,83 & & 3202,15 & & 2128,30 & & 735,73 & & 2300,96 \\
\hline$\sigma_{\mathrm{pa}}^{2}$ & & & & & & & & & & 312,93 \\
\hline$\sigma_{\mathrm{f}}^{2}$ & & 2331,95 & & 1376,23 & & 1247,73 & & 2059,09 & & 969,31 \\
\hline $\mathrm{h}_{\mathrm{x}}^{2}$ & & 0,55 & & 0,20 & & 0,42 & & 0,88 & & 0,69 \\
\hline IC $h_{x}^{2}-L I$ & & $-0,05$ & & $-0,89$ & & $-0,37$ & & 0,72 & & 0,34 \\
\hline IC $h_{x}^{2}-L S$ & & 0,79 & & 0,62 & & 0,73 & & 0,94 & & 0,85 \\
\hline IC $h_{x}^{2}(\mathrm{LS}-\mathrm{L})$ & & 0,84 & & 1,51 & & 1,10 & & 0,22 & & 0,51 \\
\hline $\mathrm{CVg}$ & & 16,48 & & 11,07 & & 21,26 & & 43,99 & & 18,04 \\
\hline $\mathrm{CVg} / \mathrm{CVe}$ & & 0,64 & & 0,29 & & 0,50 & & 1,57 & & 0,54 \\
\hline
\end{tabular}


Tabela 62. Análise de variância da tabela dialélica e estimativa de parâmetros segundo o modelo de GRIFFING (1956) método 4, para os caracteres Altura da Planta na Maturação (cm / planta) e Produtividade de Grãos (gramas / parcela), na geração $F_{2}$.

\begin{tabular}{|l|c|c|c|c|c|}
\hline Fonte de Variacão & Gl & \multicolumn{2}{|c|}{ Soma de Quadrados } & \multicolumn{2}{c|}{ Ouadrados Médios } \\
\hline & & Altura & Produção & Altura & Producão \\
\hline Populacões & 26 & 3513,34 & 506,92 & $135,13^{*+*}$ & 19,50 \\
\hline C.G.C. & 7 & 3146,57 & 403,53 & $449,51^{* *}$ & $57,65^{* *}$ \\
\hline C.E.C. & 19 & 366,76 & 103,39 & $19,30^{* *}$ & $3,57^{15}$ \\
\hline Erro & 156 & - & - & 6,12 & 3,41 \\
\hline
\end{tabular}

\begin{tabular}{|c|c|c|c|c|c|c|}
\hline \multirow{2}{*}{$\begin{array}{l}\text { Parâmetro } \\
\text { Estimado }\end{array}$} & \multicolumn{2}{|c|}{ Modelo Compl. $\left(\mu, g_{i}, s_{i i}\right)$} & \multicolumn{2}{|c|}{ Modelo Reduzido $\left(\mu, g_{i}\right)$} & \multicolumn{2}{|c|}{ Modelo Reduzido (u) } \\
\hline & Altura & Producão & Altura & Produção & Altura & Produção \\
\hline$\mu$ & 76,81 & 28,25 & 76,81 & 28,25 & 77,13 & 28,24 \\
\hline$g_{1}$ & $-5,78$ & $-1,71$ & $-5,78$ & $-1,71$ & & \\
\hline$g_{2}$ & 6,69 & 2,36 & 6,69 & 2,36 & & \\
\hline$g_{3}$ & $-7,51$ & 2,53 & $-7,51$ & 2,53 & & \\
\hline $\mathrm{g}_{4}$ & $-7,67$ & 2,74 & $-7,67$ & 2,74 & & \\
\hline$g_{5}$ & $-2,99$ & 1,90 & $-2,99$ & 1,90 & & \\
\hline $\mathrm{g}_{6}$ & $-6,77$ & $-5,46$ & $-6,77$ & $-5,46$ & & \\
\hline$g_{7}$ & 11,36 & $-3,26$ & 11,36 & $-3,26$ & & \\
\hline$g_{8}$ & 12,67 & 0,91 & 12,67 & 0,91 & & \\
\hline$s_{12}$ & 4,98 & $-4,79$ & & & & \\
\hline$S_{13}$ & $-3,22$ & 5,83 & & & & \\
\hline$s_{14}$ & $-9,60$ & $-2,97$ & & & & \\
\hline$s_{15}$ & - & - & - & & - & \\
\hline$s_{16}$ & 2,80 & $-3,41$ & & & & \\
\hline$s_{17}$ & 4,05 & 2,68 & & & & \\
\hline $\mathbf{s}_{18}$ & 10,97 & 2,67 & & & & \\
\hline$s_{23}$ & $-1,32$ & 3,37 & & & & \\
\hline$s_{24}$ & 4,66 & 4,08 & & & & \\
\hline $\mathbf{S}_{25}$ & 6,44 & 1,23 & & & & \\
\hline$s_{26}$ & 7,94 & $-1,15$ & & & & \\
\hline$s_{27}$ & $-18,59$ & $-4,98$ & & & & \\
\hline $\mathrm{S}_{28}$ & 5,86 & 2,24 & & & & \\
\hline$s_{34}$ & $-1,72$ & $-1,39$ & & & & \\
\hline$S_{35}$ & $-0,26$ & $-8,63$ & & & & \\
\hline$S_{36}$ & 9,82 & 3,79 & & & & \\
\hline$S_{37}$ & 4,53 & $-2,74$ & & & & \\
\hline$S_{38}$ & $-7,82$ & $-0,23$ & & & & \\
\hline $\mathrm{S}_{45}$ & 0,82 & 4,57 & & & & \\
\hline$S_{46}$ & $-6,36$ & $-5,77$ & & & & \\
\hline $\mathrm{s}_{47}$ & 14,81 & 3,66 & & & & \\
\hline $\mathbf{S}_{48}$ & $-2,60$ & $-2,18$ & & & & \\
\hline$S_{56}$ & $-12,58$ & $-1,09$ & & & & \\
\hline$S_{57}$ & 4,45 & 1,46 & & & & \\
\hline S58 & 1,12 & 2,47 & & & & \\
\hline$S_{67}$ & $-1,67$ & 6,26 & & & & \\
\hline $\mathrm{S}_{68}$ & 0,06 & 1,36 & & & & \\
\hline$S_{78}$ & $-7,56$ & $-6,34$ & & & & \\
\hline $\mathrm{r}^{2}$ & 1 & 1 & 0,90 & 0,80 & & \\
\hline
\end{tabular}


Tabela 63. Médias observadas e estimadas a partir dos parâmetros do modelo de GRIFFING (1956) método 4, para os caracteres Altura da Planta na Maturação (cm / planta) e Produtividade de Grãos (gramas / parcela), na geração $F_{2}$.

\begin{tabular}{|c|c|c|c|c|c|c|c|c|}
\hline \multirow[t]{2}{*}{$\begin{array}{l}\text { Cruza- } \\
\text { mento }\end{array}$} & \multicolumn{2}{|c|}{ Média Original } & \multicolumn{2}{|c|}{$\begin{array}{l}\text { Média Estimada } \\
\text { Modelo Compl. } \\
\left(\mu, g_{i}, g_{i}, s_{i j}\right)\end{array}$} & \multicolumn{2}{|c|}{$\begin{array}{l}\text { Média Estimada } \\
\text { Modelo Reduzido } \\
\left(\mathrm{u}, \mathrm{g}_{\left.\mathrm{i}, \mathrm{g}_{\mathrm{j}}\right)}\right. \\
\end{array}$} & \multicolumn{2}{|c|}{$\begin{array}{c}\text { Média Estimada } \\
\text { Modelo Reduzido } \\
(\mu) \\
\end{array}$} \\
\hline & Altura & Produção & Altura & Producão & Altura & Produção & Altura & Produção \\
\hline $1 \times 2$ & 75,23 & 26,50 & 75,23 & 26,50 & 77,72 & 28,90 & 77,13 & 28,24 \\
\hline $1 \times 3$ & 61,91 & 31,98 & 61,91 & 31,98 & 63,52 & 29,07 & 77,13 & 28,24 \\
\hline $1 \times 4$ & 58,56 & 27,79 & 58,56 & 27,79 & 63,36 & 29,28 & 77,13 & 28,24 \\
\hline $1 \times 5$ & - & - & - & 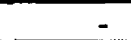 & - & - & - & - \\
\hline $1 \times 6$ & 65,66 & 19,37 & 65,66 & 19,37 & 64,26 & 21,08 & 77,13 & 28,24 \\
\hline $1 \times 7$ & 84,41 & 24,62 & 84,41 & 24,62 & 82,39 & 23,28 & 77,13 & 28,24 \\
\hline $1 \times 8$ & 89,18 & 28,79 & 89,18 & 28,79 & 83,70 & 27,45 & 77,13 & 28,24 \\
\hline $2 \times 3$ & 75,33 & 34,82 & 75,33 & 34,82 & 75,99 & 33,13 & 77,13 & 28,24 \\
\hline $2 \times 4$ & 78,16 & 35,38 & 78,16 & 35,38 & 75,83 & 33,34 & 77,13 & 28,24 \\
\hline $2 \times 5$ & 83,73 & 33,12 & 83,73 & 33,12 & 80,51 & 32,51 & 77,13 & 28,24 \\
\hline $2 \times 6$ & 80,70 & 24,57 & 80,70 & 24,57 & 76,73 & 25,14 & 77,13 & 28,24 \\
\hline $2 \times 7$ & 85,56 & 24,86 & 85,56 & 24,86 & 94,86 & 27,35 & 77,13 & 28,24 \\
\hline $2 \times 8$ & 99,10 & 32,64 & 99,10 & 32,64 & 96,17 & 31,52 & 77,13 & 28,24 \\
\hline $3 \times 4$ & 60,77 & 32,82 & 60,77 & 32,82 & 61,63 & 33,51 & 77,13 & 28,24 \\
\hline $3 \times 5$ & 66,18 & 28,36 & 66,18 & 28,36 & 66,31 & 32,68 & 77,13 & 28,24 \\
\hline $3 \times 6$ & 67,44 & 27,21 & 67,44 & 27,21 & 62,53 & 25,31 & 77,13 & 28,24 \\
\hline $3 \times 7$ & 82,92 & 26,15 & 82,92 & 26,15 & 80,66 & 27,52 & 77,13 & 28,24 \\
\hline $3 \times 8$ & 78,06 & 31,58 & 78,06 & 31,58 & 81,97 & 31,69 & 77,13 & 28,24 \\
\hline $4 \times 5$ & 66,56 & 35,17 & 66,56 & 35,17 & 66,15 & 32,89 & 77,13 & 28,24 \\
\hline $4 \times 6$ & 59,19 & 22,64 & 59,19 & 22,64 & 62,37 & 25,52 & 77,13 & 28,24 \\
\hline $4 \times 7$ & 87,90 & 29,56 & 87,90 & 29,56 & 80,50 & 27,73 & 77,13 & 28,24 \\
\hline $4 \times 8$ & 80,51 & 30,81 & 80,51 & 30,81 & 81,81 & 31,90 & 77,13 & 28,24 \\
\hline $5 \times 6$ & 60,76 & 24,14 & 60,76 & 24,14 & 67,05 & 24,69 & 77,13 & 28,24 \\
\hline $5 \times 7$ & 87,40 & 27,62 & 87,40 & 27,62 & 85,18 & 26,89 & 77,13 & 28,24 \\
\hline $5 \times 8$ & 87,05 & 32,30 & 87,05 & 32,30 & 86,49 & 31,06 & 77,13 & 28,24 \\
\hline $6 \times 7$ & 80,56 & 22,66 & 80,56 & 22,66 & 81,40 & 19,53 & 77,13 & 28,24 \\
\hline $6 \times 8$ & 82,74 & 24,38 & 82,74 & 24,38 & 82,71 & 23,70 & 77,13 & 28,24 \\
\hline $7 \times 8$ & 97,06 & 22,74 & 97,06 & 22,74 & 100,84 & 25,91 & 77,13 & 28,24 \\
\hline$r$ & & & 1 & 1 & 0,95 & 0,89 & & \\
\hline
\end{tabular}


Tabela 64. Análise de variância da tabela dialélica e estimativa de parâmetros segundo o modelo de GRIFFING (1956) método 4, para os caracteres Altura da Planta na Maturação (cm / planta) e Produtividade de Grãos (gramas / parcela), na geração $F_{2: n}$ ano agrícola 1992/93.

\begin{tabular}{|c|c|c|c|c|c|}
\hline Fonte de Variação & Gl & \multicolumn{2}{|c|}{ Soma de Quadrados } & \multicolumn{2}{c|}{ Quadrados Médios } \\
\hline & & Altura & Produção & Altura & Produção \\
\hline Populações & 24 & 2047,96 & 64409,71 & $85,33^{* *}$ & $2683,74^{* *}$ \\
\hline C.G.C. & 7 & 1858,26 & 51886,15 & $265,47^{* *}$ & $7412,31^{* *}$ \\
\hline C.E.C. & 17 & 189,70 & 12523,56 & $11,16^{* *}$ & $736,68^{* *}$ \\
\hline Erro & 36 & - & - & 2,11 & 180,62 \\
\hline
\end{tabular}

\begin{tabular}{|c|c|c|c|c|c|c|}
\hline \multirow{2}{*}{$\begin{array}{r}\text { Parâmetro } \\
\text { Estimado }\end{array}$} & \multicolumn{2}{|c|}{ Modelo Compl. $\left(\mu, g_{i}, s_{i j}\right)$} & \multicolumn{2}{|c|}{ Modelo Reduzido $\left(\mu, g_{j}\right)$} & \multicolumn{2}{|c|}{ Modelo Reduzido $(\mu)$} \\
\hline & Altura & Produção & Altura & Produção & Altura & Producão \\
\hline $\bar{\mu}$ & $\overline{73,44}$ & 261,18 & 73,44 & 261,18 & 73,67 & 259,03 \\
\hline$g_{1}$ & $-7,23$ & $-15,67$ & $-7,23$ & $-15,67$ & & \\
\hline$g_{2}$ & 10,18 & $-7,01$ & 10,18 & $-7,01$ & & \\
\hline$g_{3}$ & $-4,64$ & 30,77 & 4,64 & 30,77 & & \\
\hline $\mathrm{g}_{4}$ & $-2,98$ & 51,72 & $-2,98$ & 51,72 & & \\
\hline$g_{5}$ & $-5,22$ & 16,30 & $-5,22$ & 16,30 & & \\
\hline$g_{6}$ & $-5,31$ & $-70,63$ & $-5,31$ & $-70,63$ & & \\
\hline$g_{7}$ & 4,23 & $-22,21$ & 4,23 & $-22,21$ & & \\
\hline $\mathrm{g}_{8}$ & 10,97 & 16,74 & 10,97 & 16,74 & & \\
\hline$s_{12}$ & 0,74 & 9,16 & & & & \\
\hline$s_{13}$ & 1,57 & 2,73 & & & & \\
\hline $\mathrm{s}_{14}$ & $-3,75$ & 8,10 & & & & \\
\hline$s_{15}$ & - & - & - & & $=$ & \\
\hline$\overline{s_{16}}$ & $-0,65$ & $-38,31$ & & & & \\
\hline$\overline{s_{17}}$ & 3,58 & 13,58 & & & & \\
\hline$S_{18}$ & $-1,49$ & 4,73 & & & & \\
\hline$\overline{S_{23}}$ & $-2,45$ & 8,27 & & & & \\
\hline$s_{24}$ & 0,21 & $-9,62$ & & & & \\
\hline$S_{25}$ & 1,04 & 5,53 & & & & \\
\hline$S_{26}$ & $-2,83$ & $-17,75$ & & & & \\
\hline$S_{27}$ & - & - & & & $=$ & \\
\hline$S_{28}$ & 3,29 & 4,43 & & & & \\
\hline$\overline{s_{34}}$ & - & - & & & - & \\
\hline$S_{35}$ & 0,49 & $-20,02$ & & & & \\
\hline$S_{36}$ & 4,39 & 12,68 & & & & \\
\hline$S_{37}$ & $-3,14$ & $-11,47$ & & & & \\
\hline$S_{38}$ & $-0,87$ & 7,82 & & & & \\
\hline$S_{45}$ & 1,03 & 44,66 & & & & \\
\hline$S_{46}$ & 4,94 & $-45,44$ & & & & \\
\hline$\overline{S_{47}}$ & 5,75 & 11,91 & & & & \\
\hline$S_{48}$ & 1,71 & $-9,60$ & & & & \\
\hline$S_{56}$ & 3,54 & 11,32 & & & & \\
\hline S57 & 4,75 & $-30,93$ & & & & \\
\hline $\mathrm{S}_{58}$ & $-1,34$ & $-10,56$ & & & & \\
\hline$S_{67}$ & 0,18 & 45,62 & & & & \\
\hline$s_{68}$ & 0,32 & 31,89 & & & & \\
\hline$S_{78}$ & $-1,62$ & $-28,71$ & & & & \\
\hline $\mathrm{r}^{2}$ & 1 & & 0,91 & 0,81 & & \\
\hline
\end{tabular}


Tabela 65. Médias observadas e estimadas a partir dos parâmetros do modelo de GRIFFING (1956) método 4, para os caracteres Altura da Planta na Maturação (cm / planta) e Produtividade de Grãos (gramas / parcela), na geração $F_{2: n}$ ano agrícola 1992/93.

\begin{tabular}{|c|c|c|c|c|c|c|c|c|}
\hline \multirow[t]{2}{*}{ Cruzamento } & \multicolumn{2}{|c|}{ Média Original } & \multicolumn{2}{|c|}{$\begin{array}{c}\text { Média Estimada } \\
\text { Modelo Completo } \\
\left(\mu, g_{i}, g_{i}, s_{i j}\right)\end{array}$} & \multicolumn{2}{|c|}{$\begin{array}{l}\text { Média Estimada } \\
\text { Modelo Redurido } \\
\left(\mathrm{u}, \mathrm{g}_{\left.\mathrm{i}, \mathrm{g}_{\mathrm{j}}\right)}\right.\end{array}$} & \multicolumn{2}{|c|}{$\begin{array}{c}\text { Média Estimada } \\
\text { Modelo Reduzido } \\
(\mu)\end{array}$} \\
\hline & Altura & Produção & Altura & Producão & Altura & Produção & Altura & Producão \\
\hline $1 \times 2$ & 77,13 & 247,66 & 77,13 & 247,66 & 76,40 & 238,51 & 73,67 & 259,03 \\
\hline $1 \times 3$ & 63,14 & 279,01 & 63,14 & 279,01 & 61,57 & 276,28 & 73,67 & 259,03 \\
\hline $1 \times 4$ & 59,48 & 305,33 & 59,48 & 305,33 & 63,23 & 297,2 & 73,67 & 259,03 \\
\hline $1 \times 5$ & & - & - & - & -1 & - & - & - \\
\hline $1 \times 6$ & 60,25 & 136,58 & 60,25 & 136,58 & 60,90 & 174,89 & 73,67 & 259,03 \\
\hline $1 \times 7$ & 74,02 & 236,88 & 74,02 & 236,88 & 70,44 & 223,31 & 73,67 & 259,03 \\
\hline $1 \times 8$ & 75,70 & 267,01 & 75,70 & 267,01 & 77,18 & 262,25 & 73,67 & 259,03 \\
\hline $2 \times 3$ & 76,54 & 293,21 & 76,54 & 293,21 & 78,98 & 284,94 & 73,67 & 259,03 \\
\hline $2 \times 4$ & 80,85 & 296,27 & 80,85 & 296,27 & 80,64 & 305,89 & 73,67 & 259,03 \\
\hline $2 \times 5$ & 79,44 & 276,00 & 79,44 & 276,00 & 78,40 & 270,47 & 73,67 & 259,03 \\
\hline $2 \times 6$ & 75,49 & 165,79 & 75,49 & 165,79 & 78,31 & 183,54 & 73,67 & 259,03 \\
\hline $2 \times 7$ & - & - & - & - & - & - & - & - \\
\hline $2 \times 8$ & 97,89 & 275,34 & 97,89 & 275,34 & 94,59 & 270,91 & 73,67 & 259,03 \\
\hline $3 \times 4$ & $=$ & - & - & - & - & - & - & - \\
\hline $3 \times 5$ & 64,06 & 288,23 & 64,07 & 288,23 & 63,58 & 308,25 & 73,67 & 259,03 \\
\hline $3 \times 6$ & 67,87 & 233,99 & 67,87 & 233,99 & 63,49 & 221,32 & 73,67 & 259,03 \\
\hline $3 \times 7$ & 69,89 & 258,27 & 69,89 & 258,27 & 73,02 & 269,74 & 73,67 & 259,03 \\
\hline $3 \times 8$ & 78,90 & 316,50 & 78,90 & 316,50 & 79,77 & 308,69 & 73,67 & 259,03 \\
\hline $4 \times 5$ & 66,27 & 373,86 & 66,27 & 373,86 & 65,24 & 329,20 & 73,67 & 259,03 \\
\hline $4 \times 6$ & 60,20 & 196,82 & 60,20 & 196,82 & 65,15 & 242,27 & 73,67 & 259,03 \\
\hline $4 \times 7$ & 80,43 & 302,60 & 80,43 & 302,60 & 74,69 & 290,69 & 73,67 & 259,03 \\
\hline $4 \times 8$ & 83,14 & 320,03 & 83,14 & 320,03 & 81,43 & 329,64 & 73,67 & 259,03 \\
\hline $5 \times 6$ & 66,45 & 218,17 & 66,45 & 218,17 & 62,91 & 206,85 & 73,67 & 259,03 \\
\hline $5 \times 7$ & 67,69 & 224,35 & 67,69 & 224,35 & 72,45 & 255,27 & 73,67 & 259,03 \\
\hline $5 \times 8$ & 77,85 & 283,65 & 77,85 & 283,65 & 79,19 & 294,22 & 73,67 & 259,03 \\
\hline $6 \times 7$ & 72,53 & 213,96 & 72,53 & 213,96 & 72,35 & 168,34 & 73,67 & 259,03 \\
\hline $6 \times 8$ & 79,41 & 239,18 & 79,41 & 239,18 & 79,10 & 207,29 & 73,67 & 259,03 \\
\hline $7 \times 8$ & 87,01 & 226,99 & 87,01 & 226,99 & 88,64 & 255,71 & 73,67 & 259,03 \\
\hline$r$ & & & 1 & 1 & 0,95 & 0,90 & & \\
\hline
\end{tabular}


Tabela 66. Análise de variância da tabela dialélica e estimativa de parâmetros segundo o modelo de GRIFFING (1956) método 4, para os caracteres Altura da Planta na Maturação (cm / planta) e Produtividade de Grãos (gramas / parcela), na geração $F_{2: n}$ ano agrícola 1993/94.

\begin{tabular}{|l|c|r|r|r|r|}
\hline Fonte de Variação & Gl & \multicolumn{2}{|c|}{ Soma de Quadrados } & \multicolumn{2}{c|}{ Quadrados Médios } \\
\hline & & Altura & Produção & Altura & \multicolumn{1}{c|}{ Produção } \\
\hline Populações & 24 & 4780,46 & 39582,30 & $199,19^{* *}$ & $1649,26^{* *}$ \\
\hline C.G.C. & 7 & 4409,95 & 32088,37 & $629,99^{* *}$ & $4584,05^{* *}$ \\
\hline C.E.C. & 17 & 370,51 & 7493,94 & $21,80^{* *}$ & $440,82^{* *}$ \\
\hline Erro & 16 & - & - & 5,75 & 111,92 \\
\hline
\end{tabular}

\begin{tabular}{|c|c|c|c|c|c|c|}
\hline \multirow{2}{*}{\begin{tabular}{c|} 
Parâmetro \\
Estimado
\end{tabular}} & \multicolumn{2}{|c|}{ Modelo Compl. $\left(\mu, g_{i}, s_{i i}\right)$} & \multicolumn{2}{|c|}{ Modelo Reduzido $\left(\mu, g_{j}\right)$} & \multicolumn{2}{|c|}{ Modelo Reduzido $(\mu)$} \\
\hline & Altura & Produção & Altura & Produção & Altura & Producão \\
\hline$\mu$ & 84,10 & 212,43 & 84,10 & 212,43 & 84,55 & 209,98 \\
\hline$g_{1}$ & $-10,07$ & $-1,69$ & $-10,07$ & $-1,69$ & & \\
\hline $\mathrm{g}_{2}$ & 12,08 & 15,21 & 12,08 & 15,21 & & \\
\hline $\mathrm{g}_{3}$ & $-5,10$ & 36,57 & $-5,10$ & 36,57 & & \\
\hline$g_{4}$ & $-7,71$ & 27,85 & $-7,71$ & 27,85 & & \\
\hline$g_{s}$ & $-8,98$ & 20,94 & $-8,98$ & 20,94 & & \\
\hline$g_{6}$ & $-7,47$ & $-38,81$ & $-7,47$ & $-38,81$ & & \\
\hline$g_{7}$ & 8,46 & $-37,58$ & 8,46 & $-37,58$ & & \\
\hline $\mathrm{g}_{8}$ & 18,80 & $-22,49$ & 18,80 & $-22,49$ & & \\
\hline$s_{12}$ & 0,11 & 17,95 & & & & \\
\hline$s_{13}$ & 6,24 & 15,91 & & & & \\
\hline$s_{14}$ & $-7,71$ & 7,32 & & & & \\
\hline$s_{15}$ & - & - & - & & - & \\
\hline$s_{16}$ & 0,45 & $-20,39$ & & & & \\
\hline $\mathrm{s}_{17}$ & 4,03 & $-13,86$ & & & & \\
\hline $\mathrm{S}_{18}$ & $-3,13$ & $-6,93$ & & & & \\
\hline$S_{23}$ & $-7,06$ & $-6,79$ & & & & \\
\hline$s_{24}$ & 5,24 & $-0,40$ & & & & \\
\hline$S_{25}$ & $-1,58$ & $-1,26$ & & & & \\
\hline$s_{26}$ & 3,07 & 4,69 & & & & \\
\hline$S_{27}$ & - & - & - & & - & \\
\hline$\overline{S_{28}}$ & 0,23 & $-14,19$ & & & & \\
\hline$s_{34}$ & - & - & - & & - & \\
\hline$S_{35}$ & 1,61 & 2,53 & & & & \\
\hline$\overline{S_{36}}$ & 0,04 & $-15,45$ & & & & \\
\hline$S_{37}$ & $-2,18$ & $-0,29$ & & & & \\
\hline $\mathrm{S}_{38}$ & 1,34 & 4,08 & & & & \\
\hline $\mathrm{S}_{45}$ & 2,75 & 16,96 & & & & \\
\hline $\mathrm{S}_{46}$ & 4,13 & $-45,80$ & & & & \\
\hline$S_{47}$ & 6,20 & 7,84 & & & & \\
\hline$\overline{S_{48}}$ & $-2,34$ & 14,08 & & & & \\
\hline$S_{56}$ & 3,51 & 13,57 & & & & \\
\hline$S_{57}$ & $-6,34$ & $-22,20$ & & & & \\
\hline S58 & 0,05 & $-9,59$ & & & & \\
\hline$S_{67}$ & 4,26 & 39,69 & & & & \\
\hline$S_{68}$ & 1,32 & 23,71 & & & & \\
\hline S78 & 2,54 & $-11,17$ & & & & \\
\hline$r^{2}$ & 1 & & 0,92 & 0,81 & & \\
\hline
\end{tabular}


Tabela 67. Médias observadas e estimadas a partir dos parâmetros do modelo de GRIFFING (1956) método 4, para os caracteres Altura da Planta na Maturação (cm / planta) e Produtividade de Grãos (gramas / parcela), na geração $F_{2: n}$ ano agrícola 1993/94.

\begin{tabular}{|c|c|c|c|c|c|c|c|c|}
\hline \multirow[t]{2}{*}{ Cruzamento } & \multicolumn{2}{|c|}{ Média Original } & \multicolumn{2}{|c|}{$\begin{array}{c}\text { Média Estimada } \\
\text { Modelo Completo } \\
\left(\mu, \mathrm{g}_{i}, \mathrm{~g}_{\mathrm{i}}, \mathrm{s}_{\mathrm{ii}}\right) \\
\end{array}$} & \multicolumn{2}{|c|}{$\begin{array}{c}\text { Média Estimada } \\
\text { Modelo Reduzido } \\
\left(\mathbf{u}, \mathbf{g}_{\mathrm{i}}, \mathrm{g}_{\mathrm{j}}\right)\end{array}$} & \multicolumn{2}{|c|}{$\begin{array}{l}\text { Média Estimada } \\
\text { Modelo Redurido } \\
(\mu)\end{array}$} \\
\hline & Altura & Produção & Altura & Produção & Altura & Producão & Altura & Produção \\
\hline $1 \times 2$ & 86,22 & 243,90 & 86,22 & 243,90 & 86,11 & 225,95 & 84,55 & 209,98 \\
\hline $1 \times 3$ & 75,17 & 263,22 & 75,17 & 263,22 & 68,93 & 247,30 & 84,55 & 209,98 \\
\hline $1 \times 4$ & 58,60 & 245,91 & 58,60 & 245,91 & 66,31 & 238,59 & 84,55 & 209,98 \\
\hline $1 \times 5$ & & - & -1 & - & - & - & - & - \\
\hline $1 \times 6$ & 67,02 & 151,53 & 67,02 & 151,53 & 66,56 & 171,92 & 84,55 & 209,98 \\
\hline $1 \times 7$ & 86,51 & 159,30 & 86,51 & 159,30 & 82,48 & 173,16 & 84,55 & 209,98 \\
\hline $1 \times 8$ & 89,69 & 181,33 & 89,69 & 181,33 & 92,82 & 188,25 & 84,55 & 209,98 \\
\hline $2 \times 3$ & 84,02 & 257,42 & 84,02 & 257,42 & 91,08 & 264,21 & 84,55 & 209,98 \\
\hline $2 \times 4$ & 93,70 & 255,10 & 93,70 & 255,10 & 88,46 & 255,49 & 84,55 & 209,98 \\
\hline $2 \times 5$ & 85,62 & 247,32 & 85,62 & 247,32 & 87,20 & 248,58 & 84,55 & 209,98 \\
\hline $2 \times 6$ & 91,78 & 193,52 & 91,78 & 193,52 & 88,71 & 188,83 & 84,55 & 209,98 \\
\hline $2 \times 7$ & -1 & - & -1 & - & -1 & - & $\rightarrow$ & - \\
\hline $2 \times 8$ & 115,20 & 190,97 & 115,20 & 190,97 & 114,97 & 205,16 & 84,55 & 209,98 \\
\hline $3 \times 4$ & - & - & -1 & - & - & - & - & - \\
\hline $3 \times 5$ & 71,63 & 272,46 & 71,63 & 272,46 & 70,02 & 269,93 & 84,55 & 209,98 \\
\hline $3 \times 6$ & 71,57 & 194,73 & 71,57 & 194,73 & 71,53 & 210,18 & 84,55 & 209,98 \\
\hline $3 \times 7$ & 85,27 & 211,13 & 85,27 & 211,13 & 87,45 & 211,41 & 84,55 & 209,98 \\
\hline $3 \times 8$ & 99,13 & 230,59 & 99,13 & 230,59 & 97,79 & 226,51 & 84,55 & 209,98 \\
\hline $4 \times 5$ & 70,16 & 278,18 & 70,16 & 278,18 & 67,41 & 261,22 & 84,55 & 209,98 \\
\hline $4 \times 6$ & 64,78 & 155,66 & 64,78 & 155,66 & 68,92 & 201,47 & 84,55 & 209,98 \\
\hline $4 \times 7$ & 91,04 & 210,54 & 91,04 & 210,54 & 84,84 & 202,70 & 84,55 & 209,98 \\
\hline $4 \times 8$ & 92,84 & 231,88 & 92,84 & 231,88 & 95,18 & 217,79 & 84,55 & 209,98 \\
\hline $5 \times 6$ & 71,16 & 208,12 & 71,16 & 208,12 & 67,65 & 194,55 & 84,55 & 209,98 \\
\hline $5 \times 7$ & 77,23 & 173,58 & 77,23 & 173,58 & 83,57 & 195,79 & 84,55 & 209,98 \\
\hline $5 \times 8$ & 93,97 & 201,30 & 93,97 & 201,30 & 93,92 & 210,88 & 84,55 & 209,98 \\
\hline $6 \times 7$ & 80,83 & 175,72 & 80,83 & 175,72 & 85,09 & 136,04 & 84,55 & 209,98 \\
\hline $6 \times 8$ & 96,74 & 174,84 & 96,74 & 174,84 & 95,43 & 151,13 & 84,55 & 209,98 \\
\hline $7 \times 8$ & 113,89 & 141,19 & 113,89 & 141,19 & 111,35 & 152,36 & 84,55 & 209,98 \\
\hline$r$ & & & 1 & 1 & 0,91 & 0,90 & & \\
\hline
\end{tabular}


Tabela 68. Análise de variância da tabela dialélica e estimativa de parâmetros segundo o modelo de GRIFFING (1956) método 4, para os caracteres Altura da Planta na Maturação (cm / planta) e Produtividade de Grãos (gramas / parcela), na geração $F_{2: n}$ ano agrícola 1994/95.

\begin{tabular}{|c|c|c|c|c|c|}
\hline Fonte de Variação & Gl & \multicolumn{2}{|c|}{ Soma de Quadrados } & \multicolumn{2}{c|}{ Quadrados Médios } \\
\hline & & Altura & Produção & Altura & Produção \\
\hline Populacõos & 24 & 1702,34 & 35324,94 & $70,93^{* *}$ & $1471,87^{* *}$ \\
\hline C.G.C. & 7 & 1533,36 & 28327,74 & $219,05^{* *}$ & $4046,82^{* *}$ \\
\hline C.E.C. & 17 & 168,98 & 6997,20 & $9,94^{\text {ns }}$ & $411,60^{* *}$ \\
\hline Erro & 36 & - & - & 5,70 & 101,44 \\
\hline
\end{tabular}

\begin{tabular}{|c|c|c|c|c|c|c|}
\hline \multirow{2}{*}{$\begin{array}{l}\text { Parâmetro } \\
\text { Estimado }\end{array}$} & \multicolumn{2}{|c|}{ Modelo Compl. $\left(\mu, g_{i}, s_{i j}\right)$} & \multicolumn{2}{|c|}{ Modelo Reduzido $\left(\mu, g_{i}\right)$} & \multicolumn{2}{|c|}{ Modelo Redurido $(\mu)$} \\
\hline & Altura & Produção & Altura & Produção & Altura & Produção \\
\hline$\mu$ & 77,05 & 155,86 & 77,05 & 155,86 & 77,21 & 154,13 \\
\hline $\mathrm{g}_{1}$ & 4,06 & 11,69 & $-4,06$ & 11,69 & & \\
\hline $\mathrm{g}_{2}$ & 8,53 & 4,25 & 8,53 & 4,25 & & \\
\hline $\mathrm{g}_{3}$ & $-3,53$ & 44,40 & $-3,53$ & 44,40 & & \\
\hline $\mathrm{g}_{4}$ & $-3,51$ & 32,50 & $-3,51$ & 32,50 & & \\
\hline $\mathbf{g}_{5}$ & $-6,48$ & $-2,52$ & $-6,48$ & $-2,52$ & & \\
\hline$g_{6}$ & $-5,93$ & $-36,30$ & $-5,93$ & $-36,30$ & & \\
\hline $\mathrm{g}_{7}$ & 5,18 & $-38,50$ & 5,18 & $-38,50$ & & \\
\hline$g_{8}$ & 9,79 & $-7,02$ & 9,79 & $-7,02$ & & \\
\hline$s_{12}$ & 4,97 & 25,06 & & & & \\
\hline$s_{13}$ & 0,87 & $-11,07$ & & & & \\
\hline $\mathrm{s}_{14}$ & $-4,23$ & 32,09 & & & & \\
\hline$s_{15}$ & - & - & - & & - & \\
\hline$s_{16}$ & $-1,90$ & $-29,37$ & & & & \\
\hline$s_{17}$ & 1,74 & $-16,01$ & & & & \\
\hline$s_{18}$ & $-1,45$ & $-0,70$ & & & & \\
\hline$s_{23}$ & $-3,89$ & 6,36 & & & & \\
\hline$S_{24}$ & $-0,12$ & $-23,87$ & & & & \\
\hline$S_{25}$ & $-3,96$ & $-11,27$ & & & & \\
\hline$S_{26}$ & $-0,45$ & 0,65 & & & & \\
\hline$S_{27}$ & - & $=$ & - & & $=$ & \\
\hline$S_{28}$ & 3,44 & 3,07 & & & & \\
\hline$S_{34}$ & - & - & - & & - & \\
\hline$S_{35}$ & 0,37 & $-19,75$ & & & & \\
\hline$S_{36}$ & 3,15 & 8,65 & & & & \\
\hline$S_{37}$ & 0,29 & 2,30 & & & & \\
\hline$S_{38}$ & $-0,79$ & 13,50 & & & & \\
\hline$S_{45}$ & 3,10 & 27,36 & & & & \\
\hline $\mathrm{S}_{46}$ & $-3,44$ & $-26,05$ & & & & \\
\hline$S_{47}$ & 4,03 & $-3,39$ & & & & \\
\hline$S_{48}$ & 0,67 & $-6,14$ & & & & \\
\hline$S_{56}$ & 2,93 & 20,34 & & & & \\
\hline$S_{57}$ & $-1,50$ & $-7,88$ & & & & \\
\hline $\mathrm{S}_{58}$ & $-0,95$ & $-8,80$ & & & & \\
\hline$S_{67}$ & $-1,97$ & 25,84 & & & & \\
\hline$S_{68}$ & 1,68 & $-0,06$ & & & & \\
\hline S78 & $-2,59$ & $-0,86$ & & & & \\
\hline $\mathrm{r}^{2}$ & 1 & & 0,90 & 0,80 & & \\
\hline
\end{tabular}


Tabela 69. Médias observadas e estimadas a partir dos parâmetros do modelo de GRIFFING (1956) método 4, para os caracteres Altura da Planta na Maturação (cm / planta) e Produtividade de Grãos (gramas / parcela), na geração $F_{2: n}$ ano agrícola 1994/95.

\begin{tabular}{|c|c|c|c|c|c|c|c|c|}
\hline \multirow[t]{2}{*}{ Cruzamento } & \multicolumn{2}{|c|}{ Média Original } & \multicolumn{2}{|c|}{$\begin{array}{c}\text { Média Estimada } \\
\text { Modelo Completo } \\
\left(\mu, g_{j}, g_{j}, s_{j i}\right)\end{array}$} & \multicolumn{2}{|c|}{$\begin{array}{c}\text { Média Estimada } \\
\text { Modelo Redurido } \\
\left(u, g_{i}, g_{j}\right) \\
\end{array}$} & \multicolumn{2}{|c|}{$\begin{array}{c}\text { Média Estimada } \\
\text { Modelo Redurido } \\
(\mu)\end{array}$} \\
\hline & Altura & Produção & Altura & Producão & Altura & Producão & Altura & Prouducão \\
\hline $1 \times 2$ & 86,50 & 188,36 & 86,50 & 188,36 & 81,53 & 163,30 & $\overline{77,21}$ & 154,13 \\
\hline $1 \times 3$ & 70,33 & 200,88 & 70,33 & 200,88 & 69,47 & 211,95 & 77,21 & 154,13 \\
\hline $1 \times 4$ & 65,26 & 232,14 & 65,26 & 232,14 & 69,49 & 200,05 & 77,21 & 154,13 \\
\hline $1 \times 5$ & & - & & - & - & - & - & - \\
\hline $1 \times 6$ & 65,17 & 101,88 & 65,17 & 101,88 & 67,07 & 131,25 & 77,21 & 154,13 \\
\hline $1 \times 7$ & 79,92 & 113,04 & 79,92 & 113,04 & 78,17 & 129,05 & 77,21 & 154,13 \\
\hline $1 \times 8$ & 81,33 & 159,83 & 81,33 & 159,83 & 82,79 & 160,53 & 77,21 & 154,13 \\
\hline $2 \times 3$ & 78,17 & 202,38 & 78,17 & 202,38 & 82,05 & 196,02 & 77,21 & 154,13 \\
\hline $2 \times 4$ & 81,95 & 160,25 & 81,95 & 160,25 & 82,07 & 184,11 & 77,21 & 154,13 \\
\hline $2 \times 5$ & 75,15 & 137,82 & 75,15 & 137,82 & $\overline{79,11}$ & 149,10 & 77,21 & 154,13 \\
\hline $2 \times 6$ & 79,21 & 115,97 & 79,21 & 115,97 & 79,66 & 115,32 & 77,21 & 154,13 \\
\hline $2 \times 7$ & - & - & - & - & - & - & - & - \\
\hline $2 \times 8$ & 98,81 & 147,66 & 98,81 & 147,66 & 95,37 & 144,60 & 77,21 & 154,13 \\
\hline $3 \times 4$ & 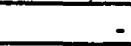 & - & - & - & - & - & $=$ & - \\
\hline $3 \times 5$ & 67,42 & 177,99 & 67,42 & 177,99 & 67,05 & 197,75 & 77,21 & 154,13 \\
\hline $3 \times 6$ & 70,75 & 172,62 & 70,75 & 172,62 & 67,60 & 163,97 & 77,21 & 154,13 \\
\hline $3 \times 7$ & 78,99 & 164,07 & 78,99 & 164,07 & 78,70 & 161,76 & 77,21 & 154,13 \\
\hline $3 \times 8$ & 82,52 & 206,75 & 82,52 & 206,75 & 83,31 & 193,25 & 77,21 & 154,13 \\
\hline $4 \times 5$ & 70,17 & 213,21 & 70,17 & 213,21 & 67,07 & 185,85 & 77,21 & 154,13 \\
\hline $4 \times 6$ & 64,17 & 126,01 & 64,17 & 126,01 & 67,62 & 152,07 & 77,21 & 154,13 \\
\hline $4 \times 7$ & 82,75 & 146,47 & 82,75 & 146,47 & 78,72 & 149,86 & 77,21 & 154,13 \\
\hline $4 \times 8$ & 84,00 & 175,20 & 84,00 & 175,20 & 83,33 & 181,35 & 77,21 & 154,13 \\
\hline $5 \times 6$ & 67,58 & 137,39 & 67,58 & 137,39 & 64,65 & 117,05 & 77,21 & 154,13 \\
\hline $5 \times 7$ & 74,25 & 106,96 & 74,25 & 106,96 & 75,75 & 114,84 & 77,21 & 154,13 \\
\hline $5 \times 8$ & 79,42 & 137,52 & 79,42 & 137,52 & 80,37 & 146,33 & 77,21 & 154,13 \\
\hline $6 \times 7$ & 74,34 & 106,90 & 74,34 & 106,90 & 76,31 & 81,06 & 77,21 & 154,13 \\
\hline $6 \times 8$ & 82,59 & 112,49 & 82,59 & 112,49 & 80,92 & 112,55 & 77,21 & 154,13 \\
\hline $7 \times 8$ & 89,43 & 109,48 & 89,43 & 109,48 & 92,02 & 110,34 & 77,21 & 154,13 \\
\hline $\mathrm{r}$ & & & 1 & 1 & 0,95 & 0,90 & & \\
\hline
\end{tabular}


Tabela 70. Análise de variância da tabela dialélica e estimativa de parâmetros segundo o modelo de GRIFFING (1956) método 4, para os caracteres Altura da Planta na Maturação (cm / planta) e Produtividade de Grãos (gramas / parcela), na geração $F_{2: n}$ ano agrícola 1995/96.

\begin{tabular}{|l|c|r|r|r|r|}
\hline Fonte de Variação & G1 & \multicolumn{2}{|c|}{ Soma de Quadrados } & \multicolumn{2}{c|}{ Quadrados Médios } \\
\hline & & Altura & Produção & Altura & Produção \\
\hline Populações & 24 & 2222,99 & 27882,86 & $92,63^{* *}$ & $1161,79^{* *}$ \\
\hline C.G.C. & 7 & 1999,51 & 25873,63 & $285,65^{* *}$ & $3696,23^{* *}$ \\
\hline C.E.C. & 17 & 223,48 & 2009,23 & $13,15^{* *}$ & $118,19^{* *}$ \\
\hline Erro & 36 & - & - & 3,42 & 32,10 \\
\hline
\end{tabular}

\begin{tabular}{|c|c|c|c|c|c|c|}
\hline \multirow{2}{*}{$\begin{array}{c}\text { Parâmetro } \\
\text { Estimado }\end{array}$} & \multicolumn{2}{|c|}{ Modelo Compl. $\left(\mu, g_{i}, s_{i i}\right)$} & \multicolumn{2}{|c|}{ Modelo Reduzido $\left(\mu, g_{i}\right)$} & \multicolumn{2}{|c|}{ Modelo Reduzido $(\mu)$} \\
\hline & Altura & Produção & Altura & Produção & Altura & Produção \\
\hline$\mu$ & 66,31 & 143,61 & 66,31 & 143,61 & 66,33 & 141,81 \\
\hline $\mathrm{g}_{1}$ & $-5,86$ & 4,58 & $-5,86$ & 4,58 & & \\
\hline $\mathrm{g}_{2}$ & 10,33 & 5,04 & 10,33 & 5,04 & & \\
\hline $\mathrm{g}_{3}$ & $-3,14$ & 30,65 & $-3,14$ & 30,65 & & \\
\hline $\mathrm{g}_{4}$ & $-2,51$ & 26,62 & $-2,51$ & 26,62 & & \\
\hline$g_{5}$ & $-4,23$ & 15,62 & 4,23 & 15,62 & & \\
\hline$g_{6}$ & $-9,65$ & $-42,06$ & $-9,65$ & $-42,06$ & & \\
\hline $\mathrm{g}_{7}$ & 4,98 & $-37,40$ & 4,98 & $-37,40$ & & \\
\hline$g_{8}$ & 10,08 & $-3,04$ & 10,08 & $-3,04$ & & \\
\hline$s_{12}$ & $-0,51$ & $-2,35$ & & & & \\
\hline$S_{13}$ & 5,13 & 3,82 & & & & \\
\hline $\mathbf{S}_{14}$ & $-2,62$ & 13,01 & & & & \\
\hline $\mathrm{s}_{15}$ & - & - & - & & - & \\
\hline $\mathbf{S}_{16}$ & 0,03 & $-18,10$ & & & & \\
\hline$s_{17}$ & 2,65 & 1,91 & & & & \\
\hline$S_{18}$ & 4,69 & 1,71 & & & & \\
\hline $\mathrm{S}_{23}$ & $-7,01$ & 4,79 & & & & \\
\hline$S_{24}$ & 4,13 & 0,83 & & & & \\
\hline$S_{25}$ & $-1,38$ & $-1,41$ & & & & \\
\hline $\mathrm{S}_{26}$ & $-0,72$ & $-1,17$ & & & & \\
\hline $\mathbf{S}_{27}$ & - & $=$ & - & & $=$ & \\
\hline$S_{28}$ & 5,49 & 8,88 & & & & \\
\hline$S_{34}$ & - & - & - & & - & \\
\hline$S_{35}$ & 1,66 & 7,78 & & & & \\
\hline$s_{36}$ & 2,72 & 4,99 & & & & \\
\hline$S_{37}$ & $-3,93$ & $-3,90$ & & & & \\
\hline S38 & 1,43 & 2,08 & & & & \\
\hline$S_{45}$ & $-1,09$ & 10,29 & & & & \\
\hline$S_{46}$ & $-1,78$ & $-11,28$ & & & & \\
\hline$S_{47}$ & 2,51 & $-8,64$ & & & & \\
\hline$S_{48}$ & $-1,16$ & $-4,22$ & & & & \\
\hline $\mathbf{S}_{56}$ & 3,22 & $-0,53$ & & & & \\
\hline$S_{57}$ & $-1,02$ & $-3,28$ & & & & \\
\hline$S_{58}$ & $-1,39$ & $-12,86$ & & & & \\
\hline $\mathbf{S}_{67}$ & $-1,99$ & 22,77 & & & & \\
\hline$S_{68}$ & $-1,47$ & 13,28 & & & & \\
\hline$S_{78}$ & $1, \overline{78}$ & $-8,87$ & & & & \\
\hline$r^{2}$ & 1 & & 0,90 & 0,93 & & \\
\hline
\end{tabular}


Tabela 71. Médias observadas e estimadas a partir dos parâmetros do modelo de GRIFFING (1956) método 4, para os caracteres Altura da Planta na Maturação (cm / planta) e Produtividade de Grãos (gramas / parcela), na geração $F_{2: n}$ ano agrícola 1995/96.

\begin{tabular}{|c|c|c|c|c|c|c|c|c|}
\hline \multirow[t]{2}{*}{ Cruzamento } & \multicolumn{2}{|c|}{ Média Original } & \multicolumn{2}{|c|}{$\begin{array}{c}\text { Média Estimada } \\
\text { Modelo Completo } \\
\left(\mu, g_{i}, g_{i}, s_{i j}\right)\end{array}$} & \multicolumn{2}{|c|}{$\begin{array}{l}\text { Média Estimada } \\
\text { Modelo Reduzido } \\
\left(\mu, g_{i}, g_{i}\right)\end{array}$} & \multicolumn{2}{|c|}{$\begin{array}{c}\text { Média Estimada } \\
\text { Modelo Redurido } \\
(\mu)\end{array}$} \\
\hline & Altura & Produção & Altura & Produção & Altura & Produção & Altura & Produção \\
\hline $1 \times 2$ & 70,27 & 150,88 & 70,27 & 150,88 & 70,79 & 153,23 & 66,33 & 141,81 \\
\hline $1 \times 3$ & 62,44 & 182,65 & 62,44 & 182,65 & 57,31 & 178,84 & 66,33 & 141,81 \\
\hline $1 \times 4$ & 55,32 & 187,82 & 55,32 & 187,82 & 57,94 & 174,81 & 66,33 & 141,81 \\
\hline $1 \times 5$ & & - & - & - & - & - & & - \\
\hline $1 \times 6$ & 50,83 & 88,03 & 50,83 & 88,03 & 50,80 & 106,13 & 66,33 & 141,81 \\
\hline $1 \times 7$ & 68,08 & 112,70 & 68,08 & 112,70 & 65,43 & 110,79 & 66,33 & 141,81 \\
\hline $1 \times 8$ & 65,84 & 146,86 & 65.84 & 146,86 & 70,53 & 145,15 & 66,33 & 141,81 \\
\hline $2 \times 3$ & 66,49 & 174,51 & 66,49 & 174,51 & 73,50 & 179,30 & 66,33 & 141,81 \\
\hline $2 \times 4$ & 78,26 & 176,10 & 78,26 & 176,10 & 74,13 & 175,27 & 66,33 & 141,81 \\
\hline $2 \times 5$ & 71,03 & 162,86 & 71,03 & 162,86 & 72,41 & 164,27 & 66,33 & 141,81 \\
\hline $2 \times 6$ & 66,28 & 105,42 & 66,28 & 105,42 & 66,99 & 106,59 & 66,33 & 141,81 \\
\hline $2 \times 7$ & -1 & - & -1 & - & -1 & - & - & - \\
\hline $2 \times 8$ & 92,21 & 154,49 & 92,21 & 154,49 & 86,72 & 145,61 & 66,33 & 141,81 \\
\hline $3 \times 4$ & - & - & - & - & - & - & - & - \\
\hline $3 \times 5$ & 60,60 & 197,65 & 60,60 & 197,65 & 58,94 & 189,88 & 66,33 & 141,81 \\
\hline $3 \times 6$ & 56,23 & 127,21 & 56,23 & 127,21 & 53,52 & 132,20 & 66,33 & 141,81 \\
\hline $3 \times 7$ & 64,22 & 132,97 & 64,22 & 132,97 & 68,15 & 136,86 & 66,33 & 141,81 \\
\hline $3 \times 8$ & 74,67 & 173,30 & 74,67 & 173,30 & 73,24 & 171,22 & 66,33 & 141,81 \\
\hline $4 \times 5$ & 58,48 & 196,13 & 58,48 & 196,13 & 59,57 & 185,85 & 66,33 & 141,81 \\
\hline $4 \times 6$ & 52,37 & 116,89 & 52,37 & 116,89 & 54,15 & 128,17 & 66,33 & 141,81 \\
\hline $4 \times 7$ & 71,29 & 124,20 & 71,29 & 124,20 & 68,78 & 132,83 & 66,33 & 141,81 \\
\hline $4 \times 8$ & 72,71 & 162,98 & 72,71 & 162,98 & 73,87 & 167,19 & 66,33 & 141,81 \\
\hline $5 \times 6$ & 55,64 & 116,64 & 55,64 & 116,64 & 52,43 & 117,17 & 66,33 & 141,81 \\
\hline $5 \times 7$ & 66,04 & 118,55 & 66,04 & 118,55 & 67,06 & 121,83 & 66,33 & 141,81 \\
\hline $5 \times 8$ & 70,76 & 143,34 & 70,76 & 143,34 & 72,15 & 156,19 & 66,33 & 141,81 \\
\hline $6 \times 7$ & 59,64 & 86,93 & 59,64 & 86,93 & 61,64 & 64,15 & 66,33 & 141,81 \\
\hline $6 \times 8$ & 65,27 & 111,79 & 65,27 & 111,79 & 66,73 & 98,52 & 66,33 & 141,81 \\
\hline $7 \times 8$ & 83,14 & 94,31 & 83,14 & 94,31 & 81,36 & 103,18 & 66,33 & 141,81 \\
\hline$r$ & & & 1 & 1 & 0,95 & 0,96 & & \\
\hline
\end{tabular}


Tabela 72. Análise de variância da tabela dialélica e estimativa de parâmetros segundo o modelo de GRIFFING (1956) método 4, para os caracteres Altura da Planta na Maturação (cm / planta) e Produtividade de Grãos (gramas / parcela), na geração $\mathrm{F}_{2: \mathrm{n}}$ análise conjunta.

\begin{tabular}{|l|c|c|c|c|c|}
\hline Fonte de Variação & Gl & \multicolumn{2}{|c|}{ Soma de Quadrados } & \multicolumn{2}{c|}{ Quadrados Médios } \\
\hline & & Altura & Produção & Altura & Produção \\
\hline Anos & 3 & 4517,30 & 252896,96 & $1505,77^{* *}$ & $84298,99^{* *}$ \\
\hline Populações & 27 & 13983,52 & 207644,80 & $517,91^{* *}$ & $7690,55^{* *}$ \\
\hline C.G.C. & 7 & 12899,23 & 177112,50 & $1842,75^{* *}$ & $25301,79^{* *}$ \\
\hline C.E.C. & 20 & 1084,29 & 30532,30 & $54,22^{* *}$ & $1526,62^{* *}$ \\
\hline Popul. x Anos & 81 & 1208,67 & 30102,72 & $14,92^{* *}$ & $371,64^{* *}$ \\
\hline C.G.C. x Anos & 21 & 922,74 & 20835,43 & $43,94^{* *}$ & $992,16^{* *}$ \\
\hline C.E.C. x Anos & 60 & 285,93 & 9267,29 & $4,77^{\text {ns }}$ & $154,46^{*}$ \\
\hline Erro & 124 & - & - & 4,24 & 106,52 \\
\hline
\end{tabular}

\begin{tabular}{|c|c|c|c|c|c|}
\hline \multirow{2}{*}{$\begin{array}{l}\text { Parâmetro } \\
\text { Estimado }\end{array}$} & \multicolumn{2}{|c|}{$\begin{array}{c}\text { Modelo Comp. } \\
\left(\mu, a_{k}, g_{i,}, g_{i}, s_{i i}, g_{i j k}, g_{i k}, s a_{i i k}\right)\end{array}$} & \multirow{2}{*}{$\begin{array}{l}\text { Parâmetro } \\
\text { Estimado }\end{array}$} & \multicolumn{2}{|c|}{$\begin{array}{c}\text { Modelo Comp. } \\
\left(\mu, a_{k}, g_{i}, g_{i}, s_{i j}, g a_{i k}, g_{i k k}, s_{i j k}\right)\end{array}$} \\
\hline & Altura & Produção & & Altura & Produção \\
\hline$\mu$ & 75,60 & 196,23 & $s_{12}$ & 0,16 & 11,34 \\
\hline$g_{1}$ & $-7,53$ & 0,51 & $s_{13}$ & 4,17 & $-6,19$ \\
\hline$g_{2}$ & 11,81 & $-0,39$ & $s_{14}$ & $-3,86$ & 6,09 \\
\hline$g_{3}$ & $-4,47$ & 40,89 & $S_{15}$ & $-0,69$ & 20,89 \\
\hline $\mathrm{g}_{4}$ & $-4,54$ & 39,97 & $s_{16}$ & 0,28 & $-26,84$ \\
\hline$g_{5}$ & $-6,96$ & 13,37 & $S_{17}$ & 1,83 & $-4,71$ \\
\hline $\mathrm{g}_{6}$ & $-7,52$ & $-50,40$ & $S_{18}$ & $-1,90$ & $-0,59$ \\
\hline$g_{7}$ & 7,24 & $-36,56$ & $S_{23}$ & $-6,64$ & $-4,86$ \\
\hline $\mathrm{g}_{8}$ & 11,97 & $-7,40$ & $S_{24}$ & 0,82 & $-13,88$ \\
\hline & & & $S_{25}$ & $-2,64$ & $-3,21$ \\
\hline & & & $S_{26}$ & $-1,70$ & $-0,27$ \\
\hline & & & $S_{27}$ & 8,34 & 7,20 \\
\hline & & & $S_{28}$ & 1,65 & 3,67 \\
\hline & & & $S_{34}$ & 0,79 & 38,92 \\
\hline & & & $S_{35}$ & 1,75 & $-16,40$ \\
\hline & & & $S_{36}$ & 3,00 & $-4,58$ \\
\hline & & & S37 & $-3,78$ & $-8,95$ \\
\hline & & & $S_{38}$ & 0,70 & 2,07 \\
\hline & & & $S_{45}$ & 2,17 & 15,78 \\
\hline & & & $S_{46}$ & $-3,15$ & $-36,95$ \\
\hline & & & $S_{47}$ & 3,09 & $-3,69$ \\
\hline & & & $S_{48}$ & 0,14 & $-6,27$ \\
\hline & & & $S_{56}$ & 4,09 & 10,88 \\
\hline & & & $S_{57}$ & $-4,57$ & $-17,18$ \\
\hline & & & $\mathrm{S}_{58}$ & $-0,12$ & $-10,75$ \\
\hline & & & $S_{67}$ & $-3,48$ & 36,60 \\
\hline & & & $S_{68}$ & 0,96 & 21,14 \\
\hline & & & $S_{78}$ & $-1,44$ & $-9,28$ \\
\hline
\end{tabular}


Tabela 73. Valores da média, e desvio padrão entre cruzamentos nas gerações $F_{2} e$ $\mathrm{F}_{\text {2:n, }}$ para os caracteres Altura da Planta na Maturação (cm / planta) e Produtividade de Grãos (gramas / parcela), utilizados como limite para predição da freqüência de linhagens superiores.

\begin{tabular}{|l|r|r|r|r|r|r|r|r|}
\hline \multicolumn{1}{|c|}{ Avaliação } & \multicolumn{2}{|c|}{ Média } & \multicolumn{2}{c|}{ Desvio Padrão } & \multicolumn{2}{c|}{ Maior Valor } & \multicolumn{2}{c|}{ Menor Valor } \\
\hline & \multicolumn{1}{|c|}{ Altura } & Produção & Altura & Produção & Altura & Produção & Altura & Produção \\
\hline Geração $\mathrm{F}_{2}$ & 76,60 & 169,44 & 15,44 & 91,32 & 99,10 & 212,28 & 58,56 & 116,22 \\
\hline $1992 / 93$ & 73,88 & 258,72 & 14,07 & 80,86 & 123,33 & 574,00 & 38,67 & 55,33 \\
\hline $1993 / 94$ & 85,01 & 196,63 & 19,92 & 68,07 & 136,50 & 394,23 & 42,09 & 20,27 \\
\hline $1994 / 95$ & 77,37 & 152,57 & 13,10 & 57,56 & 116,67 & 367,43 & 41,67 & 15,53 \\
\hline $1995 / 96$ & 66,46 & 141,19 & 14,76 & 48,90 & 121,67 & 264,28 & 34,67 & 41,14 \\
\hline Análise Conjunta & 75,66 & 186,66 & 14,00 & 52,31 & 116,27 & 354,17 & 43,49 & 47,36 \\
\hline
\end{tabular}

Nota: As médias de cruzamentos na geração $\mathrm{F}_{2}$ foram multiplicadas por seis, para que se mantivesse a mesma escala para os dados em todas as gerações. 
Tabela 74. Freqüências observadas e esperadas de linhagens superiores ao valor da média dos cruzamentos, para o caráter Altura da Planta na Maturação (cm / planta), para as gerações $F_{2}$ e $F_{2: n}$ nos quatro anos agrícolas de experimentação e na análise conjunta.

\begin{tabular}{|c|c|c|c|c|c|c|c|c|c|c|c|}
\hline \multirow[t]{2}{*}{ Cruz. } & \multirow{2}{*}{$\frac{F_{2}}{\text { Esper. }}$} & \multicolumn{2}{|c|}{$1992 / 93$} & \multicolumn{2}{|c|}{$1993 / 94$} & \multicolumn{2}{|c|}{$1994 / 95$} & \multicolumn{2}{|c|}{$1995 / 96$} & \multicolumn{2}{|c|}{ Conjunta } \\
\hline & & Obs. & Esper. & Obs. & Esper. & Obs. & Esper. & Obs. & Esper. & Obs. & Esper. \\
\hline $1 \times 2$ & 0,3956 & 0,6500 & 0,6153 & 0,5500 & 0,6018 & 0,7500 & 0,7484 & 0,6316 & 0,6186 & 0,6842 & 0,6347 \\
\hline $1 \times 3$ & 0,1758 & 0,1000 & 0,0644 & 0,0500 & 0,1238 & 0,1000 & 0,1895 & 0,4000 & 0,3637 & 0,1000 & 0,1758 \\
\hline $1 \times 4$ & 0,0000 & 0,0769 & 0,0608 & 0,0000 & 0,0009 & 0,0769 & 0,0656 & 0,0769 & 0,0804 & 0,0000 & 0,0113 \\
\hline $1 \times 5$ & & & & & & & & & & & \\
\hline $1 \times 6$ & 0,0989 & 0,0000 & 0,0000 & 0,0500 & 0,0387 & 0,1000 & 0,1394 & 0,0500 & 0,0632 & 0,0000 & 0,0048 \\
\hline $1 \times 7$ & 0,6749 & 0,5500 & 0,6018 & 0,5500 & 0,6035 & 0,7000 & 0,6275 & 0,6000 & 0,6049 & 0,5000 & 0,6075 \\
\hline $1 \times 8$ & 0,8994 & 0,6000 & 0,6153 & 0,7500 & 0,6834 & 0,7000 & 0,6899 & 0,5000 & 0,3448 & 0,7500 & 497 \\
\hline $2 \times 3$ & 0,3970 & 0,7000 & 0,6143 & 0,4000 & 0,6011 & 0,5000 & 0,6023 & 0,5500 & 0,6011 & 0,5500 & 6030 \\
\hline $2 \times 4$ & 0,6023 & 0,6500 & 0,6411 & 0,7000 & 0,6428 & 0,6000 & 0,6317 & 0,8000 & 0,7435 & 0,7000 & 0,6688 \\
\hline $2 \times 5$ & 0,6428 & 0,7500 & 0,6248 & 0,6000 & 0,6018 & 0,5500 & 0,3973 & 0,7500 & 0,6235 & 0,7500 & 0,6068 \\
\hline $2 \times 6$ & 0,6332 & 0,4500 & 0,6164 & 0,6500 & 0,6899 & 0,5500 & 0,6061 & 0,5500 & 0,6011 & 0,5500 & 0,6198 \\
\hline $2 \times 7$ & 0,7964 & & & & & & & & & & \\
\hline $2 \times 8$ & 0,7701 & 1,0000 & 0,9710 & 0,9500 & 0,9901 & 0,9500 & 0,9551 & 0,9500 & 0,8818 & 0,9500 & 0,9935 \\
\hline $3 \times 4$ & 0,0325 & & & & & & & & & & \\
\hline $3 \times 5$ & 0,2589 & 0,1000 & 0,1895 & 0,0000 & 0,0721 & 0,0500 & 0,1315 & 0,2500 & 0,1965 & 0,0500 & 0,0909 \\
\hline $3 \times 6$ & 0,0404 & 0,2500 & 0,3144 & 0,1000 & 0,0551 & 0,3500 & 0,2420 & 0,1000 & 0,0310 & 0,1000 & 0,1736 \\
\hline $3 \times 7$ & 0,6411 & 0,4500 & 0,3752 & 0,6000 & 0,6011 & 0,6000 & 0,6115 & 0,4000 & 0,3894 & 0,5000 & 0,3977 \\
\hline $3 \times 8$ & 0,6039 & 0,6500 & 0,6497 & 0,8000 & 0,7629 & 0,7000 & 0,6609 & 0,7368 & 0,7701 & 0,7895 & 0,7268 \\
\hline $4 \times 5$ & 0,2059 & 0,1000 & 0,1919 & 0,0000 & 0,0241 & 0,1500 & 0,1334 & 0,1500 & 0,0848 & 0,0500 & 0,0540 \\
\hline $4 \times 6$ & 0,0241 & 0,1000 & 0,1626 & 0,1000 & 0,2036 & 0,1000 & 0,1919 & 0,2000 & 0,1942 & 0,1500 & 0,1669 \\
\hline $4 \times 7$ & 0,7011 & 0,7000 & 0,6571 & 0,7500 & 0,6317 & 0,7000 & 0,7011 & 0,6500 & 0,6317 & 0,7000 & 0,6462 \\
\hline $4 \times 8$ & 0,6124 & 0,8000 & 0,8626 & 0,7500 & 0,7411 & 0,8000 & 0,8081 & 0,8000 & 0,8011 & 0,9000 & 0,7988 \\
\hline $5 \times 6$ & 0,0833 & 0,1000 & & 0,1000 & 0,0189 & 0,1000 & 0,1057 & 0,0500 & 0,0270 & 0,0000 & 0,0104 \\
\hline $5 \times 7$ & 0,6813 & 0,3000 & 0,3391 & 0,4500 & 0,3605 & 0,4000 & 0,3867 & 0,5500 & 0,3984 & 0,4000 & 0,3668 \\
\hline $5 \times 8$ & 0,7701 & 0,7000 & 0,7484 & 0,6500 & 0,6497 & 0,4500 & 0,6124 & 0,6500 & 0,6363 & 0,7000 & 0,6590 \\
\hline $6 \times 7$ & 0,6411 & 0,4500 & 0,3951 & 0,3000 & 0,3752 & 0,4000 & 0,3876 & 0,3500 & 0,3621 & 0,3500 & 0,3725 \\
\hline $6 \times 8$ & 0,6347 & 0,7500 & 0,7484 & 0,7500 & 0,6834 & 0,8000 & 0,7103 & 0,4000 & 0,3951 & 0,6500 & 0,6628 \\
\hline $7 \times 8$ & 0,8544 & 0,9000 & 0,8606 & 0,9000 & 0,9251 & 0,9500 & & 0,9000 & 0,8646 & 0,9000 & 0,9629 \\
\hline $\mathbf{r}$ & $0,7294 \mathrm{~s}$ & 0,95 & & 0,9 & & 0,5 & & & & & \\
\hline
\end{tabular}

Nota: * Correlação efetuada entre as probabilidades esperadas a partir de $\mathrm{F}_{2} \mathrm{e}$ os valores observados na análise conjunta. $s=$ coeficiente de correlação de Spearman. 
Tabela 75. Freqüências observadas e esperadas de linhagens superiores ao valor da média dos cruzamentos, para o caráter Produtividade de Grãos (gramas / parcela), para as gerações $F_{2}$ e $F_{2: n}$ nos quatro anos agrícolas de experimentação e na análise conjunta.

\begin{tabular}{|c|c|c|c|c|c|c|c|c|c|c|c|}
\hline \multirow[t]{2}{*}{ Cruz. } & \multirow{2}{*}{$\frac{\mathrm{F}_{2}}{\text { Esper. }}$} & \multicolumn{2}{|c|}{$1992 / 93$} & \multicolumn{2}{|c|}{$1993 / 94$} & \multicolumn{2}{|c|}{$1994 / 95$} & \multicolumn{2}{|c|}{$1995 / 96$} & \multicolumn{2}{|c|}{ Conjunta } \\
\hline & & Obs. & Esper. & Obs. & Esper. & Obs. & Esper. & Obs. & Esper. & Obs. & Esper. \\
\hline $1 \times 2$ & 0,3939 & 0,4500 & 0,3697 & 0,8000 & 0,7773 & 0,8000 & 0,8219 & 0,4000 & 0,6175 & 0,6842 & 0,8762 \\
\hline $1 \times 3$ & 0,6210 & 0,8000 & 0,7988 & 0,7000 & 0,6791 & 0,8000 & 0,8762 & 0,9000 & 0,8666 & 0,8500 & 0,7845 \\
\hline $1 \times 4$ & 0,3986 & 0,6923 & 0,6590 & 0,6154 & 0,6317 & 0,8462 & 0,8331 & 0,7692 & 0,7869 & 0,7692 & 0,7268 \\
\hline $1 \times 5$ & & & & & & & & & & & \\
\hline $1 \times 6$ & 0,0681 & 0,0000 & 0,0001 & 0,0000 & 0,0989 & 0,1500 & 0,1826 & 0,1000 & 0,0989 & 0,0000 & 0,0033 \\
\hline $1 \times 7$ & 0,3712 & 0,3000 & 0,3101 & 0,2000 & 0,0001 & 0,0500 & 0,0355 & 0,1000 & 0,0270 & 0,0500 & 0,0332 \\
\hline $1 \times 8$ & 0,6018 & 0,5500 & 0,6729 & 0,2000 & 0,2732 & 0,5000 & 0,6115 & 0,6000 & 0,6082 & 0,4500 & 0,3910 \\
\hline $2 \times 3$ & 0,8011 & 0,6500 & 0,6668 & 0,7500 & 0,9703 & 0,9000 & & 0,9000 & 0,9999 & 0,8500 & 0,8818 \\
\hline $2 \times 4$ & 0,6966 & 0,7500 & 0,6791 & 0,7000 & 0,7387 & 0,4500 & 0,6027 & 0,9000 & 0,7580 & 0,8000 & 0,6921 \\
\hline $2 \times 5$ & 0,6379 & 0,6000 & 0,6428 & 0,8500 & 51 & 0,2500 & 0,3637 & 0,7000 & 0,6899 & 0,6000 & 5332 \\
\hline $2 \times 6$ & 0,3712 & 0,1000 & 0,0339 & 0,3500 & 0,3555 & 0,1500 & 0,1354 & 0,2000 & 0,2083 & 0,0500 & 0,0940 \\
\hline $2 \times 7$ & 0,3467 & & & & & & & & & & \\
\hline $2 \times 8$ & 0,6303 & 0,5000 & 0,3951 & 0,4500 & 0,0000 & 0,5000 & 0,3857 & 0,7000 & 0,6317 & 0,4500 & 0,3939 \\
\hline $3 \times 4$ & & & & & & & & & & & \\
\hline $3 \times 5$ & 0,6014 & 0,8000 & 0,6899 & 0,8000 & 0,7773 & 0,6500 & 0,6877 & 0,9000 & 0,9683 & 0,9000 & 0,7845 \\
\hline $3 \times 6$ & 0,3939 & 0,2000 & 0,2589 & 0,5000 & 0,3894 & 0,6500 & 0,6248 & 0,3000 & 0,3209 & 0,3000 & 0,3653 \\
\hline $3 \times 7$ & 0,3910 & 0,5000 & 0,3847 & 0,4500 & 0,3825 & 0,6000 & 0,6515 & 0,2500 & 0,3725 & 0,4000 & 0,3945 \\
\hline $3 \times 8$ & 0,6411 & 0,7500 & 0,8762 & 0,5000 & 0,6395 & 0,7500 & 0,8151 & 0,7368 & 0,7725 & 0,8947 & 0,7580 \\
\hline $4 \times 5$ & 0,6791 & 0,9500 & 0,9481 & 0,7000 & 0,7749 & 0,9500 & 0,9225 & 1,0000 & & 1,0000 & 683 \\
\hline $4 \times 6$ & 0,1518 & 0,2500 & 0,3292 & 0,1500 & 0,2943 & 0,3500 & 0,2920 & 0,3000 & 0,3589 & 0,2500 & 0,3056 \\
\hline $4 \times 7$ & 0,6035 & 0,8500 & 0,9596 & 0,4000 & 0,3932 & 0,4500 & 0,3932 & 0,3000 & 0,3271 & 0,4500 & 0,6098 \\
\hline $4 \times 8$ & 0,6090 & 0,9000 & 0,9945 & 0,7000 & & 0,7500 & 0,7677 & 0,8000 & & 0,9000 & \\
\hline $5 \times 6$ & 0,3683 & 0,3000 & 0,2780 & 0,3000 & 0,3272 & 0,4500 & 0,3876 & 0,4000 & 0,3352 & 0,2000 & 0,3034 \\
\hline $5 \times 7$ & 0,3982 & 0,2000 & 0,2943 & 0,2000 & 0,2299 & 0,1500 & 0,1109 & 0,3000 & 0,3332 & 0,2000 & 0,1497 \\
\hline $5 \times 8$ & 0,6363 & 0,9500 & & 0,5000 & 0,6082 & 0,3000 & 0,3485 & 0,6500 & 0,7057 & 0,6000 & 0,6791 \\
\hline $6 \times 7$ & 0,3332 & 0,1500 & 0,2943 & 0,1500 & 0,3312 & 0,2000 & 0,2966 & 0,0500 & 0,1276 & 0,2000 & 0,2637 \\
\hline $6 \times 8$ & 0,3101 & 0,4500 & 0,6011 & 0,2000 & 0,3589 & 0,3000 & 0,2516 & 0,1000 & 0,2155 & 0,2500 & 0,3391 \\
\hline $7 \times 8$ & & 0,2000 & 0,2083 & 0,1500 & 0,0053 & 0,0000 & 0,0540 & 0,1000 & 0,2347 & 0,1000 & 0,0925 \\
\hline $\bar{r}$ & 3 & $\overline{0,96}$ & & & & & & & & & \\
\hline
\end{tabular}

Nota: * Correlação efetuada entre as probabilidades esperadas a partir de $\mathrm{F}_{2}$ e os valores observados na análise conjunta. $s=$ coeficiente de correlação de Spearman. 
Tabela 76. Freqüências observadas e esperadas de linhagens superiores ao valor da média dos cruzamentos mais um desvio padrão, para o caráter Altura da Planta na Maturação (cm / planta), para as gerações $F_{2}$ e $F_{2: n}$ nos quatro anos agrícolas de experimentação e na análise conjunta.

\begin{tabular}{|c|c|c|c|c|c|c|c|c|c|c|c|}
\hline \multirow[t]{2}{*}{ Cruz. } & $\mathrm{F}_{2}$ & \multicolumn{2}{|c|}{$1992 / 93$} & \multicolumn{2}{|c|}{$1993 / 94$} & \multicolumn{2}{|c|}{$1994 / 95$} & \multicolumn{2}{|c|}{ 1995/96 } & \multicolumn{2}{|c|}{ Conjunta } \\
\hline & Esper. & Obs. & Esper. & Obs. & Esper. & Obs. & Esper. & Obs. & Esper. & Obs. & Esper. \\
\hline $1 \times 2$ & 0,1200 & 0,1500 & 0,2589 & 0,0500 & 0,1669 & 0,4500 & 0,3653 & 0,4211 & 0,2874 & 0,2105 & 0,2565 \\
\hline $1 \times 3$ & 0,0126 & 0,0000 & 0,0000 & 0,0000 & 0,0000 & 0,0000 & 0,0009 & 0,0500 & 0,0355 & 0,0000 & 0,0006 \\
\hline $1 \times 4$ & 0,0000 & 0,0000 & 0,0003 & 0,0000 & 0,0000 & 0,0000 & 0,0001 & 0,0000 & 0,0001 & 0,0000 & 0,0000 \\
\hline $1 \times 5$ & & & & & & & & & & & \\
\hline $1 \times 6$ & 0,0001 & 0,0000 & 0,0000 & 0,0000 & 0,0000 & 0,0000 & 0,0046 & 0,0000 &, 0003 & 0,0000 & 0,0000 \\
\hline $1 \times 7$ & 0,3271 & 0,1000 & 0,0000 & 0,0500 & 0,1145 & 0,0500 & 0,1238 & 0,1500 & 0,2275 & 0,1000 & 0,1257 \\
\hline $1 \times 8$ & 0,3712 & 0,1500 & 0,0000 & 0,0000 & 0,0283 & 0,1000 & 0,1040 & 0,0500 &, 0000 & 0,0000 & 0,0235 \\
\hline $2 \times 3$ & 0,1669 & 0,2500 & 0,2371 & 0,2000 & 0,2059 & 0,1500 & 0,1691 & 0,1000 &, 1758 &, 1500 & 0,2059 \\
\hline $2 \times 4$ & 0,2989 & 0,5000 & 0,3572 & 0,4000 & 0,3123 & 0,3000 & 0,2850 & 0,5000 & 0,3894 & 0,5000 & 0,3555 \\
\hline $2 \times 5$ & 0,3429 & 0,4000 & 0,3448 & 0,2000 & 0,2468 & 0,2000 & 0,2083 & 0,3000 & 0,2989 & 0,2000 & 0,2966 \\
\hline $2 \times 6$ & 0,2083 & 0,1500 & 0,0422 & 0,1000 & 0,1626 & 0,2000 & 0,2059 & 0,1500 & 0,1604 & 0,1000 & 0,1561 \\
\hline $2 \times 7$ & 0,2803 & & & & & & & & & & \\
\hline $2 \times 8$ & 0,6222 & 0,7500 & 0,7411 & 0,8500 & 0,7315 & 0,7000 & 0,7173 & 0,6500 & 0,6791 & 0,8500 & 0,8442 \\
\hline $3 \times 4$ & 0,0000 & & & & & & & & & & \\
\hline $3 \times 5$ & 0,0283 & 0,0000 & 0,0051 & 0,0000 & 0,0000 & 0,0000 & 0,0012 & 0,0000 & 0,0001 & 0,0000 & 0,0001 \\
\hline $3 \times 6$ & 0,0000 & 0,0500 & 0,0325 & 0,0000 & 0,0000 & 0,0000 & 0,0063 & 0,0000 & 00 & 0,0000 & 0,0024 \\
\hline $3 \times 7$ & 0,3209 & 0,1000 & 0,1109 & 0,2500 & 0,2516 & 0,2000 & 0,2468 & 0,1500 & 15 & 0,1500 & 0,2083 \\
\hline $3 \times 8$ & 0,2107 & 0,2500 & 0,2613 & 0,4000 & 0,3621 & 0,2000 & 0,2709 & 0,3684 & 89 & 0,4211 & 0,3292 \\
\hline $4 \times 5$ & 0,0055 & 0,0500 & 0,0009 & 0,0000 & 0,0000 & 0,0000 & 0,0001 & 0,0000 & 0,0000 & 0,0000 & 0,0000 \\
\hline $4 \times 6$ & $\overline{0,0000}$ & 0,0000 & 0,0096 & 0,0500 & 0,0246 & 0,0000 & 0,0258 & 0,0500 & 0,0194 & 0,0500 & 0,0158 \\
\hline $4 \times 7$ & 0,3836 & 0,3000 & 0,3352 & 0,2000 & 0,2661 & 0,2000 & 0,2203 & 0,2500 & 0,2943 & 0,3000 & 0,3101 \\
\hline $4 \times 8$ & 0,3101 & 0,3000 & 0,2897 & 0,2000 & 0,2203 & 0,1500 & 0,1989 & 0,1500 & 0,0681 & 0,3000 & 0,2565 \\
\hline $5 \times 6$ & 0,0009 & 0,0000 & 2 & 0,0000 & 0,0000 & 0,0000 & 0,0003 & 0,0000 & 0,0000 & 0,0000 & 0,0000 \\
\hline $5 \times 7$ & 0,3825 & 0,1000 & 0,0694 & 0,0500 & 0,1334 & 0,1000 & 0,1758 & 0,0500 & 0,1394 & 0,0500 & 0,0973 \\
\hline $5 \times 8$ & 0,3521 & 0,0500 & 0,0355 & 0,2500 & 0,3312 & 0,1500 & 0,1736 & 0,2000 & 0,2347 & 0,2000 & 0,2371 \\
\hline $6 \times 7$ & 0,1647 & 0,0500 & 0,1145 & 0,0500 & 0,1127 & 0,1000 & 0,1669 & 0,1000 & 0,1415 & 0,1000 & 0,1040 \\
\hline $6 \times 8$ & 0,3251 & 0,2000 & 0,1257 & 0,4500 & 0,3538 & 0,2000 & 0,1965 & 0,2000 & 0,0940 & 0,2000 & 0,2492 \\
\hline $7 \times 8$ & 0,6248 & 0,4500 & 0,3970 & 0,7500 & 0,6571 & 0,4000 & 0,1919 & 0,4500 & 0,6068 & 0,7000 & 0,6395 \\
\hline r & $0,6525^{\prime \prime} \mathrm{s}$ & 0,8 & & $\overline{0,97}$ & & & & & $1 \mathrm{~s}$ & & \\
\hline
\end{tabular}

Nota: * Correlação efetuada entre as probabilidades esperadas a partir de $\mathrm{F}_{2}$ e os valores observados na análise conjunta. $s=$ coeficiente de correlação de Spearman. 
Tabela 77. Freqüências observadas e esperadas de linhagens superiores ao valor da média dos cruzamentos mais um desvio padrão, para o caráter Produtividade de Grãos (gramas / parcela), para as gerações $F_{2}$ e $F_{2: n}$ nos quatro anos agrícolas de experimentação e na análise conjunta.

\begin{tabular}{|c|c|c|c|c|c|c|c|c|c|c|c|}
\hline \multirow[t]{2}{*}{ Cruz. } & $\mathrm{F}_{2}$ & \multicolumn{2}{|c|}{$1992 / 93$} & \multicolumn{2}{|c|}{$1993 / 94$} & \multicolumn{2}{|c|}{$1994 / 95$} & \multicolumn{2}{|c|}{$1995 / 96$} & \multicolumn{2}{|c|}{ Conjunta } \\
\hline & Esper. & Obs. & Esper. & Obs. & Esper. & Obs. & Esper. & Obs. & Esper. & Obs. & Esper. \\
\hline $1 \times 2$ & 0,1127 & 0,0500 & 0,0297 & 0,4000 & 0,3292 & 0,5000 & 0,3956 & 0,1579 & 0,2107 & 0,1053 & 0,0009 \\
\hline $1 \times 3$ & 0,2492 & 0,2000 & 0,1604 & 0,3000 & 0,2989 & 0,7500 & 0,6571 & 0,5000 & 0,3984 & 0,3500 & 0,3572 \\
\hline $1 \times 4$ & 0,1435 & 0,3846 & 0,3825 & 0,4615 & 0,3372 & 0,8462 & 0,7150 & 0,5385 & 0,3986 & 0,3846 & 0,3989 \\
\hline $1 \times 5$ & & & - & - & & & & 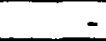 & - & E & \\
\hline $1 \times 6$ & 0,0000 & 0,0000 & 0,0000 & 0,0000 & 0,0012 & 0,1000 & 0,0508 & 0,0000 & 0,0017 & 0,0000 & 0,0000 \\
\hline $1 \times 7$ & 0,0562 & 0,0000 & 0,0003 & 0,0000 & 0,0000 & 0,0000 & 0,0001 & 0,0000 & 0,0000 & 0,0000 & 0,0000 \\
\hline $1 \times 8$ & 0,0940 & 0,0050 & 0,0198 & 0,1000 & 0,0001 & 0,2000 & 0,1849 & 0,1000 & 0,0644 & 0,0000 & 0,0001 \\
\hline $2 \times 3$ & 0,1182 & 0,2500 & 0,3209 & 0,5500 & 0,3918 & 0,5500 & & 0,2500 & 0,1435 & 0,6000 & 0,3894 \\
\hline $2 \times 4$ & 0,2827 & 0,2500 & 0,2492 & 0,2500 & 0,2966 & 0,3000 & 0,3144 & 0,3500 & 0,3668 & 0,1500 & 0,3230 \\
\hline $2 \times 5$ & 0,2565 & 0,1500 & 0,1558 & 0,2000 & 0,2420 & 0,1000 & 0,1497 & 0,2000 & 0,2444 & 0,1500 & 0,2780 \\
\hline $2 \times 6$ & 0,0596 & 0,0000 & 0,0002 & 0,1000 & 0,0339 & 0,1000 & 0,0107 & 0,1000 & 0,0073 & 0,1000 & 0,0006 \\
\hline $2 \times 7$ & 0,0058 & & - & - & - & - & - & & & & \\
\hline $2 \times 8$ & 0,2516 & 0,0000 & 0,0048 & 0,1000 & 0,0000 & 0,2500 & 0,2492 & 0,0500 & 0,0804 & 0,0000 & 0,0147 \\
\hline $3 \times 4$ & & & & & & & & & & - & \\
\hline $3 \times 5$ & 0,0000 & 0,2000 & 0,2850 & 0,4000 & 0,3802 & 0,5500 & 0,3951 & 0,6000 & 0,6115 & 0,3500 & 0,3885 \\
\hline $3 \times 6$ & 0,0136 & 0,0000 & 0,0219 & 0,0000 & 0,0167 & 0,5000 & 0,3621 & 0,0500 & 0,0270 & 0,0000 & 0,0734 \\
\hline $3 \times 7$ & 0,1040 & 0,1000 & 0,0761 & 0,0500 & 0,1074 & 0,3500 & 0,3312 & 0,0500 & 0,0957 & 0,1500 & 0,1561 \\
\hline $3 \times 8$ & 0,1040 & 0,2500 & 0,1626 & 0,2000 & 0,3790 & 0,6500 & 0,6571 & 0,3158 & 0,3312 & 0,2105 & 0,3503 \\
\hline $4 \times 5$ & 0,2920 & 0,6500 & 0,6791 & 0,5500 & 0,3986 & 0,7500 & 0,7411 & 0,6500 & & 0,6500 & 0,6877 \\
\hline $4 \times 6$ & 0,0000 & 0,1000 & 0,1057 & 0,1000 & 0,0519 & 0,1000 & 0,0989 & 0,1000 & 0,1238 & 0,0500 & 0,0734 \\
\hline $4 \times 7$ & 0,2036 & 0,2000 & 0,1965 & 0,1000 & 0,0694 & 0,3000 & 0,1354 & 0,1000 & 0,0332 & 0,1000 & 0,1023 \\
\hline $4 \times 8$ & 0,2444 & 0,3500 & 0,1604 & 0,3000 & & 0,4500 & 0,3739 & 0,1000 & & 0,2000 & 0,0000 \\
\hline $5 \times 6$ & 0,0681 & 0,0000 & 0,0339 & 0,0500 & 0,0189 & 0,2000 & 0,2803 & 0,0000 & 0,0804 & 0,0500 & 0,0347 \\
\hline $5 \times 7$ & $\overline{0,1276}$ & 0,0500 & 0,0044 & 0,0000 & 0,0024 & 0,0000 & 0,0107 & 0,0500 & 0,0620 & 0,0000 & 0,0004 \\
\hline $5 \times 8$ & 0,2012 & 0,3000 & & 0,0500 & 0,2966 & 0,1000 & 0,0775 & 0,0000 & 0,0000 & 0,0500 & 0,0761 \\
\hline $6 \times 7$ & 0,0325 & 0,0500 & 0,0310 & 0,0500 & 0,1163 & 0,1500 & 0,1691 & 0,0000 & 0,0053 & 0,1000 & 0,0584 \\
\hline $6 \times 8$ & 0,0000 & 0,2500 & 0,1895 & 0,1000 & 0,1006 & 0,0500 & 0,0748 & 0,0500 & 0,0060 & 0,1000 & 0,0596 \\
\hline $7 \times 8$ & & 0,0000 & 0,0012 & 0,0000 & 0,0000 & 0,0000 & 0,0017 & 0,1000 & 0,0363 & 0,0000 & 0,0004 \\
\hline $\mathrm{r}$ & $0,3919 \mathrm{~s}$ & $\overline{0,91}$ & & $\overline{0,81}$ & & $\overline{0,96}$ & & 0,8 & & & $2 \mathrm{~s}$ \\
\hline
\end{tabular}

Nota: * Correlação efetuada entre as probabilidades esperadas a partir de $\mathrm{F}_{2}$ e os valores observados na análise conjunta. $s=$ coeficiente de correlação de Spearman. 
Figura 1. Efeitos das capacidades gerais de combinação $\mathrm{g}_{\mathrm{i}}$ 's, estimados segundo o modelo de GRIFFING (1956) método 4, para o caráter Altura da Planta na Maturação (cm / planta), para as gerações $F_{2}$ e $F_{2: n}$ nos quatro anos agrícolas de experimentação e análise conjunta.

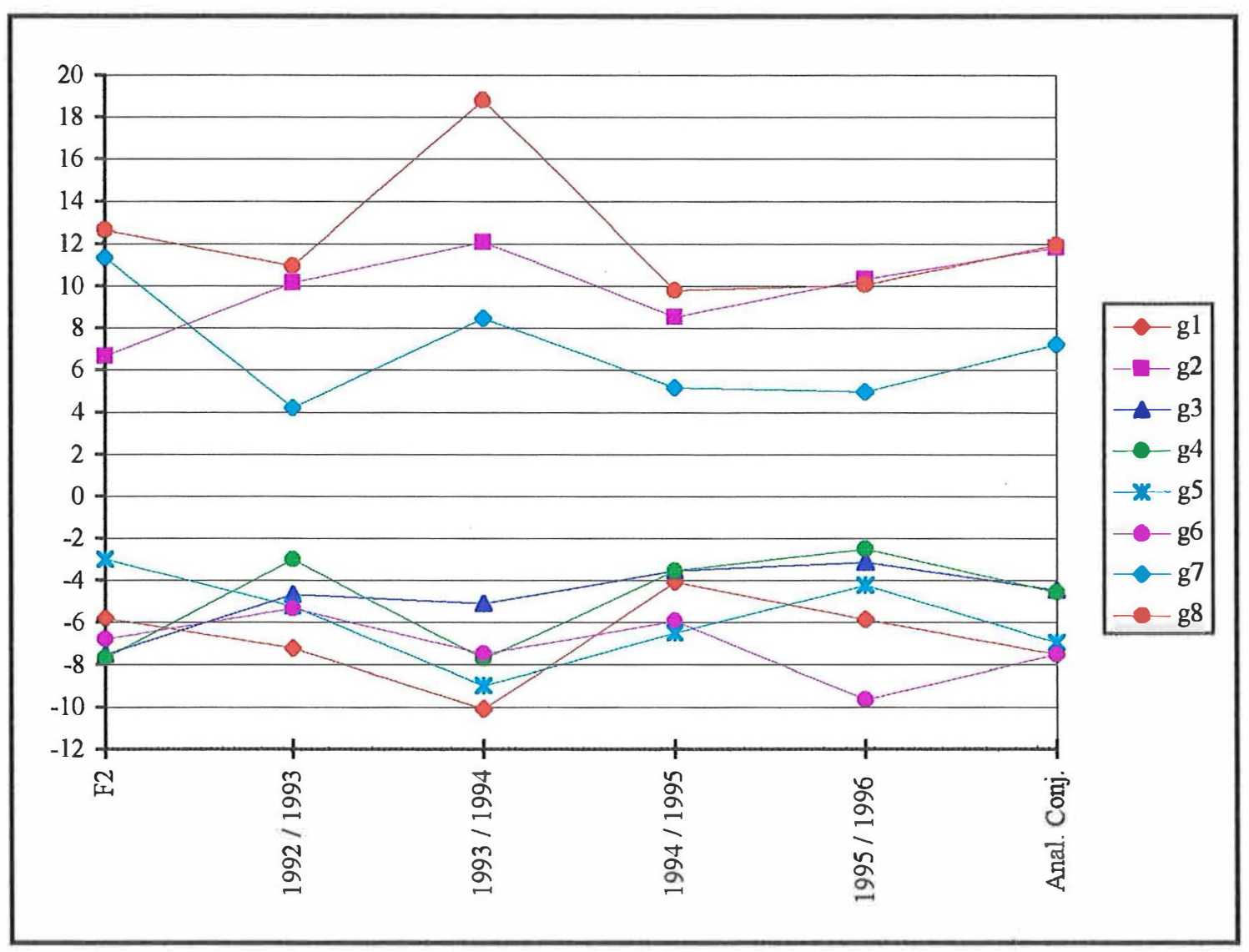


Figura 2. Efeitos das capacidades gerais de combinação $g_{i}$ 's, estimados segundo o modelo de GRIFFING (1956) método 4, para o caráter Produtividade de Grãos (gramas / parcela), para as gerações $F_{2}$ e $F_{2: n}$ nos quatro anos agrícolas de experimentação e análise conjunta.

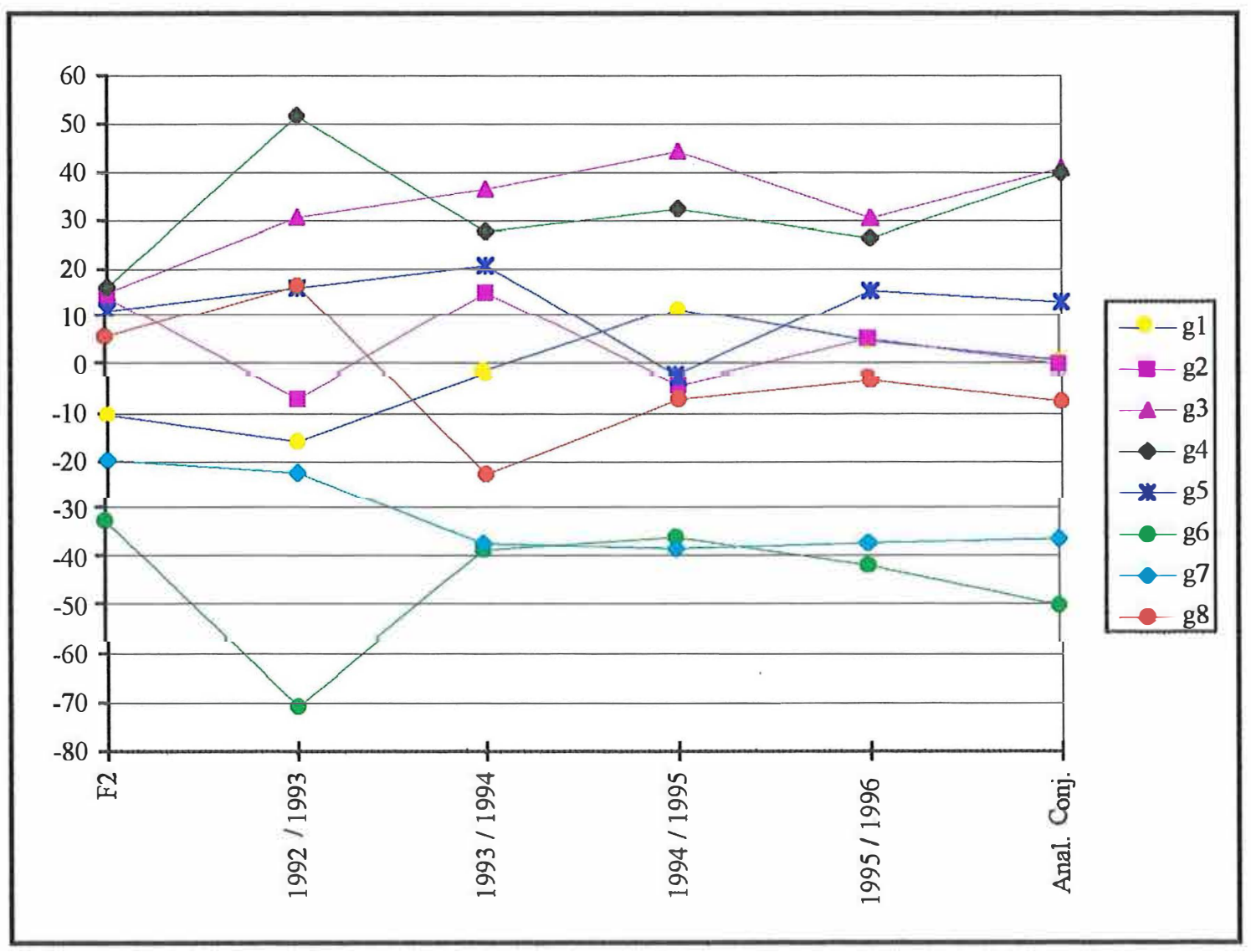

Nota: Os efeitos $g_{i}$ 's estimados na geração $F_{2}$ foram multiplicadas por seis, para que se mantivesse a mesma escala para os dados em todas as gerações. 
Figura 3. Efeitos das capacidades específicas de combinação $s_{\mathrm{ij}}$ 's, estimados segundo o modelo de GRIFFING (1956) método 4, para o caráter Altura da Planta na Maturação (cm / planta), para as gerações $F_{2}$ e $F_{2: n}$ nos quatro anos agrícolas de experimentação e análise conjunta.

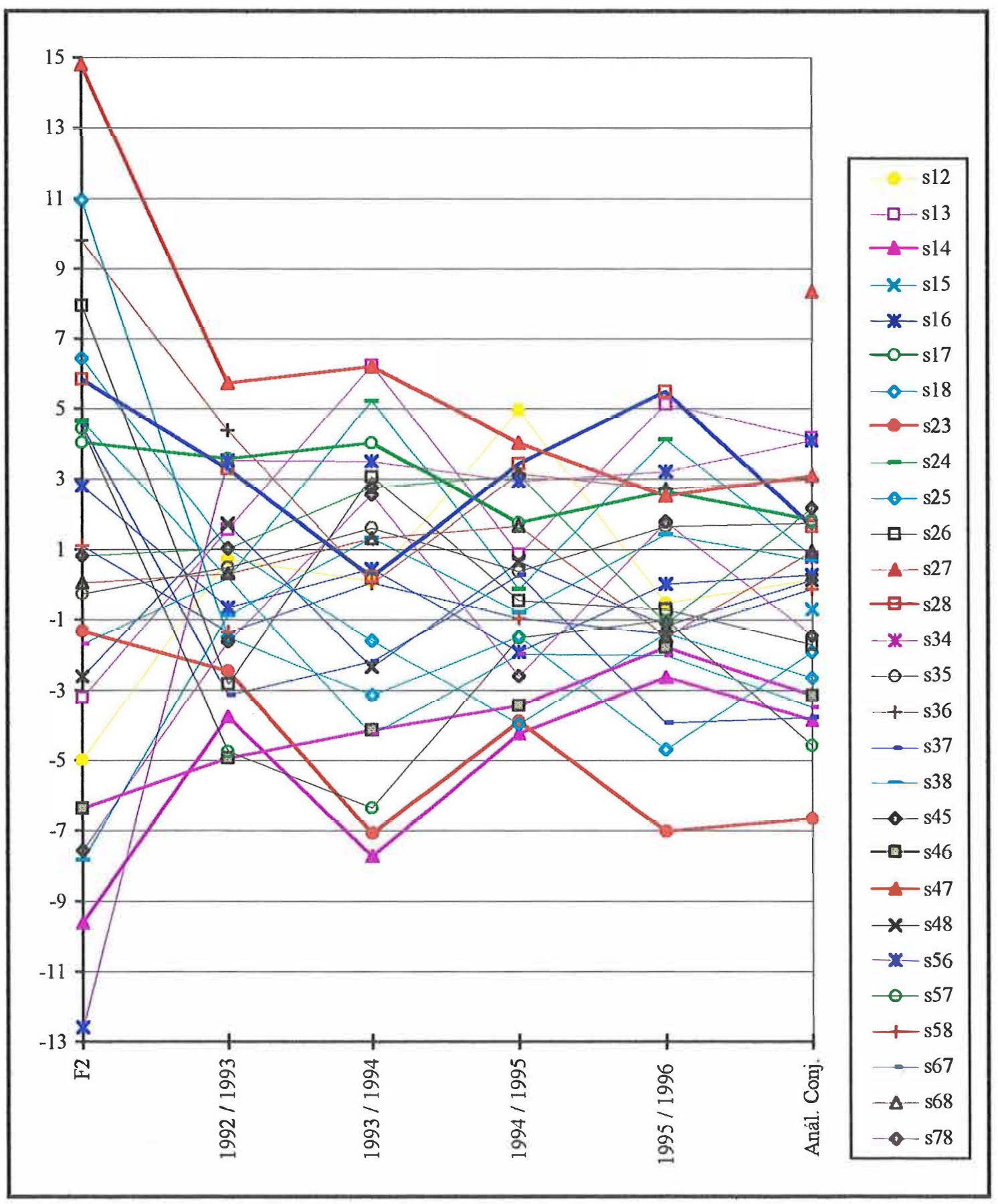


Figura 4. Efeitos das capacidades específicas de combinação $s_{\mathrm{ij}}$ 's, estimados segundo o modelo de GRIFFING (1956) método 4, para o caráter Produtividade de Grãos (gramas / parcela), para as gerações $F_{2}$ e $F_{2: n}$ nos quatro anos agrícolas de experimentação e análise conjunta.

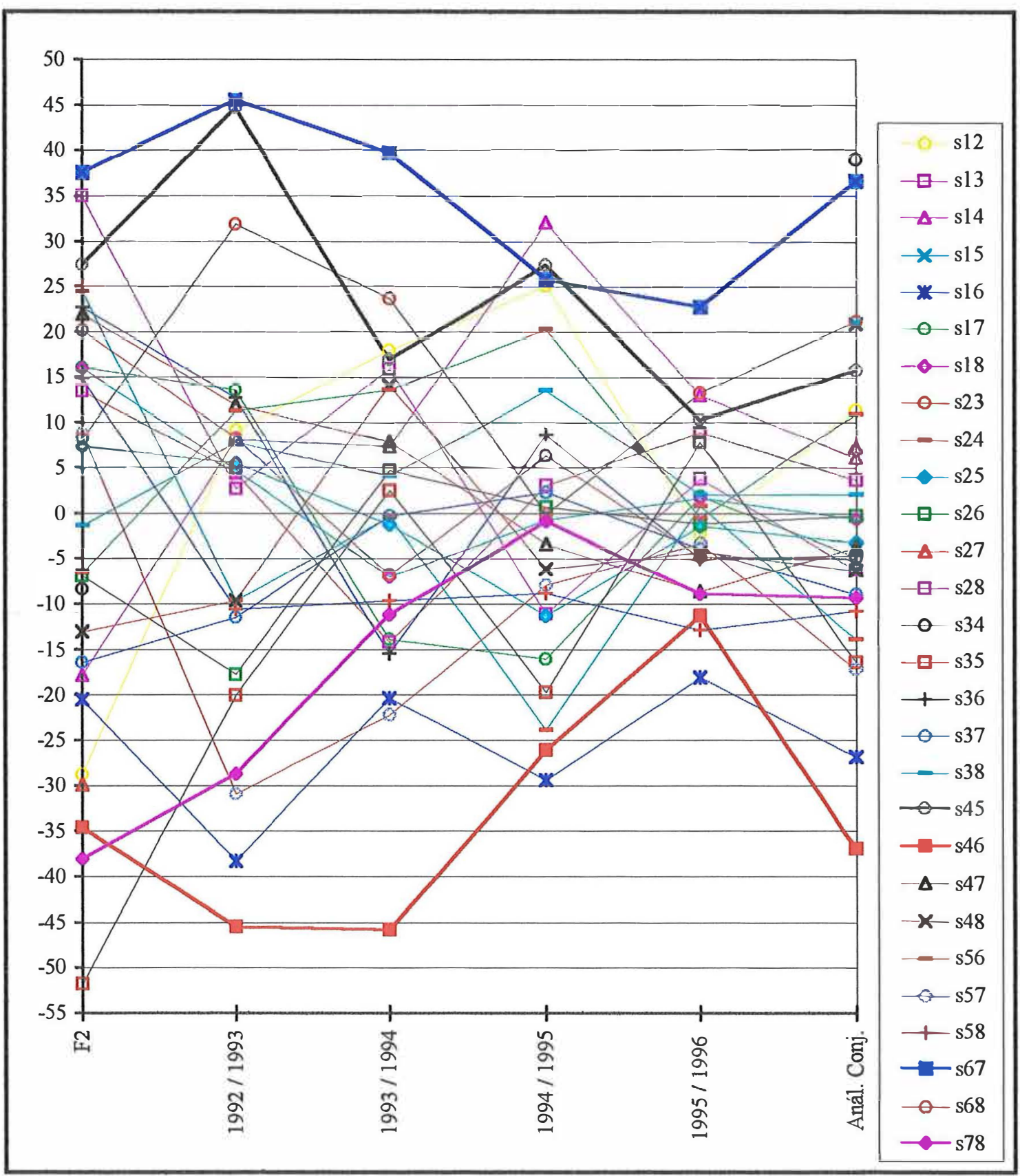

Nota: Os efeitos $\mathrm{s}_{\mathrm{ij}}$ 's estimados na geração $\mathrm{F}_{2}$ foram multiplicadas por seis, para que se mantivesse a mesma escala para os dados em todas as gerações. 
Figura 5. Médias estimadas segundo o modelo de GRIFFING (1956) método 4, para o caráter Altura da Planta na Maturação (cm / planta), para as gerações $\mathrm{F}_{2}$ e $\mathrm{F}_{2: \mathrm{n}}$ nos quatro anos agrícolas de experimentação e análise conjunta.

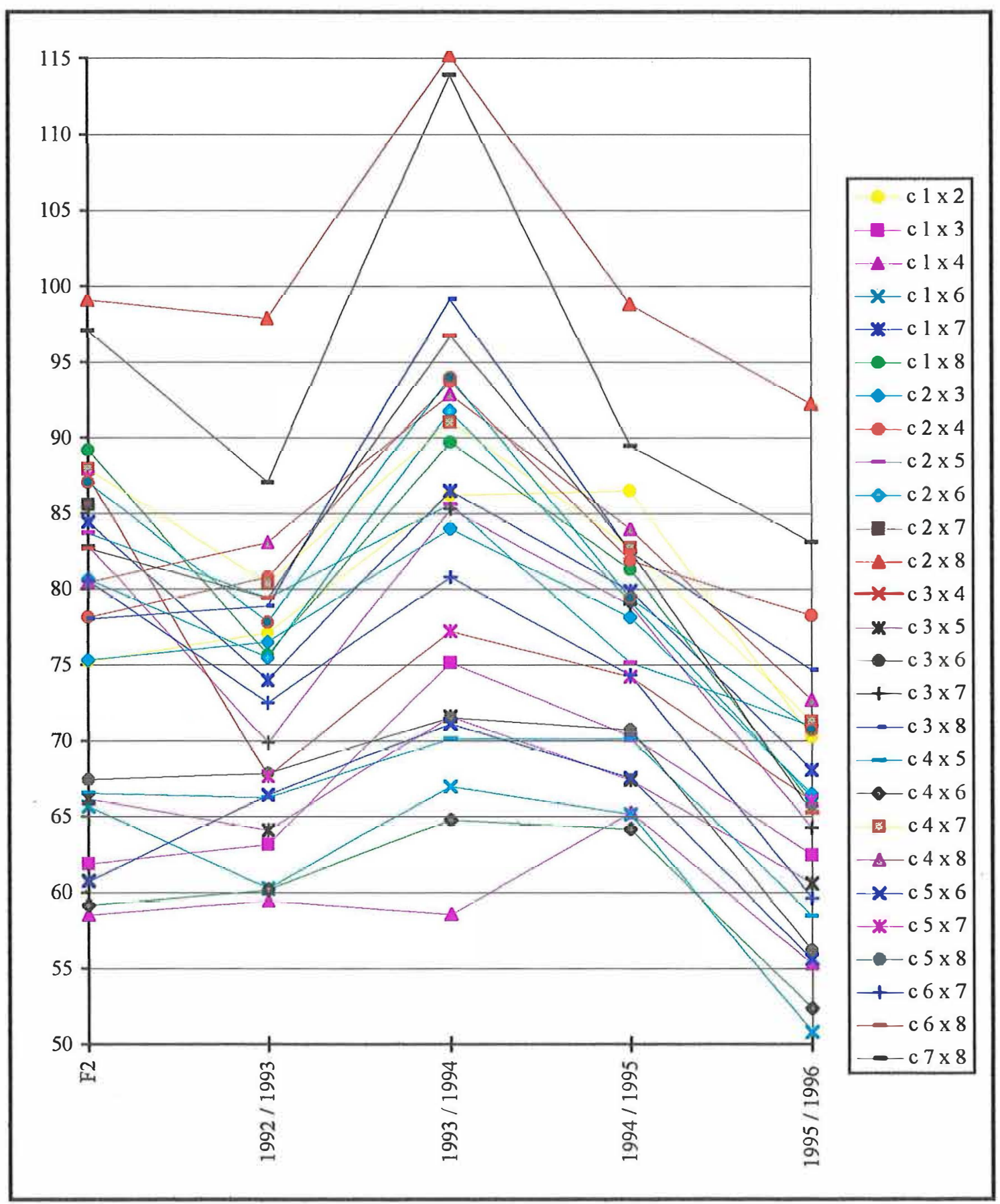


Figura 6. Médias estimadas segundo o modelo de GRIFFING (1956) método 4, para o caráter Produtividade de Grãos (gramas / parcela), para as gerações $F_{2}$ e $F_{2: n}$ nos quatro anos agrícolas de experimentação e análise conjunta.

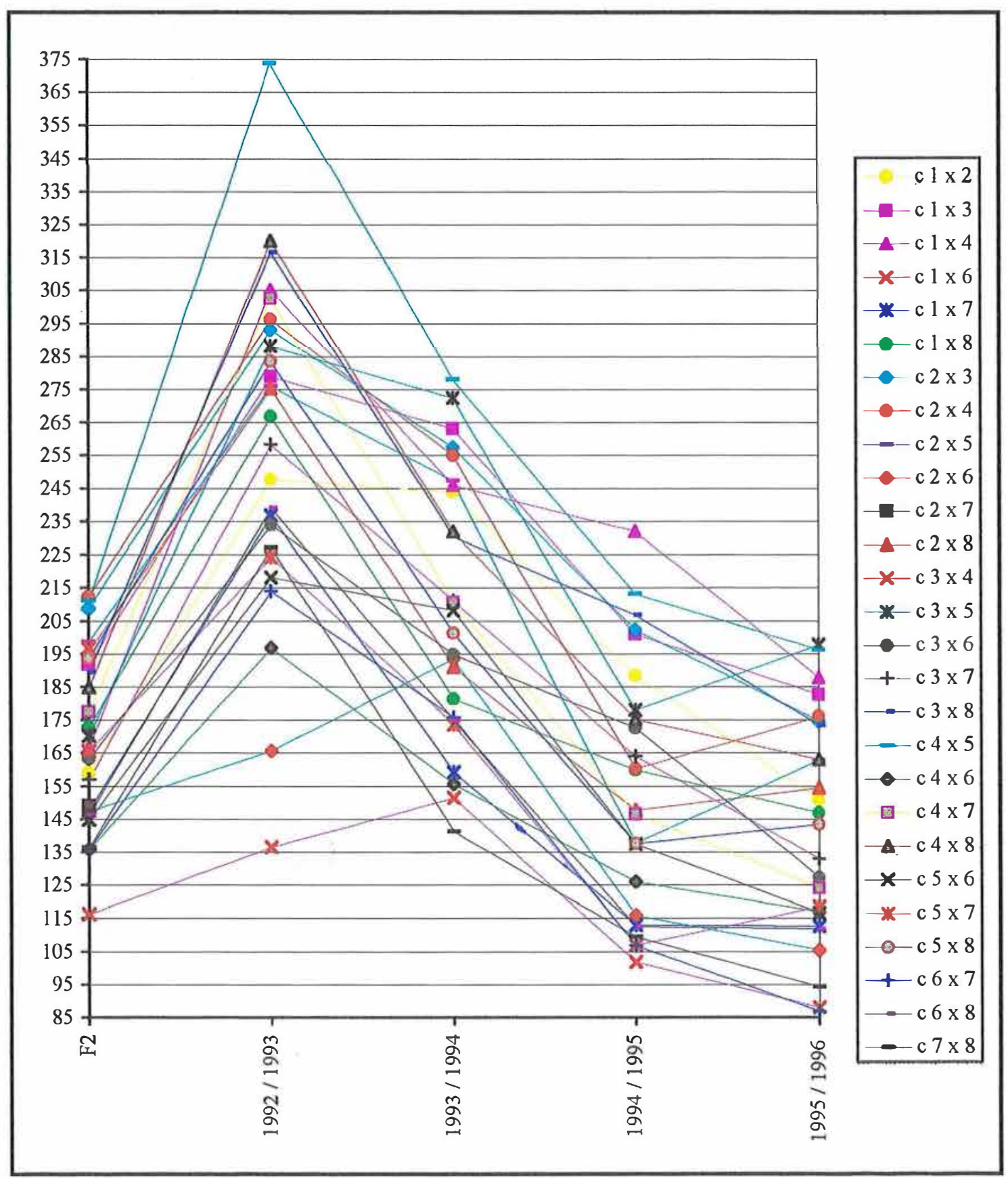

Nota: As médias de cruzamentos na geração $F_{2}$ foram multiplicadas por seis, para que se mantivesse a mesma escala para os dados em todas as gerações. 